\title{
Steering integrated care in England and the Netherlands: the case of dementia care : a neo- institutionalist comparative study
}

Citation for published version (APA):

Kümpers, S. N. S. (2005). Steering integrated care in England and the Netherlands: the case of dementia care : a neo-institutionalist comparative study. [Doctoral Thesis, Maastricht University]. Maastricht University. https://doi.org/10.26481/dis.20050519sk

Document status and date:

Published: 01/01/2005

DOI:

10.26481/dis.20050519sk

Document Version:

Publisher's PDF, also known as Version of record

Please check the document version of this publication:

- A submitted manuscript is the version of the article upon submission and before peer-review. There can be important differences between the submitted version and the official published version of record.

People interested in the research are advised to contact the author for the final version of the publication, or visit the DOI to the publisher's website.

- The final author version and the galley proof are versions of the publication after peer review.

- The final published version features the final layout of the paper including the volume, issue and page numbers.

Link to publication

\footnotetext{
General rights rights.

- You may freely distribute the URL identifying the publication in the public portal. please follow below link for the End User Agreement:

www.umlib.nl/taverne-license

Take down policy

If you believe that this document breaches copyright please contact us at:

repository@maastrichtuniversity.nl

providing details and we will investigate your claim.
}

Copyright and moral rights for the publications made accessible in the public portal are retained by the authors and/or other copyright owners and it is a condition of accessing publications that users recognise and abide by the legal requirements associated with these

- Users may download and print one copy of any publication from the public portal for the purpose of private study or research.

- You may not further distribute the material or use it for any profit-making activity or commercial gain

If the publication is distributed under the terms of Article 25fa of the Dutch Copyright Act, indicated by the "Taverne" license above, 
Steering integrated care in England and The Netherlands: The case of dementia care

A neo-institutionalist comparative study

Susanne Nicola Sophie Kümpers 
The study described in this thesis was performed at the Department of Health Organisation, Policy and Economics of the Maastricht University in cooperation with the University of Leeds, Institute for Health Sciences and Public Health Research, Health and Social Care Policy Group (former Nuffield Institute for Health). The latter provided extensive scientific, administrative and personal support in all stages of the research, especially by Dr. Brian Hardy. Without his contribution the study would not have been possible. For the fieldwork in England a travel grant was received from the Netherlands Organization for Scientific Research (NWO). The Care and Public Health Research Institute (caphri) at the Maastricht University also financially supported this research.
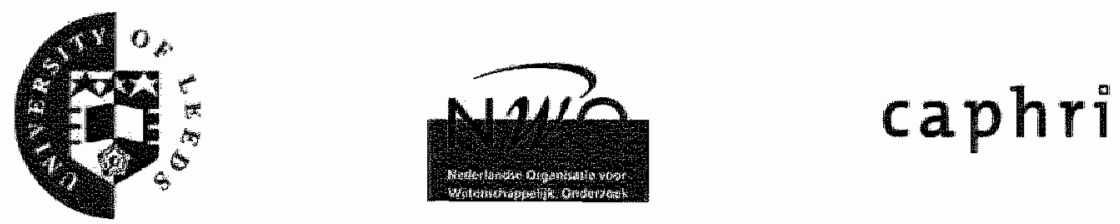

Printing: PrintPartners Ipskamp, Enschede, The Netherlands Cover design: BiFab, Bianca Fraats Lay-out: BiFab, Bianca Fraats 


\title{
Steering integrated care in England and The Netherlands: The case of dementia care
}

\author{
A neo-institutionalist comparative study
}

\section{PROEFSCHRIFT}

ter verkrijging van de graad van doctor aan de Universiteit Maastricht op gezag van de Rector Magnificus,

Prof. mr. G.P.M.F. Mols

volgens het besluit van het College van Decanen

in het openbaar te verdedigen

op donderdag 19 mei 2005 om 16.00 uur

door

Susanne Nicola Sophie Kümpers

geboren te Rheine, Duitsland, op 15 mei 1956 


\section{Promotor:}

Prof. dr. Hans Maarse

\section{Co-promotoren:}

Dr. Ingrid Mur

Dr. Arno van Ralak

\section{Beoordelingscommissie:}

Prof. dr. Cor Spreeuwenberg (Voorzitter)

Prof. dr. Murna Downs, University of Bradford, UK

Dr. Henk Nies, Nederlands Instituut voor Zorg en Welzijn, Utrecht Prof. dr. Ruud ter Meulen

Prof. dr. louke van der Zee 
Erklären bedeutet, das, was rätselhaft erscheint, mit dem, was wir bereits über die Welt wissen, in Verbindung zu bringen.

To explain means to relate what appears puzzling to what is already known about the world. 



\section{Overview}

1 GENERAL INTRODUCTION 15

2 CONCEPTUAL FRAMEWORK AND RESEARCH METHODOLOGY 27

3 THE INFLUENCE OF INSTITUTIONS AND CULTURE ON HEALTH POLICIES:

DIFFERENT APPROACHES TO INTEGRATED CARE IN ENGLAND AND

$\begin{array}{ll}\text { THE NETHERLANDS } & 59\end{array}$

4 STANDARDS AND PRACTICE OF DEMENTIA CARE IN ENGLAND AND

THE NETHERLANDS $\quad 85$

5. INTEGRATING DEMENTIA CARE IN ENGLAND AND THE NETHERLANDS.

FOUR COMPARATIVE LOCAL CASE STUDIES $\quad 115$

6 THE IMPORTANCE OF KNOWLEDGE TRANSFER BETWEEN SPECIALIST AND GENERIC SERVICES IN IMPROWING DEMENTIA CARE

$7 \quad$ GENERAL DISCUSSION AND CONCLUSIONS $\quad 179$

$\begin{array}{ll}\text { APPENDICES } & 207\end{array}$

$\begin{array}{ll}\text { SUMMMAYY } & 241\end{array}$

SAMENVATTING (SUMMARY IN DUTCH) 247

ZUSAMMENFASSUNG (SUMMARY IN GERMAN) 253

ACKNOWLEDGEMENTS - DANKWOORD - DANKWORT 259

$\begin{array}{ll}\text { CURRICULUM VITAE } & 263\end{array}$ 



\section{CONTENT TABLE}

1 GENERAL INTRODUCTION

1.1 Opening 17

1.1.1 Towards a definition of integrated care 17

1.11.2 The background of integrated care 18

1.1.3 Why a focus on "steering"? 19

1.2 Developing aims and scope of the research 20

1.2.1 How to steer integrated care - towards a first problem definition 20

1.2.2 The selection of dementia care as the target area 21

1.2.3 A cross-national and comparative perspective:

England and The Netherlands as the countries for study 21

1.2.4 Research goals 22

1.3 An outline of the study 23

1.3.1 Stage one: Analysis and comparison of the national health care systems and steering processes regarding integrated care in England and The Netherlands

1.3.2 Stage two: Analysis and comparison of integrated dementia care in England and The Netherlands. Recommended standards, achievements and shortcomings

1.3.3 Stage three: Analysis and comparison of local processes of integrated dementia care. Four local case studies 24

$\begin{array}{lll}1.4 & \text { An outline of the thesis } & 24\end{array}$

References 25

2 CONCEPTUAL FRAMEWORK AND RESEARCH METHODOLOGY 27

2.1 Introduction 29

2.2 Developing the conceptual framework 30

2.2.1 Neo-institutionalism 30

2.2.2 Defining institutions 31

2.2.3 Unravelling the context: The concept of configuration 31

2.2.4 A view on the role of actors 33

2.2.5 Institutional endurance and change 34

2.2.6 Configurations in process: Steering 35

2.2.7 Hierarchy, market and network 37

2.3 General research questions 38

2.4 The study methodology 39

2.4.1 Developing the research design 39 
2.4.1.1 A cross-national comparative approach

2.4.1.2 The case study design $\quad 40$

2.4.1.3 Steps in generating knowledge: The design in process $\quad 40$

2.4.1.4 The research process: Allowing for extensions and complementations 43

2.4.2 Qualitative approaches to data collection, processing and analysis 44

2.4.2.1 The two-fold function of triangulation 46

2.4.2.2 Analysis and writing $\quad 46$

2.4.2.3 Ensuring rigour - issues of verification in cross-national research 48

2.4.2.4 Verbal bias? $\quad 49$

2.4.2.5 Classical criteria redefined? Discussing reliability and validity 50

2.4.2.6 Generalisation $\quad 52$

2.4.3 Ethical considerations and procedures 54

References $\quad 54$

3 THE INFLUENCE OF INSTITUTIONS AND CULTURE ON HEALTH POLICIES: DIFFERENT APPROACHES TO INTEGRATED CARE IN ENGLAND AND THE NETHERLANDS $\quad 59$

$\begin{array}{lll}3.1 & \text { Abstract } & 61\end{array}$

3.2 Introduction 61

3.3 Theory 63

3.4 Methodology 64

3.5 England 65

3.5.1 1990 - 1997: NHS and community care reform 67

3.5.2 1997 - The modernisation agenda: The 'New NHS' and

$\begin{array}{ll}3.6 & \text { The Netherlands } \\ 3.6 .1\end{array}$

3.6.1 Change processes in the 1990s 72

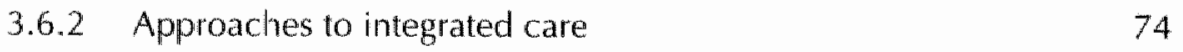



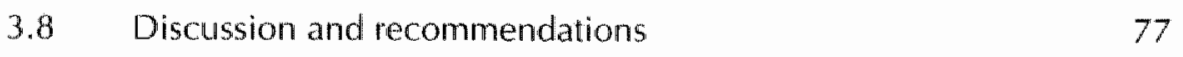
$\begin{array}{ll}\text { Acknowledgements } & 79\end{array}$

References $\quad 80$

4 STANDARDS AND PRACTICE OF DEMENTIA CARE IN ENGLAND AND THE NETHERLANDS

$\begin{array}{lll}4.1 & \text { Abstract } & 87\end{array}$ 
$\begin{array}{lll}4.2 & \text { Introduction } & 87\end{array}$

4.3 Context and background 88

4.4 Theoretical framework: Neo-institutionalism 90

$\begin{array}{ll}4.5 \text { Methodology } & 90\end{array}$

4.5.1 Data collection 91

$\begin{array}{lll}\text { 4.5.2 Data analysis } & 92\end{array}$

$\begin{array}{ll}\text { 4.5.3 Ethicall considerations } & 93\end{array}$

4.6 Results 93

4.6.1 Similarities in patients' pathways in England and The Netherlands $\quad 93$

4.6.2 Similarities among recommended standards 94

4.6.3 Similar main divergences between standards and practice - descriptions and explanations 95

4.6.3.1 Primary care $\quad 95$

4.6.3.2 Acute care $\quad 96$

4.6.3.3 Social care $\quad 97$

4.6.3.4 Specialist mental health services $\quad 99$

4.6.3.5 Pathway coordination $\quad 99$

4.6.3.6 Dementia competence 100

4.6.4 Differences in patients' pathways in England and The Netherlands $\quad 100$

$\begin{array}{ll}\text { 4.6.4.1 Community care } & 102\end{array}$

4.6.4.2 Long-term (institutional) care 104

$\begin{array}{lll}4.7 & \text { Conclusions and recommendations } & 105\end{array}$

References 108

5 INTEGRATING DEMENTIA CARE IN ENGLAND AND THE NETHERLANDS. FOUR COMPARATIVE LOCAL CASE STUDIES

$\begin{array}{lll}5.1 & \text { Abstract } & 117\end{array}$

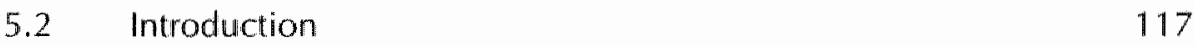

$\begin{array}{lll}5.3 & \text { Theory } & 118\end{array}$

$\begin{array}{lll}5.4 & \text { Research methods } & 119\end{array}$

5.4.1 Local case studies: Number, selection and fieldwork design 119

5.4.2 Analysis and case descriptions 120

5.5 Centrall-local interactions and local cooperation in dementia care: England $\quad 121$

5.5.1 Health and social care system and national steering context 121

$\begin{array}{ll}5.5 .1 .1 & \text { Structure and financing } \\ 121\end{array}$ 


\subsubsection{First subcase: York}

5.5.2.1 Cooperation between health and social services: organisational discontinuities

5.5.2.2 Cooperation between generic and mental health services: imbalances

5.5.2.3 A window of opportunity?

5.5.3 Second subcase: Leeds West

5.5.3.1 Cooperation between health and social services: Incremental proceedings

5.5.3.2 Cooperation between generic and mental health services: Disagreements

5.5.4 The English cases: Comparative analysis

5.6 Centra|-local interactions and local cooperation in dementia care: The Netherlands

5.6.1 Health and social care system and national steering context 129

5.6.1.1 Structure and financing

$\begin{array}{ll}\text { 5.6.1.2 Governance: Patterns and processes } & 130\end{array}$

$\begin{array}{ll}\text { 5.6.2 First subcase: Maastricht } & 131\end{array}$

5.6.2.1 Operational cooperation: An expert network needing extension 132

5.6.2.2 Strategic cooperation: Contested governance - market and network incentives

5.6.3 Second subcase: Amsterdam Nieuw West 134

5.6.3.1 Operational cooperation: Various and overlapping links $\quad 134$

5.6.3.2 Strategic cooperation: Concerted solutions $\quad 135$

5.6.4 The Dutch cases: Comparative analysis 136

$\begin{array}{lll}5.7 & \text { Cross-national analysis and discussion } & 138\end{array}$

$\begin{array}{lll}\text { 5.7.1 Central-local governance processes } & 138\end{array}$

5.7.1.1 The impact of imposed organisational changes on local cooperation

5.7.1.2 Changing power balances $\quad 139$

5.7.2 Local service development and delivery $\quad 139$

5.7.2.1 The case of early support for dementia 139

5.7.2.2 At the heart of integrated dementia care: The cooperation of generalists and specialists $\quad 140$

5.8 Lessons to be learnt: Conclusions and recommendations $\quad 140$ $\begin{array}{ll}\text { Acknowledgements } & 141\end{array}$

$\begin{array}{ll}\text { References } & 142\end{array}$ 
6 THE IMPORTANCE OF KNOWLEDGE TRANSFER BETWEEN SPECIALIST AND GENERIC SERVICES IN IMPROVING DEMENTIA CARE

$\begin{array}{lll}6.1 & \text { Abstract } & 149\end{array}$

6.2 Introduction 149

6.3 Context and background 151

6.4 A provisional conceptual framework 153

6.5 Methods 155

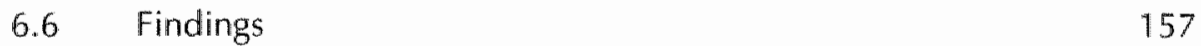

6.6.1 Service models 157

6.6.2 Knowledge transfer: Features of success and failure 158

6.6.2.1 Organisational and professional culture 158

6.6.2.2 Domain consensus 160

6.6.2.3 Perceived dependency 164

6.6.2.4 Resources 165

6.6.2.5 Continuity 166

$\begin{array}{ll}\text { 6.7 Discussion and conclusions } & 167\end{array}$

6.7.1 Building a conceptual model: Knowledge transfer performance in dementia care $\quad 168$

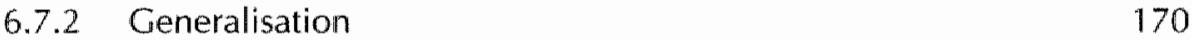

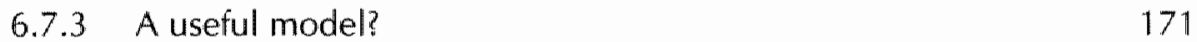

$\begin{array}{ll}\text { Acknowledgements } & 171\end{array}$

$\begin{array}{ll}\text { References } & 171\end{array}$

$7 \quad$ GENERAL DISCUSSION AND CONCLUSIONS $\quad 179$

$\begin{array}{lll}7.1 & \text { Introduction } & 181\end{array}$

7.2 An overview of the research results 183

7.2.1 National steering processes regarding integrated care 183

7.2.2 Integrated dementia care standards and mainstream care 186

7.2.3 Steering integrated dementia care at local level 189

7.2.4 Knowledge transfer between specialists and generalists in integrated dementia care 192

7.3 Turning answers into questions: A framework for the analysis of steering processes of integrated dementia care 194

7.4 Reflections on the research process - methodological Issues 196

7.4.1 The absence of a real research team 196

7.4.2 Reflections on the "small n' 197

$\begin{array}{ll}\text { 7.4.3 Reflecting the 'verbal bias' } & 198\end{array}$ 
7.4.4 Writing up: Consequences arising from the article-based format of the dissertation

7.4.5 Concluding remarks

7.5 Options for future research

7.6 Epilogue: The essential lessons?

References

APPENDICES

Appendix Chapter 2

Appendices Chapter 4

223

Appendix Chapter 7

SUMMARY

SAMENWATTING (SUMMARY IN DUTCH)

ZUSAMMENFASSUNG (SUMMARY IN GERMAN)

ACKNOWLEDGEMENTS - DANKWOORD - DANKWORT 


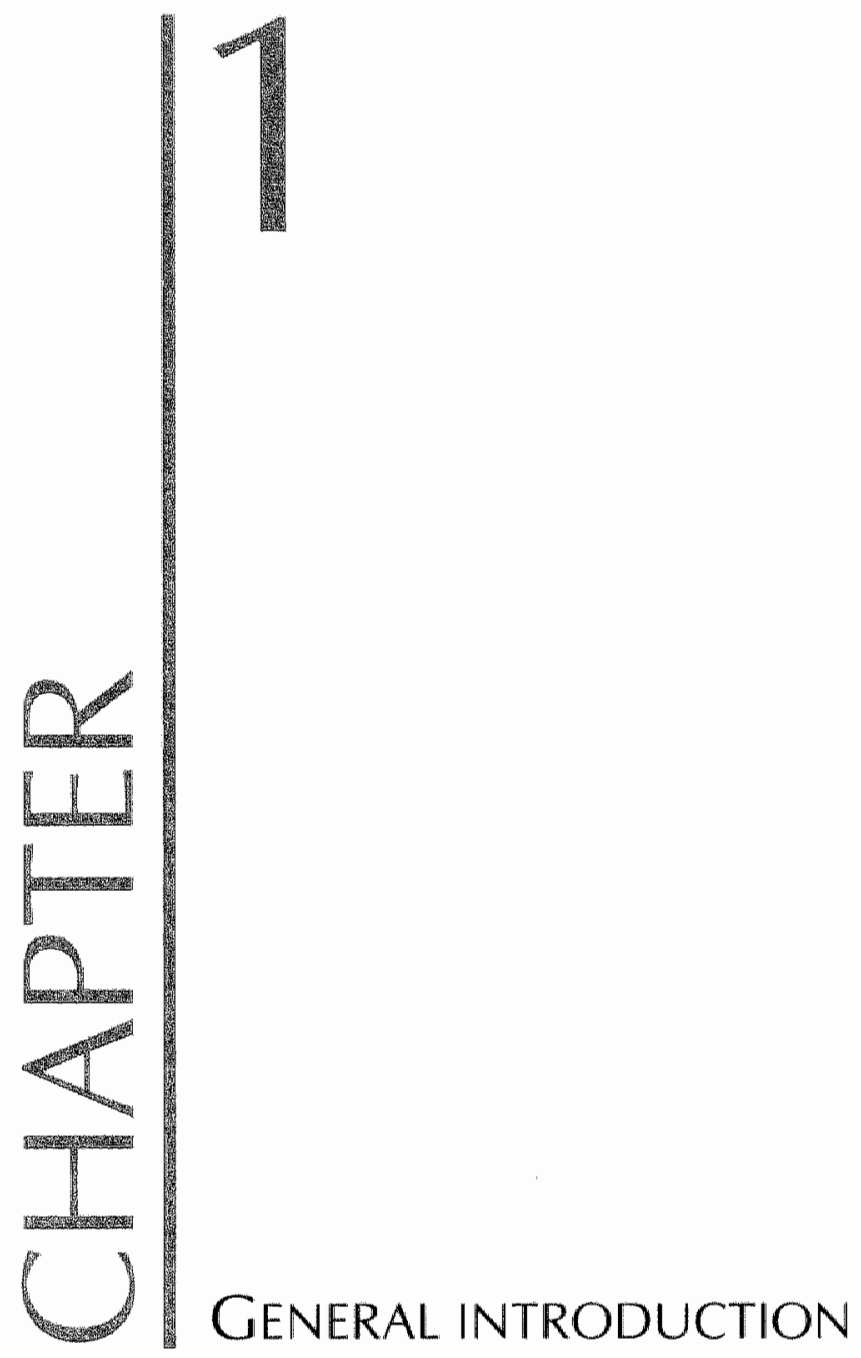


16 Chapter 


\subsection{OPENING}

The subject of this thesis is a comparison of steering processes that facilitate integrated care, in particular integrated dementia care, within real-life settings in England and The Netherlands. Steering here is understood in a broad sense - comprising governance, managerial and professional processes at national and local level. The PhD project (1999-2004) has been based at the University of Maastricht, Faculty of Health Sciences, Department of Health Policy, Organisation and Economics, in cooperation with the University of Leeds, Institute for Health Sciences and Public Health Research, Health and Social Care Policy Group (formerly within the Nuffield Institute of Health) in England.

In the following section, the concept of integrated care is introduced, and its societal background is outlined. I explain why integrated care constitutes a challenge for steering - justifying the focus of this research. Subsequently the aims and scope of the study are elaborated, followed by an outline of the essential research steps. Finally, an overview of the thesis is given.

\subsubsection{Towards a definition of integrated care}

Integrated care has become a key concept in health policies over the last 15 years in Western countries, describing a way of service provision, in which, as a minimal definition, "the single unit acts in a coordinated way" (Leichsenring, 2004). Integrated care is one more term in a line of related terms used in different contexts and countries, such as shared care, seamless care, transmural care, integrated care pathways, case and care management, all with broadly overlapping meanings. Important differences in more sophisticated definitions regard the scope of integrated care, i.e. whether it is restricted largely to a health care focus (e.g. Gröne \& Garcia-Barbero, 2001; Kodner \& Spreeuwenberg, 2002) or whether, as especially advocated in two extended European comparative endeavours studying concepts and approaches to integrated care (Leichsenring \& Alaszewski, 2004; van Raak et al., 2003), the social services realm is included:

"Integrated care refers to a coherent and co-ordinated set of services which are planned, managed and delivered to individual service users across a range of organisations and by a range of co-operating professionals and informal carers. It covers the full spectrum of health and healthcare-related social care. ... The essence of integrated care is that individuals receive the 
care services they are in need of, when and where they need them." (van Raak et al, 2003, p.11)

As partly implied in this definition, integrated care can be perceived and elaborated on from different angles, although they are clearly inter-related and partly overlapping:

- From a user's perspective it represents a care concept, emphasising seamless care for the user.

- From an organisational and management perspective it refers to intra- and interorganisational coordination, and comprises arrangements like case management and multidisciplinary teams.

- As a logistic concept it describes patients' pathways, i.e. the recommended routes of patients through the system and the links between its component parts.

- As a policy concept it refers to respective legislation, regulation systems and policy programmes.

- As an economics concept it emphasises aspects of efficiency in terms of gaps and overlaps in service delivery.

One could argue that the first - the humanitarian rationale - and the last - the economic rationale - are substantial with the others seen as instrumental to their achievement. While the humanitarian and the economic rationale are not contradictory, by definition they also cannot be perceived as naturally synergetic. This study, however, deals essentially with the instrumental perspectives 'in-between'.

\subsubsection{The background of integrated care}

Integrated care can be seen as a response to changing characteristics of service users and their needs and demands, and to a developing understanding of many of the inefficiencies connected with increasing fragmentation within health and social care systems.

With respect to services users, integrated care is especially pertinent to older people, and to those with handicaps and chronic illnesses, among them people with dementia. These groups have multiple and diwerse care needs, for longer periods and changing over time, and therefore need flexible and co-ordinated responses. Inter-related socio-economic, medical, epidemiological, demographic and cultural developments in Western countries over the last decades have contributed to the care needs of these groups accounting for increasing percentages of demand in health and social care systems. Improved welfare and associated living conditions as well as progress in medicine and medical technologies have led to the successful prevention, treatment and even eradication of many communicable diseases, and contributed to 
changed epidemiological profiles with longer life expectancy, and higher percentages of non-communicable and chronic diseases.

Demographical developments, resulting in ageing societies, reinforce these trends at least for the coming decades. Socio-cultural changes have brought about new orientations: with health and social services now expected not only to cure patients' illness, but to facilitate users' autonomy and quality of life and well-being. This also contributes to a wide-spread preference for community care to avoid the negative consequences of institutionalisation and hospitalisation (Leichsenring, 2004). Simultaneously, health and social care systems operate under increasing political pressures for cost containment, resulting from steeply rising health care costs and the increasing competitive pressures countries face in a global economy in recent decades. Preferences for care at home as an alternative to institutionalised care are also fed from this economic rationale. For all these reasons, system inefficiencies, in terms of gaps and overlaps caused by disintegration and fragmentation, therefore have assumed considerable political importance.

\subsubsection{Why a focus on 'steering'?}

In general, health and social care systems are described as increasingly fragmented systems, divided by structural and cultural boundaries between organisations and professions. They have developed through ever-increasing specialisation and differentiation, which are reflected in different regulation systems and different organisational and cultural values. For comprehensively integrated service delivery systems therefore need re-design and managed integration.

In this, however, health and social care systems are typical of some of the coordination problems in complex societies:

"Every organized human activity - from the making of pots to the placing of a man on the moon - gives rise to two fundamental and opposing requirements: the division of labour into various tasks to be performed, and the coordination of these tasks to accomplish the activity." (Mintzberg, 1983, p.2)

Indeed, some authors describe health care systems as being among the most complex and interdependent in current societies (Kodner \& Spreeuwenberg, 2002). The differentiation into ever more systems and subsystems has created significant problems for societal and political steering in post-modern societies (e.g. Rhodes, 1997; Willke, 1998). This is especially the case with 'cross-cutting issues' - such as integrated care, which seek to address those problems, the solutions to which are not restricted to one (sub)system, actor or sector, but require capacities for re-integration across system 
boundaries, and call for network solutions (O'Toole, 1997; Willke, 1998). In this sense, the challenge to create integrated care whilst not unique is exemplary for steering challenges in complex societies. The often cited fragmentation therefore can be regarded as inherent characteristic of such societies, which therefore cannot be solved in a principle way, but has to be managed (van Raak, 2004).

\subsection{DEVELOPING AIMS AND SCOPE OF THE RESEARCH}

In the following section, the essential elements of the research - the steering of integrated care, the focus on dementia care, and the comparative approach to national and local settings, are subsequently elaborated to spell out the study's scope and goals.

\subsubsection{How to steer integrated care - towards a first problem definition}

Steering approaches to achieve integrated care apply at different levels (cf. Delnoij \& Klazinga, 2002). Mainly at national level, sometimes also at regional level, health and social care systems and the respective governance activities - legislation and policy programmes - shape the conditions for local integrated care approaches, notwithstanding the fact that health and social care systems are embedded in general national political systems, and, to some degree and increasingly, in supra-national entities.

Integrated care development and delivery definitely take place at local level. The local level therefore on the one hand encompasses strategic governance and managerial activities to facilitate development, planning and commissioning of integrated care. On the other hand, efforts to integrate day-to-day care delivery encompass not only operational management but also inter-professional working. Steering integrated care - steering defined as activities to maintain or change rules of aclion (van Raak, 1998 ) with respect to issues of public interest - thus involves a continuum of interacting governance, managerial and professional activities.

This research aimed to develop insights into steering processes and their outcomes with respect to integrated care at all levels, and with respect to the interaction among these levels. It has also sought to contribute to the development of an analytical framework, which can be used to promote steering strategies for integrated care at national and local level. 


\subsubsection{The selection of dementia care as the target area}

In seeking to investigate real-life steering processes for integrated care development and delivery at local level, the researcher is faced with manifold care pathways for different user groups with long-term multiple care needs, for all of whom integrated care is essential. One way to define a feasible sector for research is to identify an exemplary target group. For this research dementia care was the chosen focus, for the following reasons.

People with dementia represent an especially vulnerable group with complex and difficult care needs requiring integrated care and support across health and social services, not only for themselves, but also for their family carers. Additionally their number is rising both absolutely and relatively (with respect to total population) because of demographic changes ("double greying") combined with the fact that prevalence increases with age. To date there is no effective medical treatment or preventive option. In both England and The Netherlands a two to threefold increase is expected between now and 2050 (Alzheimer's Society, 2000; Gezondheidsraad, 2002), which adds to the importance of effective and efficient integrated care pathways. Finally, care concepts in the field of dementia have been the subject of considerable professional debate and have been significantly re-defined over the last 15 years ( $c$ f. Chapter 4). The challenge for integration of dementia care therefore is closely associated with a general challenge to incorporate new findings and approaches into care planning and daily care processes.

This study has sought to identify best practice in integrated dementia care in the countries under study, and to investigate and understand the current achievements and shortcomings - and in particular the role of the respective steering processes.

\subsubsection{A cross-national and comparative perspective: England and The Nether- lands as the countries for study}

As stated above, integrated care is a policy focus for many Western countries as they face comparable challenges with respect to demography, epidemiology, economy and socio-cultural developments. However, while there is some convergence at the supranational level regarding those challenges, remarkable divergences seem to exist when we look at how different countries and regions and localities within countries attempt to respond to them (Leichsenring, 2004; van Raak et al., 2003).

A cross-national and comparative perspective is intended to render insights that go beyond purely national perspectives, by identifying similarities and differences and searching for possible explanations. A study can be said to be cross-national and 
comparative, "if one or more units in two or more societies, cultures or countries are compared in respect of the same concepts and concerning the systematic analysis of phenomena, usually with the intention of explaining them and generalising from them" (Hantrais \& Mangen, 1996, p.3).

This study compared England and The Netherlands. Both countries have had integrated care high on their national health and social policy agendas for more than a decade (cf. Chapter 3), represent interestingly different types of health care systems and welfare states. In both countries dementia care has been the subject not only of considerable professional debate but innovative care approaches ( $c$. Chapter 4). Moreover, existing cooperative work between the Universities of Maastricht and Leeds in the field of integrated care (Hardy et al., 1999; Mur-Veeman et al., 2003) provided an excellent starting point. The decision to limit the study to two countries was based on a preference for an in-depth approach. In view of the limited timeframe of a PhD research project, this focus appeared to offer the possibility of realising the very advantage of cross-national comparisons; that is, that "at their best, they force researchers to look at a totall context and enable them to discover the greatest number of factors that are interactive and interdependent" (Hantrais \& Mangen, 1996, p.3). To extend the comparative approach at the local level, local case studies were undertaken in four communities, two in each country.

The comparative approach adopted in this study has been used to explore and understand the variations between the countries with respect to steering processes for integrated care at national level, with respect to best practice ideas and achievements regarding dementia care, and with respect to integrated dementia care pathways at local level.

\subsubsection{Research goals}

To summarise, the research aims were as follows:

- to explore steering processes with respect to complex societal problems such as integrated care;

- to investigate the context of dementia care in England and The Netherlands, by examining and analysing best practice approaches, current achievements and shortcomings;

- to specify what the concept of integrated care then means when applied to the field of dementia care;

- to explore and understand the steering processes affecting integrated (dementia) care, their effects at national and local level, and their interdependencies; 
- to use a comparative approach to explore and understand the variations between countries, and the variations between communities within and between countries, and

- to contribute thereby to the dlevellopment of an analytical framework, which can be used to promote steering strategies for integrated care in communities and countries.

To achieve the above research goals, the study has been designed as a cross-national comparative multiple case study, comprising national and local cases. It is based essentially on a qualitative methodology using a neo-institutional conceptual framework, both of which will be explicated in Chapter 2. The framework consists of concepts describing steering processes as embedded in contexts of historically developed institutions that shape and limit, but not determine steering options of respective actors. By focusing on institutional contexts, neo-institutional approaches enable us to identify and investigate differences and similarities across countries and therefore are especially suitable for comparative studies.

\subsection{OUTLINE OF THE STUDY}

The study has been structured in three stages of data collection and analysis, each one building on the previous stage. The focus has thus moved from national to local steering processes, from integrated care as a general policy goal to a framework specifically for integrated dementia care, and finally, in detail, to the local processes of integrated care development and delivery for dementia patients.

\subsubsection{Stage One: Analysis and comparison of the national health care systems and steering processes regarding integrated care in England and the Netherlands}

The first stage focused on the national level, i.e. the comparative study of the national systems of health and social care in England and The Netherlands, and the national policies (and their broad success and failure) with respect to integrated care development and delivery. Aggregated national evidence - excluding local variations in this stage - was investigated, compared and analysed. Since national policy initiatives and strategies dedicated to integrated care are mainly general rather than aiming at specific target groups, integrated care developments in this stage were analysed at this general level. 


\subsubsection{Stage Two: Analysis and comparison of integrated dementia care in England and the Netherlands: Recommended standards, achievements and short- comings}

In the second stage, the focus of the comparison in the two countries was dementia care. An inventory was compiled of the characteristics of good practice in each country; this inventory was further discussed within the expert community including patients' and carers organisations. On this basis recommended standards were identified differentiating between service delivery, activities for integration and competence development. With respect to the recommended standards, aggregated national evidence about achievements and shortcomings regarding integrated dementia care development and delivery was investigated, compared and analysed. Similarities and differences between the countries were analysed. A starting point was thereby provided to differentiate between nation-specific and trans-national phenomena.

\subsubsection{Stage Three: Analysis and comparison of local processes of integrated de- mentia care: Four local case studies}

This stage was dedicated to studying the local level, at which integrated care policy development and delivery is visible. Two localities in each country were selected as local case study sites, Leeds West, York, Amsterdam Nieuw West, and Maastricht. Findings from the first and second stages were used to guide data collection and description, and also as a reference frame for analysis. Information about all aspects of local integrated dementia care development and delivery was collected including those of national-local governance interactions.

Local steering processes for integrated dementia care, their interaction with national processes, and their outcomes were analysed and compared within and between the countries.

Finally, knowledge transfer as part of cooperative relationships between specialists and generalists in dementia care was explored and analysed with respect to the interand intra-organisational characteristics associated with success or failure.

\subsection{AN OUTLINE OF THE THESIS}

Chapter 2 introduces and discusses the conceptual framework. It then develops the research design and methodology. Finally, the approach to ethical issues arising during this study is described.

Chapter 3 compares, analyses and discusses the national policies for integrated care in England and The Netherlands and their identified outcomes (research step 1). 
Chapter 4 describes the responses in England and The Netherlands to challenges of dementia care at national level: recommended standards, achievements and shortcomings are inventoried, discussed and compared (research step 2).

In Chapter 5 four local case studies in England and The Netherlands are presented. Local steering processes, their interaction with national policies, and their outcomes, are analysed and compared within and between both countries (research step 3 ).

Chapter 6 investigates knowledge transfer as an essential part of cooperation between specialists and generalists in dementia care. Evidence from the case studies is used to develop a model conceptualising factors influencing success and failure of knowledge transfer (research step 3).

Chapter 7 presents overall conclusions and suggests an analytical framework for the development of steering strategies for integrated care at the different levels involved. Furthermore a discussion of the challenges encountered during the research is provided.

\section{REFERENCES}

Alzheimer's Society. 2000. What's the Society's position on ...? Alzheimer's. Dementia care \& research: London, UK.

Delnoij D \& Klazinga NS. 2002. Integrated care in an international perspective: EUPHA proceedings December 2001. International fournal of Integrated Care 2.

Gezondheidsraad. 2002. Dementie. Advies van een commissie van de gezondheidsraad (Dementia. Advice by a committee of the Health Council). Gezondheidsraad (Health Council of the Netherlands). Publication no. 2002/04: Den Haag, The Netherlands.

Grome $O \&$ Garcia-Barbero M. 200\%. Integrated Care. A position paper of the WHO European office for integrated health care services. International Journal of Integrated Care 1: mww.ijic.org.

Hantrais L \& Mangen S. 1996. Method and management of cross-national social research. In Cross-national research methods in the social sciences, Hantrais L, Mangen $S$ (eds); Pinter, London; $1-12$.

Hardy B. Mur-Veeman I, Steenbergen M \& Wistow G. 1999. Inter-agency services in England and The Netherlands. A comparative study of integrated care development and delivery. Health Policy 48: 87-105.

Kodner DL \& Spreeuwenberg C. 2002. Integrated care: Meaning, logic, applications and implications: A discussion paper. International lournal of Invegrated Care 2: www. ijic.org.

Leichsenring K. 2004. Providing integrated health and social care for older persons - A European overview. In Providing integrated health and social care for older persons. A 
$26 \|$ Chapter 1

European Overview of issues at stake, Leichsenring $\mathrm{K}$, Alaszewski AM (eds); Ashgate, Aldershot; $9-52$.

Leichsenring K \& Alaszewski AM (eds). 2004. Prowiding integrated health and social care for older persons. A European Overview of issues at stake. Ashgate: Aldershot.

Mintzberg H. 1983. Structure in fives. Prentice Hall: Englewood Cliffs.

Mur-Veeman 1, Hardy B, Steenbergen M \& Wistow G. 2003. Development of integrated care in England and the Netherlands: Managing across public-private boundaries. Health Policy 65: 227-241.

O'Toole L.). 1997. Treating networks seriously: Practical and research-based agendas in public administration. Public Administration Review 57: 45-52.

Rhodes RAW. 1997. Understanding governance. Policy networks, governance, reflexivity and accountability. Open University Press: Buckingham.

van Raak AlA. 1998. Zorgvernieuwing: een kwestie var routine. Een studie naar de vorming van interorganisationele netwerken en nat systeemveranderingen in de thuiszorg vanuit interactionistisch perspectief (Health care innovation: A matter of routine. A study about the building of interorganisational networks, and about system changes in home care from an interactionistic approach). Universiteit Maastricht: Maastricht.

van Raak AJA. 2004. Can we solve fragmentation or should we manage it? In Network $\| C$ (Ed.), ICN-Events, Integrated Care for Older People: Birmingham City Centre, Birmingham.

van Raak AlA, Mur-Veeman I, Hardy B, Steenbergen M \& Paulus A (eds). 2003. Integrated care in Europe. Description and comparison of integrated care in six EU countries. Elsevier: Maarssen, The Netherlands.

Willke H. 1998. Steuerungstheorie: Grundzüge einer Theorie der Steverung komplexer Sozialsysteme (Theory of steering: Basic theoretical lines for the steering of complex social systems. Lucius \& Lucius: Stuttgart. 


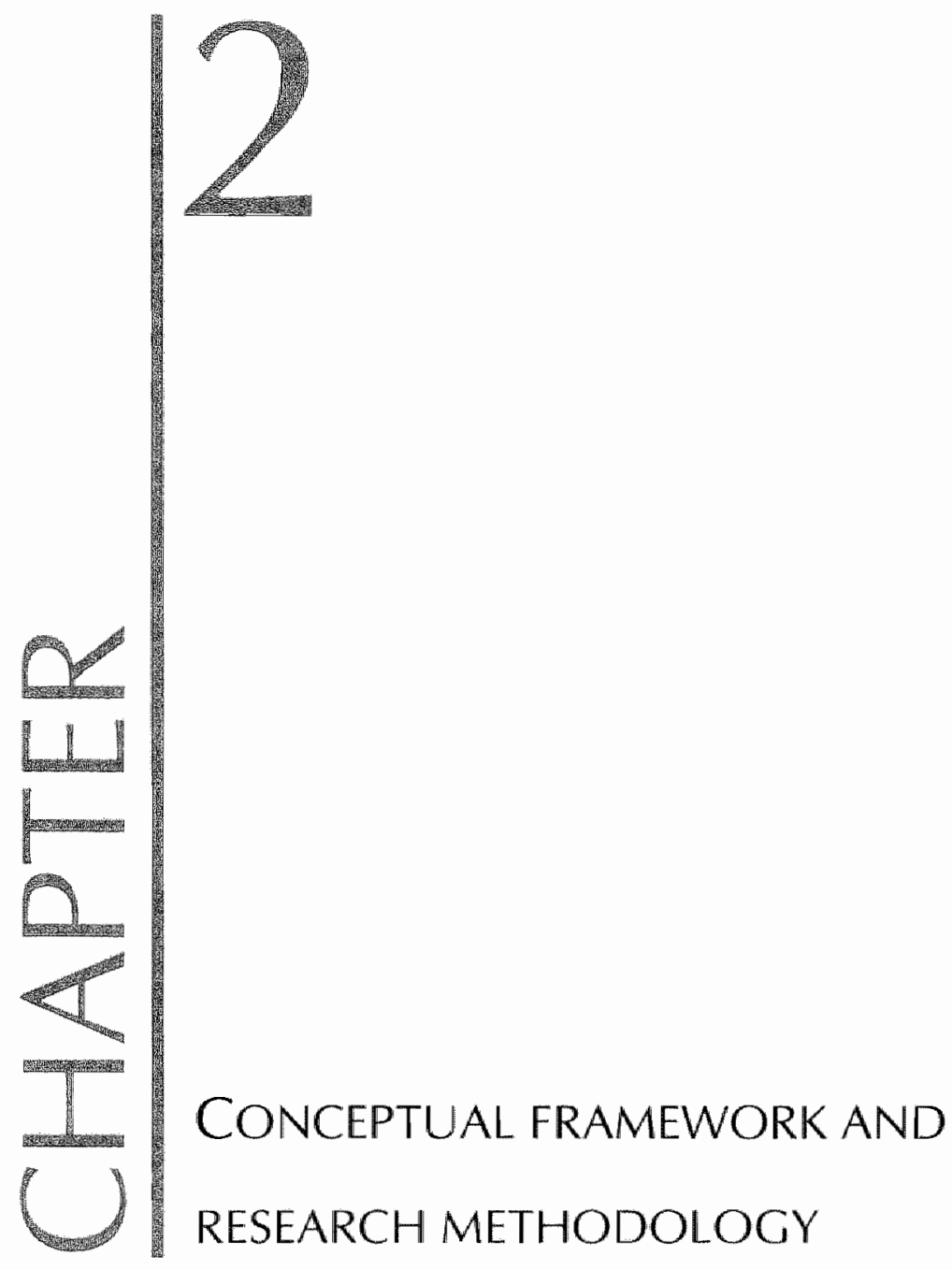


28 Chapter 2 


\subsection{INTRODUCTION}

The aims and scope of this research require theoretical foundations, which support a cross-national, comparative in-depth evaluation of health policy and health and social care systems. Furthermore they have to facilitate an understanding of steering issues regarding integrated care at different levels. Neo-institutionalist approaches are appropriate concepts on both grounds. They are used here as general propositions and sensitising concepts, providing an open framework to be further developed, differentiated and thickened with respect to the questions addressed by this research project. in this sense the research is explorative, descriptive and explanatory' in character, and the analysis has been partly deductive - theory-driven - and partly inductive - data-driven; to a small extent proposition-testing and, to a greater extent, proposition-generating.

Following Yin's classification this study has been designed as a multiple embedded case study (Yin, 1994). It comprises cases at national and embedded cases at local level. Since the research is based on an interpretive onlology and 'verstehend' in its approach to analysis, a qualitative methodology will be employed. Furthermore, institutional ethnography requires the iterative and accumulative approach to data collection and analysis at the different case levels. It aims to unravel 'ruling relations', i.e. investigating how specific "practices and experiences are tied into extended social relations or chains of action" (De Vault \& McCoy, 2002, p. 754).

'In quantitative methodologies the term 'explain' is strictly reserved to define statistically confirmed causal relations. Qualitative methodologies, often as strichly, discriminate between explaining as asking for causes and reasons for phenomena or processes, and understanding (Weberian 'verstehen') as striving to grasp their meaning (Lamnek, 1995, p. 79, 86 r.). Case study apologists, however, often are less strict in their use of the term, implicitly blending in some way understanding and explanation (cf. Agranoff \& Radin, 1991; Yin, 1994). This should not be seen as accidental: In the case study endeavour - unravelling the connections within real complex societal processes - e.g. interviewees give their causal explanations for particular facts and circumstances, and contribute theirby to the construction of meaning as well as 10 the generation of explanatory propositions by the researcher. The other way round, meanings of facts or events, as living in the field, can become causal for courses of action. For this thesis, "explain" therefore is used respectively broadly, and includes a significant interpretive element (cf. paragraph 2.3). 


\subsection{DEVELOPING THE CONCEPTUAL FRAMEWORK}

\subsubsection{Neo-institutionalism}

The following sections outline the theoretical propositions that build the starting point for the study.

In the $1980 \mathrm{~s}$ and 1990 s the 'rationality project' in positivist and behaviourist policy analysis was criticized because of its mechanical and reductionist paradigm and its therefore limited capacity to depict and understand complex real life policy processes $^{2}$. This criticism opened a new stage in policy analysis (Heritier, 1993), which, in parallel with theoretical developments in the social sciences in general, paved the way to new context-oriented approaches.

In particular, neo-institutionalist approaches in political science present a framework suitable for exploring cross-national differences in policy development and implementation. What was essentially new was their focus on the interrelation between action and different institutional settings (Nørgaard, 1996). The neo-institutional framework is capable of grasping the context-specifity of steering processes, thereby their diversity, and thence a better understanding of their outcomes.

"Only detailed knowledge about the institutional landscape and its linked policies allows us, taking into consideration the existing structures and policies, to make statements about the chance of a new policy being successful or, respectively, its potential undesirable consequences for other policies."

Within neo-institutionalism, competing approaches exist, often differentiated as sociological, historical and rationalist institutionalism, with remarkable diversity internally, and also with vague lines between them (Thelen, 1999). They differ especially with respect to their conceptualisation of institution, the role of actors, and the formation of preferences. Recently, some authors have emphasised the potential for the convergence of these approaches rather than their incompatibility (e.g. Aspinwall \& Schneider, 2000; Scharpf, 2000a; Theten, 1999).

\footnotetext{
3. "It virtually bleeds the political life out of the policy making process, leaving little room for the dilemmas, contradictions, and paradoxes that characterise the interesting and difficult political problems." (Fischer, 1989, p. 944)

- "Nur die gemaue Kenntnis der der institutionellen Landschaft und der damit verknüpften Policies erlaubt zu sagen, ob angesichts der gegebenen Strukturen und Politikbestände eine neve Massnahme eine Erfolgschance hat bzw. ob die neue Massnahme die alten in unerwünschter Weise beeinflusst." (Héritier, 1993, p. 13)
} 


\subsubsection{Defining institutions}

'Institutions' refers to stable features within societies. Rationalist institutionalists tend to define institutions as any man-made form of constraint shaping human interaction, both formal and informal (North, 1990). In so doing, they move away from the origin of neoclassical economics with its assumption of 'homo economicus', and define institutions as broader than just formal rules and regulations. Historical institutional. ists define institutions as "structural and constraining features" (Aspinwall \& Schneider, 2000, p. 7 f.), evolving over time. At the other end of the continuum, sociological institutionalists understand institutions as "cognitive and culturally embedded" phenomena, including also "socially constructed and culturally taken-for-granted worldviews and shared normative notions of appropriateness" (Aspinwall \& Schneider, 2000).

Corresponding more with the latter, this thesis adopts a broad definition of institutions, comprising "legal arrangements, routines; procedures, conventions, norms, and organisational forms ${ }^{\prime \prime}$ (Nørgaard, 1996). Of course, these categories are initially abstract and cannot describe real phenomena with defined properties, since the forms and content of institutions differ infinitely and therefore "produce causal effects only in their concrete form." (Scharpf, 1997, p.38).

A distinction is made between institutional structure and culture. 'Structure' refers to the more formal constraints, namely legal arrangements, financial frameworks, procedures and organisational forms. 'Culture' embraces the more informal constraints, namely organisational, professional, political and public values, norms and routines. Interacting with each other, institutional structure and culture shape steering options. Institutions have a double character, as indicated by 'constraint' and 'shaping'; they restrict as well as facilitate or empower action. Furthermore, institutions are manmade and of developing character. Not only do institutions shape human actions and interactions, but the latter shape institutions (Aspinwall \& Schneider, 2000; Scharpf, $2000 \mathrm{~b}$ ). This reciprocal relationship between actors and institutions dealt with below.

\subsubsection{Unravelling the context: The concept of configuration}

For this study, it is important to introduce the concept of configuration, as used by Lehmbruch (1996) to describe the national and sectoral set of institutions that build the context around the topic of analysis. The characteristics of specific systems are 
understood as historically evolved 'configurations'. Their institutional structure and culture analytically interact with each other and mould the strategic options and limits of actors in policy development and implementation - thus their steering opportunities. The features of national and sectoral public policies can be understood as historically developed paths, arising from a "sequential interaction of the organisation of state and society" (Lehmbruch, 1996, p. 75). From this perspective policy processes are seen as 'path dependent' (Boase, 1996), though it is important to note that dependence here means something short of and other than being 'determined by" institutional configurations. The relations between institutions and actors, and between stability and change, are more extensively discussed in the paragraphs below. Even if institutions are defined relatively broadly for this thesis, their definition does not encompass everything: there is a context 'outside', independent from the institutional configuration, comprising very different phenomena such as demographic or economic developments or personal characteristics. In the shorter or longer run, however, they might be expected to affect existing institutions and contribute to their change.

In the first stage of the research the configurations under study are the systems of health and social care of England and The Netherlands at the national level and the policies in both countries that affect the development of integrated care (cf. Chapter 3). The second stage comprises an analysis of the field of dementia care and the specific policies and actors involved in shaping integrated dementia care at national level in both countries, which constitute the configurations to be studied. Evidence about dementia care practice is taken into account in an aggregated form (cf. Chapter 4). In the third stage, the analysis is extended to local institutional configurations of integrated dementia care development and delivery (cf. Chapter 5). Local contexts are conceptualised as institutional configurations of their own, although embedded in and significantly shaped by the national configuration, in which they exist.

Describing and comparing configurations also implies the question of how far certain features can be identified and understood as configuration-specific or generic. Institutional patterns show similarities and differences among nations, as will be demonstrated in Chapter 4 and Chapter 5 . Generic features may indicate common sectoral characteristics across nations (cf. Chapter 4), or common characteristics of large versus medium-sized cities (cf. Chapter 5).

"The concept of configuration here is defined similarly to Scharpf"s concept of the "institutional setting", used "as a shorthand term to describe the most important influences on those factors that in fact drive our explanations - namely, actors with their orientations and capabilities, actor constellations, and modes of interaction." (Scharpf, 1997, p.39) 


\subsubsection{A view on the role of actors}

It is important to clarify, to what extent institutions affect actors, their preferences, choices, and actions. There are important differences between the three institutionalist approaches when comparing their conceptualisations of preferences. Sociological and most historical institutionalists understand preferences as 'endogenous': they see humans' preferences rooted in institutional contexts and therefore "their menu of options and preferences (as) limited by the repeated historical practice of interaction and by the social setting in which they find themselves" (Aspinwall \& Schneider, 2000, p. 6). Rationalist institutionalists, in contrast, espouse a methodological individualism, and consider human preferences and actions as 'exogenous' to the institutional environment. In searching for some convergence, Scharpf has attempted to bridge the gap and conceptualises an actor-centred institutionalist approach. He treats "actor orientations (i.e. their preferences and perceptions) as a theoretically distinct category - influenced but not determined by the institutional framework within which interactions occur" (Scharpf, 2000a). Simillarly to Scharpf, but even more broadly, this thesis assumes individual actors to be intentional and reflective human beings, but simultaneously rooted in history and culture, as reflected by institutions (cf. Nørgaard, 1996, p.32).

This twofold description of individual actors is substantiated by the fact, that institutions in all societies are varied, complex, and diverse. Individual actors often perform different roles and represent different interests (Scharpf, 1997), whereby they are subject to different sets of institutions. Correspondingly, collective actors consist of multiple individual actors, who are likely to develop ambiguous preferences. Such conditions promote cognitive dissonances, and thus the development of mixed preferences and perspectives and even meta-perspectives. Such processes have the capacily to prompt individual actors to think independently of particular institutions to some degree, and incorporate the actors' potential for consciously changing existing institutions or creating new institutions.

Therefore, in contrast to the historical, sociological, and the rationalist school of institutionalism the relation between actors and institutions is not conceptualised for this thesis as purely dependent or independent, but simultaneously as both. This refers to the fundamental interaction between institutions and humans which is assumed in this thesis: man-made institutions shape the preferences, perceptions, decisions and actions of actors to some degree, whilst at the same time actors themselves initiate, shape and change institutions. Thus, the individual, however embedded, still represents a relevant ontological entity. 


\subsubsection{Institutional endurance and change}

As Clemens and Cook simply assert, "institutions endure" (1999, p. 441). The concept of path dependency especially highlights the fact that political processes do not start from scratch, but are influenced by policy legacies, resulting from political decisions made in the past. Institutionalists emphasise "that the patterning of social life is not produced solely by the aggregation of individual and organizational behavior but also by institutions that structure action" (Clemens \& Cook, 1999, p. 442). An important concept here is institutional inertia, whereby institutions become "taken for granted', and resistant to change. Through repeated use they become internalised scripts. Moreover, they can get 'legitimate' through authoritative individuals. Institutions therefore are assumed to be stable as long as they remain unchallenged by exogenous shocks or crises.

The strong emphasis upon the endurance and stability of institutions, however, reveals a theoretical weakness of institutionalism, as it tends to neglect institutional change - and, in the words of Clemens and Cook, "to marginalize the processes of conflict and innovation that are central to politics" (1999, p. 442). Thus institutionalists might fail to explain institutional change and the role of actors in that change, by suggesting that "structure indeed may be created by agents; but subsequently, like Frankenstein's monster, structure takes on a life of its own" (Aspinwall \& Schneider, 2000, p. 10).

Reacting to such a shortcoming, recent theoretical work has explicitly focused on institutional change. Lin defines institutional change as "the introduction of new rules or rule interpretations that supplement or replace existing rules and interpretations" (2003, p. 913). Among others, Clemens and Cook explore the change drivers of institutional configurations (1999, p. 448f.). The first driver they identify concerns the variation evolving from different degrees of binding effects connected to institutions, whether they imply a "must", "must not" or "may". Second, they refer to internal contradictions of institutions that reduce their problem-solving capacity, leading to performance crises. Also external influences, e.g. resulting from economic crises or demographic changes, may produce a mismatch between institutions and new demands and needs (cf. Norgaard, 1996), which provoke institutional change. Finally, the multiplicity of institutions within specific configurations challenges the 'taken-forgranted' character of institutions. Individual actors increasingly participate in multiple networks and thereby in diverse institutional settings. In so doing they become independent from particular institutional perspectives and develop meta-perspectives. All three patterns can contribute to actors' capabilities to take a role as a 'change agent', since they include mechanisms contributing to individuals' cognitive dissonances. 
Moreover, the relations between institutions of a different order may have important consequences for stability and change. This can be clarified by an example taken from this study (cf. Chapter 3): The British Westminster model assumes a strong governmental capacity and a habit of implementing frequent structural changes in public services. These frequent changes can be understood as an institutionalised governance pattern; it involves the implementation of changes in organisations at local level that are subject to these measures. Thus, institutional characteristics at national level may change, disrupt or destroy institutions at local level. Under certain circumstances this might trigger cynicism as a new institutionalised pattern amongst those, who time and again have to adapt their daily practices and procedures to new regulations.

Finally, institutional changes quite often lead to unintended consequences. Planning and control of changes by steering is difficult. As this thesis is devoted to analysing steering processes facilitating integrated care, it deals with the potential for and ways to plan changes. Describing success and failure of steering processes, however, requires the unravelling of the institutional configurations as well as an analysis of the courses of change within real configurations. For example in Chapter 1, among other things, the adherence or otherwise to nation-specific modes of governance is proposed as an important explanatory factor in the success or failure of policies aimed at integrated care.

\subsubsection{Configurations in process: Steering}

Neo-institutionalists claim that a steering capacity within political systems exists, as well as the 'steerability' of other functional systems within a society or nation (Scharpf, 1989). In this thesis this claim serves as a core concept. This position contrasts with that of Luhmann (the influential theorist of 'second order cybernetics' and new system theory), who has postulated that political (sub)-systems as self-referential entities can steer only themselves but not other (sub)-systems (Luhmann, 1989). Institutionalists see steering capacity as something "difficult in principle and dependent on institutional conditions ${ }^{\prime \prime}$. Therefore it is important to unravel these conditions in order to understand successful or unsuccessful attempts at steering.

Scharpf discriminates between two directions of policy research (Scharpf, 1997, p. 10ff.):

" "Sie ist vielmehr prinzipiell prekär und von institutionellen Voraussetzungen abhängig." (Scharpif, 1989, p. 18) 
Problem-oriented policy research analyses the causes of political problems and proposes effective and efficient solutions - like those a 'benevolent dictator', committed solely to the 'common good" ${ }^{6}$, would suggest - passing aver the very topic of steering. In this thesis, integrated care is assumed to be a policy concept oriented at the common good, thus involving a normative starting point. Chapter 4 to some degree fits to this type of research - it presents and compares best practice standards of dementia care and analyses the widespread failures to meet them. Chapter 6, similarly, describes promoting and inhibiting factors for desirable processes of cooperation and knowledge transfer between generalist and specialist professionals in dementia care. Interaction-oriented policy research, on the other hand, analyses the steering processes by which, within institutional configurations, policies are made in real-life situations. Real-life steering processes, however, quite often lead to sub-optimal solutions in contrast to those suggested from a 'benevolent-dictator perspective' (Scharpf, 1997). This underlines the importance of such research, which is central to the goal of this thesis: to explore and seek to understand steering processes and their outcomes as facilitating and shaping integrated (dementia) care by analysing their interaction with institutional configurations. Such analyses, focussing on steering processes at national and local level, are presented in Chapter 3 and Chapter 5, while Chapter 4 and 6 provide essential background analyses.

The concept of 'steering' is defined as the interactive processes ${ }^{7}$ by which governmental and other relevant actors influence each other (Kooiman \& Associates, 1997) to maintain or change rules of actions (van Raak, 1998). Steering processes are conceptualised as complex phenomena: structures, processes, attitudes of actors, and outcomes are closely intertwined with each other, and may differ among national as well as local configurations. For this thesis, steering is broadly defined, comprising those governance, managerial and professional activities at national and local level, which affect the development and delivery of integrated care in general as well as in operational detail.

The first and the third stage of the study especially focus on a comparative analysis of steering processes at national level and local level (cf. Chapter 3 and Chapter 5). The first stage includes an analysis of the steering processes at the national level regarding integrated care and their outcomes. As integrated care essentially is delivered at local level, the third stage involves the analysis of locall steering processes with respect to integrated dementia care. It is proposed that local steering processes produce local

"Following Scharpf, the concept of 'common good' is determined by two dimensions, namely welfare production and distributive justice (Scharpif, 1997, p.15).

7 Processes are defined here as sequences of situations, connected with and caused by decisions and respective actions. 
outcomes in interaction with national steering processes (ct. Jones, 2000), with a strong role for local institutional configurations in shaping variations in processes and outcomes.

Chapter 4 deals with the development of standards (norms) for integrated dementia care, and with an analysis of the divergences between these standards and mainstream care processes. It thereby renders important information for steering processes of integrated dementia care. Chapter 6 analyses and conceptualises the circumstances for success and failure of steering processes at the micro-level of interprofiessional cooperation and knowledge transfer.

\subsubsection{Hierarchy, market and network}

Defined as 'models of coordination' in society (Thompson et al., 1991) or as "institutionalized modes of interaction" (Scharpf, 1997, p. 15), the concepts of hierarchy, market and network enable us to analyse steering processes within institutional configurations.

The market is characterised by automatic coordination - the 'invisible hand' of independent and interacting actors who pursue their individual goals. Hieranchy works by systematic administration - bureaucracy - and is connected with super-ordination and sub-ordination. Networks are described as interactions between autonomous but interdependent actors within more or less informal and long-term relationships that are buit on negotiation and trust (Thompson et al., 1991). The steering potential which hierarchies, markets and networks provide to governmental and other actors in certain fields, and their limitations, are discussed from various perspectives (Scharpf, 1993, 1997; Williamson, 1985; Willke, 1998). Hierarchy and markel are seen as the typical modes of interaction of modern societies. Networks are often described as emerging from the particularities of 'post-modern" societies (O'Toole, 1997; Willke, 1998), and are associated with 'governance' as opposed to "government" (Kickent et al., 1997; Kooiman \& Associates, 1997). Networks are sometimes characterised as intermediate between hierarchies and markets (Williamson, 1985), but elsewhere as a new form with specific qualities (Mildenberger, 1997; Willke, 1998). Networks above all are seen as suitable especially for those complex issues - variously named 'cross-cutting issues' (Martin, 2000) or 'wicked problems' (O'Toole, 1997) - that emerge in differentiated and fragmented societies (Willke, 1998), and are characterised by not being amenable to solution by hierarchical or market mechanisms (Atkinson \& Coleman, 1992).

Integrated care can be seen as an examplar of such a complex task structure to be tackled by public policy: it relies on flexible cooperation of different individual and 
collective actors - public, semi-public and private organisations, at different levels of those organisations, operating in different professional domains. Governmental steering at national level must facilitate this cooperation at local level. The relation between integrated care as a 'cross-cutting' issue and the network form seen as the appropriate mode of governance (O'Toole, 1997) is further explored in this thesis (cf. Chapter 3 and 5 ).

As the concepts of hierarchy, market, and network describe ideal types, rarely occurring in isolation, the question arises how they operate in different combinations. Specific national institutional arrangements will be shown to be associated with characteristic combinations of modes of interaction (cf. Chapter 3). In general, these concepts are capable of analysing steering processes and their outcomes as embedded in the national and local institutional configurations. They thereby contribute to the analysis of the differences between countries and communities with respect to processes and outcomes. National and local health and social care systems thus become visible as 'configurations in process' rather than as static pictures. It is the exploration of developments and changes, and the comparison between countries and communities, which sheds light on steering processes and mechanisms.

\subsection{GeNERAL RESEARCH QuESTIONS}

Given this conceptual framework the research goals described in the introduction are translated into the following central research questions for this study:

- How can national steering processes and outcomes for integrated care in England and The Netherlands be described and understood as being shaped by national configurations? (Chapter 3)

- How can similarities and differences in dementia care in England and The Netherlands be described and understood as being shaped by these specific national configurations or by generic patterns? (Chapter 4)

- How can local configurations and their interaction with national configurations be described and understood as shaping local steering processes regarding integrated dementia care? How can variations within and across countries be understood? (Chapter 5)

- How can local (governance, managerial and professionall) steering processes and outcomes for integrated dementia care be described and understood as shaped by national and local configurations or generic patterns? (Chapter 5 and 6 )

- What conclusions can be drawn from these analyses for successfull steering processes for integrated (dementia) care and their required conditions? (Chapter 3, $4,5,6$ and 7 ) 


\subsection{THE STUdY METHODOLOGY}

The following section outlines the study design. Subsequently the produres of data collection, processing and analysis are focussed on. Finally, the ethical considerations applied to this study are discussed.

\subsubsection{Developing the research design}

\subsubsection{A cross-national comparative approach}

In an increasingly globalised academic world, cross-national comparative research is important for a wide range of subjects and disciplines - e.g. sociology, political and/or cultural sciences (Bowen \& Petersen, 1999a; Hantrais \& Mangen, 1996a; Kennett, 2001; Kohn, 1989b). Such research has the potential to exceed the limits of nation-centred views, whilst forcing the researcher

"to attempt to adopt a different cultural perspective, to learn to understand the thought processes of another culture and to see it from the native's viewpoint, while also reconsidering their own country from the perspective of a skilled observer from outside." (Hantrais \& Mangen, 1996b, p. 3)

In this respect, the situation in this project was special, since the researcher's background was neither English nor Dutch, but German. This meant that both countries were examined from an outsider perspective.

Cross-national research is seen as a means to establish "the generality of findings and the validity of interpretations derived from single-nation studies" (Kohn, 1989a, p.77). The identification and interpretation of similarities and differences between countries lies at the heart of comparative research (Kohn, 1989a). A comparative approach, as chosen for this study, enables us to discriminate between those features that can be attributed to a particular national configuration, and those, which might be significant beyond a single nation. Such research thus has "the potential to inform debates which have significance beyond the boundaries of the single country" (Kennett \& Yeates, 2001). Analogously we can examine, which local features are specific for a particular local configuration and which might be attributed to the national configuration or even broader to a European or Western configuration.

Small-scale comparative case studies (i.e. involving a small number of cases) are suitable to address "much of the complexity of political life while maintaining an ability to generalize" (Bowen \& Petersen, 1999b, p. 11; cf. also Scharpf, 2000a). Though, generalisation here is meant in a non-statistical, theoretical sense (see below). As outlined above (cf. Chapter 1), England and The Netherlands were chosen as countries for study, with two localities in each country then selectied as local case 
studies. This allowed a comparative approach at both national and local level, to account for variations not only between localities within a national configuration, but between localities across countries. It also provided the particular opportunity to investigate national and local complexity in some depth. However, certain limitations arise from the decision to limit the study to the two countries. A comparative lens always tends to focus the view on differences, and might fail to point out similarities with respect to those configurational features that, from the field perspective, are perceived as quasi-natural, and therefore are no point of discussion or even mentioning in written or oral data. If the researcher is not alert regarding such issues, maybe because also literature so far does not cover them, there will be no reference point for investigation and analysis. If we look at other countries or cases, which are in some important respects significantly different, then we can put in perspective what is often taken for granted in the countries or cases.

\subsubsection{The case study design}

Yin defines a case study as "an empirical inquiry that investigates a contemporary phenomenon within its real-life context, especially when the boundaries between phenomenon and context are not clearly evident" (Yin, 1994, p. 13). Case studies are seen as appropriate when contextual conditions are assumed to be important for the phenomenon under study - which clearly applies to this research and corresponds with the neo-institutionalist framework.

This study can be described as a series of three inter-linked multiple case studies as indicated in the three steps of the research (cf. Chapter 1). Multiple case studies involve more than a single case and comprise a comparative rationale according to the classifications provided by Yin (1994, p. 38 ff.). Following Agranoff and Radin (1991), a multiple case study design requires that the same research questions or propositions are examined in each case, but allows their further development and specification for each case during the course of the study in order to trail the particularities of each case. The cross-case analyses that are generated then from the in-depth analyses of each case proceed from the specific to the general. The propositions derived from these analyses are both descriptive and explanatory in character (see below).

\subsubsection{Steps in generating knowledge: The design in process}

A formalised picture of the research process is given in Figure 2.1:

Initially in the research process the case studies performed in the first and second research stage were conceptualised as 'holistic' case studies (Yin, 1994, p. 38 ff.); i.e. they elaborated a question at a general level and did not study potential sub-units specifically. 
Figure 2.1: Steps in the research process

National case studies stage $1 \& 2$

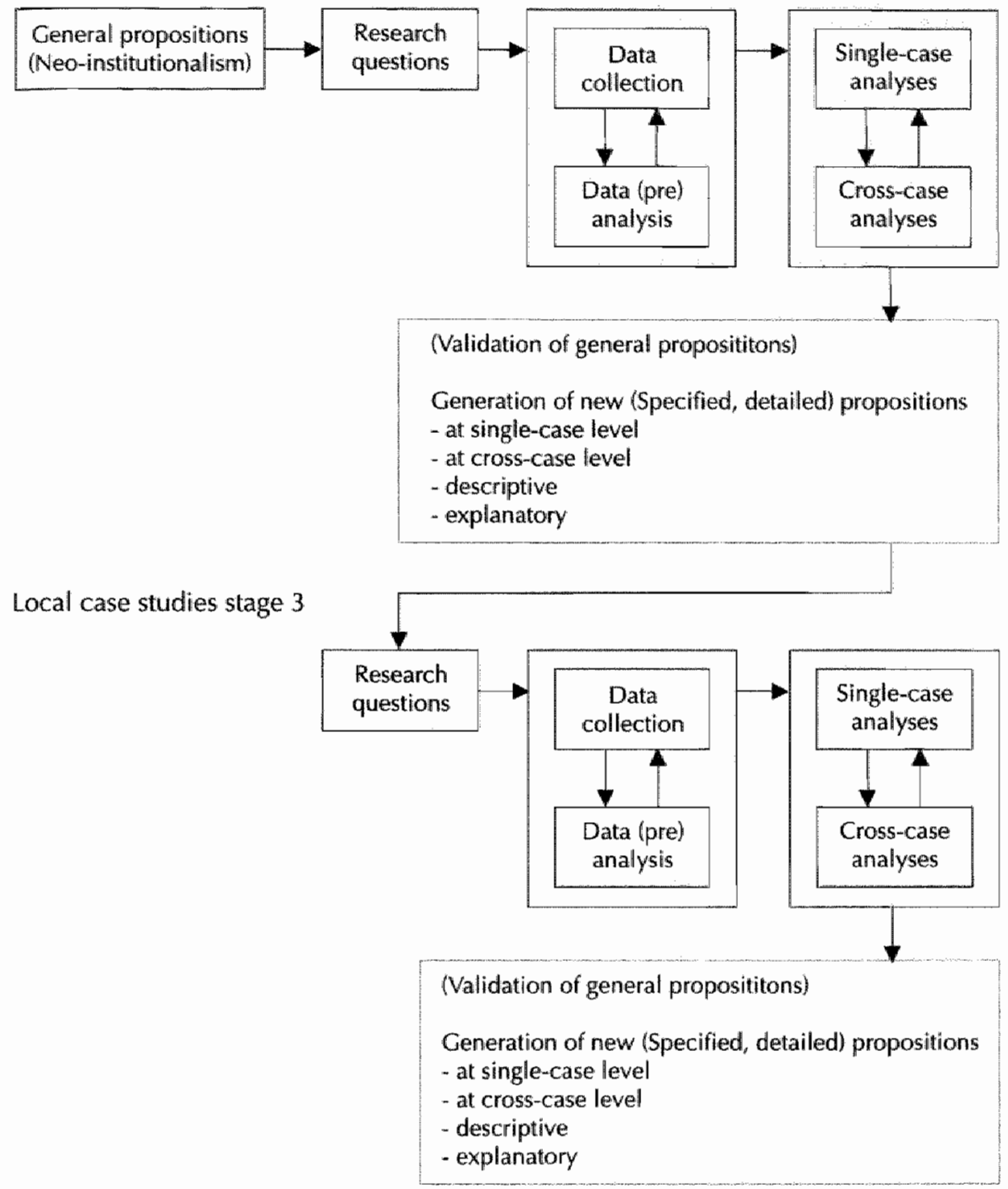

Two comparative case studies (ct. Chapter 3 and 4) were subsequentlly conducted in England and The Netherlands at national level - on steering of integrated care in general, and on standards and practice of integrated dementia care, as outlined above and described in more detail below. Covering different questions, they define different configurations as the units of analysis. The results from these two stages have 
then informed the preparation of the third stage of the research, the local studies (cf. Chapter 5), leading to the development of additional specific research questions, and thereby guiding the subsequent data collection. Together the three comparative case studies can be defined as an 'embedded' design, with the local $\operatorname{cases}^{8}$ embedded in the national cases of England and The Netherlands as investigated in the preceding stages. To realise the capacity of an embedded design, the analysis must link the level of the embedded cases to the larger unit of analysis (Yin, 1994, p.44). For this study this means investigating local processes not in isolation, but including the analysis of central-local interactions relating to the steering of integrated dementia care. Furthermore the embedded design requires comparing the local cases first within the countries - i.e. treating them as sub-units of the national configurations - before comparing them across countries.

In Chapter 3, describing the first stage of the project, national policy developments for integrated care and their overall successes and shortcomings are studied and compared. Steering processes within the national health and social care systems are described and understood by analysing their institutional structure and culture. Significant configurational features are identified in both countries that contribute to an understanding of the relative success and failure of the steering processes. For example, differences in the prevailing modes of governance between the countries appeared as essential to the steering processes regarding integrated care development and delivery. Recommendations are developed for steering strategies in both countries, and also, at a different level, for the analytical steps required to develop such strategies.

In Chapter 4, describing the second stage, prevailing ideas are investigated about best practice (recommended standards) in dementia care and the overall achievements and problems perceived in mainstream dementia care pathways in both countries. Similarities and differences between recommended standards, and between achievements and problems in integrated dementia care are identified, described and interpreted as either configuration-specific or generic features, with respect to the national configurations under study. Features which appear as generic, are shown to be rooted in sectoral cross-national characteristics of health and social care systems, e.g. certain features of medical professionalism, in Western countries.

Chapter 5 then deals with the third stage of the project: an investigation of integrated dementia care development and delivery at local level in four localities. Local steering processes and their embeddedness in the national configurations and steering processes (as investigated during the first and second stage) are analysed. The con-

\footnotetext{
The rationale for their selection is described in chapter 5 .
} 
stuent elements of local configurations which shaped steering processes regarding integrated dementia care are identified; and he concept of local configurations is thereby developed and specified. The vartations between local configurations and steerng processes are explored within countries and beween countries, as well as variations in central-local relationships. Differences in central-local modes of govemance between the countres, and, therefore, their configuration-specific potential and imits, are also explicated and discussed.

For mutiple case studies Yin recommends a replication-logic (Yin, 1994, p.45 14 ): the first case is analysed betore data collection and analysis of the next; the research questions and propositions are successively refined and further developed according to the results of each case. The purpose, by bulding on existing theoretical insights, is to generate knowledge by gradually bulling and developing explanations (Vin. 1994, p. $110 \mathrm{ff}$ ). This sudy applied a limited replication-logic for all three steps (c). figure 2.1), by performing a provisional pre-analysis of each case (and re-defining on differentiating research questions and propositions) betore proceeding to the next case. By this means it is possible for in-depth analysis of the respective earlier cases to be informed by the pre-analysis of the later case. The fieldwork periods of the local cases were scheduled to alternate between the countries in order to enhance the researcher's cross-national perspective. These modifications of the replication-logic sought to achieve a more iterative relationship between the diferent case analyses rather than the sequental one proposed by Yin. This, one could argue, is more appropriate to the comparative nature of the study.

In all thee steps general propostions from neo-institutionalism, as outlined above, are taken as a starting point. They are further developed, specified and detalled throughout the research process to shape the specific questions at each step. Therefore the study is theory-and explanation-building in its focus, since the generation of new propositions contributes to a deeper knowledge and more specific understanding of the particular issues in question.

\subsubsection{The research process: Allowing for extensions and complementations}

An explorative qualitative approach implies openness and flexibility on the side of the researcher. This does not mean an absence of direction, but an initially wicle perspective in investigating a social issue or area of social life. The research approach should involve the capacity to take up emerging issues and to adapt the methoclological strategies and conceptual framework accordingly (Lamnek, 1995). Case studies, especially, produce huge amounts of data, via observation, interviews and documents, which extend the originally defined scope of study and thereby open up new topics relevant to the general research goal. The opportunity to address these 
topics, however, also brings the danger of a shift in perspective, which might challenge the consistency of the research process as a whole. Research protocols, defining the research goals and questions and the scope of data collections and analysis, are designed to prevent such drifts in perspective (cf. par. 2.4.2.5). To deal with topics, which evolve over the course of the research, a further, more specific protocol is required in order to explore the connection between these topics and the study"s central line of inquiry.

During the second and third stage of the research one issue emerged repeatedly as an important topic related to cooperation and quality development in dementia care: the issue of knowledge transfer as part of the cooperation between specialists and generalists. As a managerial and, especially, professional topic it was judged essential for the diffusion of new knowledge about dementia care and thus for the improvement of integrated dementia care. As a result, it was decided to perform a separate analysis of this topic, methodologically and conceptually slightly different to the preceeding analyses (cf. Chapter 6). In terms of its content, this topic was a reasonable and logical extension to the study.

The local case study databases provided rich information about what participants thought were the ways in which well-developed or poorly developed inter- and intraorganisational cooperation and integration promoted or inhibited knowledge transfer. The analysis focuses on the participants' perspectives, using specific concepts about inter-organisational networks and knowledge management. A conceptual model about success and failure of knowledge transfer between specialists and generalists within health and social services is developed. Since a preliminary comparative analysis of these data showed significant similarities between countries and localities, knowledge transfer was treated as generic; as a consequence a comparative approach was not attempted, and all four local studies were used as a pooled database for further analysis.

\subsubsection{Qualitative approaches to data collection, processing and analysis}

Qualitative research relates to what the philosopher Stephen Toulmin, in his framework of "humanizing modernity", argued is necessary for natural and social sciences and philosophy to overcome their societal dysfunctionality: a re-focus on language, communication and discourse, a re-orientation to the particularity of cases, a return to the specifity of the local, and a time-bound approach (Toulmin, 1990). Qualitative research has seen a renaissance during the last decades of the $20^{\text {th }}$ century. It corresponds with post-modernist views about the relation between research and its subjects, or more generally, between man and the world. "If interpretations constitute the 
'social construction of reality' (Berger \& Luckmann, 1969); theory-building about society has to be an interpretive process ${ }^{\prime \prime 9}$ "Qualitative research aims at the discovery of new understanding of its topics and at the generation of theories grounded in empirical data - theories understood as versions of and perspectives of how to see the world (cf. Flick, 1995, p.60).

The central topic of this study - steering processes for integrated care development and delivery - are seen and therefore studied in the following three chapters as complex processes bound by their locality and historical contexts (i.e. institutional configurations), constituted through communicative and interpretive practices. This research seeks to expand the understanding of such processes. Starting with general propositions and sensitising concepts drawn from neo-institutionalism, it seeks to develop and differentiate them with respect to specific empirical contexts, and use in particular the comparative design to investigate and discuss the generalisation and transferability of the findings (Chapter 3 to Chapter 5). In Chapter 6, as described above, a slightly different approach is taken, to which the following methodological considerations apply also.

Ideas from 'institutional ethnography' as developed in the 1990s (cf. De Vault \& McCoy, 2002; Grahame, 1998) support the qualitative methodology used in this study, since they accord with neo-institutionalist theory and case study design. As with ethnomethodologists and symbolic interactionists, institutional ethnographers are adherents of an "ontology that views the social as the concerting of people's activities" (De Vault \& McCoy, 2002, p. 752), but expands it by the concept of social relations, or "ruling rellations'. Such research takes everyday activities as a starting point and investigates how they are "hooked into, shaped by, and constituent of the institutional relations under exploration" (De Vaull \& McCoy, 2002, p. 753). It refers to the inter-connectedness between the micro and the macro, which for this study means between local and national, between integrated (dementia) care development and delivery, and between professional, managerial and political steering processes. and their embeddedness in national, sectoral and local configurations.

Data collection comprised literature reviews, document study and analysis, semistructured interviews, and, to a small extent in the third step, observation. A 'Qualitative Data Analysis' (QDA) sofitware programme (ATLAS.ti 4.2) has been used to process the data and to support the analysis. The specific approaches to and the procedures around data collection, processing and analysis at the different stages of the research are described in more detail in the methodology sections of the following

9 "Wenn Deutungen konstitutiv sind für die "gesellschattliche Konstruktion der Wirklichkeit" (Berger \& Luckmann, 1969), dann muss die Theoriebildung über diesen Gegenstandsbereich als interpretativer Prozess angelegt sein." (Lamnek, 1995, p.43) 
chapters. In the subsequent paragraphs of this chapter, some important general topics of qualitative methodology are discussed, with their application to this research being specified.

\subsubsection{The two-fold function of triangulation}

A common strand in the approach to data collection and analysis in qualitative methodology lies in methodological triangulation. The term triangulation originally stems from military and navigation strategies and refers to the precise definition of the position of an object by multiple reference points (Lamnek, 1995). Analogously, triangulation in the field of research mainly means the use of different methods to establish multiple sources of evidence for the validation of results (Yin, 1994, p. $91 \mathrm{ff}$.) and for the enrichment and completion of what we can know (Flick, 1995, p.250 f.). Since this study's primary aim is not the establishment of facts, but the search for and interpretation of contexts and meanings, triangulation "serves also to clarify meaning by identifying different ways the phenomenon is being seen" (Stake, 1998, p. 97), and to develop sensitising concepts.

Corresponding with this two-fold function of triangulation, the different data sources are used in this research for the purpose of confirmation and vallidation, and simultaneously to allow emerging findings to develop and differentiate concepts and propositions.

Similarly, interviews were used not primarily to reveal and investigate subjective states, but to shed light on particular circumstances and, as important, to identify possible next steps in a cumulative inquiry which goes beyond the particular perspective (cf. De Vault \& McCoy, 2002). As one interviewee during a local case study put it:

"You certainly have raised issues with me that I am glad you have raised because I could say something about it, which I suppose comes from having talked to other people and gradually you develop an agenda and you start to ask more relevant questions. And I just hope from my perspective ... I contribute something you need."

\subsubsection{Analysis and writing}

Interviewees impart their knowledge, their perceptions and their interpretations, when responding to questions. Their experience is part of the configuration to be investigated and, therefore, to a certain extent, shaped by institutional structure and culture, or as referred to by institutional ethnographers, by its 'ruling relations'. The same holds, in a slightly different manner "for literature and documents. The re- 
searcher"s task is to use the statements "to put together an integrated view based on these otherwise truncaled accounts" (De Vault \& McCoy, 2002, p. 7536), which means interpreting them as part of the developing picture of the configuration under study (cf. Chapter 3 to Chapter 5).

The analytical process, already begun during data collection, continues whilst processing the data, i.e. coding and retrieving them according to emerging strands, and interpreting them in the light of the developing concepts. This evolves into the story or narrative, which is built for each case. The case narratives, in classical qualitative approaches, present thick descriptions" "However, the form of the narratives presented in the following chapters is somewhat different due to the nature of the doctoral process. Thus the narrative text is summarised, concentrated, distilled to some degree for the particular purpose of matching the criteria of different academic journats"s. Still it is sought to convey the essential information supporting the analysis for the reader ${ }^{12}$, whilst preserving the specific features of each case, and the richness and collour of cross-national fieldwork. A narrative of a case, however, is more than just a description; the analysis continues in the process of writing. "The analyst weaves several stories though a narrative style that then becomes wrapped up in an overall story." (Agranoff \& Radin, 1991, p. 206). Therefore, rather than claiming that "a case tells it own story' the researcher's active part should be emphasised. "Even though committed to empathy and multiple realities, it is the researcher who decides what is the case's own story, or at least what of the case"s own story he or she will report." (Stake, 1998, p. 93). The difference between some ordinary daily understanding and scientific understanding of the cases lies in the reflected and systematic methodological approach (Flick, 1995; Morse, 1999), an important part of which in this study has been the comparative perspective. The case narratives yield 'local theories', yet informed by the knowledge derived from the other cases and the conceptual framework, therefore not restricted purely to insider perspectives. Beyond the single case analyses, the cross-case analyses were undertaken at each stage, in order to formulate general propositions and to generate theories as described above (Chapter 3 to Chapter 5). The last analysis (Chapter 6) weaves a thick description from similar settings across cases, generating generalising propositions for these sort of settings.

\footnotetext{
10 "A thick description... gives the context of an experience, states the intentions and meanings that organized the experience, and reveals the experience as a process. Out of this process arises a text's claim for truth, or its verisimilitude." (Denzin, 1994)

"The limited format of the case reports is due to a PhD process, increasingly common in The Netherlands, which requires the dissertation to be a collection of published articles (or articles to be published), and therefore subject to journals' conditions.

12 "...müssen die $2 . T$. sehr umfangreichen Interpretionen 50 dokumentiert werden, dass auch hier ein intersubjektiver Nachwollzug gewährleistet ist." (Lamnek, 1995, p. 156)
} 
Several processes of transfer and interplay between experiences, interpretations and the construction of texts happen during and after such research processes: the transfer of experiences and their interpretations into the narratives told by interviewees, prompted by the researcher's questions and building the interview texts; the interpretation of those transcripts (and other primary and secondary data) by the researcher and her construction of the case narratives and generalised propositions, as versions of how to see the world; and finally, the possible transfer of the reading experience into changed views of the world by readers of the reports (cf. Flick, 1995, p.52).

\subsubsection{Ensuring rigour - issues of verification in cross-national research}

Cross-national comparative research requires similar challenges to rigour to other research, but has added complexity, and poses some specific cultural and linguistic questions.

In terms of culture there is the danger of interference from the "researcher's own cultural value system, assumptions and thought patterns" (Hantrais \& Mangen, 1996b, p. 9) with the analysis. In terms of language challenges can emerge from the need for translation. In terms of both there is the question of the equivalence of concepts used across countries.

As regards 'cultural interference', this research has dealt with three cultures, with those of the two countries under study, and, more implicitly, with the German background of the investigating researcher. Although all three countries can be regarded as closely related, still significant cultural differences have been stated (cf. Hofstede, 1991). It is, therefore, "vital that the researcher does not assume a 'value consensus" across societies, nor 'impose' meaning and interpretations on particular social phenomenon, influencing interpretations about what is legitimate and normal" "Kennett \& Yeates, 2001, p. 45). In order to prevent such uncontrolled cultural interference, there has been continuous contact with 'native' academics with in-depth knowledge of the field in both countries, in fact the supervisory board. These contacts have been used to reflect and discuss events and phenomena the researcher encountered and the perceptions she developed, during all stages of the study - to prevent misunderstandings, biased interpretations and to facilitate the development of a comprehensive cross-national meta-perspective.

With respect to questions of language and translation, it was stipulated from the outset that the researcher spoke English and Dutch sufficiently well to understand original documents from both countries, and to communicate fluently during the fieldwork. Interviews were transcribed by native speakers in order to ensure high quality transcriptions, and to filter out purely linguistic misunderstandings. Thus all primary 
data were dealt with in the original language, with only the writing finally done in English.

Methodologists often express concerns about the equivalence of concepts and meanings applied in cross-national comparative research. Functional equivalence means that "the components and their properties being compared are 'the same' or indicate something equivalent" (Kennett \& Yeates, 2001, p. 44), a formulation, which in itself indicates part of the definitional uncertainty. This research began with sensitising concepts; and the subsequent exploration and specification of these concepts by case and by country has been at the heart of the whole comparative endeavour. Thus, it was an essential part of the research to examine the equivalence or otherwise of concepts (Chapter 3 to 5) by investigating the ways in which these concepts are operationalisationed in both countries.

It became clear that issues of culture, language and their interaction with processes of conceptualisation in cross-national research cannot be resolved conclusively, since "language is not simply a medium for conveying concepts, it is part of the conceptual system, reflecting institutions, thought processes, values and ideology, and implying that the approach to a topic and interpretation of it will differ." (Hantrais \& Mangen, 1996b, p.7). The approaches described above, however, were intended to control for such factors as far as was possible.

\subsubsection{Verbal bias?}

Another methodological concern with respect to language in qualitative research is not specifically related to cross-national research, but perhaps also applies to it: the concern about the ambiguous relation between language and action, between what is said and what is done - not only due to the issue of telling the truth, which is discussed here, but also fundamentally to those of interpretation and social construction. Qualitative research, which relies heavily on interviews, is sometimes said to be vulnerable to a sort of 'verbal bias', failing to explore this ambiguity. Methodological triangulation, including also documentary analysis, can provide some validation of interview-based statements; though, this can be seen only as a partial solution, since professionals' and managers' jargon language might have been similarly influenced by a politicised environment in the health and social care field, with the temptation to describe practices and experiences euphemistically. Literature study, especially as applied in the first and second research stage, has, of course, more 'triangulating power'. Observation is seen by some as the gold standard method (Lambert \& Mckevitt, 2002) to prevent verbal bias. The research questions investigated in this study, however, are suitable for observational methods only to a small degree. Observation therefore has been conducted in this research only to a small extent, and thus has 
been insufficient to fulfil the function of triangulation. However, at all three stages of the research interviewees have been chosen to represent a diagonal slice across agencies and professions, therefore capable of showing any major dissonance between language and action.

With respect to cross-national research as carried out in this study there remains an open question: whether there are national general patterns regarding the relation between language and action, due to national cultures. The chosen instruments would not be able to identify them. This question will be dealt with again in the last chapter.

\subsubsection{Classical criteria redefined? Discussing reliability and validity}

Among qualitative methodologists it is a contested question whether qualitative research should establish its own criteria of rigour - a position which is associated especially with Lincoln and Guba (1985) and their dominant influence in North America - or whether the classical criteria of reliability and validity should be redefined and adapted to the qualitative paradigm - as is more common in Europe (Flick, 1995; Morse et al., 2002). Lincoln and Guba's approach to establish 'trustworthiness ${ }^{\prime 13}$ as an alternative concept has been criticised because of its vagueness and because of the shift from constructive to evaluative procedures. Morse et al. advocate sticking to the concepts of reliability and validity as a better way to ensure qualitative rigour, and also to prevent a weakness of self-representation of qualitative research within the general scientific community (2002). However, the use of the same terminology, differently defined within a substantially dissimilar scientific paradigm, also is in danger of producing confusion (Lamnek, 1995). It is the very nature of qualitative research, that the concepts of reliability and validity adapted and applied to such qualitative research cannot result in quantifiable procedures, but rely basically on interpretive and communicative processes, as shown below.

Reliability in the sense that data and findings can be reproduced exactly is rejected as an inappropriate concept in qualitative research. More appropriate is the concept of 'synchronic reliability', which refers to the consistency and complementarity of findings established through different methods in a setting within a certain period of time (Flick, 1995, p. 241); which, again, relates to triangulation (see above).

Furthermore, strategies to achieve 'procedural reliability' (Flick, 1995), comprising procedural rules for data collection, processing and analysis, improve the reliability of data and interpretations. Research protocols, describing the rationale and the

\footnotetext{
1. Trustworthiness is described with four aspects: credibillity, transferability, dependability and confirmability.
} 
course of action before and during the conduct of a situdy, are essential for establishing reliability (Yin, 1994). For this study, explicit research protocols were used especially for the local case studies performed in the third research stage ${ }^{\text {s }}$. Careful documentation during the conduct of a study, differentiating between data and interpretation, and simultaneously documenting the connections between them, is also required to establish procedural reliability. During this study, fieldwork notes were written locating the sources of data (interviews, documents) within their context, making notes of observations and conversations in-between, documenting open questions and earlier strands of analysis. For data processing, ATLAS.ti 4.2 has been used, because it facilitates the reconnection of quotations to the original text at all stages, and therefore technically supports controlled iterative movements between data and analysis. During analysis, tabular displays have been elaborated do document emerging analytical lines from close-to-data to more abstract stages of analysis. Inter-rater reliability in coding (Flick, 1995) could not be established due to the solitary character of the PhD.

Scientific validity develops "primarily in the details of action during research and is insufficiently verifiable from an external point of view. It appears as the present or absent willingness to challenge any gained insight ... at any time ${ }^{\prime \prime 15}$. Following Morse, a lack of such investigator responsiveness is "the greatest hidden threat to validity $(2002$, p. 5), and is not only due to moral categories but also to those of knowledge and capacity (cf. also Scharpf, 2000b, p. 61).

Strategies to safeguard validity in qualitative research comprise methodological coherence, appropriate sampling, a concurrent approach to data collection and analysis, theoretical thinking and a deliberate approach to theory development (Morse et al., 2002). The handling of these topics for this study is described partly in the chapters below , but will be noted here briefly. Methodological coherence means the consistency of the research questions with the methods, matching the data and the analytic processes (cr. also Lamnek, 1995). It evolves through relevant decision-making before and during the research process and is the overarching topic of this chapter as a whole, complemented by the conceptual and methodological sections of the following chapters. Appropriate sampling refers to the selection of cases and interviewees, which are described and explained in the paragraph above and in the methodom logical sections of Chapter 3 to Chapter 6 . The concurrent approach to data collec-

\footnotetext{
is For illustration one of the research protocols, which were slightly adapted to respective national and local conditions, is added (Appendix 1).

15 "Wissenschaftlichkeit (vollzieht sich für mich) primär im Detail des Forschungshandelns und ist nur umzureichend von aussen überprüfbar. Es drückt sich in der vorhandenen oder nicht vorhandenen Bereitschaft aus, jede gewonnene Einsicht permanent wieder in Zweifel zu ziehen ... stets in gleichem Masse." (Küchler, 1983, p. 24, cited in Lamnek 1995, p. 153)
} 
tion and analysis is described in the paragraph on research design in this chapter (2.2.3). The approaches to theoretical thinking and to theory development in this study, which comprise especially the iterative move between micro and macro perspectives, between concrete and abstract categories, between sensitising concepts and their subsequent specification during the research process is also discussed in this chapter, especially in the link between the conceptual framework and the research design, and in the sub-section on analysis and writing.

A further strategy to strengthen validity - 'communicative validity' - entails asking participants to judge the outcomes of analysis (Flick, 1995; Lamnek, 1995). Relying on such strategies, however, brings the danger of restricting the analysis, keeping close to the data for inappropriate reasons and streamlining the results to please the audience (Morse et al., 2002). Another suggestion is the use of an expert panel, to check research processes and results (Lamnek, 1995). For this study, several steps were taken. The participants in the local case studies, both informants and interviewees, were provided with drafts of the articles reporting on the results (cf. Chapter 5 and 6). This was in part straightforward feedback to the field, making the results accessible and usable for the respective communities of those involved in integrated dementia care development and delivery, as promised at the outset of the case studies. Participants were asked to answer questions about the correspondence between their interpretation of events and the analysis, about changes in the field after the time of fieldwork, and about the utility of the comparative analysis. The participants were asked to forward their answers by letter, e-mail or phone call. Seven participants responded, three from York, one from Leeds, two from Maastricht and none from Amsterdam. Six expressed their agreements with the analysis and findings, and made some reflections about further developments, which, on a more abstract level, confirmed the analyses. The other participant reported some reservations about some points of their locality case study. Based largely on local political sensitivities these were reservations about views expressed by a wide range of other interviewees within the locality.

As a strategy in building up expert validity the supervisory group was important in advising and supervising the course of the research process at all stages. A further step to establish expert validity is the submission of articles to peer-reviewed and indexed scientific journals, reporting the results of the research (ct. Chapter 3 to Chapter 6).

\subsubsection{Generalisation}

The capacity for generalisation - external validity - is most contested with respect to qualitative research. Abstaining from statistical representativeness, qualitative re- 
search seeks to recognise essential and typical connections within specific situations (cases). Qualitative research is context-bound - in our case meaning the institutional context - and from this it often develops its specific expressiveness and validity. Qualitative research, in studying complex contextual phenomena and trying to do justice to, cope with, cover, maintain, and unravel the complexity, has to address the question of how far a transfer can be made from one context to the other (Flick, 1995). In this it cannot and does not strive to create universal generalisations, but tries to define comparable contexts to which a transfer of theories or propositions might be possible. A common approach is to analyse and compare the validity of propositions from one case to another (Flick, 1995; Lamnek, 1995; Yin, 1994), and thereby explore and explain the contextual conditions of generalisability. This approach, referred to as 'analytical generalisation' (as distinct from statistical generalisation), implies that as qualitative researchers we generate "sometimes true theories" providing explanations, ... that hold only under specific institutional conditions" (Scharpf, 1997, p.22). Further, as Elster emphasises, "we should concentrate on specifying small and medium mechanisms for human action and interaction" (Elster, 1989, VIII, cited in Scharpf), because there are no 'general-law-like regularities' capable of explaining complex social phenomena. Scharpf argues that complete and comprehensive explanations, which are possibly valid only for one specific case, still consist of generalisable elements:

"But that also implies that the complete explanations, which we nevertheless must strive for, can only be modular constructs, combining and linking several theoretical "modules" to account for complex and potentially unique empirically observed phenomena or events. The linkages among these modules could then be narrative, or they could themselves have the character of partial theories" (Scharpf, 1997, p.30).

This underlines that generalising from qualitative case studies is an analytical activity, by which the transferability of propositions to other cases has to be considered, thereby establishing and applying contextual specific criteria.

This study, first of all, has sought a 'complete explanation' for each case; i.e. to answer the central research questions by writing an in-depth narrative from a comparative as well as conceptually framed ('sensitised') perspective. The explicit comparative analysis in each research stage, then, links the elements of the case narratives (whether they deal with differences or similarities between the cases under study) with more abstract explanations (propositions) in terms of the theoretical framework. Finally, from a meta-perspective the propositions are discussed with respect to their generalisability - and it has often been more the questions and their rationale than the case-specific answers which are considered generalisable. 


\subsubsection{Ethical considerations and procedures}

The conduct of this research has been dictated by legal and ethical requirements. At all stages the interviewees were provided with written information about the project to establish informed consent, and were asked for their agreement for taping and transcribing. The interview transcripts have been handled in a way which ensures strict confidentiality and anonymity.

For the first and second stage of the research there was no involvement of ethical committees. Following Dutch norms, an ethical review preceding interviews with highly educated professionals is not required ${ }^{16}$. In England, over recent years, Ethics Committee and Research Governance processes have strengthened the requirement for approval for all research that involves any health or social care professionals and workers (Department of Health, 2001). For the third step, comprising the local case studies, the approval of Ethics Committees was necessary in both countries, since the interviews involved not only professionals and managers, but also carers of people with dementia. This in particular was a significant criterion for Ethics Committees in The Netherlands. The material submitted to the Ethics Committees included comprehensive research protocols describing all steps of the project ${ }^{14}$ (see above) and the information material for interviewees; subsequently all local Ethics Committees gave their approval. The procedures, however, have revealed some significant differences between England and The Netherlands regarding what was judged as (un)ethical. For example in England it was impossible in principle to get permission from Ethics Committees to attend and observe multi-agency professional meetings discussing patients' affairs. In The Netherlands such observation was not a problem subject to guarantees of confidentiality. Since the observation of meetings made up only a small part of collected data the exclusion of these specific meetings affected the research process to a negligible extent. But the ways in which such differences affect comparative cross-national research, might well merit separate detailed study.

\section{REFERENCES}

Agranoff R \& Radin BA. 1991. The comparative case study approach in public administration. Research in Public Administration 1: 203-231.

Aspinwall MD \& Schneider G. 2000. Same menu, separate tables: The institutionalist turn in political science and the study of European integration. European Journal of Political Research 38: 1-36.

${ }^{16}$ This is confirmed in personal communication by an expert involved in ethical evaluation of health research proposals at the University of Maastricht. 
Atkinson MM \& Coleman WD. 1992. Policy networks, policy communities and the problems of governance. Governance: An international joumal of Policy and Administration 5: 154-180.

Berger PL \& Luckmann T. 1969. Die gesellschaftliche Konstruktion der Wirklichkeit. Eine Theorie der Wissenssoziologie (The social construction of reality: a treatise in the so. ciology of knowledgel. Fischer: Frankfurt a.M.

Boase JP. 1996. Institutions, institutionalized networks and pollicy choices: Health policy in the US and Canada. Governance: An International Joumal of Policy and Administratiom 9: 287-310.

Bowen JR \& Petersen R (eds). 1999a. Critical Comparisons in Politics and Culture. Cambridge University Pfess: Cambridge.

Bowen JR \& Petersen R. 1999b. Introduction: Critical comparisons. In Critical Comparisons in Politics and Culture, Bowen JR, Petersen R (eds); Cambridge University Press, Cambridge: $1-20$.

Clemens ES \& Cook M. 1999. Politics and institutionalism: Explaining Durability and Change. Annual Review of Sociology 25: 441-466.

De Vault ML \& MCCoy L. 2002. Institutional Ethnography. Using interviews to investigate ruling relations. In Handbook of Interview Research. Context and Method, Gubrium JF, Holstein IA (eds); Sage, Thousand Oaks; $751-776$.

Denzin NK. 1994. The art and politics of interpretation. In Handbook of qualitative research, Denzin NK, Lincoln YS (eds); Sage, Thousand Oaks; 500-515.

Deparment of Health. 2001. Research Governance Framework for health and social care. Department of Health Publications: London.

Elster 1. 1989. The cement of society: A study of social order. Cambridge Universily Press: Cambridge.

Fischer F. 1989. Beyond the rationality project: policy analysis and the postpositivist challenge. Policy Studies Journal 17: $941-951$.

Flick U. 1995. Qualitative Forschung. Theorie, Methoden, Anwendung in Psychologie und Sozialwissenschaften (Qualitative research. Theory, methods, application in psychology and social sciences). Rowohlt: Reinbek.

Grahame PR. 1998. Ethnography, institutions, and the problematic of the everyday world. Human Relations 21: 347-360.

Hantrais L \& Mangen S leds). 1996a. Cross-national research methods in the social sciences. Pinter: London. 
Hantrais L \& Mangen S. 1996b. Method and management of crossmational social research. In Cross-national research methods in the social sciences, Hantrais L. Mangen S leds): Pinter, London; $1-12$.

Heritier A. 1993. Policy-Analyse. Elemente der Kritik und Perspektiven der Neuorientienung. Einleitung (Pollicy analysis. Elements of criticism and perpectives of a new orientation. Introduction), In Policy-Analyse. Kritik und Neuorientierung (Policy analysis. Criticism and new orientation), Heritier A. (ed); Westdeutscher Verlag, Opladen; 9-36.

Hofstede G. 1991. Cultures and organizations: sofware of the mind. McGraw-Hill: London.

Jones 1. 2000. Mental health care reforms in Britain and ltaly since 1950: a cross-national comparative study. Health \& Place 6: 171-187.

Kennett P (ed). 2001. Comparative social policy. Theory and research. Open University Press: Buckingham.

Kennett $P$ \& Yeates $N$. 2001. Defining and constructing the research process. In Comparative social policy. Theory and research, Kennett $P$ (ed); Open University Press, Buckingham; 40-61.

Kickent WIM, Klijn E-H \& Koppenjan IFM. 1997. Marnaging complex networks. Strategies for the public sector. Sage: London etc.

Kohn ML. 1989a. Cross-national research as an analytic strategy. In Cross-national research in sociology, Kohn ML. (ed); Sage, Newbury Park; 77-102.

Kohn ML (ed). 1989b. Cross-national research in sociology. Sage: Newbury Park.

Kooiman I \& Associates. 1997. Social-political governance and management. Conceptualizatron. Erasmus Universiteit/Rotterdam School of Management: Rotterdam.

Kuchler M. 1983. "Qualitative" Sozialforschung - ein neuer Königsweg? (Qualitative' social enquiry - A new golden rule?). In Brauchen wir andere Forschungsmethoden? Beiträge zur Diskussion interpretativer Verfahren (Do we need different research methods? Contributions to discuss interpretive approaches), Garz D, Kraimer L. (eds); Scriptor, Frankfurt; 9-30.

Lambert H \& McKevitt C. 2002. Anthropology in health research: from qualitative methods to multidisciplinarity, BMJ, Vol. 325, 210-213, http:/bmi.com.

Lamnek S. 1995. Qualitative Sozialforschung (Qualiative research in social science). Beltz, Psychologie Verlags Union: Weinheim.

Lehmbruch G. 1996. The organization of society, administrative strategies, and policy networks. In institurions and political choice. On the limits of rationality, Czada $\mathrm{R}$, Héritier A, Keman H (eds); VU University Press, Amusterdam, The Netherlands; 61-84.

Lincaln YS \& Guba EG. 1985. Naturalistic inquiry. Sage: London. 
Lindner J. 2003. Institutional stability and change: two sides of the same coin. Journal of Eurom pean Public Policy 10: 912.935.

Luhmann N. 1989. Politische Steuerung: Ein Diskussionsbeitrag (Political steering: contributing to the discussion). Politische Vierteljahresschrift $30: 4-9$.

Martin S. 2000. Implementing 'Best Value': Local public services in transition. Public Administration 78: 209-227.

Mildenberger U. 1997. Selbstorganisation von Produktionsnetzwerken. Erklarungsansatze aut Basis der neueren Systemtheorie (Self organisation of production networks. Explanatory approaches based on the new systems theory). Deutscher Universitatswerlag: Wiesbaden.

Morse IM. 1999. Myth 19: Qualitative inquiry is not systematic. Qualitative Healhh Research $9:$ 573-574.

Morse IM, Barrett M, Mayan M, Olson K \& Spiers 1. 2002. Verification strategies for eslablishing reliability and validity in qualitative research. International Journal of Qualitative Methods 1: Article 2.

Norgaard AS. 1996. Rediscovering reasonable rationality in institutional analysis. European Journal of Political Research 29: 31-57.

North D. 1990. Instritutions, institutional change, and econonic performance Cambridge University Press: Cambridge.

O'Toole L). 1997. Treating networks seriously: Practical and research-based agendas in public administration. Public Administration Review 57: 45-52.

Scharpf FW. 1989. Politische Steuerung und politische Institutionen (Politicall steering and politicall institutions). Politische Vierteljahresschrift 30: 10-21.

Scharpf FW. 1993. Positive und negative Koordination in Verhandungssystemen. (Positive and negative coordination in negotiation systems). In Policy-Analyse. Kritik und Neworientierung. Policy analysis. Criticism and reorientation. Hëritier A led); Westdeutscher Verlag, Opladen; 57.83.

Scharpf FW. 1997. Games real actors play. Actor-centered institutionalism in policy research. Westriew Press: Oxford.

Scharpf FW. 2000a. Institutions in comparative policy research. Comparative Political Studies 33: $762-790$.

Scharpf FW. 2000b. Interaktionsformen. Akteurzentrierter Institutionalismus in der Politikforschung (Original: Games real actors play. Actor-centered institutionalism in policy research). Leske \& Budrich: Opladen.

Stake RE. 1998. Case studies. In Strategies or qualitative inquiry, Denzin NK, Lincoln YS "eds); Sage, Thousand Oaks; $86-109$. 
58 Chapter 2

Thelen K. 1999. Historical institutionalism in comparative politics. Annual Review of Political science 2: $369-404$.

Thompson Gi, Frances I, Levacic R \& Mitchell J (eds). 1991. Markets, hierarchies and networks. The coordination of social lite. Sage: London elc.

Toulmin S. 1990. Cosmopolis. The hidden agenda of modernity. The Free Press: New York.

van Raalk AIA. 1998. Zorgvernieuwing: een kwestie van routine. Een studie naar de vorming van interorganisationele netwerken en naar systeemveranderingen in de thuiszorg vanuit interactionistisch perspectief (Health care innovation: A matter of routine. A study about the building of interorganisational networks, and about system changes in home care from an interactionistic approach). Universiteit Maastricht: Maastricht.

Williamson OE. 1985. The economic institutions of capitalism: firms, markets, relational contracting. The Free Press: New York.

Willke H. 1998. Steuerungstheorie: Grundzüge einer Theorie der Steuerung komplexer Sozialsysteme (Theory of steering: Basic theoretical lines for the steering of complex social systems. Lucius \& Lucius: Stuttgart.

Yin RK. 1994. Case study research. Design and methods. Sage: Thousand Oaks. 


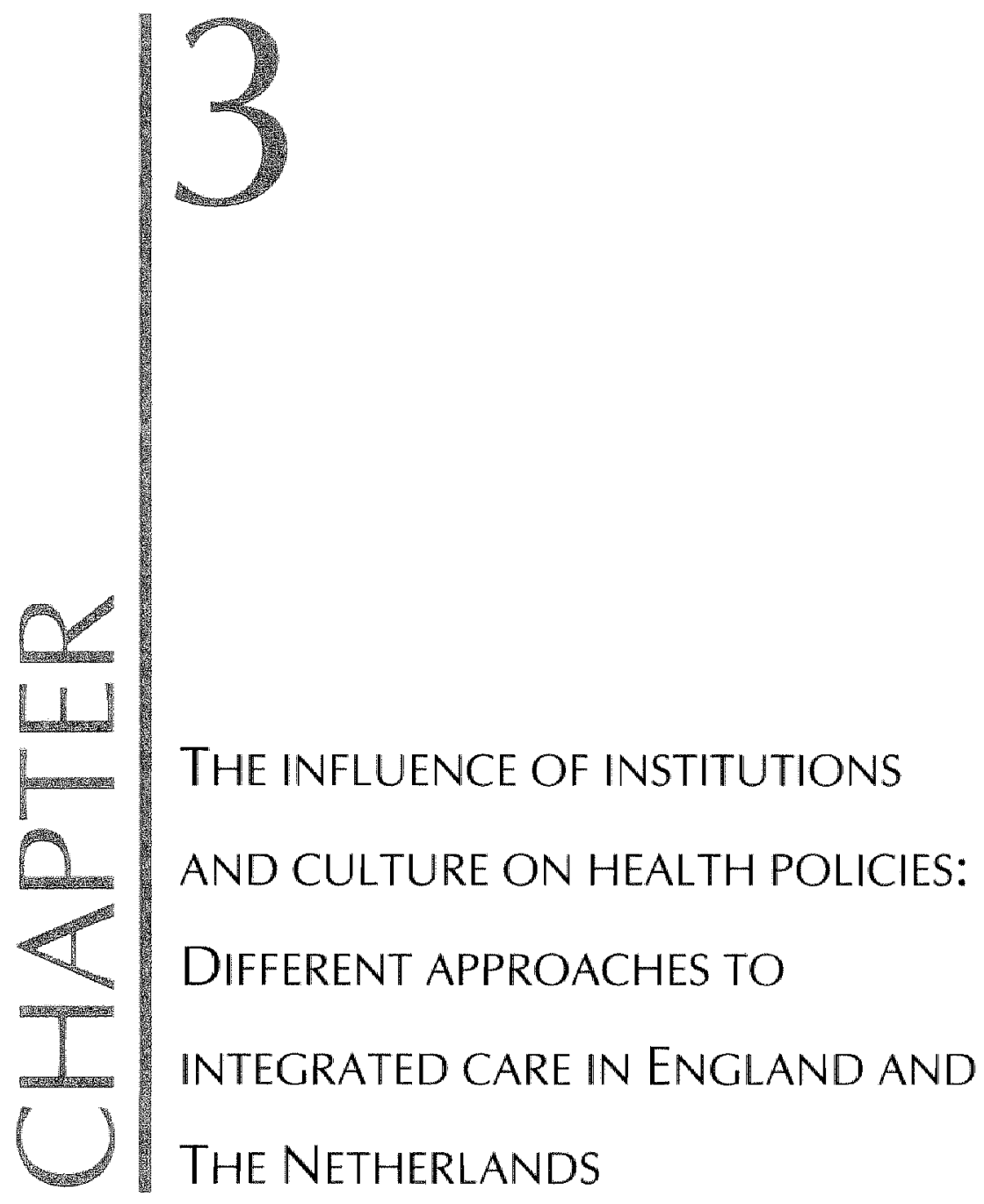

This chapter is based on

Kümpers, S., Raak, A. I. A. v., Hardy, B., \& Mur-Veeman, I. (2002). The influences of institutions and culture on health policies: different approaches to integrated care in England and The Netherlands. Public Administration, 80(2), 339-358. (Short-listed for the Karolinska Medical Management Centre/ European Health Management Association Research Award 2004) 
60

Chapter 3 


\section{$3.1 \quad$ ABSTRACT}

This article compares the characteristics of the Dutch and English health and social care systems and policies, analysing how they create the conditions for integrated care. Integrated care is outlined as health and health care-related social care, as needed by patients with multi-faceted needs. It has assumed growing importance on the policy agendas in industrialised countries, so in England and the Netherlands. Corresponding to the dissimilarities in the structure and cultural background of the health care systems in these two countries, political strategies and conditions for integrated care differ considerably. Health care systems are understood as specific national and historical configurations. By reviewing the last decade's development in health policy with respect to integrated care, we aim to gain insight into the respective processes in both countries. Using the concepts of hierarchies, markels and networks, pollicy processes are described and explained in their effects on the conditions of network development for integrated care. The state health care system in England relies mainly on hierarchical steering, thus creating tight network structures for integrated care at local level. The Netherlands, relying on multiple actor governance structures at national level, and owning a health care system in a public-private mix, set incentives for voluntary loosely coupled and partly market-driven cooperation at locall level. Implications for success or failure are mixed in both configurations. Policy recommendations have to be tailored to systems" characteristics.

\subsection{INTRODUCTION}

Developments in demography and medical technology bring about an increasing number of people with multiple care demands in the EC countries - the elderly, people with handicaps and/or chronic illnesses. They are in need of medical treatment, nursing and social care in changing combinations, and in a coherent, integrated way. Under the heading 'integrated care' health policy in several countries tries to promote organisational solutions to respond to the complexity of needs. The concept describes the organising processes needed to develop and deliver coherent, co-ordinated and continuous sets of services, delivered by cooperating actors, covering the full spectrum of health and (health care related) social care (van Raak et al., 2003). Policymakers and care providers perceive integrated care as a response to patients' needs, and to the urgent demands for better cost effectiveness in health care as well; integrated care thus is based simultaneously on a humanitarian and an economic rationale. 
Health care systems are often ill-prepared for the integration of care. Fragmentation and inflexibility of services exist, with difficulties in, or the absence of co-ordination between them, causing waste and under-supply on the systems' side, and undersupply and neglect for the service users, leading to premature hospitalisation and the early loss of independence (House of Commons: Health Committee, 1998; Johansson \& Borell, 1999\%. Consequently, the development of integrated care is seen as a challenge for government steering in several European countries. The Netherlands and the U.K. in particular have focused on the integration of care in their national political programmes for several years (Hardy et al., 1999).

Ongoing debates however indicate that, in spite of a strong political emphasis, government steering of integrated care takes place in difficult and fragile circumstances, with uncertain results (Hudson et al, 1997; O'Hagan, 1999; van Raak, 1998). It appears difficult for governments to change the national health care system in a way that makes it favourable for integrated care development and delivery. Therefore policy makers could want to search outside their countries for useful concepts of steering to apply them in their own setting. According to neo-institutional theories, however, the adoption of policies from elsewhere cannot succeed. It is argued that policy concepts, originating inside or outside the system, are adjusted and readjusted during the policy process. The characteristics of a national system, including its institutions and culture, are taken as a historically evolved 'configuration' (Lehmbruch, 1996), within which the adaptation of concepts takes place. The configuration thus. limits or fosters options for steering, and results in different modes of governance. In this view steering by national governments, even if pursued under a similar rhetoric and responding to common challenges, takes shape differently and leads to different results (Giaimo \& Manow, 1999). In short, steering is embedded in and shaped by the national configuration, and so are its outcomes.

Neo-institutional theory and particularly the concept of 'configurations' are suitable to clarify why phenomena such as steering appear to be context-specific, and thus different. We have used this theoretical perspective to analyse government steering, directed to the promotion of integrated care, in two cases: England and the Netherlands. Hereby it is shown how national configurations shape the steering processes, their successes and failures. We start with outlining neo-institutional theory and the concepts relevant for our analysis. Next we describe our research methodology. We then present and discuss the two cases. Differences and similarities between the two countries will become visible. In the final section we discuss the implications of our findings for policy development at both the national and supranatural level. 


\subsection{THEORY}

Over the last 15 years, neo-institutionalist approaches in political sciences have built a framework to explore cross-national differences in policy development and implementation. The institutional structure and culture of the national and sectoral political systems are seen as interacting with each other and shaping the processes of policy development and implementation, their strategic options and limits (Nørgaard, 1996). Lehmbruch (1996) describes these constellations as national configurations. The concept of configuration frames the features of national and sectoral public policies as historically developed paths, emerging from a "sequential interaction of the organisation of state and society" (p.75). They are based on processes of social learning in institutional contexts and collective interpretation processes. Boase (1996) among others speaks about 'path dependency' of policy-making. These approaches do not contradict the notion of a "cross-national transfer of health policy ideas" (Marmor \& Maynard, 1994). They claim, however, that such ideas take their specific shape within the respective configuration.

To define the role of actors, i.e. individuals and collectivities in the configuration such as organisations and the national government, several policy analysts combine views from sociological, historical, and rational-actor institutionalism (Aspinwall \& Schneider, 2000; Scharpf, 2000; Thelen, 1999). Following them, actors are neither determined by institutions, nor independent of them, but "intentional and reflective, yet deeply historically embedded at the same time" (Nørgaard, 1996, p.32). In this view government steering - modes of governance including the strategies, contents and effects of health policies - is embedded in and part of the national configuration. Government steering is considered processual and interactive. Steering efforts trigger responses from actors within the configuration, whose responses act as 'policy feedback' and have an impact on further policy formulation (Kooiman \& Associates, 1997: Piersion, 1993).

In this paper we use the concepts of hierarchy, market and network - meant as ideal types of coordinating mechanisms in society - to characterise government steering. Hierarchy works by systematic administration and is connected with super-ordination and sub-ordination. The market mechanism is characterised by automatic coordination of independent and interacting actors pursuing individual goals. Networks are described in terms of interactions between autonomous but interdependent actors within more or less informal, long-term relationships that are built on negotiation and trust (Thompson et al., 1991). Strengths and limitations of hierarchies, markets and networks, and the steering potential they provide to governments for certain fields, have been discussed from various perspectives (Scharpf, 1993; Williamson, 1985; Willke, 1998). Hierarchy and market are seen as being typical of modern societies, 
while networks are often described as emerging from the characteristics of postmodern' societies (O'Toole, 1997; Willke, 1998). Sometimes they are seen as intermediate between hierarchies and markets (Williamson, 1985), but elsewhere as a new form with particular qualities (Mildenberger, 1997; Willke, 1998). They are often associated with 'governance' as opposed to 'government' (Kickert et al., 1997; Kooiman \& Associates, 1997). The network form is seen as suitable especially for those complex problems that can only be solved by a holistic approach, avoiding the pitfall of being superficial, i.e. where re-integration without losing the advantages of specialisation and differentiation is desirable (Willke, 1987, 1998). These are named 'cross-cutting issues' (Martin, 2000), or 'wicked problems' (O'Toole, 1997), and are further characterised by the notion that they cannot be handled adequately simply by hierarchical or market mechanisms (Atkinson \& Coleman, 1992).

The concepts of hierarchy, market and network enable us to focus on particular structural and cultural characteristics of configurations, which is necessary to understand success and failure of steering for integrated care in England and the Netherlands. With respect to 'structure' we describe the relations between governments and other actors, including their positions within the relations. 'Culture' in this paper reflects values and expectations of actors about each other"s actions and interactions, in particular about modes of governance. Culture here also refers to the appreciation of modes of governance by actors and their willingness to comply. The combination and interaction of these cultural and structural characteristics result in different modes, possibilities and limitations of government steering.

We outline integrated care as a set of flexible organisational processes responding to complex and diverse needs, which change over time. It needs contributions from various organisations in several sectors: health care, social work, housing etc., at local level. It therefore requires cooperation, information exchange, agreements on task distribution, and within this frame, at least partly autonomous, responsible actions by different actors. The actual features of integrated care are shaped in the configuration. Nevertheless, our outline indicates that integrated care is a 'cross-cutting issue". We therefore expect that successful governance regarding integrated care will create favourable conditions for network development, which fit into the respective national configuration.

\subsection{Methodolocy}

A cross-national comparison helps to examine the policy options embedded in a national configuration.

The cases of England and the Netherlands provide examples of different political systems, different political cultures, and different health care systems: Beveridge and 
Bismarckian. Due to the holistic character of configurations we analyse the instlitutional structure and culture, and the modes of governance in health policy intertwined with the concrete policy measures directed to integrated care. For each country a brief description of the institutional structure of the health care system is given. Then substantial developments in the last decade with respect to integrated care are analysed, focusing on the interaction of policy measures and institutional behaviour, in order to understand the outcomes. Attitudes of actors will be shown to shed light on the cultural context.

Our findings rely on extensive literature study (policy analyses), and document analysis (national policy programmes and policy evaluations), and semi-structured indepth interviews (NL: $n=5, E: n=8$; May 2000). The latter serve to triangulate the findings of the literature and document study. Furthermore, quotations from the interviews illustrate the cultural context of described policy processes. In cooperation with experts in both countries we selected a cross-organisational sample of interviewees, which spans a range of stakeholders at different levels who are in a position to exert policy feedback, i.e. who not only react to and implement, but lend shape to governmental policies (e.g. in England a Social Service Director, a Social Service Planning Officer, a Health Authorities' Director of Performance; in the Netherlands for instance a manager in the National Insurers' Association (ZN) and a Director of a Regional Assessment Organisation). We used an iterative and triangulating method, starting with studying literature and secondary data, then collecting and analysing primary data (interviews), and returning to literature study.

There are also limitations. In this article we examine policies for integrated care in England and the Netherlands and their relative outcomes. We do not try to achieve a judgement, whether integrated care on the whole is 'better' in one country compared to the other. We also do not show processes in health care practice in detail. We show the configurational characteristics of steering, the differences and the similarities, in order to be able to give country-specific and general recommendations for policy-development. The comparison between two cases, however, tends to emphasise the differences between them more than to highlight their similarities. We therefore do not claim to grasp the full amount of factors influencing policy processes and outcomes for integrated care. Moreover, a comparison at national level relies on generalising sources and therefore neglects local variations. Developments after mid2000 were not included in the analysis.

\subsection{ENGLAND}

England has a tax funded, centrally organised, state health care system. The National Health Service was legally embodied in 1946, and established in 1948. The ministry, 
currently the Department of Health (DoH), is responsible for the essentially top-down managed National Health Service. The line of control goes via the NHS Executive, its 8 Regional Offices (ROs) to local Health Authorities (HAs). Similarly finances flow from the top to the local bodies. NHS services are free at the point of delivery; copayments are marginal. British governments are held strongly accountabie for equal access, quality and efficiency of the health care system.

Local Authorities (LAs), of which Social Service Departments (SSDs) are a part, are steered in part by the elected local government. Compared to the NHS there is more space for local decision-making, with limited scope for local tax raising. Nevertheless, LAs have to work within national legislation, and are subject to earmarked budgets; additionally there is increasing central steering through the national Social Service Inspectorate, within the DoH. SSDs are responsible for the provision of socalled social care, which is given in residential homes, nursing care homes, day care, and home care. SSDs are themselves care providers, but additionally they commission increasingly services from private and voluntary sector providers. Social care has to be charged for, means-tested.

The demarcation line between health care and social care builds a strong obstacle against integrated care (House of Commons: Health Committee, 1998) in the English configuration. Since the implementation of the NHS the organisations of the NHS and of the local authorities have worked in separate, but overlapping domains, especially in continuing care for vulnerable groups.

In the last decade two major shifts in opposite directions occurred in English health policy, both of them emphasising integrated care as one of their main goals.

First, the Conservatives (1990: NHS and Community Care Act) turned to the introduction of market principles into public services' policies, simultaneously announcing inter-agency cooperation. In fact, they created competitive obstacles against networkbuilding for integrated care. Consequently, integrated care did not progress, on the whole. Since these policies were also felt as incompatible with inherent cultural values of British public services, decisive impediments arose against their extensive implementation.

Secondly. New Labour's approaches to health and social policy again emphasised the search for cooperation and integration of services (Department of Health, 1997). Since Labour hereby effectively returned to cultural values within the NHS and other public services, they could rely on high commitment. New cooperative structures at local level were hierarchically imposed to facilitate and enforce cooperation. On the other side, strong political pressure on the services to show quick and visible changes 
partly could jeopardise the conditions for thorough network-building for integrated care. These developments are described and analysed below in more detail.

\subsubsection{0 - 1997: NHS and community care reform}

At the beginning of the 1990 s the dominant coordinating mechanism with regard to the NHS, hierarchy, was complemented the newly introduced quasi-markets at regional and local level, set out in the Conservative Government's reforms (1990: NHS and Community Care Act; 1991: start of the 'internal market' and GP-fundholding; 1993: full implementation of the community care reforms). The strategies of the "New Public Management" should bring the rigours of the private sector into the NHS and to Local Authorities (for a discussion of neoliberalist policies in the health sector see Allsop, 1995; Harrison \& Wood, 1999; Light, 2000). A purchaser/provider split was created, expecting that competition would increase health care efficiency and userorientation. Simultaneously programmatic emphasis was laid on inter-agency collaboration especially for community care - meaning care outside the hospital - between health and social services (Department of Health, 1989).

The introduction of competitive and market elements was alien to both the NHS and the Local Authorities. These new structures unfolded differently while being implemented. Their impact on integrated care within the NHS and between the NHS and social services is examined.

First, within the NHS there were ambiguous tendencies. Structural and cultural characteristics built constraints against the unfolding of market mechanisms. Local monopolies determined many situations between purchasers and providers. The NHS culture is built on a tradition of altruistic commitment to common goals and a common pride in being the 'NHS familly' (Allsop, 1995, p. 189), supported by corresponding expectations within the public. So several actors in the $\mathrm{NHS}$, expected to act as competitive purchasers and providers, continued their former non-competitive relationships (Allsop, 1995; Klein, 1998; Light, 2000). Contradictory processes occurred: "the competition-based fragmentation which undermined existing networks created pressures to form new networks which, in turn, undermined the competitive rationale of marketisation." (Rhodes, 2000, p. 353). In line with Rhodes and others (Allsop, 1995), our interviewees confirmed damaging consequences of the reforms, namely competitive fragmentation, for intermal cooperation.

The Conservative government, as the founder and main advocate of the quasi-market, soon reacted to the resistance of the field. Market forces were constrained to prevent, for example, closing expensive hospitals (Giaimo \& Manow, 1999; Klein, 1998). By numerous directives central control was carried out to prevent market failure and 
mismanagement, and to foster long-term contracting (Klein, 1998). The term 'purchase' was replaced in the mid-90s by the more vague and less market-like term 'commission' (Klein, 1998; Light, 1998). Thus, policy feedback, rooted in the inherent culture of the NHS, partly mitigated the introduction of a competitive culture. Light, a sharp critic of market advocates in health care, remarked ironically, that "the contracting parties were saving the champions of competition from the consequences of their own policies" (Light, 2000, p. 406).

Second, problems increased between health and social services. The government advocated the cooperation for community care, and simultaneously strengthened competitive public/private markets (Department of Health, 1989). Community care until then had a history of difficulties rather than of successful collaboration (Allsop, 1995; Hardy et al., 1992). The 1990 reforms are often described as having worsened this situation (Allsop, 1995; House of Commons: Health Committee, 1998). Again we can identify institutional structure and cultural characteristics interacting: Two separated agencies were differently managed, with bureaucratic processes and procedures not adapted to each other (Hardy et al., 1999). Local Authorities were given the overall responsibility for community care, but, according to some, remained underfunded (Allsop, 1995). 'Caring for People' (Department of Health, 1989) set definitions about the boundaries between health and social services, which couldn't be maintained in reality. In fact, there was "a huge grey area in between them" and "no cut-off point between domiciliary care and nursing care" (House of Commons: Health Committee, 1998, p. 12). The attribution of needed services to health care or social care exerted an impact on the respective budgets, and decided also whether the user had to be charged for it. This created incentives to push responsibilities upon each other, and cost-shunting especially became an issue, for instance around hospital discharge (Allsop, 1995; House of Commons: Health Committee, 1998).

"During the previous government's administration ... there were a lot of tensions between health and social services. Health was needing to get people out of hospital quickly, but that was placing demands on social services. We thought they were cost-shunting. We thought they were passing the buck and we didn't like that, so we got into fights ..." (SSD, Standard and Service Development Manager)

To be committed to a common culture, to follow a 'mission', is one of the strengths of unified bureaucracies (Willke, 1998). NHS and SSDs worked in overlapping domains, but committed to their own, partly competing value systems. The NHS has been professionally dominated by doctors and nurses, the SSDs by social workers. The NHS "family" was managed as a whole from top to bottom, while local authori- 
ties were proud of their local mandate. Thus different professional and organisational ethics and diverging priorities added to the structural problems and increased the difficulties at local level.

"The old beliefs ... are that nurses can't be managed by social workers. That social workers ... can't be managed by nurses or by doctors, or by health visitors - or anybody from our side of the fence." (Mental Health Services, Clinical Team Leader, emphasis added)

Distance, lack of cooperation, and distrust have come to prominence between health and social services (House of Commons: Health Committee, 1998): the boundary between them has been called the 'Berlin Wall' (p. 10); the actors are described as exhibiting 'tribal' behaviour ( $p .12$ ), and a 'blame culture' ( $p .38$ ). Positive exceptions of constructive cooperations, based on locall commitment and functioning relationships, are also reported; but in general disappointing outputs from integrative frameworks and activities are stated (Hudson et al., 1997; O'Hagan, 1999). Thus, on the basis of the historically difficult relations between health and social services the competitive incentives introduced by the 1990 Act seem to have unfolded damaging effects. They created new barriers against successful network development, despite governmental claims for cooperation.

\subsubsection{7 - The modernisation agenda: The 'New NHS' and Modernising Social Services}

The new Labour government in 1997 created the next 'big change' for the health and social care system, with the promise to build on the achievements of the 1990 s reform - e.g. the primacy of primary care - while countering the main criticisms of this reform (damaging competition, fragmentation, bureaucracy and inequity) via the socalled 'Third Way". Partnership, as a new statutory duty, should replace damaging competition. Again, heath and social services should deliver 'integrated care'. The emphasis on financial efficiency would be complemented by the emphasis on quality (Department of Health, 1997).

Primary Care Groups (PCGs) were introduced to replace the GP fundholding model: they were to encompass all GPS and community nurses in localities of approximately 100000 inhabitants. Developing into Primary Care Trusts (PCT5) they were to take over commissioning responsibility from Health Authorities for most of the services for their patients. PCGs are given the task to shape and realise a community-oriented and integrated development of services. The cooperation of PCGs with Social Services was to be facilitated by a local authority representative on the Board of the PCGs. 
HAs would fulfil a more strategic leadership role. The work of PCG/PCTs is embedded in local Health Improvement Programmes (HImPs), developed under the responsibility of HAs, together with all PCG/PCTs, NHS Trusts and LAs in a local community. Following 'Partnership in Action' (Department of Health, 1998), the Health Act 1999 added further instruments to enable the parties to overcome the traditional structural and financial boundaries between health and social care: Pooled Budgets, Lead Commissioning, and Integrated Provision. Joint Investment Plans (JIPs) are intended to use these tools to shape concrete action plans for certain user groups (e.g. dementia patients) by all actors in an area.

In general we can describe the measures of New Labour for integrated care as a use of hierarchy to create prescribed network structures at local level, with a statutory duty on the respective actors to work in partnership. For these networks limited scope for local decision-making is left open, to determine priorities and to divide tasks among each other.

Referring to a public service ethos and the genuine values of NHS and LAs, New Labour could achieve the approval of many NHS and SSD professionals and the public for the goal of integrated care (Klein, 1998). In addition, coerced cooperation is widely perceived as inevitable. Further research will have to show whether the commitment will overcome local distrust and fragmentation.

"So there is a big issue about integrated care. ... The market philosophy means all about badging organisations, you were good if you achieve for your organisation. What we want now is people forgetting whom they belong to and actually badging the service so that they are proud to be part of the whole system delivering services to older people.... It is a subtle change, but it is a very big attitudinal change." (HA, Director of Performance)

On the whole, our interviews showed broad commitment and widespread networkbuilding activities with regard to integrated care, based on Labour's policy directives. Despite these positive impressions, some counterproductive tendencies were also evident. Health policy in England is a highlly politicised issue. The Blair government has committed itself to quick and visible changes, raising high expectations in the public and bringing strong pressure upon the services. Our interviews repeatedly gave evidence of growing tensions.

"You can't make it in five minutes, I know that, and they know that. But they are pushing it and pushing it. ... I like some of their initiatives; / like the idea behind it. But it could fail, because we can't keep up ... because too high 
expectations too soon. Because it takes a lot longer to change than we all want it to." (SSD, Planning Officer)

The government perhaps risks the conditions for network-building and the commitment for integrated care, since it needs and demands evident results at once, and seems to be preoccupied with control mechanisms. Thus, long-term goals for integrated care could be counteracted by contradictory implementation strategies (cf. Martin, 2000).

On the whole, New Labour's policy efforts to promote integrated care can be judged as successful. They were able to gain general commitment beyond the borders between health and social services; their structural innovations created new opportunities for cooperation at local level.

\subsection{The Netherlands}

The Dutch health care system is a complex mix of public and private organisations with relatively weak governmental hierarchical power. On the provision side there are mainly non-governmental, non-profit foundations and a few private providers. The financing system is organised through a statutorily detailed described insurance system.

From a merely background role up to the 1970s, the shaping role of the government, represented by the Ministry of Health, Welfare and Sports (VWS), has emerged in order to address problems of cost explosion connected with the medicaltechnological development and the ageing of the population. Dutch governments are held responsible for equal access, quality and efficiency of the health care system. Their scope to get through comprehensive and controversial reforms, however, seems limited. Dutch governments are always coalitions among two or more parties and have to negotiate consensus with the independent actors. Comprehensive change programmes were set up more than once since World War II, but were not implemented due to the opposition of important interest groups. Changes were brought forward, but in incremental and consensual steps (Elsinga, 1997: Mur-Veeman et al., 1999; van Raak \& Mur-Veeman, 1996). Discussions about far-reaching reforms are still going on (e.g. about a unified basic insurance system); but some policy analysts describe these recurring debates as rituals, as 'pseudo-politics' (Grinten, 1997), considering the incremental nature of change, built on societal consensus, as inherent to the Dutch political culture.

In the Netherlands, the insurance system is divided into two compartments for longterm and short-term care; or, more simply, for care and cure. Different laws regulate the compartments. Long-term care, including care for the elderly, people with handi- 
caps and mental health problems, is considered to be uninsurable in a privately organised insurance system. Therefore the Exceptional Medical Expenses Act (AWBZ) was set up as a compulsory public insurance scheme in 1967. Since 1942 the shortterm insurance, covering primary care provided in GP-practices, acute care and specialised care, has been built up as a compulsory social insurance system for employees up to a certain salary limit (Social Health Insurance Act, ZFW). For other groups there are different voluntary schemes, with a statutory price limit for basic packages of care. The coverage of the Netherlands' population is virtually $100 \%$. This institutional structure with separated financial flows has created two areas of providers, with separate organisations and regulations. This is seen as important barrier against integrated care.

In the case of the Netherlands the distinctions between periods of policies are less clear than in the case of England, reflecting the incremental character of Dutch policy processes.

In the end of the 1980s, beginning of the 1990s the government tried to implement a comprehensive change to unify and simplify the ossified and fragmented health care system by a blueprint-plan, using a hierarchical top-down approach. This attempt lost gradually support since it failed to involve the strong independent actors in the Dutch health care field, i.e. insurers and providers, and neglected hereby the culture of negotiation and consensus. The evolving debacle of this policy gave way to a transition period: the comprehensive system change was still under discussion, but simultaneously a step-wise and negotiated policy style was revived. From 1994, the incremental strategy of step-wise deregulation and of incentives for cooperation was openly adopted. It was more successful in promoting an innovative climate favourable to numerous integrative networks among health services, and to a wave of mergers with ambiguous effects for integrated care. Below, we discuss these processes in more detail.

\subsubsection{Change processes in the $1990 \mathrm{~s}$}

In 1987 the 'Dekker Commission' proposed a far-reaching reform plan. It pleadedcorresponding with policy ideas elsewhere - for increased market incentives, for the sake of improved efficiency. Simultaneously, a blueprint plan was launched to introduce a unified basic insurance for all inhabitants of the Netherlands, in order to simplify the financial and administrative system and thereby to promote integrated care. During the implementation of the first steps in 1989 and 1992 the reform as a whole met with increasing opposition. The government, instead of entering into new negotiations and thereby complying with the consensus culture, ignored this; the then 
health minister Simons (Christian Democratic and Socialist coalition 1989-1994) lost the support from his government and the public. The reform came to a standstill. This policy failure was ascribed to the disregard of the political culture (Elsinga, 1997; van Raak \& Mur-Veeman, 1996). The separation between the AWBZ-and the ZFW-area was perpetuated. Nevertheless, some reform ideas have diffused further, and were realised in incremental steps.

In 1992 some of the proposed measures of deregulation were implemented, with stronger effects in the cure than in the care sector: the insured could switch between their insurers; regional borders for insurers in the cure sector were abolished. The right of approved providers being contracted was gradually challenged, for simall provider groups in the cure compartment. Fixed tariffs for services (negotiated nationally between insurers, providers and the National Health Tariffs Authority, COTG) were replaced by maximum tariffs to allow flexibility in contract negotiations between insurers and providers. The COTG, however, was authorised to fit the tariffs to a general maximum budget. This put a governmental constraint on market developments.

Thus, traditional regulations, which had kept the conditions stable but inflexible and ossified, were gradually loosened. In general, more regullating power was given to insurers, thereby challenging the position of providers, who were perceived as too powerful. Insurers and providers, expecting increasing competition, reacted with mergers and alliances, to stabilise their positions. In fact the relationships also developed in mutual agreements: the respective dominant insurer negotiated contracts with providers regionally, which were then taken over by the other insurers. Providers negotiated contracts mostly via associations of provider groups (Grünwald \& Kwartel, 1996). This practice enhanced transparency, trust, and diminished uncertainty on both sides. It can be understood as a pattern that is culturally typical for the Dutch society: to seek group-based solutions (Grinten, 1996, 1997) without losing sight of one's own interests. The smooth adoption of market mechanisms in the health care system can be related to long-lasting Dutch cultural attitudes towards business values: they are not seen as adversarial to public interests. State and business are perceived as supporting each other; cooperative networks are common features of Dutch markets (Waarden, 1992).

From 1994, the new health minister Borst (Social-liberal coalition 1994-1998, reelected in 1998) put an end to blueprint policy strategies in health care, and chose an incremental approach (Grinten, 1997). Additionally, the new government announced measures to achieve more patient-oriented and integrated care, by enabling regulated regional decision-making of important actors. Financial incentives were provided to stimulate cooperation between providers. Patients' rights were strengthened in sev- 
eral laws between 1994 and 1996. Direct payments were introduced for AWBZservices. Independent Regional Assessment Organisations (RIOs) were implemented to assess the care needs of the AWBZ users, and to facilitate integrated service planning and delivery. Thus, together with a change to an incremental policy strategy, governmental power was used to implement indirect regulations.

\subsubsection{Approaches to integrated care}

In the beginning of the 90 s the delay or fallure of the basic insurance project was foreseeable, and other ways had to be developed to reintegrate the fragmented services. Since then financial incentives have been developed to stimulate care innovation ('zorgvernieuwing') and tallored care ('zorg op mat'). A multiplicity of cooperations emerged. The role of providers changed from an administrative function to an entrepreneurial role (Crunwald \& Kwartel, 1996). Corresponding to the non-profit status of most providers and the societal implications of the field the emerging ideal was that of a social entrepreneur ('maatschappelijk ondernemer') (Boekholdt, 1999). Continuing budget constraints, and the insurers' strengthened position connected with - if only suspected - far-reaching future contract flexibility, has prompted providers to broaden the scope and flexibility of their services in cooperation with others (Boekholdt, 1998; Grünwald \& Kwartel, 1996), e.g. in order to enable early hospital discharge by calling other services in. Also, changing user interests and their strengthened position have acted as incentive for the development of integrated care. Approaches to integration have taken two different, complementary forms: timelimited cooperation projects, and mergers.

From the beginning of the $90 \mathrm{~s}$ a multitude of innovative projects at regional and local level, have been developed, many of them focusing on integrated care. They have shaped networks between the actors and smoothed the splits within the system, among providers within and across the cure and care sectors, with participation of insurers and/or other regional or local steering bodies. The projects together created a patchwork of innovation and cooperation permeating the inflexible structures, without abolishing them. They have therefore created a proliferating bureaucracy:

"For everybody a separated budget, ... yes, on the one hand this is innovative and brings about flexibility, but on the other hand it is more complicated. ... You have numerous budgets, but you try, so to speak, to build the connections with these budgets." (Dutch Insurers' Association, ZN)

On the other hand, they maintain and promote long-term innovation and integration concepts, and support an innovative culture, creating a "laboratory situation where 
everybody is engaged in projects." (National Patients/Clients Federation). The cooperation has been voluntary, without legal pressure. Because incentives and disincentives to participate change over time, cooperation initiatives are built up, but often also given up again, because e.g. subsidies come to an end or other conditions change. A fundamental problem of this Dutch 'innovation landscape' therefore - as well as the bureaucracy - is its fragility and questionable sustainability (Wieffering \& Dukkers van Emden, 1996); and of course, the fragmentary realisation of those efforts.

A wave of mergers has taken place among providers in both compartments. During the 90 s the government favoured this, partly by financial incentives (Vries \& Breedveld, 2000), in order to promote cost-efficiency and integration of services. The wave of mergers among Dutch care providers is continuing on a large scale; however, gains in care integration, efficiency and patient orientation are increasingly being questioned (Ipenburg, 2000; Vries \& Breedveld, 2000). The ongoing increase in scale is seen to serve market interests rather than patients' interests, whose position is endangered by the emerging regional monopolies and national oligopolies.

"The merger should be able to promote integration. If an organisation provides home care and residential care as well it is more readily prepared to deliver them as cost efficiently and appropriately as possible. ... But you get huge power units, which, moreover, engage in coalitions with hospitals. And clients have no choice any more, ... they have to put up with it." (RIO, Director)

A governmental strategy to regulate the concentration process does not exist, although announced in 1994 (Elsinga \& Kemenade, 1997); and the Dutch antitrust

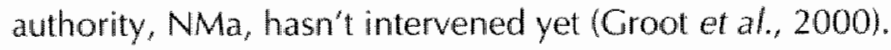

Expectations towards the roles of the actors in the health policy field show an underlying tug-of-war for power and ownership between government and independent actors to play their part in running and shaping the system. On the one hand, there is a societal consensus that government has to play a background role (Ministerie van Volksgezondheid Welzijn en Sport (Ministry of Health Welfare and Sports), 2000). Powerful and less powerful actors agree that

"the polder model is very much cherished in this society. ... It is important that the parties engage in the discussion. ... If you get things settled well altogether, then the authorities will step aside. Then the government isn't a player anymore." (National Patients/Clients Federation) 
On the other hand, public authorities, respectively their advisors, take the perspective, that e.g. providers have too much power, and must be more strictly held to account for their contributions to integrated care (Hemmen, 1999; Huijsman, 1999). The government's attempt to enhance its regulative power, however, causes protest. Providers themselves claim the credit for ongoing innovations:

"For the last ten years ... integrated care has been developing on a large scale. In my view the development relies upon the efforts of providers. In this country care innowation is done by the efforts of providers. But they receive, I think, very little recognition by the authorities for their achievements. The authorities are very much obsessed with control." (Care trust, Director)

The government has to balance this tension, inherent in the Dutch configuration, by skilful negotiation and regulation, in order to involve the capacities of the independent actors in pursuing public interests - as integrated care - and to bring their vested interests under control. Integrated care develops via management decisions of providers and insurers 'from below', influenced by their twofold commitment, and guided by governmental incentives and regulations.

In general, the incremental way of policymaking turned out to be more successful to promote integrated care. By measures of deregulation and incentives for cooperation, the government could stimulate and utilise the social entrepreneurship of the actors in the field. The created conditions promoted an innovative culture among care organisations; it has become a competitive advantage to participate in joint provision of integrated and flexible services in the regional or local care networks.

\subsection{COMPARISON}

Health policy developments in Britain and the Netherlands both reflect international trends in public policy. In both countries market mechanisms were introduced for parts of the heath and social care systems in the last decade, and had an impact on the development of integrated care; we also identified governmental regulation limiting but not abolishing market mechanisms, combined with the support for partly selfgoverning network processes at local level. We see those influences effective in both configurations, but in different country-specific ways.

There is a striking difference with respect to the role of government: the stronger role of British government, compared to the weaker role of Dutch government. In England we see a strong executive able to push forward major reorganisations twice within the last decade; this corresponds with Rhodes' statement of few constitutional constraints on executive leadership in Britain: "Once the government decided on a change, it could force it through." (Rhodes, 2000, p. 350). According to Scharpf, 
Britain has the "most hierarchical and majoritarian policy processes of any Western European countries" (Scharpf, 1996, p. 60). The Dutch mode of governance is characterised by a mix of market and network structures, with the government having to compensate for its limited scope to exert hierarchical power by indirect regulations. Dutch governments' successes rely on skilful negotiation strategies to achieve majorities for step-wise developments to promote integrated care, and on steering by financial incentives as well.

These differences cannot be explained by considering them as two different strategic options of health policy: governmental roles and political styles are intertwined with the configuration. Compared to the Netherlands the British government still might be regarded as nearer to a single-actor system (Westminster model') (Scharpf, 2000 ). The Netherlands are characterised as a multiple-actor system. Additionally, in Britain health and social services are still mainly public organisations, though with inde. pendent providers of social care playing an increasing role. In the Netherlands the health care system is traditionally shaped by well-organised independent actors, bound, however, to legal regulation systems guaranteeing collective interests.

In both countries the institutional structure corresponds with societal expectations about the responsibilities of actors in shaping the health care systems. In England the services have to, but are also willing to respond to governmental "top-down' instructions to a greater extent, notwithstanding that local actors have got some scope of decision. The government's role is to set a frame of action, and to push the realisation at local level. This is widely accepted, provided it is felt to be in line with the longstanding values of British public services. In the Netherlands the independent actors see the shaping and creating of the care sector as their responsibility. They show commitment to the values of affordable access, equity and efficiency of health care, and also to the aim of integrated care. This commitment, however, is partly challenged by their vested interests. The government has to build a regulating frame, which safeguards public interests.

To sum up, in England hierarchy, setting a defined frame for local network-building has a greater potential within the mix of steering mechanisms. In the Netherlands, self-governing networks play a stronger role, though influenced by market incentives and governmental regulations.

\subsection{Discussion AND RECOMMENDATIONS}

The cases of England and the Netherlands show different approaches to steering. In both countries policy fallures occurred, when configurational characteristics were neglected. Policy processes failed to gain acceptance in the countries, and to achieve better outcomes for integrated care. Progress occurred when policies made use of the 
configurations' potentials. This refers to the path dependency of successful political options. In both countries a change in political strategies took place, (re)considering the national political configuration, and leading to a more successfull approach towards integrated care. These changes can be seen as emerging from political learning processes, and as the effects of policy feedback. The ways of change, however, again differed corresponding to the configurational characteristics: In England we saw clear-cut shifts from one policy to the other, orchestrated in the public. In the Netherlands policy changes were under public discussion for years and implemented step by step.

Both configurations show characteristic potentials and weakmesses, which have to be considered for policy development. Scharpf attributes a higher capability for political change in general to single-actor constellations since they more easily might pass over unresolved conflicts inherent to political plans. In those systems, "hierarchical direction is an institutionally available mode of interaction" (Scharpf, 2000, p. 776). The stronger change potential as such, however, is not necessarily considered superior to multiple-actor constellations (Scharpf, 1993, p.767). In fact, radical changes may cause destructive ruptures and damage 'social capital' (Kickert \& Koppenjan, 1997; Ostrom et al., 1994). Moreover, also health policy developments in England were vulnerable to opposing public and stakeholder reactions - but later in the policy process, during implementation. Therefore, the English government's hierarchical power has to be used with care and wisdom, resisting the temptation of "too much too soon". Appropriate strategies have to support the achievement of political goals. Contents and methods of implementation and control must be adjusted to the characteristics of the configuration; and to the requirements of the issue in question, which in this case is long-term network-building for integrated care.

Multiple-actor systems are said to have the potential for incremental changes, which can be fine-tuned to complex situations. Thus, the incremental nature of Dutch health policy is occasionally considered advantageous, because thorough debates can minimise the risks of radical or premature policy plans (Grinten, 1997), blocking their realisation. On the other hand, the capacity to achieve necessary changes is sometimes lacking (Scharpf, 2000; van Raak \& Mur-Veeman, 1996). Given the relative autonomy of independent actors, also the implementation of changes might remains tragmented, as it is the case with Dutch integrated care. The government has to keep ahead of the other actors to maintain its regulating functions - which are perhaps increasingly challenged by rising market forces in the field. The outstanding regulation of the market concentration is an illustrating example. 
Referring to the requirements of complex issues like integrated care, we expected successfult policies to have in common that they facilitate and support networkbuilding at regional or local level, i.e. that they set favourable conditions for cooperative and flexible decision-making among partly autonomous actors. The cases show that conditions for local networks have been created in both countries. Again, these differ considerably, with respect to the degree of autonomy of the actors, and with respect to the extent to which hierarchical or market-like mechanisms exert steering impacts on these networks, too. It is in line with the logic of these concepts that a more extended use of hierarchy goes together with a lower autonomy of local actors, whereas a greater influence of market mechanisms corresponds with a higher degree of actiors' autonomy.

The comparison of these two cases thus indicates that policy approaches and policy successes are not transferable in a narrow sense. It is not possible to generalise from the failures and successes in England or the Netherlands, that one strategy or the other is the very best. We can generalise, however, that complex issues like integrated care need governmental efforts to create conditions for network-building to progress; but the way to generate these conditions tions themselves have take to their specific configurative shape in every country. It seems that it is strongly dependent on the structural and cultural characteristics of the national configuration whether or not a specific mix of coordinating mechanisms works successfully in a country - as neo-institutional theory suggests, and as our cases confirm. Therefore, policy makers have to consider these characteristics and determine to what extent an example from abroad will fit. "If it fits, go ahead. If it doesn"t fit, try to determine if you can make it fit, e.g. by adjusting it a little. If you can't make it fit, don't waste your time, don't bother to incorporate the mechanism". It seems to us, therefore, that the art of policy is to rune and play the national instruments, in order to compose a national melody - for which it is certainly very helpfult to know and understand many pieces of music from other countries.

\section{ACKNOWLEDGEMENTS}

We want to thank Hans Maarse, Jan van der Made and louke van der Zee for their valuable comments on an earlier draft of this article. 
$80 \mid$ Chapter 3

\section{REFERENCES}

Allsop 1. 1995. Health Policy and the NHS towards 2000. Longman: London, N.Y.

Aspinwall MD \& Schneider G. 2000. Same menu, separate tables: The institutionalist turn in political science and the study of European integration. European Journal of Political Research 38: 1-36.

Alkinson MM \& Coleman WD. 1992. Policy networks, policy communities and the problems of governance. Governance: An International Joumal of Policy and Administration 5: 154-180.

Boase $\mathbb{N}$. 1996. Institutions, institutionalized nelworks and policy choices: Health policy in the US and Canada. Governance: An International Journal of Policy and Administration 9: $287-310$.

Boekholdt M. 1998. Strategische vernieuwing in de gezondheidszorg: een organisatieveranderingskundig perspectief (Strategic innovation in health care: a perspective from an organisational change approach). In Wie is aan zet? Het veranderen van individuen, groepen en organisaties (Whose move is it? The change of individuals, groups, and organisations), Kuipers H, Midden C., Steensma H (eds); Elsevier/De Tijdstroom, Maarssen; $213-228$.

Boekholdt MC. 1999. Het spel en de regels. Dynamiek of verstarring in het regionale zorgbeleid (The game and the rules. Dynamics or rigidity in regional care politics). ZM Magazine 15: 10-15.

Department of Health. 1989. Caring for people: Community care in the next decade and beyond. HMSO: London.

Department of Health. 1997. The new NHS. Modern. Dependable. HMSO: London, UK.

Department of Health. "1998. Partnership in action. New opportunities for joint working beween health and social care. NHS Executive: London, UK.

Eisinga E. 1997. Van Dekker tot Borst. Tien jaar overheidsbeleid in de zorgsector. (From Dekker to Borst. Ten years" governance in the care sector). In Van revolutie naar evolutie. Tien jaar stelsehwijziging in de Nederlandse gezondheidszorg (From revolution to evolution. Ten years' change in the Dutch health care system), Elsinga $\mathrm{E}$, wan KYW (eds); De Tijdstroom, Utrecht; $27-77$.

Elsinga E \& Kemenade YWv (eds). 1997. Van revolutie naar evolutie. Tien jaar stelselwijziging in de Nederlandse gezondheidszong (From revolution to evolution. Ten years' change in the Dutch health care system. De Tijdstroom: Utrecht.

Giaimo S \& Manow P. 1999. Adapting the welfare state. The case of health care reform in Britain, Germany, and the United States. Comparative Political Studies 32: 967-1000. 
Grinten TEDvd. 1996. Scope for policy: essence, operation and reform of the policy system of Dutch health care. In Fundamental questions about the future of health care. Conference Report, Gunning-Schepers LI, Kronjee G), Spasoff RA (eds); SDU Uitgevers, The Hague; $135-154$.

Grinten TEDvd. 1997. Tien jaar hervormingsbeleid. Pendelen tussen overheid, marknowledge transfer en middenveld (Ten years" reform policies. Commuting between government, market, and 'middle field'). In Van revolutie naar evolutie. Tien jaar stelselwiziging in de Nederlandse gezondheidszorg. (From revolution to evolution. Ten years' change in the Dutch health care system), Elsinga E, Kemenade YWv (eds); De Tijdstroom. Utrecht; $162-178$.

Groot W, Merode Fv, Maarse $H$ \& Spreeuwenberg C. 2000. Fusies in gezondheidszorg: wel groter, maar niet beter (Mergers in health care: bigger but not better). Het Financiële Dagblad.

Grünwald CA \& Kwartel Allvd. 1996. Ordeningsprocessen in de regio. De ongrijpbare regio (Processes of regullation in the region. The intractable region). Beleid \& Maatschappij 23: $223 \cdots 234$.

Hardy B, Mur-Veeman I, Steenbergen M \& Wistow G. 1999. Inter-agency services in England and The Netherlands. A comparative study of integrated care development and delivery. Health Policy 48: 87-105.

Hardy B, Turrell A \& Wistow G. 1992. Innovations in community care management. Avebury: Aldershot.

Harrison S \& Wood B. 1999. Designing health service organization in the UK, 1968 to 1998: From blueprint to bright idea and 'manipulated emergence. Public Administration 77: $751-768$.

Hemmen DHAv. 1999. Modemisering AWBZ dringend gewenst (Urgently required: The mod.. ernisation of the AWBZ). ZM Magazine 10:17-25.

House of Commons: Health Committee. 1998. The relationship between health and social services. First report. The Stationery Office: London.

Hudson B, Hardy B, Henwood M \& Wistow G. 1997. Inter-agency collaboration. Nuffield Institute for Health: Leeds.

Huijsman R. 1999. Vraaggerichtheid, ontschotting en regionalisering in de care (Needs orientition, re-integration, and regionalisation in the care sector). ZM Magazine 15: 2-5.

Ipenburg B. 2000. Fusie of netwerkorganisatie. Paardenmiddel of paardenmodel (Merger or network organisation. Drastic cure or fallacy). Ouderenzorg 03: 22-24.

Johansson R \& Borell K. 1999. Central steering and locall networks: Old-age care in Swedem. Public Administration 77: 585-598. 
821 Chapter 3

Kickert WIM, Klijn EHH \& Koppenjan IFM. 1997. Managing complex networks. Strategies for the public sector. Sage: London etc.

Kickert WJM \& Koppenjan IFM. 1997. Public management and network management: An overview. In Managing complex networks. Strategies for the public sector, Klijn $\mathbb{E}$., Koppenjan IFM, Kickert W.J.M. (eds); Sage, London; 35-60.

Klein R. 1998. Why Britain is reorganizing its National Health Service - yet again. Health Affairs 17: 111-125.

Kooiman 1 \& Associates. 1997. Social-political governance and management. Conceptualization. Erasmus Universiteil / Rotterdam School of Management: Rotterdam.

Lehmbruch G. 1996. The organization of society, administrative strategies, and policy networks. In Institutions and political choice. On the limits of rationality, Czada R, Heritier A, Keman H (eds); VU University Press, Amsterdam, The Netherlands; 6*-84.

Light D. 1998. Effective Commissioning. Beyond the NHS White Papers. Office of Health Economics: London.

Light D. 2000. The sociological character of health care markets. In Handbook of social studies in heafth and medicine, Albrecht GL, Fitzpatrick R, Scrimshaw SC (eds); Sage, London, San Francisco; 304-408.

Marmor TR \& Maynard A. 1994. Cross-national transfer of health policy ideas: The case of 'managed competition'. Imternational Political Science Association: Sixteenth World Congress, August 21-25: Berlin.

Martin S. 2000. Implementing 'Best Value': Local public services in transition. Public Administration 78: 209-227.

Mildenberger U. 1997. Selbstorganisation won Produktionsnetzwerken. Erklärungsansätze auf Basis der neueren Systemtheorie (Self organisation of production networks. Explanatory approaches based on the new systems theory). Deutscher Universitatsverlag" Wiesbaden.

Ministerie van Volksgezondheid Welzijn en Sport (Ministry of Heath Welfare and Sports). 2000. Zorgnota 2001: Den Haag.

Mur-Veeman I, van Raak AJA \& Paulus A. 1999. Integrated care: the impact of governmental behaviour on collaborative networks. Health Policy $49: 149-159$.

Norgaard AS. 1996. Rediscovering, reasonable rationality in institutional analysis. European Journal of Political Research 29: 31-57.

O'Hagan G. 1999. Of primary importance. Inspection of social services departments' links with primary health services - older people. Department of Health: London.

Ostrom E, Gardner R \& Walker J. 1994. Rules, games, and common-pool resources. University of Michigan Press: Michigan. 
OToole L). 1997. Treating networks seriously: Practical and research based agendas in public administration. Public Administration Review 57: 45-52.

Pierson P. 1993. When effect becomes cause: Policy feedback and political change. World Politics 45: 595-628.

Rhodes RAW. 2000. The governance narrative: Key findings and lessons from the ESRC'S Whitehall Programme. Public Administration 78: 345-363.

Scharpf FW. 1993. Positive und negative Koordination in Verhandlungssystemen. (Positive and negative coordination in negotiation systems). In Policy-Analyse. Kritik und Nevorientierung. (Policy analysis. Criticism and reorientation), Heritier A (ed); Westdeutscher Verlag, Opladen; 57-83.

Scharpl FW. 1996. Political institutions, decision styles, and policy choices. In institutions and political choice. On the limits of rationality, Czada $\mathrm{R}$, Heritier $\mathrm{A}$, Keman $\mathrm{H}$ (eds); VU University Press, Amsterdam; 43-60.

Scharpf FW. 2000. Institutions in comparative policy research. Comparative Political Studies 33: $762-790$.

Thelen K. 1999. Historical institutionalism in comparative politics. Annual Review of Political Science 2: $369-404$.

Thompson G, Frances J, Levacic R \& Mitchell J (eds). 1991. Markets, hierarchies and networks. The coordination of social life. Sage: London etc.

wan Raak AJA. 1998. Zorgvernieuwing: een kwestie van routine. Een studie naar de vorming van interorganisationele netwerken en naar systeemveranderingen in de thuiszorg vanuit interactionistisch perspectief (Health care innovation: A matter of routine. A study about the building of interorganisational networks, and about system changes in home care from an interactionistic approach). Universiteit Maastricht: Maastricht.

van Raak AIA \& Mur-Veeman I. 1996. Home care policy in the Netherlands. Reforming legislation to facilitate the prowision of multi-disciplinary home care. Health Policy 36: 37 . 51.

van Raak AJA, Mur-Veeman I, Hardy B, Steenbergen M \& Paulus A (eds). 2003. Integrated care in Europe. Description and comparison of integrated care in six EU countries. Elsevier: Maarssen, The Netherlands.

Vries Bld \& Breedveld EJ. 2000. Concernvorming in de Nederlandse gezondheidszorg (The building of trusts in Dutch health carel. ZM Magazine 6: 2-13.

Waarden Fv. 1992. The historical institutionalization of typical national patterns in policy networks between the state and industry. A comparison of the USA and the Netherlands. European Journal of Political Research 21: 131-162. 
84 Chapter 3

Wieffering CH \& Dukkers van Emden DM. 1996. Institutionalisering van zorgvernieuwingsprom jecten (The Institutionalisation of care innovation projects). Medisch Contact $51: 644$ 646.

Williamson OE. 1985. The economic institutions of capitalism: firms, markets, relational contracting. The Free Press: New York.

Willke H. 1987. Systemtheorie: Eine Einführung in die Grundprobleme (System theory: An introduction to the basic problems). Fischer: Stuttgart, New York.

Willke H. 1998. Steuerungstheorie: Grundzüge einer Theorie der Steuerung komplexer Sozialsysteme (Theory of steering: Basic theoretical lines for the steering of complex social systems. Lucius \& Lucius: Stuttgart. 


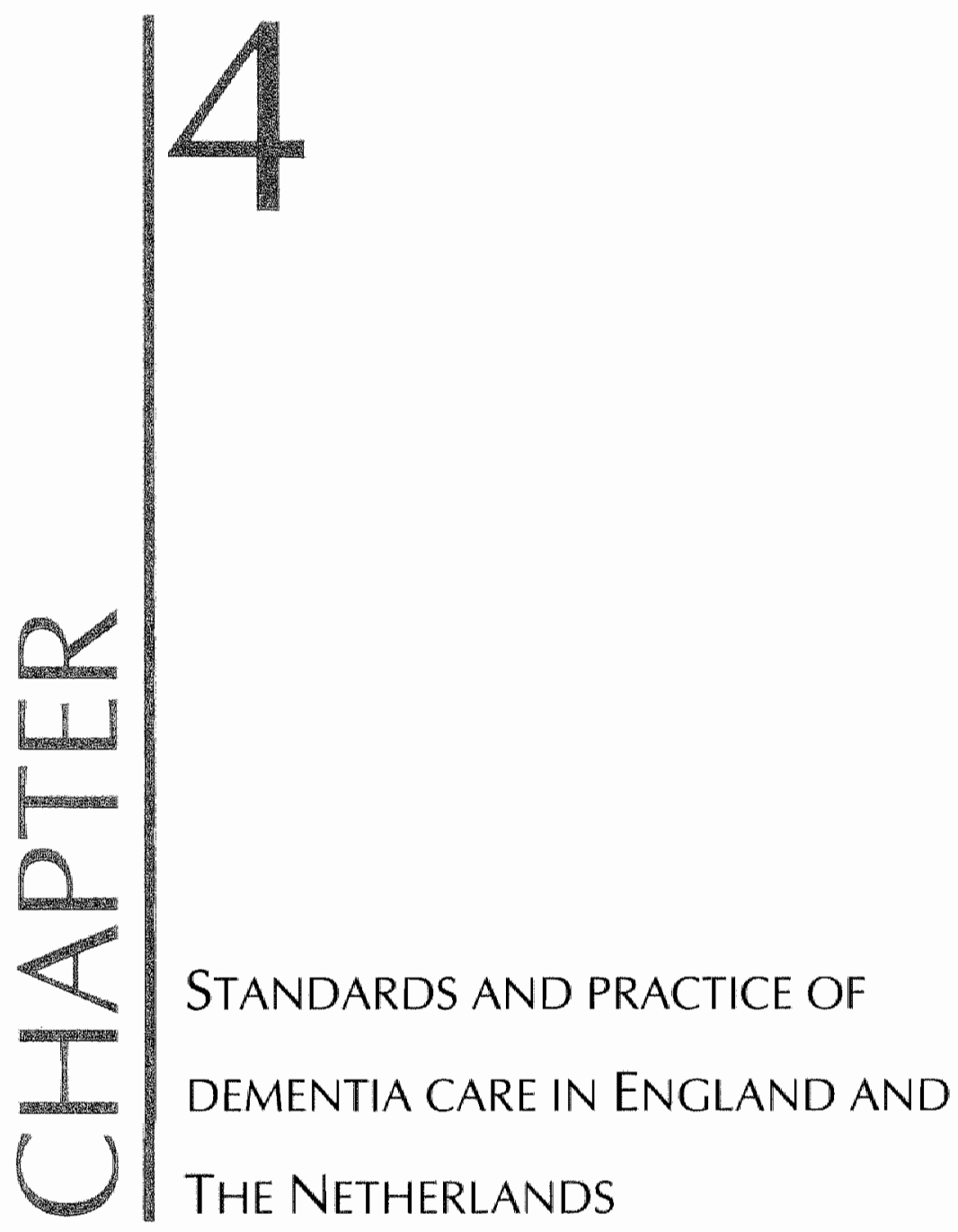

This chapter is based on:

Kümpers, S., Mur, l., Maarse, H., \& Raak, A. J. A. v. (forthcoming). Understanding similarities and differences in dementia care in England and The Netherlands: A qualitative comparative study using neo-institutionalist perspectives. Qualitative Health Research. 
86 Chapter 4 


\subsection{ABSTRACT}

In this article we compare dementia care in England and The Netherlands. Qualitative methods were used to explore recommended standards of service provision, and perceived achievements in mainstream care. We found some similarities in recommended standards and in major shortcomings in mainstream services: notably, weaknesses of generic services in supporting patients and carers, and failures to achieve integrated care. Priorities regarding service provision differed. While in England a social model of care was used to encourage empowerment of both the person with dementia and the carer, Dutch care professionals focused more on 'warm care concepts', and on support of the carer rather than the patient. The balance between community care and institutional care also differed. We used neo-institutionalist concepts to explore these similarities and differences as embedded in the (historically developed) structural and cultural contexts of the respective health and social care systems.

\subsection{INTRODUCTION}

Care for people with dementia poses multiple challenges to the health and social care systems of ageing societies in all Western countries. Due to demographic changes the numbers of those affected are rising. Knowledge about dementia care has increased. Professional concepts and social constructions of dementia, which affect the perceptions of desirable health and social services, are changing.

In this article we compare how two different health and social care systems, the English and the Dutch, are reacting to these challenges. England' and The Netherlands constitute interesting comparative cases: both countries are engaged in professional, political and public discussions on dementia care development. Innovative projects are being set up in many localities in both countries, but appear to be difficult to feed into mainstream care. Finally, health and social care systems and welfare state backgrounds differ interestingly between the two countries.

Using a qualitative methodology we seek to explain how particular cultural and structural characteristics of the health and social care systems in the two countries variously promote or hinder service development in the field of dementia care. We draw on neo-institutional approaches, which help to explain cross-national differences in policy development and implementation, and focus on the ways, in which

1 This study focuses on England and does not consider eventual divergences in other parts of the United Kingdom, as resulting, from the devolution policy. 
cultural and structural features of the respective contexts interact. Such a comparative study highlights important cross-mational similarities and differences, the relevance of which, we would argue, is wider than our particular focus here on dementia care. But because of the significance of some of the contextual differences we would caution against any suggestion that the lessons from one country can or should simply be translated to the other.

We set out an inventory of recommended standards for dementia care, and the perceived achievements and problems in each country. We then focus on reported shortcomings in mainstream services, common to both countries, and seek to identify cross-national barriers to change. Next we look for characteristic differences of standards and implementation patterns between the two countries and try to understand them within their national contexts. From these steps we develop recommendations for policy and service development regarding dementia care.

Before reporting our findings ${ }^{2}$, we describe, in the following section, the context and background of our study, reterring to changing models of dementia care and their role in service development. Subsequently we outline our theoretical approach based on neo-institutionalism, and the methodology applied.

\subsection{CONTEXT AND BACKGROUND}

The number of dementia patients in ageing societies is rising. Since prevalence increases with age, these societies might expect a two to threefold growth in the coming decades (Alzheimer's Society, 2000; Gezondheidsraad, 2002). These prospects have contributed to a growing awareness of dementia and an intensified debate about how health and social care systems should respond (Audit Commission, 2002; Department of Health, 2001b; Gezondheidsraad, 2002). Social constructions of dementia and dementia care influence the attitudes of professionals, informal carers and people with dementia themselves, as well as the relationships that develop, and the services provided. In many Western countries traditional ways of thinking about dementia and dementia care were seriously questioned during the 1990s (Marshall, 1997). The bilomedical model of dementia was for a long time associated with therapeutic nihilism' and a pessimistic view of people with dementia, defining them mainly in terms of a progressive disease of the brain (Cox et al., 1998). Losses of memory and functioning often were equated with loss of personality (Kitwood, 1997). This perspective widely shaped the professional and service approach, and contributed to the still prevalent public fear and stigma associated with dementia. Recently

\footnotetext{
${ }^{2}$ The scope of our study is restricted to 'ondinary' dementia care; i.e. specific user groups such as ethnic minorities or young people with dementia are not considered.
} 
knowledge has increased and become differentiated, reflecting diverse approaches within and beyond the medical paradigm (Cantley, 2001; Marshall, 1997). The gradual shift away from the biomedical model of dementia has broadened perceptions of the person with dementia, reflecting a social model of disability, as well as psychosocial or person-centred models (Bond, 2001). ${ }^{3}$ New therapeutic approaches such as validation, reminiscence work and sensory stimulation have become more common. These focus on the person, her relatedness to other humans and her capacity to experience life (Miesen \& Jones, 1997). The maintenance of emotion, rather than the decline of cognition, and the possibilities of communication are made the bases of caring relationships. Perspectives from the social model of disability have underlined that the capacities of people with dementia to live a personal life and to participate in social life are dependent on the context of social and environmental conditions (Cameron, 2000; Cox et al., 1998; Kitwood, 1997; Strässer \& Cofone, 2000). Also in recent years, progress made in the pharmacological treatment of early stage Alzheimer's. Disease $(A D)^{4}$ has reoriented medical approaches towards dementia (McKeith \& Fairbairn, 2001), requiring, for example, early differential diagnosis and information given to patients and their families.

Innovative ideas, based on a social model of care, have been promulgated amongst professionals, but a great deal is required for these ideas to be translated into integrated service development and delivery. Care pathways increasingly are seen as an important instrument in achieving integrated care processes for patient groups with complex needs. The term 'care pathway refers' to a "predeterminedl plan designed for patients who have a specific diagnosis" (Naidoo \& Bullock, 2001, p.3), that provides a recommended route for patients through the care system. Care pathways define the services needed, the task distribution and the required links between the organisations and professions involved. They represent current knowledge and perceptions, and thus are developmental rather than static. For the scope of our study we have defined the concept more broadly, to include issues of service cuality; and crucially, to encompass both health and social care rather than merely clinical processes (Campbell et al., 1998).

To enable a better contextual understanding of the results for readers unfamiliar with the health and social care systems in England and the Netherlands, we summarise their main features in Appendix 4.1.

\footnotetext{
"For this article we summarise them under "social model".

"For some patients cholinesterase inhibitors (ChEl) delay temporarily the progress of AD, the most frequent diagnosis underlying dementia.
} 


\subsection{THEORETICAL FRAMEWORK: NEOINSTITUTIONALISM}

Processes, which shape care pathways and implement innovative care concepts exist within historically developed contexts of health and social care systems. Neoinstitutionalist concepts focus on the institutional contexts and thereby on the context-specifity of policy processes (Aspinwall \& Schneider, 2000; Czada et al., 1996; Nørgaard, 1996). Such approaches became influential in political sciences during the 1990s, especially for comparative political analysis (e.g. Boase, 1996; Giaimo \& Manow, 1999; Scharpf, 2000; Waarden, 1992). They can help to explore similarities and differences in the development and implementation of care pathways in different countries with different health and social care systems.

Lehmbruch conceptualises national and sectoral - e.g. health care - policy constellations as historically evolved 'configurations' (1996), emerging from a "sequential interaction of the organisation of state and society" (p.75). Institutional structure and culture in these configurations are assumed to interact with each other, shaping current and future policy processes (Nørgaard, 1996), and thereby restricting - but not determining - policy options. This latter constraint is described as the 'path dependency' of policy-making (Boase, 1996), and refers also to the specific shape policy developments take within their respective national and/or sectoral configuration (Giaimo \& Manow, 1999). For the scope of this article we associate with 'structure' such phenomena as organisational and service patterns, balances of power, and financial frameworks. 'Culture" reflects organisational, professional, political and public values, as well as attitudes and routines. Health and social care systems can thus be described as sectoral configurations with their specific structural and cultural characteristics, historically grown, embedded in national configurations. Institutionalists strive to explain both similarities and differences between sectors across nations, in terms of specific national features (John \& Cole, 2000; Lehmbruch, 1996). For the purposes of this article we look for structural and cultural features at both sectoral and national level to explain emerging similarities and differences.

\subsection{METHODOLOGY}

Our discussion is based on an extended comparative study of integrated care for people with dementia in England and The Netherlands, which seeks to identify and understand the steering mechanisms and processes of integrated care. Previously we have published our analyses of mational policies for integrated care in both countries (Kümpers el al., 2002). Here we seek to describe and explain the current developments in dementia care in either country, as well as the changing standards and achievements to date. 


\subsubsection{Data collection}

For our study we relied principally upon reviews of the academic literature and other documentary analysis, and semi-structured interviews with dementia care experts in both countries. Guiding questions for all data collection aimed at identifying and explaining: what was perceived as the 'state of the art' of comprehensive dementia care throughout patients' pathways in the two countries; in how far mainstream practice was seen to match that 'standard', and which main problems were observed.

We started the literature and documentary analyses with handbooks on dementia care (Alkema et al., 2001; Jones \& Miesen, 1992; Marshall, 1997; Miesen \& Jones, 1997), and did literature searches using Current Contents on emerging themes (starting with dementia and care, subsequently looking for specific themes, e.g. early diagnosis, community care, case management, and others combined with dementia). In focusing on current developments we concentrated on the period 1997-2001; the collected literature was subsequently used for further snowball search. Relevant scientific and professional Dutch journals were searched in the home university's Iibrary. Documents were searched on websites from English and Dutch government, government-related, research, professional and voluntary agencies. The literature and document study was complemented by searching in specialist libraries (Alzheimer's Society London, DSDC Stirling) in 2001; the updates of the Alzheimer's Society's library were searched monthly between 6/2001 and 12/2002.

We conducted a series of in-depth, face-to-face semi-structured interviews within the expert communities for dementia care. The interviewees comprised researchers and professionals in dementia care, consultants in health and social care development, and Alzheimer's Societies' representatives. These experts were identified from the literature and documentary study, and by experts from the Leeds and Maastricht universities concerned with the study. The interviews served to triangulate and deepen the findings from the literature and document studly, to gain experts' perceptions about the state of the art of dementia care, about achievements and problems of current practice, and their respective explanations and interpretations. Eight interviews, lasting 60 to 90 minutes, were conducted in each country, between May and August 2001. Where permission was given - which it was in all cases - interviews were recorded and subsequently transcribed. In all cases interviewees were guaranteed confidentiality and anonymity in any written reports or publications 


\subsubsection{Data analysis}

Primary and secondary data collection and analysis were used in an iterative and interactive manner. Literature and document study informed the preparation and conduct of the interviews; findings from the interviews led to further literature search. Since our interviewees were acknowledged experts, we treated their statements as authoritative, whilst nevertheless, looking to the literature to triangulate such statements.

The interview transcripts were caded. Qualitative data analysis software (atlas-ti 4.2) was used for coding and retrieving. Purely descriptive codes linked quolations to types of services, procedures, agencies and professions; other codes were used to identify explanatory statements, e.g. about philosophy or models of care, or about political or cultural backgrounds of certain service situations. An initial code list was extracted from the literature; it was differentiated and complemented by topics emerging from the interviews. The interview material was searched to complement, sharpen, detail, and illustrate the findings from literature and document study. It led us to pay attention to some subjects, which were less apparent from the initial literature search (e.g. problems in general hospitals in both countries, differences regarding advocacy between the countries etc).

Our analysis involved descriptive and explanatory steps, as outlined below.

First, we established 'recommended standards' for dementia care pathways in each country, summarizing recommendations in the literature from governmental, government-related and relevant scientific and professionall agencies. These sources showed a broad consensus within and between both countries. The standards act as reference frames for the findings about reported prevailing practice.

Second, to provide an inventory of achievements and shortcomings of dementia care, in relation to the recommended standards, all the material from searched documents, literature and interview transcripts was collated according to types of services and summarised. There was, in fact, considerable correspondence between the accounts of interviewees and the literature and documents searched.

We present the main findings from the inventories of standards and practice for each country in tabular form (see Appendices 4.2 for England and 4.3 for The Netherlands). We categorised pathway components (rows) and the different levels of professional and managerial activities, i.e. 'service provision', "pathway-oriented activities', and 'enabling activities'. For each of the latter we built a separate table. Thus for every component and for every level, standards and practice (columns) are compared and contrasted, and the most essential services or activities are reported. We give short qualitative descriptions reflecting broad tendencies emerging from the literature, 
documents and interviews; in some cases these are complemented with quantitative information.

In the third and fourth steps we perform exploratory explanation-building (Yin, 1994), using neo-institutional concepts. Again, all types of collected data are used. After describing the main divergences between standards and practice, which have emerged from the inventory as being similar across both countries, we explore underlying cultural and structural institutional characteristics to seek an understanding of cross-national barriers to change. Subsequentlly, we focus on differences between the care pathways of the two countries, in terms of their standards and implementation patterns. We explain them by illustrating their embeddedness in the historically developed configurations. Within the text we qualify the aforementioned similarities and differences in terms of the guiding concepts by ( $s=$ structure) and ( $c=c u l t u r e)$.

Any comparative cross-national study by definition involves accounts of one country affecting those of others. A comparative "lens" automatically changes the view one would obtain of a country seen in isolation - e.g. the emphasis on the autonomy of people with dementia in England will focus the researcher's attention on a more paternalistic approach in The Netherlands and vice versa. Any difference challenges the idea of a phenomenon as quasi-natural ${ }^{5}$.

\subsubsection{Ethical considerations}

The conduct of this research fulfilled legal and ethical requirements. The interviewees were provided with written information about the project and asked for their consent for taping and transcribing. The interviews were handled in strict confidentiality and anonymity.

\subsection{RESULTS}

\subsubsection{Similarities in patients' pathways in England and The Netherlands.}

The tables in Appendices 4.2 and 4.3 compare and contrast the recommended standards and the reported current practice for each level of activities and for each country. For the latter we concentrate on what is described as the principal achievements

\footnotetext{
${ }^{5}$ In this respect it might be interesting for readers that the main investigator of this study was neither Dutch nor English (but German), and thus had an outside perspective on both national contexts.
} 
and shortcomings in mainstream services, rather than focusing on local variations and existing islands of best practice.

\subsubsection{Similarities among recommended standards}

There is broad international professional agreement about the broad goals and means and goals of dementia care (e.g. EACH, 1997a; EACH, 1997b; Furnish, 2002). Increasingly these goals incorporate innovative care concepts as described above. Below we give a textual summary of similar recommendations for dementia care in English and Dutch sources (provided in more detail in the left-hand side of the tables im Appendices 4.2 and 4.3), along the stages of a typical pathway:

Strong emphasis is placed on the initial steps - early identification, diagnosis and subsequent needs assessment (Alzheimer Nederland, 2001a; Alzheimer's Society, 2000; Audit Commission, 2000; Department of Health, 2001 b; Gezondheidsraad, 2002). Early differential diagnosis facilitates the treatment of reversible causes of dementia symptoms (Eccles et al., 1998; Nederlands Huisartsen Genootschap, 1998), and allows the treatment of early AD with ChEl (Department of Health, 2001 b; Gezondheidsraad, 2002). Non-medical arguments (Alkema et al., 2001; Alzheimer Nederland, 2002; Alzheimer's Society, 2000; Downs, 1999; Duncan \& Siegal, 1998; Iliffe et al.,2002) stress the benefits of early diagnosis and support in getting information, understanding the symptoms, being able to plan for the future, develop coping mechanisms, and getting access to services; although, interestingly, in The Netherlands this support focuses mainly on carers, not patients.

Diagnosis and assessment, it is widely agreed, should initiate coordinated, tailored and flexible care processes in the community, trying to prevent crises rather than merely react to them. Services should enable people with dementia and their carers to maintain their functioning and their quality of life, and prevent overload. Regular review is needed to react to changes (Naidoo \& Bullock, 2001; Stoop \& Vermolen, 1999). Comprehensive case management is considered important to support patients and capers, and to ensure pathway coordination (Cameron, 2000; Gezondheidsraad, 2002; Naidoo \& Bullock, 2001; Salari, 2000); variable and intensive support in crises should be available. Flexible cooperation is required, especially between generic services and mental health specialists (Audit Commission, 2000; Gezondheidsraad, 2002; Sheard \& Cox, 1998), and there is a consensus that dementia patients should be cared for in their own home as long as possible.

Assessments for admission to institutional care need to take account of several factors: care needs, carers' capacities, safety, social inclusion, and the living environment. The transition process - decisionmaking, transfer and adaptation - needs to be 
supported by information and counselling (Audit Commission, 2000. Residential and nursing home provision should follow the same principles as community care: being pro-active and directed to the individual, maintaining functioning, autonomy and personhood, whilst reflecting existing knowledge about dementia care Alzheimer's Society, 2000). Dementia-specific services should provide small-scale group seltings, a homely environment, appropriate design, social stimulation and continuing relationships between residents and care workers (Gezondheidsraad, 2002; Nationale Raad voor de Volksgezondheid, 1994).

Throughout all stages and for all services the staff should have sufficient knowledge and training to understand and respond to dementia. The input of mental health specialists here is seen as important (Audit Commission, 2002; Gezondheidsraad, 2002).

\subsubsection{Similar main divergences between standards and practice - descriptions and explanations}

The inventories (see Appendices 4.2 and 4.3) show several areas, in which major divergences between standards and practice, similar in both countries, are reported from a variety of sources. Generic services - both health and social care - were widely perceived as often not providing the optimum of care for people with dementia; and, in particular, access to specialist mental health services often was seen as fragmentary. The interface between services, for coordination or professional development, was often reported to work poorly. Below, the main shortcomings and their impact on patients and carers are described. For each topic we then explore possible explanations within the institutional context. We seek to identify cultural and structural patterns, common to both health and social care systems, which explain the reported problems. Similar features in both countries are claimed to act, and interact, as barriers to innovative dementia care pathways: the medical professional culture; traditional care models; the imperative of cost-containment; and the difficulties of (re) integrating the differentiated and specialised service systems. In the case of general medical services we find related explanations for primary care and acute hospital care.

\subsubsection{Primary care}

Some general practitioners" (GPs) practices are reported to inhibit dementia care. Failures to make timely diagnoses, or to inform or refer, leave people with dementia and their carers without a proper understanding of the disease, and exclude them from access to treatment and available support (Alzheimer Nederland, 2001b; Audit Commission, 2000; Hout et al., 2000; Iliffe et al., 2000). The consequences for their 
whole care pathway are often detrimental: these include unresolved anxieties, omission of treatment options, being left alone with behavioural problems, carers' overload, premature crises and admissions - in sum, significant losses in quallity of life.

CPs work in a context of high work pressure and large case loads (s), which act as some incentive to stick to their traditional domains and a disincentive to adopt more comprehensive and cooperative approaches. Vague and ambiguous recommendations for referral (cf. Eccles et al., 1998; Nederlands Huisartsen Genootschap, 1998) to specialist mental health services (s) add to this, although the prescription of ChEI requires precisely their involvement. This reflects and maintains uncertainties about appropriate referral patterns (c). Moreover, 'traditional' GPs are seen as following a biomedical model of care (c), rooted in their professional culture.

"Indifferent, most of them, uninterested - GPs like to run, they are extremely active people ... thus, it's not theirs [clealing with dementia] ... In general I think, they are not good at it, they are not aware; rather, they follow the medical model, they are too ignorant." (Service development consultant, NL)

ChEls, being within the medical model (s), simultaneously reassure the medical culture, which tends to emphasise pharmacological treatment and to neglect the psychosocial aspects of dementia (c).

"It's great they (GPs) think they can do something [giving medication], but I'd hate them to think that's all they could do and that they don't know there's a support group running for people in the early stages round the corner from where they are writing their prescriptions, or that carers are entitled to benefits etc ..." (Researcher, UK)

ChEls, therefore, can be a vehicle to attract more GPs" interest in dementia ${ }^{6}$, but they need to be complemented by other measures to broaden GPs' perspectives.

\subsubsection{Acute care}

The wide-spread failure of general hospital wards to respond to elderly patients with mental health needs adequately itself brings about untreated co-morbidities like dementia itself, depression and delirium; the overall outcomes are poor with respect to length of stay, rates of institutionalisation, persistent symptoms and death (Holmes et al., 2002; Koning, 1994; Slaets et al., 1997). As one interviewee graphically put it:

6 This happens to a higher degree in England, because ChEI are used there more intensively (see below). 
"It is bouncing in and out of the acute sector, which is so disabling for people - horrendous. They go in reasonably competent, they come out just a mess time and again. And something like $40 \%$ of people who go from home into long-term care go through the acute sector." (Dementia Services DeveIopment Centre DSDC, UKI

Additionally there is a danger that admission to hospital care is denied to people with dementia. Interestingly, the severe problems in acute care for people with dementia are rarely mentioned in the main policy documents in either country, although some literature does exist. They were, however, reported by nearly all of our interviewees. The widespread unresponsiveness of general hospitals again is partly ascribed to the dominant professional medical culture (c).

"People assume that acute hospital wards are something completely different from the care of people with dementia. That it is a different world, a world that doesn't want and shouldn't have people with dementia. ... So the focus is on 'oh dear, they shouldn't be here, but if they are here we are going to get them out quickly". (DSDC, UK)

A general lack of interest in mental health (Holmes et al., 2002) may be seen as part of this acute care culture. Structural aspects, too, such as pressures on scarce hospital resources, and the dominant organisational rationale focusing on bio-medical interventions (s), might contribute to such a negative attitude (c), since patients with dementia risk being labelled 'bed-blockers' in a context of shortages in community and long-term care (s):

"But when it was known, that patients had dementia, the hospitals were keen to get rid of them; ... you get someone with big problems, not staying quietly in bed, making other patients crazy, needing additional care ... and you know you won't get him home... Yes, there are many indirect efforts to try to get rid of them." (Alzheimer Nederland, NL)

Thus, interrelated cultural and structural features hamper the adoption of more comprehensive and appropriate approaches to dementia care in general medical services.

\subsubsection{Social care}

In both home care and care homes, the low level of training of the majority of care workers has led to widespread concern and criticism (Audit Commission, 2002; Gew zondheidsraad, 2002): and the quality of the care delivered is often questioned. Home care is often scarce, limited in time and lacking in continuity of care workers. Specific teams for dementia are rare. Lack of specialist skills in home care teams can 
mean that behavioural problems, e.g. resistance to support, are not adequately dealt with, or that staff continuity is not considered important. Consequently, formal and informal carers sometimes fail to cooperate, with the latter experiencing increased rather than relieved stress (Train et al., 2001). Thus the preventive potential of home care is often not realised. Care homes in both countries, although embedded in different national contexts (see below), often fail to provide more than basic physical care; amongst the most significant consequences are premature decline in health and lower quality of life and well-being (Ballard et al., 2001; Gezondheidsraad, 2002). Both home care and long-term care operate under conditions of resource scarcity. Care work in industrialised countries increasingly has become low level and low paid work (s) (Cartier, 2003). Basic care concepts focus on physical care, keeping people clean, fed and safe (c). This minimalism corresponds well with the traditional model of the person with dementia (c) as having "turned into a vegetable" (Researcher, UK) and with traditional 'custodial care' models $(s+c)$ (Bland, 1999; Cartier, 2003). Efficiency pressures in marketised 'care industries' affect home care and care homes similarly (Oldman \& Quilgars, 1999). They stress quick performance of care tasks, sometimes characterised as "care Taylorism" (Houten, 1999), often at the cost of personal and relational qualities of care processes (c) (Malone, 2003). Such contexts do not readily incorporate more subtle interactive approaches such as those developed for dementia care $(\mathrm{s}+\mathrm{c})$. Innovative training for dementia care has been elaborated in recent years, but is not yet widespread.

"I think there is very little skill development in dementia care now in many of the long-term care providers.... The whole pricing and charging policy has driven down any element of quality in long-term care... Those of us that managed units that would deal with dementia knew well that it costs: It is people time, it is training time, and it is cost and supervision and support. ... And therefore, we haven't had the investment in developing skills in dealing with mental health problems." (Research and Development Consultant, UK)

Additionally, research in care homes in The Netherlands has confirmed that training efforts as such do not guarantee the implementation of innovative care approaches when faced with adverse organisational patterns and routines $(s+c)$ (Heusden et al., 1999; Schrijnemakers et al., 2002). Therefore, diffusion of innovations and quality improvement are proceeding slowly and with considerable inter-community and inter-agency variations. 


\subsubsection{Specialist mental health services}

The quality of specialist care delivered is seldom criticised, although memory clinics are sometimes seen as failing to provide care, which goes beyond medical treatment to include psychosocial support (Lindesay et al., 2002; Verhey et al., 1999). Restricted access to community mental health services was, however, reported as a problem for varying percentages of patients and carers. Those denied access miss availlable treatment and support, and often are left alone to cope.

The principal causes of restricted access were referral practices (c) and sheer scarcity of provision (s) (Audit Commission, 2002; Gezondheidsraad, 2002). In England, Community Mental Health Teams (CMHTs) do not exist everywhere (s) (Audit Commission, 2002), while not all of their Dutch counterparts, the RIAGGs, define dementia care after diagnosis as their task (c) (Engelhard-Salari, 1995; Gezondheidsraad, 2002). The latter is seen as reflecting a neurological (cognitive) reduction, within the biomedical model , neglecting the needs of patients for psychiatric support (Verhey, 2002). Similarly, the frequent focus of memory clinics on pharmacological treatment with ChEl in both countries is seen as culturally linked to the biomedical model.

\subsubsection{Pathway coordination}

The degree of successful coordination varies considerably across localities and regions (Audit Commission, 2002; Gezondheidsraad, 2002). The lack of comprehensive assessment procedures and of timely access to case management schemes implies higher uncertainty for patients and carers, since they don't have reliable and consistent contacts in the services. Moreover, frequent weaknesses of cooperation, especially between generic and specialist services, create or enhance weaknesses in service delivery and increase the risk of unmet needs and crises development.

The reluctance to acknowledge the need for comprehensive assessment and case management - and thereby to enhance pathway coordination - can partly be related to the context of marketisation, scarcity and efficiency pressures (s), and the maintenance of the traditional nihilistic model of dementia (c), described above. In England, intensive case management practices and competences in SSDs have been weakened by the community care reforms introduced in 1993 (s), the latter having strengthened an administrative care management approach to the disadvantage of person-oriented case work (Challis et al., 2001). Similarly in The Netherlands it has been difficult to get financing for comprehensive case management components (s):

"If you offer community care, then the care work is paid, but not the coordination; neither welfare services as stimulation of activities and social work. This is a big practical problem, to make good care packages at home for 
really integrated care with all the elements people need." (Research and Development Institute, $\mathrm{NL}$ )

Furthermore, development and implementation of assessment and case management schemes are in practice dependent on well-developed local inter-agency and interdisciplinary cooperation. They are, therefore, complicated and vulnerable $(s+c)$, as much of the literature about integrated care suggests (Hardy et al., 1999; Kümpers et al., 2002; van Raak et al., 2003).

\subsubsection{Dementia competence}

Training and consultancy for generic health and social services staff by mental health specialists is often limited or under-used. This again adds to weaknesses in generic services.

The development of dementia competence in generic services is dependent on the provision of training and consultancy by mental health services, and on the willingness and capacity of generic services to make use of them $(c+5)$. Within health services (primary care and hospital care) the dominance of the medical culture seems to hamper the adoption of broader perspectives on dementia care (embracing social models) and therefore the acceptance of dementia-related training schemes (c). Within home care and care homes also the scarcity of resources, and the focus on 'efficient' care processes (s) promote a culture in which dementia-related training schemes are under-developed (cf. citation on social care, see above).

\subsubsection{Differences in patients' pathways in England and The Netherlands}

Looking at the accounts in the Appendices 4.2 and 4.3, differences of standards and practice between dementia care pathways in the two countries initially appear to be subtle, with some slight accents or balances in service provision. Differences indicated are, for example, a variable focus of enabling services on the person with dementia herself, and a different balance between community (non-institutional) and long-term institutional care. But it became apparent that some phrases adopted as standards in both countries actually carried different meanings, e.g. "support people at home as long as possible". When synthesizing the differing structural and cultural elements for each country, however, we discovered comprehensive and distinctive societal patterns that constitute the respective national configuration - finally pointing also to different understandings of the welfare state. Table 4.1 collates and contrasts these configurational differences. 
Table 4.1: Dementia pathways: summary of main differences between England and The Netherlands (configuratilonal differences)

\section{England}

1. Dealing with people with dementia

unformationabout diagnosis To be given to patients and carers

ChEl|

Psychosocial support Strongly promoted (3 types availlable)

Advocacy (support for inter- Independent service; focus est representation)

$$
\text { on }
$$
rately, increasingly implemented

Eacus in risk management Balance between safety and Focus on safety debates autonomy needs

Eacus of Alzheimer Societies Changes to involve people with dementia
The Netherlands

To be given to carers; patients - still contested.

Reluctantly evaluated (1 type available)

Focus mainly on carers

Part of case management; focus on carers

Recent initial shifts to focus also on patients not only on carers

\section{Community care - institutional care}

Proviston of day care (in 8,5 places/ 1000 people over 2,5 places / 1000 people over 1990, more recent data not 65 found)

Provision residential \& nursing home beds

Approximately 49 per 1000 people over 65 65. Used mainly in transition before admission.

Societal attitude towards care Prevailingly negative, adhomes dressed as last resort

Approximately 80 per 1000 people over 65

Perceived as necessary and appropriate, especially in dementia care

Above $50 \%$, rising.

Some percentage

\section{Institutional care context}

Percentage psychogeriatric of Fewer than $20 \%$

all nursing home places

Residents with dementia cared for in generic residen:

lial homes

Current provision trends

Very high percentage

Decreasing; closures due to Increase in NHs; after de. insufficient funding rates, crease of RHs in the 1990s, higher care standards

Planning characteristics

No planning guidelines; frequent problems in management of local care markets.

Waiting list administration

Separated per care home

Mostly regionally coordi-

Residential \& nursing homes: Small (majority under 50 scale places)

Nursing homes. cultural Social model origin nated increase again.

National planning guidelines; service planning by insurers and providers

Big (majority above 100 places)

Medical model, replacing long-term hospital wards 


\begin{tabular}{|c|c|c|}
\hline & England & The Netherlands \\
\hline $\begin{array}{l}\text { Nursing homes: professional } \\
\text { profile }\end{array}$ & Highest level: nurses & $\begin{array}{l}\text { Highest level: doctors, psy- } \\
\text { chologists }\end{array}$ \\
\hline $\begin{array}{l}\text { Residential homes: cultural } \\
\text { origin }\end{array}$ & Social model & $\begin{array}{l}\text { Social model, originally dedi- } \\
\text { cated to healthy older people }\end{array}$ \\
\hline $\begin{array}{l}\text { Role of cale home providers } \\
\text { in regional neiworks }\end{array}$ & Small, marginalised & $\begin{array}{l}\text { Poweriul, influential (extend- } \\
\text { ing their provision into com- } \\
\text { munity care) }\end{array}$ \\
\hline 4. Welfare state context & & \\
\hline $\begin{array}{l}\text { Type of welfare state (Esping- } \\
\text { Andersen, } 1990 \text { ) }\end{array}$ & Liberall welfare state & $\begin{array}{l}\text { Social-democratic } \\
\text { state }\end{array}$ \\
\hline Role of voluntary services & $\begin{array}{l}\text { Strong role, various services } \\
\text { provided in many places }\end{array}$ & $\begin{array}{l}\text { Weak role, some services } \\
\text { provided on small scale }\end{array}$ \\
\hline $\begin{array}{l}\text { Focus of dementia service } \\
\text { provision, esp. in earlier } \\
\text { stages }\end{array}$ & Focus on autonomy & Focus on "caring for" \\
\hline
\end{tabular}

Below we describe and explicate these differences between the configurational contexts. Our discussion has to be understood from a comparative perspective, as described above. First we summarise the main features:

In England, there is a strong focus on independence for vulnerable people, including people with dementia, which helps explain the priority of non-institutional community care over institutional care, and the widespread negative altitudes towards institutional provision. The latter might contribute to weaknesses in the integration of service development and delivery of institutional care and to the low provision rates, which again enhance the emphasis on community care.

In The Netherlands the historically high level of institutional care - based on societal views about old age and the welfare state - and the significant influence of nursing home professionals' perspectives, mould dementia care pathways in general, reinforced by a still wide-spread societal taboo on dementia. The focus is on 'caring for', rather than empowering or enabling people with dementia themselves, seeming, as compared with England, relatively paternalistic. But the higher rate of institutional provision can be argued to exert less pressure on community care to enable patients and carers to cope at home.

These above main features point to specific national configurations. We describe them below alongside the contexts of community care and institutional care.

\subsubsection{Community care}

In England, the emphasis upon the autonomy of the person with dementia is strong and strengthening (Baragwanath, 1997; Dunning, 1997; Robson \& Locke, 2002). 
Activities in the early stages (cf. Table 4.1) reinforce each other, with ChEl seen as primarily having a facilitating role:

"It is really only the last three or four years with these new drugs that we have started having any significant number of early stage people. (...) But I think we are only now developing the kinds of expertise and models of ser. vice." (DSDC, UK)

Voluntary agencies such as neighbourhood charities often have a strong, innovative and creative role in services for the elderly, focusing on empowerment and social inclusion (Stanley, 2003); and they are often funded by statutory agencies (s). This emphasis on support by families, neighbours and volunteers fits with the characterization of Britain as a 'liberal welfare state' (Esping-Andersen, 1990). Simultaneously, there is a strong primacy of care in the community - in spite of the paramount scarcity of resources - rather than institutionalised care. The political and ideological priority for non-institutional services is seldom questioned (c); living at home is strongly identified with independence and a better quality of life (Andrews \& Phillips, 2002). This perception is rarely queried for people with dementia.

In The Netherlands, attitudes amongst politicians, professionals and users similarly have increasingly favoured living in the community during the last decades (c). Nevertheless, scarce provision (s), and reluctant acceptance or even rejection (c) of community care services are reported, so that the preventive and enabling potentiall of community care is seen as under-developed (Alzheimer Nederland, 2001b). The strong focus on carers' needs and on 'caring for' the person with dementia (cf. Alzheirmer Nederland, 2001b; Hout et al, 2000; Stoop \& Vermolen, 1999) fits well with care models for later stages, but is also dominant in early stages of dementia. The significant influence of nursing home professionals in innovative service development, therefore, might have a role in this (c). Care home providers also are increasingly engaged in 'extramural' activities, i.e. communily care (s), in extension of their traditional domain.

"Policy development in psychogeriatrics nearly always originates from the nursing homes. The authorities don't have a concept how to do it. The nursing homes, namely the trendsetters, made it up themselves what had to be done." (Alzheimer Nederland)

Additionally, in The Netherlands, a still widespread societal taboo on dementia is widely thought to preserve this situation (c), demonstrated in high rates of undetected cases (Afdeling SPGD/Ouderenzorg et al, 1997). The reluctant approach to ChEl might be seen as a result of and simultaneously as maintaining this situation. 
104 Chapter 4

\subsubsection{Long-term (instilutional) care}

In England, beween 1983 and 1993, while many long-stay hospital wards were closed, guaranteed social security funding initiated a remarkable growth in the private care home market, later seen as unintended (Andrews \& Phillips, 2000). The NHS and Community Care Act aimed to halt their growth, emphasizing noninstitutional care and restricting access to social security funded care home provision. This was a return to a more long-standing negative attitude towards care homes in England (c), defining them as essentially a last resort (Oldman \& Quilgars, 1999). The positive effects of admissions into care homes - e.g. people regaining strength and capacity in sheltered environments - appear in professionals' statements, but seldom in official policy documents. Critical attitudes to care home provision in general still sometimes are linked with suspicion of private for-profit provision amongst SSDs (c), which have the commissioning role, although improving relations between independent providers and SSDs have been reported (Knapp et al., 2001). Both together may contribute to the frequent absence of cooperative waiting-list administration and difficulties in strategic planning of care home provision (s) in a managed market (Kerrison \& Pollock, 2001), recently addressed by the government (Department of Health, 2001a). Low provision rates of specialist dementia care (s) can be attributed partly to poor planning, but allso to the ignorance of specific care needs (c) and funding rates (s) that are not adjusted to those care needs (Garvican \& Bickler, 2002; Kerrison \& Pollock, 2001). The fact that dementia care may be seen as the "main business of almost any residential or nursing home for older people", is still widely ignored in current policies (Macdonald \& Dening, 2002). High prevalence of dementia in non-specialist care homes, however, poses problems to care home providers and staff, and challenges the quality of care. The professional profile and relatively weak political and market position of small care home providers (Knapp et al., 2001) also may have contributed to the underdevelopment of psychogeriatric specialization.

in The Netherlands, historic patterns of provision (s) and societal attitudes (c) about institutional care explain higher rates of institutionalisation. An extensive provision of residential and nursing home beds was built up in the 1950 s and 60 s (s), perceived as the welfare state's proper service to older people - in line with The Netherlands' social-democratic welfare state model, as described by Esping-Andersen (1990). Residential homes were then described positively (c) as providing an opportunity to realise independence and what was then regarded as a beneficially 'distant' attitude to the community (Bijsterveld, 1996), which was identified with old age (Braam et al. 1981). A consequence has been one of the highest rates of institutionalisation of elderly people in Europe (s) (Ribbe et al., 1997). With rising costs and changing attitudes, negative connotations of care homes have developed; idleas about independ- 
ence now define living at home as best for those elderly who are healthy (c). Nevertheless, admissions to care homes, especially of people with dementia, are still readily made and accepted by carers and professionals (c). Local cooperative administration of waiting-lists, and long-term planning horizons for service provision, agreed by insurers, providers and public authorities (WZV-regio 27, 1998), show that care home providers form an integrated and influential part of the respective policy and service networks (s). The high and still rising number of psychogeriatric nursing homes (s) (Gezondheidsraad, 2002; Nies, 1990) may well reflect the medical professional perspective (c) - to differentiate for diseases - and the providers' efforts to focus on the most promising areas of activities for the future.

\subsection{CONCLUSIONS AND RECOMMENDATIONS}

Both England and The Netherlands must react to a similar challenge: to respond to the needs of rising numbers of people with dementia, in increasingly ageing societies with growing cost and efficiency pressures on their health and social care systems. We have outlined broad similarities in the recommended standards for dementia care pathways, reflecting in broad terms a social model of care. We have also identified a remarkable similarity in the main divergences between standards and reported practice. We have explained them in terms of significant interacting structural and cultural barriers to the realization of the recommended standards, common to both health and social care systems beyond national characteristics:

- A professional biomedical culture, often unresponsive to more comprehensive non-medical care needs, and incorporated in organisational structures

- Traditional care models in social care, focusing on basic physical care

- Efficiency pressures in health and social care related to processes of marketisation

- Difficulties in setting up complex inter-disciplinary and inter-agency care processes

We conceive of these features as sectoral characteristics beyond national configurations - i.e. as probably applying to other countries, and maybe as being inherent to current health and social care systems in European or Western industrialised countries. They show that despite system differences features like medicall professionalism have a broadly similar impact across countries, as described by Fox (1989). Efficiency constraints on health and social care systems are simultaneously increased by the age-based demographic developments inside the countries, and by globalised economic processes exerting external pressure. 
A range of innovative projects to address these shortcomings is currently being developed and implemented in both countries. Generally, however, such innovative services co-exist locally with mainstream weaknesses; thus they do not significantly alter the general picture. Further research is needed to analyse the extent to which such local initiatives can successfully permeate mainstream services, and thus overcome the described barriers. As generic services will probably continue to deliver the bulk of services, we suggest that the most promising models will be those capable of incorporating insights and approaches from a social model in generic settings, and realizing inter-disciplinary and inter-agency cooperation: e.g. a geriatric or mental health nurse complementing a GP-practice; a community psychiatric nurse who implements case management in cooperation with home care teams.

In addition to the similarities we have identified some country-specific configurational features. The social model, adopted for dementia care by both expert communities in the last decade, appears in some aspects to be operationalised differently in England and The Netherlands. Different meanings and values have been attached to services (c), interacting with different patterns of service provision (s). The differences can be cautiously related to different welfare state models, but have to be traced in more detail to specific developments in the respective country. They appear as differences in

- perspectives on issues of autonomy, especially of the dementia patient, and respectively different patterns in service provision;

- the role and importance of voluntary services and charities;

- the balance between community and institutional care provision;

- attitudes towards institutional care;

- the integration of service planning of institutional care.

These national configurational contexts restrict certain aspects of service development while supporting others. In so doing, they demonstrate the path dependency of the adoption and implementation of care models. However, in spite of the significant differences, policy-makers and service professionals in each country (and elsewhere) can learn from each other:

Those in England can llearn from the Dutch experience more about societally accepted rates of care home provision and percentages of specialist provision, which help to avoid bottlenecks in other services; and also, that care home provision can and should be a better-integrated part of dementia care. The Dutch expert community could rethink attitudes towards the person with dementia, and note how in England services are developed, which not only 'care for' but also 'care with', i.e. also involve and empower people with dementia. 
Interacting sectoral or national cultural and structural features can be identified as explaining the phenomena in both major areas of study in this article - the similar shortcomings in dementia care pathways in each country, and the differences between the profiles of those pathways. Strategies for future pathway development, therefore, also must consider the configurational characteristics at both levels. It seems logical that from a cross-national perspective these problems appear easier to solve which are already tackled to some degree in the other country. Nevertheless, because it is dangerous to underestimate the power of existing configurations, and thus the path dependency of solutions, the seductive simplicity of copying must be avoided; solutions have to be built on the potential inherent to a particular configuration.

Another question concerns the future convergence or divergence in service developments for dementia care. To describe the convergence factors for health and social care systems one would also need to take into account the developing impact of supra-national entities such as the European Union and international institutions such as the World Trade Organisation. Neo-institutional theory and its application (Boase, 1996; Giaimo \& Manow, 1999) within our analysis suggest that in spite of similar challenges, and the adoption of similar policies - or care models - the processes of adaptation and implementation are influenced by the national configurations and thus are path dependent. For example, looking at the current trends in institutional care provision, it seems that the existing difference will become larger; and there are few indications of changes in these broad trends in the future. On the other hand, if we look at the prevailing paternalism in dealing with the person with dementia in The Netherlands, the increasing awareness of early stage dementia, together with a more self-confident generation growing old will perhaps trigger changes in the future like those in England, especially since issues of empowerment and emancipation are in general deeply rooted in Dutch society (Zahn, 1989).

Finally, although the study reported here has looked only at issues in dementia care in two countries, we would argue that is has also shed some light on issues of care for frail older people in general - even though different conditions require specific questions to be considered - and in other countries as well. This, however, needs precisely the sort of specific examination, leading to a further differentiation between cross-national and nation-specific phenomena, that this article has demonstrated. 
108 Chapter 4

\section{REFERENCES}

Afdeling SPGD/Ouderenzorg, Groene Kruis Heuvelland \& Stichting Thuiszorg - Domicura.

1997. Eindevaluatie Project Ambulante Psychogeriatrie (ZAP) 1994 - 1996 (Final evaLuation of the Project Outpatient Psychogeriatric Care 1994-1996): Maastricht, The Netherllands.

Alkema FM, Bloni MM, Kootte M \& Sipsma. DH (eds). 2001. Dementeren: ziekte en zorg. Van Gorcum: Assen.

Alzheimer Nederland. 2001a. Handleiding Alzheimer Café (Instruction Alzheimer Cafë). Alzheimer Nederland: Bunnik, The Netherlands.

Alzheimer Nederland. $2001 \mathrm{~b}$. Hulp bij dementie (Help with dementia). Stichting Alzheimer Nederland: Utrecht, The Netherlands.

Alzheimer Nederland. 2002. Thema: De winst van het weten (The advantage of knowing). Alzheimer Magazine 6.

Alzheimer's Society. 2000. What's the Society's position on ...? Alzheimer's. Dementia care \& research: London, UK.

Andrews GI \& Phillips DR. 2000. Moral dilemmas and the management of private residential homes: the impact of care in the community reforms in the UK. Ageing and Society 20: 599-622.

Andrews GI \& Phillips DR. 2002. Changing local geographies of private residential care for older people 1983-1999: lessons for social policy in England and Wales. Social Science \& Medicine 55: 63-78.

Aspimwall MD \& Schneider G. 2000. Same menu, separate tables: The institutionalist turn in political science and the study of European integration. European Journal of Political Research 38: 1.36.

Audit Commission. 2000. Forget me not. Mental health services for older people. National Report. Audit Commission publications: London, UK.

Audit Commission. 2002. Forget me not 2002. Developing mental health services for older people in England. Audit Commission Publications: Wetherby, UK.

Ballard C, Fossey J, Chithramohan R, Howard R, Burns A, Thompson P, Tadros G \& Fairbaim A. 2001. Quality of care in private sector and NHS facilities for people with demenlia: cross sectional survey. British Medical Journal 323:426-427.

Baragwanath A. 1997. Bounce and balance: a team approach to risk management for people with dementia living at home. In State of the art in dementia care, Marshall M (ed); Centre for Policy on Ageing, London, UK; 102-106. 
Bijsterveld K. 1996. Geen kwestie van leeftijd. Verzorgingsstaat, wetenschap en discussies rond ouderen in Nederland 1945-1982 (No question of age. Welfare state, academia and debates about the elderly in The Netherlands 1945 - 1982). Van Gennep: Amsterdam, The Netherlands.

Bland R. 1999. Independence, privacy and risk: two contrasting approaches to residential care for older people. Ageing and Society 19: 539-560.

Boase IP. 1996. Institutions, institutionalised networks and policy choices: Health policy in the US and Camada. Governance: An International Journal of Policy and Administration 9: $287-310$.

Bond 1. 2001. Sociological perspectives. In A handbook of dementia care, Cantley C (ed); Open University Press, Buckingham, Philadelphia; $44 \times 61$.

Braam GPA, Coolen JAI \& Narafs J. 1981. Ouderen in Nederland. Sociologie van bejaarden, bejaardenzorg en -beleid (Older people in The Netherlands. Sociology of ageing, social policy and care for the elderly). Samson Uitgeverij: Alphen, The Netherlands.

Cameron K. 2000. CarenapD (Care needs assessment pack for dementia). A manual to inform care management practice. Dementia Services Development Centre, University of Stirling: Stirling, UK.

Campbell H, Hotchkiss R, Bradshaw N \& Porteous M. 1998. Integrated care pathways. British Medicai Journal 316:133-137.

Cantley C led\%. 2001. A handbook of dementia care. Open University Press: Buckingham, UK.

Cartier C. 2003. From home to hospital and back again: economic restructuring, end of life, and the gendered problems of place switching health services. Social Science \& Medicine 56:2289-2301.

Challis D, Weiner $K$, Darton $R$, Hughes $J$ \& Stewart $K$. 2001. Emerging patterns of care management: Arrangements for older people in England. Social Policy and Administration 35: 672-687.

Cox S, Anderson I, Dick S \& Elgar J. 1998. The person, the community and dementia. Developing a value framework. Dementia Services Development Centre: Stirling, UK.

Czada R, Heritier A \& Keman H (eds). 1996. Institutions and political choice. On the limits of rationality. VU University Press: Amsterdam, The Netherlands.

Department of Health. 1997. The new NHS. Modern. Dependable. HMSO: London, UK.

Department of Health. 1998. Partmership in action. New opportunities for joint working between health and social care. NHS Executive: London, UK.

Department of Health. 2001a. Building capacity and partnership in care. An agreement between the statutory and the independent social care, health care and housing sectors. Department of Health: London, UK, http:/www.doh.gov.uk/buildingcapacity. 
Deparment of Health. 2001b. National Service Framework for Older People. Department of Health: London, UK.

Downs M. 1999. How to tell? Disclosing a diagnosis of dementia. Generations: Journal of the American Society on Aging XXIII: $30-34$.

Duncan BA \& Siegal AP. 1998. Early diagnosis and management of Alzheimer's disease. Journal of Clinical Psychiatry 59 (suppl.9): 15-21.

Dunning A. 1997. Advocacy and older people with dementia. In State of the ant in dementia Care, Marshall M (ed); Centre for Policy on Ageing, London, UK; 95-101.

EACH. 1997 a. Examples of good practice in the contimum of care. Report and findings, European Alzheimer Clearing House, accessed 20.02.2001: www.each.be.

EACH. 1997b. Standards of good practice, European Alzheimer Clearing House, accessed 20.02.2001: www.each,be.

Eccles $M$, Clarke J, Livingston M. Freemantle $N$ \& Mason J. 1998. North of England evidence based guidelines development project: guideline for the primary care management of dementia. British Medical Journal 317: 802-808.

Engelhard-Salari MAT. 1995. RIAGC-Ouderenzorg. Inventariserend onderzoek naar hel hulpaanbod, de ontwikkeling van programma's en circuitvorming in de RIAGGOuderenzorg (Community mental health care for older people. An inventory of services, pathways and coordination). Nederlandse Vereniging voor Ambulante Geestelijke Gezondheidszorg (Dutch Association for Community Mental Health Care): Utrecht, The Netheriands.

Esping-Andersen G. 1990. The three worlds of welfare capitalism. Blackwell: Oxford, UK.

Fox RC. 1989. The socialogy of medicine. A participan observer"s view. Prentice Hall: New York.

Furmish S. 2002. Services for people with dementia and their carers: an EU perspective. In Alzheimer's disease. Policy and practice across Europe. Wamer M, Fumish S, Longley M, Lawlor B (eds): Radcliffe Medical Press, Oxon; 89-134.

Garvican L \& Bickler G. 2002. The relationship between the NHS and residentiall and nursing care for older people: A survey of home owners and managers in East Sussex, Brighton and Hove. Quality in Ageing . Policy, practice and research 3: $24-33$.

Gerritsen H, Linschoten Pv, Nies H \& Romijn C. 200\%. Netwerken in de gespecialiseerde gezondheidszorg voor ouderen. ITS, Stichting Katholieke Universiteit te Nijmegen: Nijmegen, The Netherlands.

Gezondheidsraad. 2002. Dementie. Advies van een commissie van de gezondherdsraad (Dementia. Advice by a committee of the Heath Council). Gezondheidsraad (Health Council of the Netherlands). Publication no. 2002/04: Den Haag, The Netherlands. 
Giaimo S \& Manow P. 1999. Adapting the welfare state. The case of health care reform in Britain, Germany, and the United States. Comparative Political Studies 32: 967-1000.

Hardy B. Mur-Veeman I, Steenbergen M \& Wistow G. 1999. Inter-agency services in England and The Netherlands. A comparative study of integrated care development and delivery. Health Policy 48: 87-105.

Heusden MITw, Widdershoven GAM, Schrijnemakers VIJ \& Rossum Ev. 1999. Een cursus gelanceerd. Een kwalitatief onderzoek naar compliance en ervaringen met belevingsgerichte zorg in verzorgingshuizen (A training launched. A qualitative study about compliance and experiences with emotion-oriented care in residential homes). Universiteit Maastricht: Maastricht, The Netherlands.

Holmes I, Bentley K \& Cameron 1. 2002. Between two stools: Psychiatric services for older people in general hospitals. Report of an UK survey. University of Leeds: Leeds, UK.

Hout Hv, Vernooij-Dassen M, Bakker K, Blom M \& Grol R. 2000. General practitioners on dementia: tasks, practices and obstacles. Patient Education and Counseling 39: 219 . 225.

Houten Dv. 1999. De standardmens voorbij. Over care, verzorgingsstaat en burgerschap (Beyond the average citizen. About care, the welfare state and the civil society). Elsevier/De Tijdstroom: Maarssen, The Netherlands.

Illffe S, Walters K \& Rait G. 2000. Shortcomings in the diagnosis and management of dementia in primary care: towards an educational strategy. Aging \& Mental Health 4: 286-291.

Iliffe S, Wilcock J, Austin T, Walters K, Rait G, Turner S, Bryans M \& Downs M. 2002. Dementia diagnosis and management in primary care. Developing and testing educational models. Dementia: The International Journal of Social Research and Practice 1: 1123.

John P \& Cole A. 2000. When do institutions, policy sectors, and cities matter? Comparing networks of local policy makers in Britain and France. Comparative Political Studies 33: $248-268$.

Jones GMM \& Miesen BML (eds). 1992. Care-giving in dementia. Research and applications. (Vol. 1). Routledge: London/New York.

Kerrison SH \& Pollock AM. 2001. Regulating nursing homes: Caring for older people in the private sector in England. BM/ 323:566-569.

Kitwood T. 1997. Personhood, dementia and dementia care. In Dementia: challenges and new directions, Hunter S (ed); Jessica Kingsley Publishers, London, UK; 9-23.

Kitwood T \& Bredin K. 1992. A new approach to the evaluation of dementia care. lournal of Advances in Health and Nursing Care 1:41-60.

Knapp M. Hardy B \& Forder 1. 2001. Commissioning for quality: Ten years of social care markets in England. Journal of Social Policy 30: 283-306. 
114 Chapter 4

concepts and services in Europe). Demenz-Verein Saarlouis e. $V_{\text {.; }}$ Landkreis Saarlouis: Leitstelle "Älter werden": Salarlouis, Cermany.

Train GH, Livingston G\& Manela M. 2001. Addressing the needs of carers of older people: the Islington study. International foumal of Geriatric Psychiatry 17:85-86.

wan Raak AIA, Mur-Veeman I, Hardy B, Steenbergen M \& Paulus A (eds), 2003. Integrated care in Europe. Description and comparison of integrated care in six EU countries. Elsevier: Maarssen, The Netherlands.

Verhey FR]. 2002. Oud en vergeten, de lessen van A/zheimer. Inaugurele rede (Old and forgotten - lessons from Alzheimer. Inaugural speech). Universitaire Pers Maastricht: Maastricht, The Netherlands.

Verhey FRJ, Nods M. Ponds RWHM \& Scheltens P. 1999. Cieheugenpoliklinieken in Nederland Memory clinics in the Netherlands). Nederlands Tijdschrift voor Neurologie 3: $169-174$.

Waarden Fv. 1992. The historical institutionalization of typical national patterns in policy networks between the state and industry. A comparison of the USA and the Netherlands. European Journal of Political Research 21: 131-162.

WZV-regio 27. 1998. Regiovisies zorg Zuid Limburg 1999 - 2000 (Regional Visions South Limburg 1999 - 2000): The Netherlands.

Yin RK. 1994. Case study research. Design and methods. Sage: Thousand Oaks.

Zahn E. 1989. Rebellen, regenten en reformatoren: een visie op Nederland en de Nederlarders (Rebels, governors, and Reformators: a perspective on The Netherlands and the Netherlanders). Contact: Amsterdam, The Netherlands. 


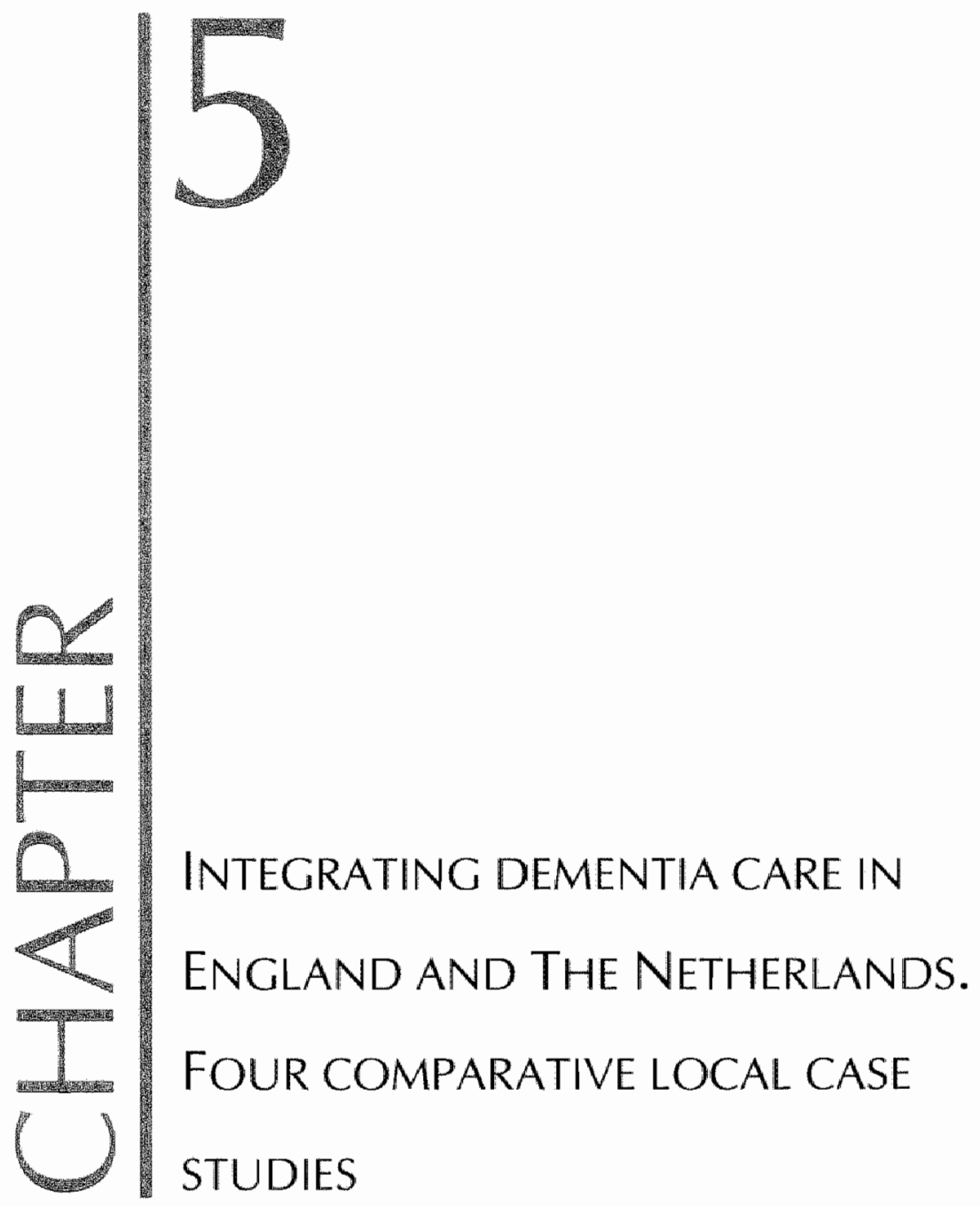

This chapter is based on:

Kümpers, S., Mur, I., Hardy B., Raak, A. I. A. v., \& Maarse, H. (provisionally accepted). Integrating dementia care in England and The Netherlands. Four comparative local case studies. Health and Place. 
116 Chapter 5 


\subsection{ABSTRACT}

The article presents a cross-national comparative study of the implementation of integrated dementia care at local level in England and The Netherlands. Four local case studies (Amsterdam Nieuw West, Leeds West, Maastricht, York) focus on the interaction between the respective national policies with local contexts and policy processes, in order to explain the variety of local outcomes regarding integrated dementia care. Localities are shown as entities with particular institutional contexts and histories (i.e. local configurations), which have specific impacts on processes of policy implementation within the respective national health and social care systems.

\subsection{INTRODUCTION}

People with dementia are in increasing need of the services of more and more different care providers, within and across health and social care. Supposing that the quality of such care to a large extent is based on continuity and comprehensiveness, providers involved need to join forces and co-ordinate their work, i.e. to integrate services planning and provision. Health policy-makers, care commissioners and providers in European countries have become increasingly aware of the need for service integration and are trying different methods of joining and co-ordination, to be implemented at local level. Through emerging local variations, the meaning of local places comes into perspective (Gieryn, 2000).

Cross-national studies of integrated care (van Raak et al., 2003) indicate that in different countries service integration faces many similar problems, but that different modes of governance are used to solve these problems, within the framework of the respective health and social care systems. Comparing integrated dementia care in England and the Netherlands, we have previously reported a range of approaches (Kümpers et al, 2002). In The Netherlands co-ordination was developed from established structures at local level, framed by incremental central governmental regulations. In England major structural changes and tight service targets were imposed from central government on local actors. Central-local interactions, however, are neither simple nor one-way roads (John \& Cole, 2000; Jones, 2000). Local contexts and processes interact with national policies, resulting in different local outcomes, in terms of - for this study - the local organisation of mechanisms for cooperation and integration with respect to dementia care development and delivery. In this paper we investigate how such local cooperation processes develop in both countries and seek to explain emerging variations in the light of national-local interactions and the local factors involved. 
We use new institutional theory to frame the evidence from local case studies in both countries. After briefly introducing the theory, and describing our research methods, we outline the two national health and social care systems and the political contexts for integrated dementia care. Subsequently we describe our local case studies, and compare them within and across countries. After discussing our findings, we draw conclusions of interest to researchers, and politicians, policy-makers and service providers.

\subsection{THEORY}

Over the last 15 years, neo-institutionalist approaches in political sciences have built a framework to explore cross-national differences in policy development and implementation. The institutional structure and culture of the national and sectoral political systems are seen as interacting with each other and shaping the processes of policy development and implementation, their strategic options and limits (Nørgaard, 1996). Lehmbruch (1996) describes these constellations as configurations. The concept of configuration frames the respective features of national and sectoral public policies as historically developed paths, emerging from a "sequential interaction of the organisation of state and society" (p.75). They are based on processes of social learning in institutional contexts and collective interpretation processes. Boase (1996), among others, speaks about 'path dependency' of policy-making, indicating that developments in the past shape, but do not wholly determine political options today. From this perspective neo-institutionalist analyses explain that similar policy concepts take quite different courses in different countries (Boase, 1996; Giaimo \& Manow, 1999). We extend this concept of configuration to local institutional contexts, in our case of integrated dementia care. The 'local configuration' is proposed as an entity with its own structural and cultural characteristics, emerging from the intertwined history of national and local policy-making and local health and social care development and delivery. We use the concept to explore and explain variations among local cooperation processes regarding dementia care, given their embeddedness in the respective national configuration. We expect that 'structure' at local level will comprise existing service provision, task distribution and power relationships, and that local 'culture' will encompass general as well as professional and political attitudes, values and behaviour. Still, the concept of 'local configurations' is a sensitising concept, and needs to be explored and fleshed out throughout this study. We contend that the interaction of the national and the local configuration shapes the local outcomes regarding integrated dementia care.

To characterise the governance processes which frame local cooperation - in other words, to describe configurations in process - we further use the concepts of hierar- 
chy, market and network. With hierarchy shaping super-and subordinative relations, market creating competitive relations, and networks comprising long-term relations among autonomous but interdependent actors built on negotiation and trust, these concepts refer to ideal types of coordinating mechanisms in society (Thompson et al, 1991), typically occurring in combination. The network form is seen as emerging from differentiated and specialised 'post-modern' societies (O'Toole, 1997; Willke, 1998), and suitable for those complex situations needing re-integration, referred to as 'cross-cutting issues' (Martin, 2000). Integrated care is such a 'cross-cutting issue' needing contributions from various actors and sectors, and requiring flexible cooperation, information exchange, and agreements on task distribution, to be realised at local level. Such issues cannot be handled adequately by pure hierarchical or market mechanisms (Atkinson \& Coleman, 1992). They need at least partly autonomous, responsible actions by involved local actors. We expect therefore that the successful development of integrated care requires favourable conditions for network development at local level.

\subsection{RESEARCH METHODS}

Our study on integrated care for people with dementia in England and The Netherlands first compared national policies for integrated care (Kümpers et al., 2002), and then current developments in dementia care (Kümpers et al., forthcoming). The next research stage was the detailed local case studies, which are the basis of this paper. We explored and analysed cooperation processes for integrated dementia care development and delivery within specific local configurations, embedded in national configurations. The design can be characterised as a multiple embedded case study (Yin, 1994) with England and The Netherlands as the two cases and the four local cases as embedded subcases. It corresponds with the institutional ethnographic mode of inquiry, investigating "linkages among local settings, ... organizations, and translocal processes of administration and governance" (De Vault \& McCoy, 2002, p. 751).

\subsubsection{Local case studies: number, selection and fieldwork design}

The number of local case studies was determined largely by the need, within limited resources, to allow for both depth and breadth of study; it was thus decided to investigate two localities per country.

Cases were decided to be entities with 100-150.000 inhabitants. The first cases in each country were selected partly on the basis of prima facie evidence of developments in the integration of dementia care services and partly on the basis of practicabillity: i.e. the localities where the research teams were based - Maastricht and Leeds 
- providing, therefore, good lacal links. The second cases in each country were matched to the first in the other principaly according to size and the - presumed associated degree of relative inter-organisational complexity. Again, however, practicability was an important consideration in terms of negotiating access (based on local knowledge) and fieldwork logistics. Thus, Amsterdam Nieuw West was chosen as matching Leeds West (parts of large cities with very mixed population), and York to match Maastricht. A four weeks' fieldwork period was arranged per case, to conduct approximately 25 semi-structured interviews with professionals, service managers and carers; to observe multi-agency meetings; and to obtain alt relevant policy and other documentary material. The formal agreement of the responsible Ethics CommitLees was obtained. Entrance to each locality was sought by approaching key representatives of leading agencies. With their support, a local mapping was performed listing relevant professionals and managers for interviews, and local cooperation and integration initiatives. During the fieldwork, this list was extended when additional information arose. Interviews addressed all relevant aspects of local integrated dementia care development and delivery, including the steering context, tailored to the experience of individual interviewees. They built "piece by piece' a view of an extended organizational process" (De Vault \& McCoy, 2002, p. 757). Our view of the respective integrative initiatives and cooperation processes was primarilly directed to the perspective of service professionals and managers; documentary analysis and the perspectives of carers were added to triangulate the emerging picture. Carers of people with dementia were identified as possible interviewees and approached through professionals during the fieldwork period'. All fieldwork was undertaken between April and December 2002.

\subsubsection{Analysis and case descriptions}

Interviews from all case studies were transcribed, and summarised according to topics; the summaries were coded. Qualitative data analysis sottware (atllas-1i 4.2) was used for coding and retrieving. Information from observed inter-agency meetings and local documents was included in the analysis.

For each country, we sketch the national health and social care systems, the characteristics of mational governance and the current context of integrated dementia care. For each case study, we briefly introduce the locality and the principal local actors. We then describe the essential cooperation processes shaping local integrated dementia care at the time of fieldwork, putting them in their historical and political

\footnotetext{
The criterion for the selection of carers was the advanced dementia of their relative.
} 
context, and striving thereby to sketch a coherent picture of each local configuration in process. In other words, starting from 'how it happens", "local practices and experiences are tied into extended social relations" (De Vault \& McCoy, 2002, p. 754). With the "focus on institutional relations not just during interviews, but in analysis and writing as well" (De Vault \& McCoy, 2002, p. 770), the descriptions of the English and Dutch cases, therefore, follow a different structure, as emerged from the fieldwork.

Subsequently the cases are analysed and compared by country, before finally a crosscountry analysis is performed.

\subsection{Central-Local interactions and local cooperation in dementia Care: EnG- LAND}

\subsubsection{Health and social care system and national steering context}

\subsubsection{Structure and financing}

England has a tax-funded, centrally organised health care system. The line of control goes from the Department of Health (DoH) through 28 Strategic Health Authorities to local trusts, which are Primary Care Trusts (PCTs), NHS Trusts (primarily for acute hospital and specialist care), and some new Care Trusts (CTs) comprising several health and social care functions. Finances similarly flow from the top to the local bodies, with an increasing and important local commissioning role for PCTs and CTs. Organisationally separated, social care (home care, day care, and long-term care) lies within the commissioning responsibility of Local Authorities (LAs). LAs are locally elected, but simultaneously subject to tight national policy directives and performance measurements. Social Service Departments (SSDs) have to compete for resources with other local authority services. Beside in-house provision, an increasingly large part of social care is delivered by independent sector (private and voluntary) providers, from small enterprises to large nation-wide companies; thus an increasingly 'mixed economy of care' has to be integrated in one whole system of care (Department of Health, 2001a).

\subsubsection{Governance patterns and processes}

The state health care system and the strong government role mean that, notwithstanding the government's policy of 'shifting the balance of power' to local level the government retains the ability to hierarchically push through major structural changes, to 
exent control through increasingly tight performance management regimes for statutory services, and to circumscribe local actors' degree of freedom.

Since coming to power in 1997, the Labour government introduced Primary Care Groups (PCGs), later becoming PCTs, as a new organisational form and actor into the system, forming an umbrella organisation for all primary and community health care, in order to focus on primary care and integrated care. Health and social services also have a statutory duty to cooperate for integrated care, for which structural and financial instruments were introduced in the Health Act (1999). Acute hospital and specialist health services continue to be organised and provided by separate NHS trusts, many of which underwent organisational restructuring. The same is valid for mental health services - important for dementia care - which were (re-lorganised in separate mental health Trusts, or as part of NHS Acute Trusts, or as part of PCTs. The scope and form of local reorganisations and mergers is always ultimately the responsibility of the DoH, even sometimes against local pireferences.

The current Labour government also developed the instrument of National Service Frameworks (NSFs), to set service development targets regarding specific health problems and client groups. The NSF for Mental Health did not address older people's mental health problems (Department of Health, 1999). The NSF for OIder People (Department of Health, 2001b) then gave some mental health guidance, although dementia care targets were seen as rather vague. Nevertheless, it was widely accepted as an essential policy framework for dementia care development, addressing common tasks for all involved actors, thereby triggering network activities. Important for dementia care, the NSF had implemented standards for single assessments by health and social services, and for intermediate care. Furthermore anti-dementia drugs (ChEl), used widely in England and perceived as stimulating primary care involvement in dementia care, were fixed as standard treatment under certain conditions. National performance targets in general were widely argued to focus mainly on acute care, partly in contradiction to the rhetoric prioritising community-oriented care.

Further developments shaped the context of dementia services development and delivery in 2002 :

- While the Labour Government had enthanced investments in health care, social services were seen as still structurally under-funded (Glendinning, 2002; Royal Commission on Long Term Care, 2003).

- The care home market had come under increasing pressure. Provision was decreasing, caused by a combination of enhanced quality standards (Care Standards Act 2000), rising property prices, tight funding and commissioning policies of LAs, and a generation of home-owners retiring (Garvican \& Bickler, 2002; 
PSSRU, 2002). The 'management' of local care home markets through strategic cooperation of LAs with the independent sector remained difficult in many places (Department of Health, 2001a).

\subsubsection{First subcase: York}

York is a medium-sized city (population approximately 100.000) in rural surroundings in North East England, with an industrial past and presence, a strong tourist industry, and a university.

Since local government reorganisation in 1996, York's social services, together with housing, have formed a single 'Community Services' department. The PCT, merged from two PCGs in 2001, covers York and Selby; and since 2002 has also hosted mental health services. A district hospital, voluntary and independent services complemented the actors participating in dementia care. In autumn 2002, the integration of dementia care services in York appeared to be on the edge of improvement after years of breaks in strategic and operational cooperation, and growing service imbalances.

5.5.2.1 Cooperation between health and social services: organisational discontinuities

Cooperation between health and social services was essentially shaped by a history of contested re-structurings. In 1996, as part of a nation-wide local government reorganisation, the City of York Council (CYC) became a Unitary Authority, taking over social services from North Yorkshire Council. The management of the new Community Services was reported to have focussed initially on housing rather than social care, with internal and external cooperative arrangements being interrupted or halted.

"And all the plans ... in social services were taken without proper consultation of what was right for the service. ... From the very first day they took over social workers were moved, it was awiul, terrible. You know, all the teams were decimated. ... Nobody died, but you know I think the damage that has been done for services is dreadful I would imagine in a lot of peoples' views. "(Community Services York)

The traditional national blame culture between health and social services (House of Commons: Health Committee, 1998) here revived. Social care for older people, especially those with dementia, became increasingly scarce. This situation put pressure on mental health services, and was said to explain a high degree of delayed dis- 
charge among dementia patients in the hospital. Internal and external reports documented the worsening situation (Herbert, 1997; Nuffield Institute for Health, 2000; Sainsbury Centre for Mental Health, 1999).

At the end of the 1990s a change in senior management and city councillors, together with governmental imperatives about integrated care, provided the basis for a renewal of cooperation with the newly implemented PCG and mental health services (York Health Services NHS Trust \& City of York Community Services, 1999).

However, in 2001, the unwanted merger to form the new PCT Selby and York brought change and uncertainty at management level, thereby once again interrupting recently developed joint initiatives with social services.

"People are just constantly wasting vast amounts of time and energy on surviving organisational change. ... There is this constant exhaustion to work across boundaries produce seamless services. Fine it's great, but there is a colossal effort involved in that and I don't think these organisational changes are helpful to that effort at all.... No they don't get used to it. I think a lot of people are very damaged by it. ... Oh it is communicated in the background all the time." (R \& D specialist, York)

Cooperation almost stopped again for nearly 18 months. A joint Task Group Mental Health for Older People was set up to implement the NSF for Older People, but was reported to progress reluctantly.

In addition, some aggravating conditions were mentioned as having impeded sacial care development: national indicators for the allocation of central funds to the community level were said to work to the $\mathrm{CYC}^{\prime}$ s disadvantage. Moreover, the independent care home market was badly hit - a high percentage of small homeowners, the new national care standards, property prices rising above average, and a restrictive council funding policy had caused a significant decrease of places. Strategic cooperation between the Council and providers, described as distant and underdeveloped, had not been able to 'manage' the market successfully.

\subsubsection{Cooperation between generic and mental health services: imbalances}

Mental health services in York had a strong tradition, with statutory services being complemented by alternative voluntary sector provision, by the Quakers' community for 200 years. To facilitate dehospitalisation, five community units for the elderly (CUES) had been built in the 1990s. They provided specialist residential and day care, and acted as bases for two Community Mental Health Teams (CMHTs), providing comprehensive support also for those with early dementia stage. York Mental Health Services were widely appreciated for their community-oriented attitude, and well- 
linked within health, but were seen as adversely affected by the generally poor relations between health and social services.Links with primary care were said to be well established, and the percentage of dementia patients known by the CMHT was reported to be high. Also the geriatric services in York District Hospital described close links with mental health services, notably with a commonly managed hospital ward, and initiatives to outreach into other wards. Among voluntary services, Age Concern especially provided some dementia support services cooperating with mental health. Still, the links with care homes were evaluated ambiguously. With the exception of one small specialist home care team, the integration of the CMHTs' work with social services, however, was described as poor in relation to e.g. assessment procedures and cooperation with home care. The CUEs had found themselves in an increasingly blocked situation: both residential and day facilities could hardly accept new patients, since discharge to the scarce social care facilities was nearly impossible.

\subsubsection{A window of opportunity?}

At the time of fieldwork the general climate for cooperation was perceived as changing again: notably the PCT was perceived as in a process of settling in. The pressures within the services were felt even more in view of the national targets in both health and social services. In 2002, three consultant groups had been commissioned to cut through the organisational blockages (Cantley, 2002; CAT, 2002; Turnock, 2002). At last, plans to restructure the CUEs were on their way; Community Services had initiated activities to stabilise the independent social care market, and to build up inhouse provision of specialist residential care. The first meeting of a strategic 'Health and Social Care Partnership Board' at directors' level took place after a 6 years' break in 2002. Thus, the situation for joint working and integrated provision was seen as promising again.

\subsubsection{Second subcase: Leeds West}

Leeds is a city with 715.000 inhabitants in the North East of England, shaped by an industrial past (wool industry) and a presence of a prospering trade and administration centre.

Leeds West with 117.000 inhabitants is covered by one of five PCTs in Leeds. The SSD and the Mental Health Trust (MHT) also worked along the PCT boundaries. Voluntary services are well-established. The two university hospitals, operating together city-wide as a large NHS Trust, were widely said to dominate spending patterns and operate to the disadvantage of community services (Dawson, 2002). In summer 2002, integrated dementia care in Leeds West appeared to be characterised by an incre- 
mentally improving cooperation of PCTs and social services with voluntary services' involvement, but with problems of integration with mental health services.

\subsubsection{Cooperation between health and social services: incremental proceedings}

In Leeds West, the PCT and SSD had a common interest in developing integrated community services. They perceived the PCGs, and then PCTs, as an opportunity to achieve a new balance of funding between hospital and community services.

"So my feeling is that a part of this willingness of social services to work with the PCT is that the PCT is going to have fairly large budgets and, I think everybody is hoping that the PCT is the answer to providing better services overall for the community. ... But then I hear they are having real problems with their budgets because the acute trust hasn't decided how much it wants. ${ }^{i}$ (Neighbourhood Network)

From 1997, joint strategic plans were made for older people's services, and coterminous boundaries between the PCGs and social services were agreed (Leeds City Council \& Leeds Health Authority, 1998). The NSF for Older People was used as a framework for joint initiatives. In Leeds West, it had been used to evaluate the current older people's services - e.g. through an 'Integrated Care Committee', involving statutory and voluntary services - and from there to start some smaller projects connecting community health and social services. Citywide, as in Leeds West, the PCGs and the SSD had set up Joint Care Management Teams (JCMTs) to provide assessments and time-limited case management for older people in complex care situations, working closely with the intermediate care teams. In contrast to the original plans, however, limited funds for the JCMTs, combined with claims from the hospitals and central government directives, restricted them mainly to hospital discharge management, and prevented them from community-oriented working. Highly politicised national targets were felt to weaken the long-term community-oriented cooperative agenda.

"Those national targets absolutely sabotage what you are trying to do... Delayed discharge is a good example of that, ... so high profille with the government, that (it) becomes the driving force and sabotages all your longerterm strategies about change. "(PCT, NSF coordinator)

Disagreements about financing and management issues of JCMTs were reported to exist between the partners. Moreover, they simply built a new cooperative layer upon old structures. Area social work staff partly felt downgraded, underprovided with training opportunities and resources and prevented from strengthening cooperation 
by over-bureaucratic procedures. Furthermore, the common problems of scarce home care and diminishing care home places affected the work of JCMTs and area social work equally, while a comprehensive strategic plan tackling care home provision did not exist. Thus, the new cooperative arrangements had met some, but not all expectations.

More positively, Leeds statutory services could build on extra social capital: the long-standing cooperation with well-developed voluntary services for older people. A strong Alzheimer's Society's Leeds branch offered advice and psychosocial support services for people with dementia and their carers citywide. Additionally a neighbourhood network of charities, promoted for years by the SSD and well represented in Leeds West, provided multiple and creative community support to older people, including those with dementia to some degree.

\subsubsection{Cooperation between generic and mental health services: disagreements}

Certain parts of mental health services liaised well with generic services such as a liaison service for care homes and a mental health nurse attached to a day centre. The West CMHT, however, was seen as being at the centre of a conflict about cooperation. The explanations given for this conflict were many and various: It was partly ascribed to the specific attitude of this CMHT ("Because they have always done their own thing really and want to continue to do that"; "It's only a problem in the West."), partly to domain conflicts, among others about the responsibility for dementia competence ("Generic services haven't done their homework" or "The CMHT is not accessible for consultation"), partly to the recent reorganisation of the former combined Community and Mental Health Trust to a pure mental health trust with exclusive professional boundaries ("then everybody got their identity back together ... but all the cross-working stopped." ). The missing links with the CMHT were perceived to challenge new services like the JCMT and the intermediate care team, but also other community services, all being confronted with older people's mental health problems but not properly equipped with specialist competence. It was argued, however, that middle managers in both the PCT and MHT had acknowledged the conflict and planned to tackle it.

At a broader level, mental health representatives had neither fully participated in the NSF Modernisation Team nor joined the Integrated Care Committee in Leeds West. A specific inter-agency committee in the West, the 'Dementia Forum', had drowned in conflicts and ceased to work. The lack of communication was also obvious in service planning: three services independently reported their initiatives to develop a specialist home care service for Leeds West. 


\subsubsection{The English cases: comparative analysis}

Both cases highlighted the issue of nationally induced structural changes in local health and social services, an inherent part of English policy. In York, they were associated with contested discontinuities of both boundaries and policies (CYC, 1996), or of just boundaries (the merger forming the Selby and York PCT, 2001), and caused organisational upheaval and breaks in local cooperation for integrated dementia care. The implemented changes did not fit well with the local configuration - with existing organisational cultures and established professional and managerial networks. They not only disrupted and complicated health and social services' cooperation at the level of daily service delivery, but also severely disturbed and delayed service development, such as the implementation of the NSF for Older People. A whole systems' perspective was inhibited, and formal and informal networks - the social capital for integrated care - were damaged. Furthermore, the delays incurred underline the importance of continuity and the danger of discontinuity in building up and sustaining cooperative networks for integrated dementia care.

Leeds West appeared to be more successful in integrating new organisational structures. The PCGs/PCTs fitted well into the local configuration, and were perceived to correspond with existing interests, in strengthening community services and challenging existing commissioning patterns and power relationships. The implementation respected agreed administrative structures, allowed the pursuit of established plans and further developed cooperation; by maintaining some continuity, major organisational upheaval and uncertainty was prevented. On the other hand, there were indications that the established local power of the teaching hospitals was too persistent to be easily challenged by the new PCTs. The PCT had to develop internal capacity and self-esteem to achieve the locall powers to change commissioning patterns, all the more since national performance targets were contradictory in this respect. This points again to the importance of time for organisational development and change, as well as for processes involving power shifting.

Furthermore, both cases show the pre-eminent role of locall mental health services for integrated dementia care in general, not only delivering specialist care, but also cooperating with generic services to transfer awareness and knowledge about dementia. In York, the strong community mental health services demonstrated the considerable importance and potential of local personal and professional agency, supported by local professionall traditions. On the other hand, the outstanding efforts could not compensate for structural gaps in other services: this again marks the importance of a whole system perspective.

The conflict around the CMHT in Leeds West highlighted that different cultural, structural and power issues might interact to challenge the essential cooperation between 
generic and specialist services (Audit Commission, 2000; Department of Health, $2001 \mathrm{~b})$ : domain conflicts, personal and professional attitudes, restructurings, here reinforcing disciplinary boundaries. The attempts to solve the problems, however, seemed to be stimulated by some service characteristics of big cities: the more complex, but open structures of services and links among them, with more layers involved and more diversity, provided examples of good practice nearby, and brought about options for communication and cooperation.

It seemed to be also the cultural features and socio-economic structure of big cities, namely more older people living alone and distant from their family, which highlighted the support needs of older people in general and those with dementia also on the generic services' and the public's agenda; in Leeds successfully communicated also through voluntary services. This probably contributed to the willingness of primary care, social and voluntary agencies in Leeds to cooperate for early support in the community.

\subsection{Central-local interactions and local cooperation in dementia care: The NETHERLANDS}

\subsubsection{Health and social care system and national steering context}

\subsubsection{Structure and financing}

Since World War II, the Netherlands has had a Bismarckian system, with health and social care organised essentially in a social insurance system, divided into two tiers for long-term and short-term care, each regulated by different laws.

Long-term care, including services for the elderly, people with handicaps and mental health problems, is considered to be uninsurable in a privately organised insurance system. A compulsory public insurance scheme (Exceptional Medical Expenses Act, AWBZ) was set up in 1967. It includes the bulk of dementia services. The short-term care insurance, covering primary care, acute and specialised care, was built up as a compulsory social insurance system with some exceptions for regulated private insurance (Social Health Insurance Act, ZFW). Both schemes are operated by the same insurance companies.

This structure has created two areas of providers, with separate regulations and financial flows. Providers are non-governmental, non-profit foundations and a few private providers. GPs are mainly independent providers, often cooperating in group prac- 
tices. Specialist dementia care for older people is mainly organised by community mental health teams (RIAGGs) and psychogeriatric nursing homes. ${ }^{2}$

Residential and nursing homes are mostly integrated in big local foundations, which also provide day hospitals and day centres, sheltered housing, and, increasingly, other community-oriented services. Home care, comprising domiciliary, personal and nursing care, is provided often by one or two dominant local provider foundations, complemented by a few smaller ones. Outside the insurance system, and thus governed by different rules, so-called 'welfare services' (e.g. meals on wheels, older people's advisors) are in the municipalities' responsibility; they are also mainly delivered by non-profit foundations.

\subsubsection{Governance: patterns and processes}

As compared with England, the Dutch government's role is relatively weak: with a higher independence of insurers and providers, and governments being always coalitions, the configuration can be characterised as a multiple-actor system, relying on broadly negotiated incrementalism. The government has to steer by legal and political regulations, to safeguard collective interests regarding quality and efficiency of service provision (Kümpers et al., 2002). Local service development, however, is essentially left to the interaction of providers and insurers; it is much less subject to direct central government intervention, or to subsequently published evaluations.

During the 1990 s the implementation of some market elements triggered an increase of scale for both insurers and providers: numerous mergers took place, partly stimulated by governmental incentives, but decided by the actors themselves. Insurers got increasing commissioning discretion. The role of providers began to change from an administrative function to an entrepreneurial role (Grünwald \& Kwartel, 1996). Financial incentives, set out by central government, stimulated innovation and integration, and initiated a multiplicity of cooperative projects, between and within cure and care providers, between in-patient and community services.

In 1998 a step-wise reform of the AWBZ was announced (VWS, 1999), to initiate a change from a service-led to a needs-led system, to enhance user- and communityorientation and care integration. Simultaneously the pathway was more formalised in stages of assessment, care allocation and care delivery. Insurers were intended to gradually assume a steering role, exerted through regional Health Care Offices (HCOs). Since insurers need to be licensed by central government for the operation of a regional HCO, they were prompted to use their increasing commissioning scope

\footnotetext{
Medical specialists represent different specialties: social geriatricians (RIAGGs) clinical geriatricians (hospitals) and nursing home physicians see dementia as part of their field; psychiatrists and neurologists are involved for complicated aspects of diagnosis and treatment.
} 
to promote cost efficiency, quality and users" satisfaction of AWBZ services. In 1997 local assessment centres (RIOs) were introduced as new independent agencies for comprehensive needs assessments of all AWBZ care (except mental health care) - an exception to the usually incremental Dutch way of reforms (Beemsterboer W.G.M., 2000; Verschuur, 2001). The system of assessments was planned to change in 2003 from a service-based to a function-based assessment, bringing along enhanced flexibillity and competition into the commissioning and allocation process; providers would be able to offer services beyond their traditional domain. Between 1998 and 2002, increased budgets for the AWBZ to tackle waiting lists allowed the extension of provision in home care and care homes; in particular care homes increased psychogeriatric provision. Simultaneously, however, with nearly fullemployment in The Netherlands, recruitment problems in the care sector became severe, especially in the big cities.

Due to the societal and political trends favouring care in the community, the municipalities' input through welfare services and also housing is becoming more important, and meeds to be linked particularly with the AWBZ provision. Even so, municipalities often have a limited impact on local service development. The same holds for the provincial authorities: they have to support and facilitate the municipalities, and Coordinate a 'Regional Vision' on AWBZ service development among all involved actors.

Further developments shaped the context of dementia services development and delivery in 2002:

- As opposed to the position in England, the use of ChEI was not widely accepted and diffused in The Netherlands (Gezondheidsraad, 2002), thus contributing less to any pro-active approach by GPs in early dementia.

- Research and development agencies in the care sector were subsidised to support mental health services with the implementation of integrated dementia care pathways at local level ('zorgprogramma's) (Salari, 2000).

\subsubsection{First subcase: Maastricht}

Maastricht is a medium-sized city (population 118.000) in a rural region in the Catholic Southern province of Limburg, surrounded by the Belgian and German border; from an historical focus on manufacturing industries it has developed into a mixed economy comprising administrative and service agencies and the university. Two providers of residential and nursing homes, also engaged in community services, and some independent residential homes were active in Maastricht; also two larger home care providers, complemented by some smaller ones. In the university hospital, 
some specialists were engaged in dementia care. The municipality provided a few older people's advisors. Both the RIAGG, and the RIO covered also the hinterland of Maasitricht, while the HCO region encompassed the whole of South Limburg. The situation of integrated dementia care was characterised by a closely cooperating network of dementia specialists, but, with links to generic and welfare services only partly developed. Strategic cooperation was mixed, and the changes in the AWBZ were causing some difficulties.

\subsubsection{Operational cooperation: an expert network needing extension}

Professionals from the RIAGG, the nursing homes and the university hospital, often working in the region for years and knowing each other, formed a close network of dementia care experts. Developing cooperative projects and services they had tackled critical points of dementia care over years, encouraged also by the presence and support of academic dementia care experts. Projects and services were dedicated, among other things, to: comprehensive mental, physical and social diagnoses and assessments in order to initiate appropriate support (Cann, 2002), to the monitoring of people with dementia in the home situation (Afdeling SPGD/Ouderenzorg et al., 1997); and to case management and intensive home care preceding and postponing admission (Projectgroep VIA-Maastricht, 1999). Activities were triggered by professional ethics and ambitions, supported or at least tolerated by the respective management level, and often financially supported by the insurer. The RIAGG, although small in manpower, had an important linking function in this by participating in nearly all the initiatives.

From an outside perspective, the cooperation partly seemed restricted to the dementha experts and not extending easily into generic services in the community, although early support was clearly advocated and some links with home care had been implemented. It was widely reported to be difficult to enhance the awareness of dementia amongst care workers. Links with the few new older people's advisors seemed not yet established. The cooperation with GPs was partly perceived as tense, and insufficient to trigger a broad proactive approach. Thus there were indications that the percentage of dementia sufferers without access to early support and specialist services was significant. The professional networks had not yet succeeded in making sufficient links beyond the established cooperative professional networks.

Interviewees saw this situation as being maintained by the conservative, familyoriented culture in Limburg with a strong taboo on dementia - familles caring without asking for help, few people with dementia living alone, and, correspondingly, traditional attitudes persisting in generic care. 


\begin{abstract}
"Residential homes, and also our own nursing homes are backward regarding care. Putting new insights in practice, is special in Maastricht. If you had chosen any other place ... the opposite would be Amsterdam, where people try out innovations much more; such things you cannot yet think about here." (Nursing home professional)
\end{abstract}

\title{
5.6.2.2 Strategic cooperation: Contested governance - market and network incen- tives.
}

The changes within the AWBZ, together with the increasing formalisation of patients' pathways and the change of relations between the local actors caused some difficulties. Maastricht's providers were seen as sticking to a culture of autonomy. The local RIO, as a pilot implemented in Maastricht preceding the national implementation, was perceived by providers as exerting a rather rigid approach, as inhibiting innovative service developments, and often in conflict with professionals about appropriate assessments; thus it had almost the role of the "favourite enemy". Because of the RIO"s formalised and limited role, however, local cooperation was not wholly affected. The $\mathrm{HCO}$ also was perceived as struggling for its new steering role, not always in charge of negotiation processes. A care allocation procedure, under negotiation for years, was still subject to a tug-of-war between the $\mathrm{HCO}$, the RIO and providers (Villevoije, 2002). The HCO saw itself in a still weak position with respect to instruments and resources to achieve a powerful steering position.

"The strategy is not yet developed. ... We are moving very cautiously. There's a risk of failure for the HCO regarding care allocation; if that's not realised, we are responsible. ... If you have an identity you state what you want, but there is not yet an identity connected with the HCO." (HCO)

On the other hand, the $\mathrm{HCO}$ was perceived as promoting service development. By stimulating innovative and cooperative initiatives through its commissioning policy, it set simulltaneously competitive incentives for providers. For issues of local service development the HCO requested proposals negotiated and agreed by all relevant prowiders, e.g. a programme for psychogeriatric units in residential homes (Stuurgroep Substitutie Maastricht/Heuvelland, 1998), thereby facilitating local communication and compromises, negotiated under the local umbrella association of AWBZ providers. As elsewhere, provider foundations had become fewer and bigger; however, no local monopoly structure for home care or care homes had developed, which seemed advantageous to trigger cooperation. Management obviously had to pursue organisational self-interests, but part of this interest was engaging in actual care trends and assuming a role as an innovative player in the care market - thus 
having their professionals participating in cooperative care networks, as described above. Some initiatives, however, were suspected of serving particular market interests more than collective interests, such as a strategic alliance between selected providers (the hospital, a home care and a care home provider) to improve and streamline referral patterns among their services: such alliances, it was argued, might restrict patients' choice.

The roles of the province and the community were not considered essential from the providers' and HCO's perspective, and were described as marginal. Neither the 'Regional Vision', nor meetings at municipality level tackling care and welfare services were seen as influential. Thus, the expected stronger role of the municipalities for care in the community was not yet realised.

\subsubsection{Second subcase: Amsterdam Nieuw West}

Amsterdam is the capital of The Netherlands, with a population of approximately 670.000 and a historically mixed economy over the centuries. The city is associated with progressive and citizen-oriented social politics over recent decades, a place open to collective solutions and experiments.

Nieuw West, with 127.000 inhabitants, is one of five Amsterdam care regions, which built the relevant administrative entities for local actors, and an area in a process of urban restructuring. Three providers of care homes were active here, also providing several community services. One of the two hospitals provided geriatric services widely used by local patients. The RIAGG operated in neighbourhood-based subteams. The municipality funded neighbourhood support centres for older people providing older people's advisors, and coordinating other welfare services. Home care was delivered by one dominant provider, and on a small scale, by care home providers. The citywide RIO ran a local office in Nieuw West; the HCO covered the whole region Amsterdam/Diemen.

The organisation of integrated dementia care was characterised by a multiplicity of overlapping operational links among generic, welfare and specialist services; however, sometimes these links were challenged by conflicts between individual organisations. At a strategic level too, cooperation was well developed, although here too competitive incentives played a role among providers. The changes in the AWBZ had been rather smoothly realised.

\subsubsection{Operational cooperation: various and overlapping links}

Responding to rising numbers of people with dementia living alone, and discontinuities in family-caring, multiple links among providers had been developed over the 
years to integrate dementia care delivery, by day-to-day cooperation or cooperative projects: these involved the older people's advisors, some GPs, district nurses, a day hospital, day centres, a specialist case management team, the RIAGG, the geriatric hospital ward, and residential homes. These multiple linkages built overlapping networks in changing combinations. Examples comprised: a recent multi-agency project for early signalling of dementia, training home care workers and GP practice assistants; the day hospital cooperating with the RIAGG and the case management team to coordinate community support; case management provided with differing intensity by older people's advisors (in the early stages), district nurses, the case management team and the RIAGG; and the geriatric day clinic, complemented by neurological and psychiatric input, offering comprehensive physical and psychogeriatric diagnosis to GPs. Informal networks, so-called 'home teams', encompassing GPs, district nurses, CPNs, and older people's advisors, met regularly in most neighbourhoods to discuss complex care issues including dementia.

"Lately our home team discussed the RIO and the rules which are relevant in dementia care, and the older people's advisor informed about their extended services, e.g. more home visits than formerly. The home team facilitates direct communication, better than all the leaflets, and I learn about other people's ways to handle certain issues."(GP)

Problems were reported especially about home care: waiting times, difficult cooperation, bureaucratic barriers, questionable quality and discontinuity of staff were reported to damage integrative efforts. Also, the home care agency was in a process of restructuring; specialisation of staff had been reduced; and staff recruitment faced bottlenecks. Nevertheless, pro-active and early approaches were being developed, and cooperation over dementia care was extended into generic and welfare services. The variety of services involved, and the interchanging levels of the care regions and the city had supported open and overlapping professional networks. Apart from that, professional cooperation seemed to follow similar incentives as in Maastricht: professionals pursued their ethics and ambitions; from a management perspective, operational cooperation was seen as advantageous being present in integrative networks providing community-oriented care.

\subsubsection{Strategic cooperation: concerted solutions}

The formalisation of the patients" pathways seemed to have proceeded more easily: The RIO was perceived as a cooperative and mostly competent partner with in the system. A care allocation centre processing all care home admissions had been set up in 1995 by the umbrella organisation of care providers in Amsterdam, now working 
under the $\mathrm{HCO}^{\prime}$ s responsibility (Geschiere, 2002). The regional insurer years before had shown innovative steering capacities (van Raak et al., 1993).

"The pressure from society, from government and from the sector brought about the energy for change in HCOs. You are right, three, four years ago this was zero, although I state that we have been very active with innovative projects eight, nine years ago. Thus, in historical sense, this HCO was very active." ( $\mathrm{HCO})$

The socio-political tradition of Amsterdam, and the complex structure of a big city might have contributed to the desirability and acceptability of concerted solutions.

The HCO consciously stimulated both cooperation and competition: commission policies preferred increasingly comprehensive care pathways for target groups like people with dementia, whether delivered by one or more providers. On the other hand, the HCO triggered providers to offer innovative services beyond their traditional domains. In Nieuw West, care home prowiders had tried to ease the competition by distributing the neighbourhoods in Nieuw West as zones of influence among each other (Antaris et al., 2001), although this was challenged by the HCO as a cartel strategy. The biggest care home provider in Nieuw West cooperated with service providers for the mentaliy, physically or socially handicapped to develop a system of neighbourhood-based centres for community care, aligned with urban restructuring agendas (Projectbureau CareWest, 2002), and supported by the HCO's commissioning policy.

Corresponding with the operational level, the $\mathrm{HCO}$ and the municipality cooperated for years to tackle the increasing grey areas and links between care and welfare services in order to avoid 'free-riders' behaviour', and to develop integrated services (Regiocommissie Ouderenbeleid Amsterdam/Diemen, 2001 ).

\subsubsection{The Dutch cases: comparative analysis}

In both Dutch cases, national policies in the 1990 s had effectively stimulated operational cooperative networks across agencies, by balancing collaborative and competitive incentives ( $c f$. Wistow \& Hardy, 1996). In Maastricht, local configurational features appeared to have contributed to the situation of a landscape of cooperative dementia care projects, well-linked to each other, but insufficiently linked with generic and welfare services. The geographical situation, limiting the labour market, had reinforced the continuing and close dementia professionals' network, which positively facilitated the cooperative project landscape. The continuing and closed structure as such, however, might also have contributed to the relatively limited links 
to generic services (Kickert \& Koppenjan, 1997) as too, did the local culture: the taboo on dementia outside the experts ${ }^{x}$ network at least partly counteracted the efforts to extend effectively early support, maintaining a reluctant attitude towards dementia care initiatives. With Dutch health policy being only loosely prescriptive, the national - and local experts' - priorities for early active support were not sufficiently influential to overcome this persistent local culture.

In Amsterdam Nieuw West, the operational networks had developed in more open and overlapping forms across generic and specialist agencies, and therefore been more suitable to realise extended early support. Certain cultural and socio-economic factors associated with a large city, like more openly expressed and perceived dementia care needs, and stronger dedication to social problems like dementia, had also triggered broad cooperation. In addition, the structure of services and of professional and managerial relationships was complex and less close; people had to act and meet each other at different levels (city, care region, neighbourhood); a greater diversity of services stimulated an innovative culture. Thus, these configurational characteristics made the development of open networks more likely. The cooperation problems with the dominant home care organisation, however, pointed to two possible sources of failure: the near monopoly situation of that agency; and the current reorganisation.

Cooperation at a strategic level was similarly influenced by local characteristics. In Maastricht, the same influences as described above - local culture, closeness, and the permissiveness of national governance - might have contributed to the slow development of strategic cooperation between care and welfare agencies, the provincial and municipal authorities and the HCO: the present societal situation in Limburg led to a neglect of what was recognised as being needed for the future. Moreover, the formalisation of the care pathway did not correspond ideally with the local configuram tion, especially with the traditional providers' focus on autonomy. So the RIO, a contested phenomenon in Dutch health policy anyway, faced even stronger disappraval and power play in Maastricht; and the HCO struggled hard to realise its politically intended steering capacity.

In Amsterdam, local traditions in social policy, expressed through the more comprehensive perspective on care development and delivery of both the insurer and the providers supported the formalisation of patients' pathways in the AWBZ, and the extended strategic cooperation beyond the AWBZ. So the implementation of the RIO, while nationally contested, fitted rather easily in the local siluation without great domain conflicts, and the $\mathrm{HCO}$ had already been able to develop steering capacities. The care home providers' strategy to avoid competition through cartel-building, 
however, can be related to a broader 'trust-friendly' Dutch pattern of combining group-based solutions with partial interests (Kümpers et al., 2002; Waarden, 1992).

\subsection{CROSS-NATIONAL ANALYSIS AND DISCUSSION}

National policies in both countries used political instruments to achieve, among other goals, joint working of the relevant local actors for integrated dementia care, with a common focus on care in the community and early support. Local outcomes regarding dementia care organisation, however, revealed remarkable differences within and between both countries, emerging from the interaction between national and local configurations. Major issues were apparent both in the different unfolding of central-local governance processes, but also in the content of local service development and delivery.

\subsubsection{Central-local governance processes}

\subsubsection{The impact of imposed organisational changes on local cooperation}

Hierarchical imposition of new organisational structures represented an important strand of English health policy-making at the time of this study, subject to much critical discussion (Fulop et al., 2002; Smith et al., 2001). Although untypical in the Dutch configuration, new organisational structures also had a role in The Netherlands.

As examples of the implementation of new organisational structures we can compare the PCTs in England with the RIOs in The Netherlands - although bearing in mind, that PCGs/PCTs involved a more comprehensive change than RIOs. Evidence from the cases points to different implications for local cooperation processes, depending on the particular aspects of local implementation and their fit with the local configuration. Fit here means the correspondence of new elements with existing structura! and cultural features, shaping the attitudes and interests of actors, and relationships between them. If corresponding sufficiently with the local configuration, new organisations can be quite smoothly integrated into existing cooperation processes in service development and delivery, like the RIO in Amsterdam Nieuw West, or contribute to progress after some time as with Leeds West PCT. When the implemented structures did not fit with the existing local configuration, however, processes of cooperation were severely interrupted and delayed, as happened in York; or they remained entangled in ongoing conflicts, as in Maastricht. Thus, imposed restructurings bear the risks of unintended negative consequences, if they are not fine-tuned to the specific local situation. This points to bases of formal and informal network building 
- the importance and interconnectedness of continuity and trust, challenged by forced and ill-fitting reorganisations.

Finally, whilst bearing in mind the small number of cases, it was interesting that in both countries the major struggle with organisational changes occurred in the smaller cities. We would suggest that the greater complexity and diversity of health and so. cial care systems in big cities may require - and thus produce - more flexibility and openness, thereby promoting the capacity to handle conflicts and changes.

\subsubsection{Changing power balances}

National policy interventions also affected local balances of power, introducing new (PCTs in England) or changing the role of existing agencies (HCOs in The Netherlands). In both cases these agencies had been given increased commissioning discretion, to be used in part to foster integrated care. Implementation processes too showed remarkable variations: in Amsterdam, where local cooperation had in fact preceded national policy developments, the HCO could build on the concerted actions of providers, and had already achieved the capacity and standing to consciously influence trends in service development. In Maastricht, the HCO could exert some influence in supporting operational cooperation but had failed yet to achieve strategic cooperative agreements against the resistance of local providers. Similarly in Leeds the PCTs could not easily pursue their agenda against the interests of the established stakeholders in the acute hospitals (cf. Glendinning, 2003). In York the PCT, although still weak as a local actor, could gain some strength from the common crisis to further joint planning with social services. Thus existing local power relationships exerted considerable influence; agencies, which had newly acquired formal steering, power needed time and competence to develop the organisational capacity and standing to realise this power.

\subsubsection{Local service development and delivery}

\subsubsection{The case of early support for dementia}

The coordinated support of older people in early stages of need, including those with dementia, appeared to be more extended, with generic services more broadly involved, in Leeds West and Amsterdam Nieuw West than in York and Maastricht. This could be explained by a different profile of perceived and expressed needs in big cities, arising from a greater percentage of older people living alone and without continuous family care-giving, combined eventually with an urban culture of addressing social problems more openly. However, the difference was more pronounced between Amsterdam and Maastricht than between Leeds and York. Local 
and national features can explain this difference. The specific local profile of York mental health services was suitable to successfully promoting local awareness of dementia within generic services; while Maastricht professionals, few in number in terms of community services also faced a rather traditional culture. Next, the use of ChEl, suggested as promoting a proactive approach of primary care to dementia, was widespread in England, but much less adopted in The Netherlands. Finally, as in Maastricht, the traditional culture might be of stronger local influence where national policy is less prescriptive.

\subsubsection{At the heart of integrated dementia care: the cooperation of generalists and specialists}

It is broadly acknowledged (Audit Commission, 2000; EACH, 1997; Gezondheidsraad, 2002) and was obvious in all localities, that the cooperation of generic with specialised services was decisive for the functioning of integrated dementia care. Mental health services could not take the burden alone, nor could generic services deliver high quality dementia care without specialist input. However, the nature and extent of such cooperation was influenced by all the various features which characterise local configurations - personal and professional agency, shared or conflicting domain perceptions, organisational history and culture, local perceptions of needs promoting or inhibiting formal and informal network-building across domains.

\subsection{LESSONS TO BE LEARNT: CONCLUSIONS AND RECOMMENDATIONS}

Localities matter. Local configurations interact with national steering activities to produce outcomes; in our case demonstrated with the example of cooperation for integrated dementia care. They exert a considerable impact on the outcomes of national steering.

Beyond local diversities, the case studies confirmed that there are general requirements for local network-building processes (Kickert \& Koppenjan, 1997), including for integrated dementia care, at both strategic and operational levels: these processes need some continuity of personnel, domains, and compatibility of interests over time to develop. Thus they are threatened by the implementation of national policies which disrupt local networks and challenge existing social capital (Ostrom, 1990). Network building can be triggered by incentives - as is the dominant pattern in The Netherlands - but can also be fostered by the 'shadow of hierarchy' (Scharpf, 2000)as is dominant in England. Looking at the different style of national policy interventions, both are inextricably intertwined with the national health and social care systems; they show both advantages and disadvantages for the implementation of inte- 
grated dementia care (Kümpers et al., 2002). While the English way shows remarkable hierarchical capacity to implement changes at local level it carries with it the danger of being disruptive to essential local network processes. The Dutch way of giving more freedom to local developments - and in so doing promoting incremental network-building - runs the risk of failure to implement changes in the face of persistent lacal barriers.

Certain features of local configurations allow some generalising propositions: the size difference appears to matter. The 'progress' of the bigger city regarding the emergence, perception and tackling of societal problems was not a surprise. The impression of a certain easiness regarding the modes of cooperation and dealing with changes, however, emerging in the larger cities in this study compared to the smaller ones, was, however, unexpected, since complexity and diversity in themselves are seen to pose a major challenge to the pursuit of cooperation and coordination (Hudson et al., 1997). Here, interestingly, the socio-economic and cultural diversity associated with larger cities appears to have fostered the potential for more flexible networking and integration across organisational and professional boundaries.

In exploring the relevant characteristics of local institutional configurations framing. integrated dementia care, the concept of local configuration has been valuable. Issues of culture, structure and power were found to interact - local traditions, established service structures and domains, political and organisational histories and preferences, and specific issues in the past or present associated with personal and professional agency. They together shaped the specific local processes for dementia care development and delivery, interacting with national steering activities. Thus local configurations cannot be perceived as just 'products' of national configurations; they are entities on their own. As national configurations appear to be path dependent, i.e. give their own shape to cross-national policy concepts (Boase, 1996; Ciaimo \& Manow, 1999), local configurations by analogy give a specific shape to the implementation of national policies. So research on policy implementation should strive to consider essential features of local configurations in order to achieve a more comprehensive understanding of local variations. This could help policy-makers to finetune national policy interventions, and thereby to prevent some of the unintended negative consequences at local level.

\section{ACKNOWLEDGEMENTS}

We would like to thank all those who facilitated the fieldwork in Amsterdam Nieuw West, Leeds West, Maastricht and York by helping to map the local context, giving interviews, allowing to attend their meetings, and providing documents. We also 
thank the Netherlands Organization for Scientific Research (NWO) for the financial support of the fieldwork in England.

\section{REFERENCES}

Afdeling SPGD/Ouderenzorg, Groene Kruis Heuvelland, \& Stichting Thuiszorg - Domicura. 1997. Eindevaluatie Project Ambulante Psychogeriatrie (ZAP) 1994 - 1996 (Final evaWation of the Project Outpatient Psychogeriatric Care 1994-1996). Maastricht, The Netherlands.

Antaris, Tabitha, \& Stichting Verenigde Amstelhuizen. 2001. Convenant Zorgaanbieders Verzorging en Verpleging. Stedelijke vernieuwing in het kader van Parkstad (Covenant of the providers of care. Urban regeneration in the framework of Park-City). Amsterdan.

Atkinson MM \& Coleman WD 1992. Policy networks, policy communities and the problems of governance. Governance: An International Journal of Policy and Administration 5: 154-180.

Audit Commission. 2000. Forget me not. Mental health services for older people. National Report . London, UK: Audit Commission publications.

Beemsterboer WGM. 2000. De ratio van de RIO's. Meerwaarde van onafhankelijke, objectieve en integrale indicatiestelling (The rationale of the RIOs. The surplus of independent, objective and integrated assessments). Tijdschrift voor Gezondheidswetenschappen 78: 238-243.

Boase IP 1996. Institutions, institutionalized networks and policy choices: Health policy in the US and Canada. Governance: An International Journal of Policy and Administration 9: $287-310$.

Cann Jv. 2002. Diagnostisch onderzoekscentrum voor psycho-geriatrie van start. RIAGG en azM: samenwerken voor de patiënt (Psychogeriatric diagnostic centre starting. RIAGG and University Hospital Maastricht: cooperating for the patient). Mediaan (Journal of the University Hospital Maastricht and the Faculty of Medicine) 4: 10-11.

Cantley C. 2002. Review of services for older people with mental health problems in York. Newcastle: Dementia North, Northumbria University.

CAT. 2002. Process Mapping Event - York. 21-22 November (Unpublished manuscript). London: Health and Social Care Change Agent Team (DoH).

Dawson D. 2002. WEST visit to Leeds Teaching Hospiral NHS Trust (Letter). London: Department of Health (Winter and Emergency Services Team).

De Vault ML. \& McCoy L. 2002. Institutional Ethnography. Using interviews to investigate ruling relations. In Gubrium JF \& Holstein JA (Eds.), Handbook of Interview Research. Context and Method (pp. 751-776). Thousand Oaks: Sage. 
Department of Health. 1999. National Service Framework for Mental Health. Modern standards and services models. London: Department of Health.

Department of Health. 2001 a. Building capacity and partnership in care. An agreement between the statutory and the independent social care, health care and housing sectors. London, UK: Department of Health.

Department of Health. 2001 b. National Service Framework for Older People. London, UK: Department of Health.

EACH. 1997. Examples of good practice in the continuum of care. Report and findings. Retrieved 20.02.2001, from www.each.be

Fulop N, Protopsaltis G, Hutchings A, King A, Allen P, Normand C et al. 2002. Process and impact of mergers of NHS trusts: multicentre case study and management cost analysis. British Medical foumal 325: 246.

Garvican L \& Bickler C. 2002. The relationship between the NHS and residential and nursing care for older people: A survey of home owners and managers in East Sussex, Brighton and Hove. Quality in Ageing - Policy, practice and research, 3: 24-33.

Geschiere R. 2002. Zorgtoewijzing. Jaarverslag SICRA 2001 (Care allocalion. Annual Report SIGRA 2001), from www.sigra.nl

Gezondheidsraad. 2002. Dementie. Advies van een commissie van de gezondheidsraad (Dementia. Advice by a committee of the Health Council). Den Haag, The Netherlands: Gezondheidsraad (Health Council of the Netherlands). Publication no. 2002/04.

Giaimo S \& Manow P. 1999. Adapting the welfare state. The case of health care reform in Britain, Germany, and the United States. Comparative Political Studies 32: 967-11000.

Gieryn TF. 2000. A space for place in sociology. Anmual Review of Sociology 26: 463-496.

Glendinning C. 2002. A charge too far. Community Care, $11-17$ July, 34-36.

Glendinning C. 2003. Breaking down barriers: integrating health and care services for older people in England. Health Policy 65: 139-151.

Grünwald CA \& Kwartel AJvd. 1996. Ondeningsprocessen in de regio. De ongrijpbare regio (Processes of regulation in the region. The intractable region). Beleid \& Maatschappif $23: 223-234$.

Herbert G. 1997. Sharing the caring: Learning logether. A review of services for older people with mental health problems in North Yorkshire and the City of York. Leeds: Nuffield Institute for Health.

House of Commons: Health Committee. 1998. The relationship between health and social services. First report ( $\mathrm{Vol}$. 11 : Minutes of evidence and appendices). London: The Stationery orfice. 
Hudson B, Hardy B, Henwood M \& Wistow G. 1997. Inter-agency collaboration. Leeds: Nuffield Institute for Health.

yohn P \& Cole A. 2000. When do institutions, pollicy sectors, and cities matter? Comparing networks of llocal policy makers in Britain and France. Comparative Political Studies 33: 248-268.

Jones 1. 2000. Mental health care reforms in Britain and Italy since 1950: a cross-national comparative study. Health \& Place 6: 171-187.

Kickert WJM \& Koppenjan IFM. 1997. Public management and network management: An

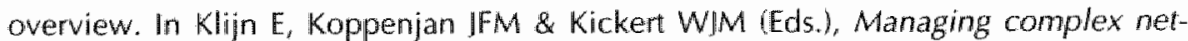
works. Strategies for the public sector (pp. 35-60). London: Sage.

Kümpers S, van Raak AlA, Hardy B \& Mur-Veeman 1. 2002. The influences of institutions and culture on thealth policies: different approaches to integrated care in England and the Netherlands. Public Administration 80: 339-358.

Kümpers S, Mur 1, Maarse H \& van Raak AJA. forthcoming. Understanding similarities and differences in dementia care in England and The Netherlands: A qualitative comparative study using meo-institutionalist perspectives. Qualitative Health Research.

Leeds Cily Council \& Leeds Health Authority. 1998. Services for older people reconfiguration programme. Policy recommendations and report on progress. Final draft. Leeds.

Lehmbruch G. 1996. The organization of society, administrative strategies, and policy networks. In Czada R, Héritier A \& Keman H (Eds.), Institutions and political choice. On the limits of rationality (pp. 61-84). Amsterdam, The Netherlands: VU University Press.

Martin S. 2000. Implementing 'Best Value': Local public services in transition. Public Adninistration 78: 209-227.

Norgaard AS. 1996. Rediscovering reasonable rationality in institutional analysis. European Jownal of Political Research 29:31-57.

Nuffield institute for Health. 2000. Making connections: a review of options for 24-hour care for older people in York. Leeds: Nuffield Institute for Health, University of Leeds.

Ostrom E. 1990. Governing the commons. The evolution of institutions for collective action. Cambridge: Cambridge University Press.

OToole LJ. 1997. Treating networks seriously: Practical and research-based agendas in public administration. Public Administration Review 57: 45-52.

Projectbureau CareWest. 2002. Parkstad woon-zorg regio. Referentiekader herontwikkeling zorg en dienstverlening in Amsterdam Nieuw West. (Park-city, a zone for housing and care. Framework for re-building care and service delivery in Amsterdam Nieuw West). Amsterdam: CareWest, Samenwerkingsverband van Antaris, Ijlanden, Amstel-. rade, HVO-Querido. 
Projectgroep VIA-Maastricht. 1999. VIA - Maastricht. Verpleeghuiszorg Integraal Ambulant. (WA - Maastricht. Integrated nursing care at home. Maastricht: Verpleeghuis Grubbeveld, RIAGG Maastricht, Groene Kruis Heuvelland, Domicura, Stichting Drielanden Thuiszorg,.

PSSRU. 2002. Closures of care homes for older people. Summary of findings, No. 1. Canterbury: PSSRU (Personal Social Services Research Unit).

Regiocommissie Ouderenbeleid Amsterdam/Diemen. 2001. Regiovisie Ouderenbeleid RRegional Vision for Older Peoplel Amsterdam/Diemen 2007-2005, 2003, from http:/www.kenniscentrumouderen.amsterdam.n//ive/attachment.db?2664

Royal Commission on Long Term Care. 2003, 29.09.2003. Longuterm care statement by Royal Commissioners, from http://www. Itc-commissioners,org.uk/4554.html

Sainsbury Centre for Mental Health. 1999. Review of Mental Health Services for the residents of Nonth Yorkshire and City of York: Sainsbury Centre for Mental Health.

Salari MA. 2000. Zorgprogramma's voor de ouderenzorg (Care pathways for older people). Utrecht, The Netherlands: GGZ Nederland (Dutch Association for Mental Health).

Scharpf FW. 2000. Interaktionsformen. Akteurzentrienter Institutionalismus in der Politikforschung (Original: Games real actors play. Actor-centered institutionalism in policy research). Opladen: Leske \& Budrich.

Smith I, Walshe K \& Hunter DI. 2001. The "redisorganisation" of the NHS. Another reorganisation involving unhappy managers can only worsen the service. British Medical Journal 323: $1262-1263$.

Stuurgroep Substitutie Maastricht/Heuvelland. 1998. Modules WBO-Zorg en aanvullende PG. verpleeghuiszorg (Modules of care in residential homes and complementing dementia nursing care). Maastricht: Samenwerkingsverband Verpleegklinieken, Verzorgingshuizen Maastricht Heuvelland.

Thompson G, Frances I, Levacic R \& Mitchell J. (Eds.). 1991. Markets, hierarchies and networks. The coordination of social life. London etic: Sage.

Turnock S. 2002. York and Selby health and social care economy. Older people's services" A functional level review. York: SDC consulting.

wan Raak AJA, Jongerius-de Gier G, Massop I \& Mur-Veeman $\mathbb{M}$. 1993. Brug lussen gisteren en morgen. Evaluatie Programma Zorgvermieuwingsprojecten Thuiszorg van WVC'. Eindrapportage (A bridge between yesterday and tomorrow. Evaluation of the Programme 'Care innovation in home care'. Final report). Maastricht: Vakgroep Belleidswetenschap, Rijksuniversiteit Limburg.

van Raak AJA, Mur-Veeman I, Hardy B, Steenbergen M \& Paulus A. (Eds.). 2003. Integrated care in Europe. Description and comparison of integrated care in six EU countries. Maarssen, The Netherlands: Elsevier. 
146 Chapter 5

Verschuur A. 2001. Geen feest in RIO. Regionale indicatie-organen bieden geen toegevoegde waarde (No party in RIO. Local centres for assessment do not bring improvements). Ouderenzorg $7 / 8,6-9$.

Villevoije A.HM. 2002. Een onthikende samenwerking?" Een onderzoek naar samenwerking ussen zorgkantoor en andere actoren bij de uitvoering van overheidsbeleid met beIrekking tot de AWBZ (A prospering cooperation? A study about the cooperation between the Health Care Office and other actors on implementation of policies regarding the AWBZ). University of Maastricht, Maastricht.

WS. 1999. Zicht op Zorg - plan van aanpak modernisering AWBZ (Prospects of care - programme for the modernisation of the AWBZ). 's-Gravenhage: Ministerie van Volksgezondheid Welzijn en Sport (Ministry of Health Welfare and Sports).

Waarden Fw. 1992. The historical institutionalization of typical national patterns in policy newworks between the state and industry. A comparison of the USA and the Netherlands. European Journal of Political Research 21: 131-162.

Willke H. 1998. Steverungstheorie: Grundzüge einer Theorie der Steverung komplexer Sozialsysteme (Theory of steering: Basic theoretical lines for the steering of complex social systems. Stuttgart: Lucius \& Lucius.

Wistow G. Hardy B. 1996. Competition, collaboration and markets. Journal of Interprofessional Care 10: 5-10.

Yin RK. 1994. Case study research. Design and methods. Thousand Oaks: Sage.

York Health Services NHS Trust, \& City of York Community Services. 1999. Proposals for enabling more effective joint working between mental health and socjal services for older people. York. 


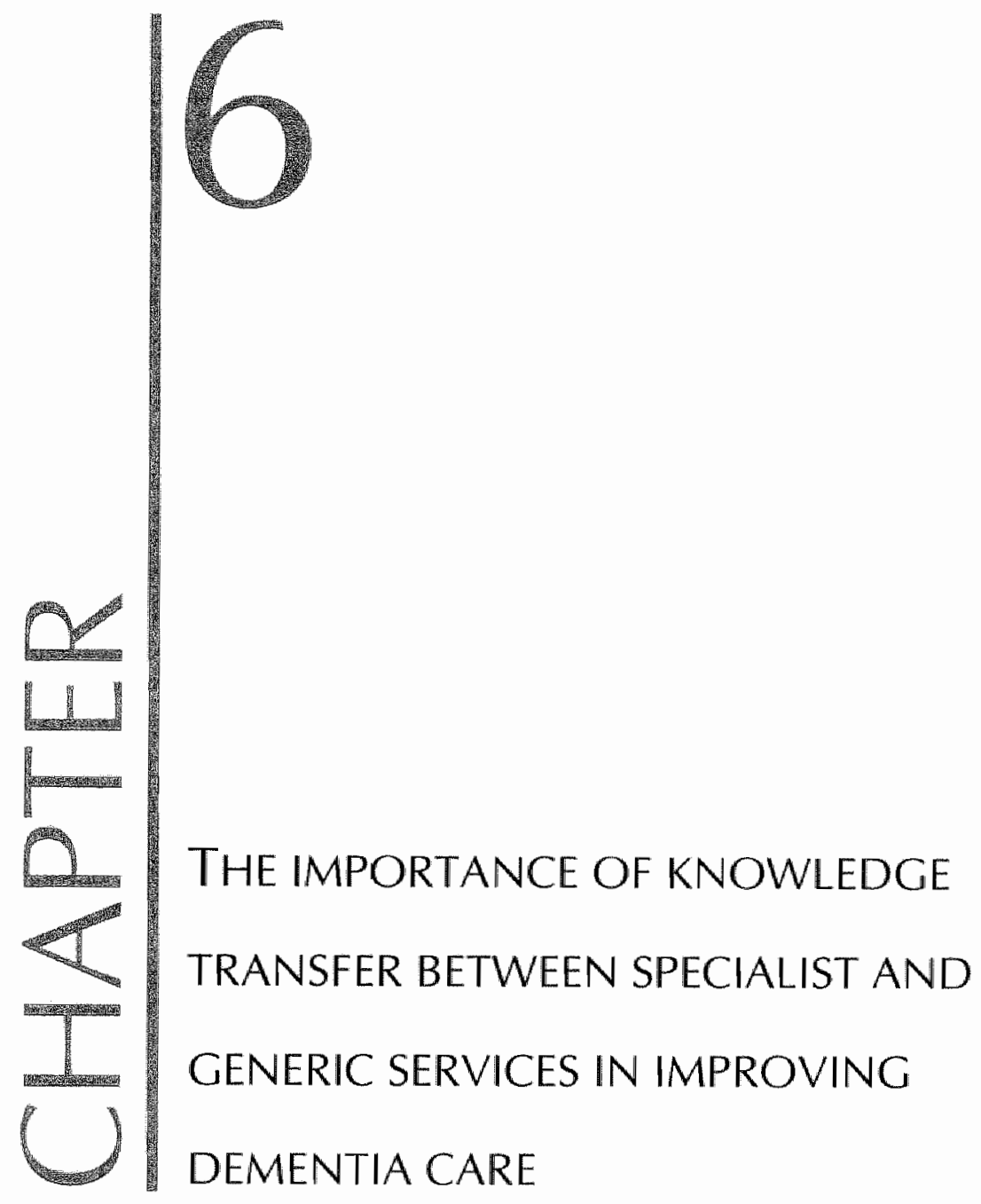

This chapter is based on:

Kümpers, S., Mur, I., Hardy B.,Raak, A. J. A. v., \& Maarse, H. (provisionally accepted). The importance of knowledge transfer between specialist and generic services in improving the quality of dementia care. A cross-national study in England and The Netherlands. The International Journal for Health Planning and Management. 
Chapter 6 


\subsection{ABSTRACT}

Knowledge transfer between specialist and generic services is widely seen as an important strategy for improving the quality of integrated dementia care. This article elaborates on intra- and inter-organisational features associated with successful knowledge transfer. A provisional conceptual framework is suggested, based on literature about inter-organisational networks and knowledge management. Professional and organisational cultures, domain perceptions, perceived dependency and the availability of resources are suggested as significant influences upon the motivation and perceived capacity to engage in knowledge transfer; personal and organisational continuity is identified as an important process quality. Data from four local case studies in England and The Netherlands are used to develop and specify the provisional framework. A conceptual model is built to explain the relative success or failure of knowledge transfer.

\subsection{INTRODUCTION}

Facing increasing differentiation in their health and social care systems and a rising number of people with multiple care needs, most Western health and social care systems have the delivery of integrated care high on their policy agendas. In the case of dementia care no less than in any other, integrated care is required in order to facilitate the development and delivery of coherent, coordinated and continuous services to patients and their carers. Cooperation for integrated care comprises several components: information exchange; inter-agency teamwork; task coordination; and, last but not least, knowledge transfer, which promotes competence development. The latter is seldom covered in more general studies of integrated care icf. Alaszewski et al., 2004; Gröne \& Garcia-Barbero, 2001; Kodner \& Spreeuwenberg, 2002), although, whether explicitly or implicitly, it is often a major issue for integrated care practice. If we look broader, at studies of inter-organisational networks as an emerging form in the knowledge-based economy, we find the topic of knowledge transfer and learning covered as essential in this development (Alter \& Hage, 1993; Barringer \& Harrison, 2000); moreover, 'knowledge management' within and between organisations is developing as an innovative field of management research (e.g. Davenport \& Prusak, 1998). Analogously, competence development in health and social care is an issue in policy and research in both our reference countries (Loughlan, 2003/2004; Modernisation Agency, 2003; ZonMw, 2004).

In our study of integrated dementia care in England and The Netherlands the issue of knowledge transfer came up continually. This was not surprising, given that whilst 
the bulk of daily dementia care is delivered by generic services often lacking specific competences, knowledge about and philosophies of dementia care have developed significantly over the last 15 years in the expert community. As a consequence, strategies to improve the knowledge and skills of generic staff are frequently recommended (Audit Commission, 2000; EACH, 1997a; Gezondheidsraad, 2002). Among such strategies, knowledge transfer as part of a cooperative relationship between specialist mental health services and generic services is widely advocated in policy programmes and studies dealing with dementia care (e.g. Department of Health, 2001; Gezondheidsraad, 2002). Indeed it is seen not just as a means of enlancing the competence and quality of care but sometimes as the heart of integrated dementia care (Herbert, 1997a). Here we define knowledge transfer in dementia care as the improvement of knowledge and understanding about dementia, and of skills to deal appropriately with people with dementia, by sharing of expertise, embedded in cooperation between generalist and specialist services. To date knowledge transfer in dementia care has not been addressed comprehensively (see below). Our article, therefore, aims to open up discussion on this topic. In order to try to identify the factors associated with successful or unsuccessful knowledge transfer, a provisional conceptual framework is presented which builds on existing work on interorganisational cooperation and knowledge management. The framework is then developed using empirical data from our fieldwork in four local case studies of integrated dementia care in England and The Netherlands. By exploring and clarifying the factors influencing success and failure of knowledge transfer in the field of dementia care a conceptual model is built, which it is hoped will facilitate further research and support service development.

First we introduce the context of our study by sketching changes in dementia care concepts and currently perceived problems in dementia care, the latter providing the background to attempt to make knowledge transfer an essential part of the cooperation between specialist and generic services. In this we rely on our own previous research (Kümpers et al., submitted) and further literature and document study. Next we introduce our theoretical framework, and describe our methods. We present the findings from our local case studies and, after discussing the structural arrangements for knowledge transter, describe and discuss these findings in relation to the provisional conceptual framework. We then develop and refine this conceptual model, before drawing conclusions and lessons for further research, for politicians, and for managers and professionals responsible for dementia services development. 


\subsection{CONTEXT AND BACKGROUND}

In this section we set out the context of changes in dementia care concepts during the last 15 years, and the frequently perceived gap between best practice and mainstream dementia care (cf. Audit Commission, 2000; Gezondheidsraad, 2002). It is within this context that efforts have been made to improve dementia competence in general.

Rising prevalence has contributed to an increasing awareness of dementia in ageing societies, and an intensified debate about what constitutes appropriate health and social care (Audit Commission, 2002a; Department of Health, 2001; Gezondheidsraad, 2002). In Western countries traditional ways of thinking about dementia care were questioned during the 1990s. The biomedical model of dementia was for a long time associated with "therapeutic nihilism", defining the person with dementia mainly in terms of a progressive disease of the brain. A gradual shift away from biomedical perceptions of dementia has broadened the perceptions of the person with dementia, reflecting social, psychosocial or person-centred models (Bond, 2001). New therapeutic approaches focus on the person, her relatedness to other humans and her capabilities of experiencing life (Miesen \& Jones, 1997). The maintenance of emotion, rather than the decline of cognition, is made the basis of caring relationships. The capacities of people with dementia to live a personal life and to participate in social life are seen as dependent on social and environmental contexts (Cameron, 2000; Cox et al., 1998; Kitwood, 1997; Strässer \& Cofone, 2000). Progress recently made in the pharmacological treatment of early stage Alzheimer's Disease (AD) has also reoriented biomedical approaches towards dementia.

Based on these perceptions there is broad agreement in the expert communities about suitable means and goals of dementia care (e.g. $\mathbb{E A C H}, 1997 \mathrm{a} ; \mathbb{E A C H}, 1997 \mathrm{~b}$; Furnish, 2002):

The emphasis now is laid on early diagnosis, information, support and eventually treatment (Alzheimer Nederland, 2001a; Alzheimer's Society, 2000; Department of Health, 2001; Eccles et al., 1998; Gezondheidsraad, 2002; Nederlands Huisartsen Genootschap, 1998). Co-ordinated, flexible and skilful community services should be in place to enable people with dementia and their carers to maintain their functioning and their quality of life, staying in their own home as long as possible. Care home provision, where necessary, should follow the same principles as community care: i.e. being pro-active and directed to the individual, maintaining their functioning,

1 Investigated in documents from governmental, government-related, research, professional and voluntary agencies (like Alzheimer's Societies) in England and The Netherlands (Kümpers. et at, forthcoming). 
autonomy and personhood (Alzheimer's 5ociety, 2000; Gezondheidsraad, 2002; Nationale Raad voor de Volksgezondheid, 1994).

These ideas are widely accepted amongst dementia care professionals, but a great deal is still required for them to be transferred to generic service development and delivery. Generic health and social services - meaning, for our study, non-specialist dementia care services - deliver the bulk of care and support for people with dementia and their carers, but are often provided without available specialist knowledge. During our investigation in 2001 (literature study and interviews with dementia care experts in both countries) wide-spread problems were cited in different generic care fields: primary care (Alzheimer Nederland, 2001b; Audit Commission, 2000; Hout et al., 2000; lliffe et al., 2000); general hospital care (Holmes et al., 2002; Koning, 1994; Slaets et al., 1997); and social care, comprising home care, day care and care homes (Audit Commission, 2002a; Ballard et al., 2001; Gezondheidsraad, 2002; Train et al., 2001). Such problems were similar in both countries in terms of diagnosis, information and support for patients and carers, especially dealing with behavioural problems, maintaining personhood and functioning (Kümpers et al., submitted).

To improve dementia care competence in generic services, different strategies, separately or in combination, have been recommended and applied, albeit insufficiently. First, the classical instrument of education and training. Second, specialisation within generic services for dementia (or mental health problems), thereby accumulating knowledge and experience over time. A third strategy - our subject here - is knowledge transfer between dementia specialists ${ }^{2}$ and generalists. This is proposed as a way to close the gaps, combining patient-oriented and staff-oriented tasks in the case of specialists, and providing generalist staff with knowledge and skills to deal with dementia, as part of a continuous cooperative relationship. knowledge transfer should address medical professionals in primary and hospital care, as well as professionals and semi-skilled staff in community and social care.

This strategy is often recommended, more strongly in England than in The Netherlands (Audit Commission, 2000, 2002b; Gezondheidsraad, 2002; Nies et al., 2003; Sheard \& Cox, 1998), but seldom properly examined. In The Netherlands, where government is involved to a lesser degree in details of service development and delivery in general (Kümpers et al., 2002), the Health Council recommends the im-

${ }^{2}$ Specialists for dementia care are not identical in England and The Netherlands: while in England psychiatric services hold this role more exclusively, in The Netherlands other medical specialists also see dementia as part of their field: social geriatricians (community mental health services), clinical geriatricians (hospitals) and nursing home physicians; psychiatrists and neurologists are involved in more complicated aspects of diagnosis and treatment. 
provement of staff competences as crucial for an appropriate quality of care, but merely mentions the role of mental health services in this regard (Gezondheidsraad, 2002). In England, by contrast, the National Service Framework for Older People (NSF) explicitly requires that mental health services engage in knowledge transfer with generic services (Department of Health, 2001). Some research, policy and practice papers refer to the function of knowledge transfer as an essential part of the broader cooperation between specialist and generic services: for primary care (Manthorpe et al., 2003); for general hospital care (Collinson \& Benbow, 1998; Holmes et al., 2002, 2003; Marshall, 1999); for home care (Herbert, 1997a, 1997b); for care homes (Ballard et al., 2002; Crouch, 1997; Herbert, 1997b; Marshall, 2001); and in general (Challis et al., 2002; Engelhard-Salari, 1995; Nies et al., 2003; Sheard \& Cox, 1998). However, few papers examine the issue more deeply. While Tunmore et al (1992) reflect upon the core activities of 'psychiatric consultation liaison nursing', describing essential tasks of knowledge transfer, we found only two practiceoriented papers addressing successful realisation (Crouch, 1997; Herbert, 1997b). Thus, for example, Herbert (1997b, p.113) describes important aspects of interprofessional relationships for successful knowledge transfer:

"This can only happen, where there is trust in the relationship and the views of the carers and care workers are treated with respect by the professionals; recognising indeed that it is often their views which contribute to learning and development of new ideas."

Given that knowledge transfer between specialist and generic services is perceived as essential for dementia care improvement it seems important to investigate the issue in some depth.

\subsection{A PROVISIONAL CONCEPTUAL FRAMEWORK}

To conceptualise success and failure of knowledge transier, we use Kerr's and Slocum's (1981) classical model of performance explained by motivation and ability as a starting point. Performance, for our purpose, is specified as successful knowledge transfer. By success we mean a situation in which knowledge transfer between speciallist and generic services is perceived by the participants as contributing signifilcantly to a more informed and thereby improved quality of generic dementia care. Since our focus is at organisational and team level, we modify the model by broadening ability - described by Kerr and Slocum as individual - to perceived organisational 
capacity ${ }^{3}$. Motivation, defined as the willingness to perform, is also investigated at organisational or team level rather than individually.

In seeking to understand levels of motivation and perceived capacity, we borrow from theories on inter-organisational networks, since we are studying knowledge transfer in the context of inter-organisational cooperation. Conceptualisations of the existence or absence, the success or failure, of inter-organisational cooperation are numerous and eclectic; concepts from different theoretical paradigms, describing various aspects, have been combined to build comprehensive pictures (Alter \& Hage, 1993; Barringer \& Harrison, 2000; Hudson et al., 1999). We have focused on concepts describing the internal characteristics of organisations, which impact on interorganisational cooperation - professional and organisational culture, domain perceptions, perceived dependency and resources. To specify them for knowledge transfer we draw on knowledge management literature.

Organisational culture is defined as the basic assumptions and beliefs, shared by members of an organisation, which define the organisation's view of itself and its environment (Schein, 1985). This can be translated similarly to professional culture. Culture is expressed in (mutuall) attitudes, which increase or diminish the motivation to engage in cooperation and knowledge transfer (Goh, 2002): The concept of trust has played a central part in the conceptualisations of inter-organisational cooperation (Nooteboom, 2002), although it remains difficult to define. Mildenberger (1997) defines trust as the mutual assumption that one will consider each other's goals and expectations in relevant decision-making. Hudson et al (1999) illustrate the volatile character of trust by describing it as simultaneously the basis, lubricant and outcome of cooperation, which has to be nurtured by transparency on the one side and personal relations on the other. This refers implicitly to the process character of trust, and thereby to the issue of time, necessary to establish trustful cooperative relationships. Next, a culture of problem-seeking and solving, handling problems as a spur to improvement, is seen as opening up the organisational climate for knowledge transfer, and contributing to a capacity amongst recipients to both absorb and retain material (Goh, 2002). Leadership style is also seen as an important factor in nurturing a culture of trust, and of problem seeking and solving (Goh, 2002).

Domain consensus is a concept anchored in classic theories of inter-organisational networks, defined as the "agreement among participants in organizations regarding the appropriate role and scope of an agency" (Benson, 1975). Domains, as well as cultures, can be defined for professions and/or organisations (cf. Johnson et al, 2003). Professional domains, often organised within hierarchical structures in health

\footnotetext{
${ }^{3}$ We assume the respective professional ability of mental health specialists as in general being given.
} 
care, are seen as a potential barrier to cooperation (Codfrey et al. 2003; Hudson, 2002) and knowledge transfer (Beveren, 2003).

The concept of resource dependency in organisational sociology (ct. Benson, 1975; Scott, 1992) or power-dependency in political sciences (Rhodes, 1997) implies that organisations must engage in exchanges with other organisations to acquire complementary resources which they need to pursue their goals. The perceived dependency (cf. Mijs, 1989) on other organisations' resources - including knowledge, information, experience etc. - therefore is seen as an essential driving force towards cooperation.

Tasks can only be carried out if the necessary resources are available to the organisation. Resources are originally defined as comprising domain possession and money (Benson, 1975). The domain issue is dealt with separately above. Monetary resources needed, however, are essentially associated with staft time (and qualifications), to provide the organisational capacity for knowledge transfer. Knowledge as such, in contrast to tangible resources, is not lost, if transferred; though, this does not guarantee a willingness to transfer knowledge (Syed-lkhsan \& Rowland, 2004).

Personal and organisational continuity emerged as an important process factor during our data collection and analysis. Continuity as such is seldom elaborated upon in studies of inter-organisational networks; implicitly, however, continuity is addressed when long-term relations are described as a characteristic of networks (Mildenberger, 1997). Local knowledge and language, and shared rulies and perceptions are conceptualised as the social capital of networks (Kickert \& Koppenjan, 1997), which is rooted in durable trustful networks. Social capital is seen as contributing remarkably to the quality of knowledge transfer, especially regarding tacit knowledge, which is seen as residing in social interactions (Lang, 2004).

The literature suggests the above concepts as appropriate for exploring and understanding relative success and failure of knowledge transfer processes. We use them as sensitising concepts to guide our descriptions of and reflections upon our findings of local cooperation/knowledge transfer. Below, we will specify and develop them with evidence from our data, and illustrate interactions between them. We then build a conceptual model of factors associated with more or less successful knowledge transfer. Before doing so, we outline our research design and methods.

\subsection{METHODS}

As indicated above, the primary data used for this article were collected from four local case studies on integrated dementia care in England and The Netherlands, undertaken in 2002. Cases were localities with $100.000-150.000$ inhabitants; in each country one medium-size city, and one part of a large city (England: York and Leeds 
West; The Netherlands: Maastricht and Amsterdam Nieuw West). The case studies focused on all aspects of local integrated dementia care development and delivery including the steering context. Agreements had been obtained from all responsible Ethics Committees. The fieldwork comprised semi-structured in-depth interviews with professionals, managers and carers of people with dementia (approximately 25 per case), attendance at multi-agency meetings and the collection of relevant documentary material. With interviewees' permission all interviews were taped and then transcribed. For data reduction (c. Miles \& Huberman, 1994, p.10), to keep the amount of data feasible and to facilitate analysis, the interviews were summarised according to main topics arising, provided with links (line numbers) to the original data. The summaries were coded and qualitative data analysis software (atlas-ti 4.2) was used for coding and retrieving.

For the topic of this paper the data were screened for all information, which had emerged related to knowledge transfer between specialist and generic services. This involved settings - defined as situations with certain specialist and generic services interacting - with existing and functioning cooperation and knowledge transfer as well as those where knowledge transfer was perceived as missing or malfunctioning. As with the academic literature, the documents obtained comprised no detailed information on knowledge transfer, with the exception of one planning document (Holmes, 2001). The bulk of specific information came from the interviews. Retrieved data were assorted first according to settings, in order to gain a comprehensive picture of each setting. After identifying the theoretical concepts, as described above, the retrieved data were attributed in a second step to the suggested concepts explaining success and failure of knowledge transfer, thus further developing the concepts, and exploring the relations between them.

We describe characteristics related to knowledge transfer from an organisational perspective. Prima facie evidence from this perspective had shown similarities rather than significant differences among the four case studies and the two countries. We therefore treat the collated data as a unified database ${ }^{4}$. Still, a database involving two countries adds to the strength of the findings and to the generalisability of the results.

Finally, knowledge transter was looked at at only one point in time, and we were not able to investigate the dewelopment or broader context of each single project or setting in detail. Our interviewees, however, reflected their long-standing experience, and their understanding of the various process characteristics of knowledge transfer.

\footnotetext{
"In a former step, we investigated the national and local political contexts (the external influences) of local interorganisational cooperation in dementia care in general using a comparative approach; the results will be published elsewhere (Kümpers et al. forthcoming).
} 


\subsection{FINDINGS}

In presenting our findings from local case studies, initially we sketch the existing service models found for cooperation and knowledge transfer, before describing and discussing our findings in terms of our provisional conceptual framework.

\subsubsection{Service models}

In our case study localities we found what we have categorised as five different service models for cooperation and knowledge transfer between specialist and generic services (see Box 6.1). From our data we found no evidence of success or failure being clearly attributed to specific service models. For all models some success and failure was reported (with the exception of model 4 , which occurred only once). In general each of them had some potential for successful knowledge transfer. Certain common characteristics across the models, however, like co-location (as in model $2,3,4)$, impact on features, which are important for success and failure such as trust and continuity.

\section{Box 6.1: Service models and knowledge transfer}

7. The outreach model. The most common structure - in both countries - was the outreach function of specialist teams into all kinds of generic teams (primary care and other community health care, hospital care, social care), combining to a varying degree treatment of patients and support for carers with consultation of staff and training activities. Linking mechanisms varied from merely patient-oriented referral mechanisms to regular team participation, and to named specialist professionals linked to certain generic services. In some cases there were extra services or teams specialising in the outreach function as their core task. The outreach model was used in all hospital settings. Further, it was the dominant arrangement for Community Mental Health Teams (CMHTs) in England and their Dutch equivalents, the RIAGGs, for their links to community care settings, including care homes. Settings using the outreach arrangement were associated with mixed success, but seemingly more successful when explicitly and specifically dedicated to knowledge transfer.

2. Connected specialised generic and specialist teams: Community mental health teams were closely related to and connected with specialised home care teams, offering services for a shared target group (people with dementia living at home). This model was connecled with joint team meetings, and close consultation patterns. It connects knowledge transfer with specialisation within generic social care. It always covered only a small part of relevant community services.

3. A mentall health specialist as a team member in a specialised generic service, providing treatment to users and support and training to staff. This model was found once, with a mental health nurse working in a social services-run specialist day centre in Leeds West. While it was perceived as successful in leeds West, the arrangement had not worked in other parts of the citv. 
4. Shared service and location, joint team: This modell also was found only once, as a shared geriatric and mental health ward in York, with implicit rather than explicit mutual knowledge transfer and competence development between physicians and nurses, described as successful.

5. Neighbourhood related round tables. This specific model was not exclusively dedicated to dementia care, but to the improvement of complex care pathways in general. In most neighbourhoods of Amsterdam Nieuw West several community health and social care professionals thome care professionals including district nurses, CPS, older people's advisors, social psychiatric nurses met regularly to discuss complex care issues, thereby mutually informing and teaching each other, with dernentia care being one issue among others. On the whole, this arrangement was well appreciated among participants, however, the degree of participation differed between neighbourhoods, and so did the perceived effects.

\subsubsection{Knowledge transfer: features of success and failure}

In the following, we summarise the findings from our empirical data. We provide composite accounts (see De Vault \& McCoy, 2002); moreover, quotations from interviews give both evidence and illustration. The intention is to identify the range of significant phenomena associated with success and failure of knowledge transfer rather than to quantify their occurrence. The quotations, however, do more than highlight success and failure of processes of knowledge transfer; they also illuminate the pressures on the services and the urgent need for competence development in dementia care. Quotations are numbered for ease of reference, with italics used for emphasis.

\subsubsection{Organisational and professional culture}

In most settings we found attitudes more typically symmetrical, i.e. where distrust was expressed on the one side, it was also likely to occur on the other. Predominantly negative attitudes mostly were associated with the absence and/or contested nature of cooperation and knowledge transfer. Such mutuality points to interactive developmental processes, which are intertwined with the cultural characteristics of the respective teams/organisations, and exert a remarkable impact on the motivation to engage in and sustain knowledge transfer.

Consistent with much organisational research on cooperation and knowledge transfer, trust was said to be vital:

(1) "If somebody rings me up ... They have a problem for about a week; I can't do it tomorrow, I've just to much on, I say I will try on Friday, ... they know that I will come whatever time, ... I think that helps with the trust and the commitment, in terms of they are desperate for some help." "Link liaison nurse, linking with care homes, England) 
To foster trust, especially in social care staff, the specialist's attitude had to be reassuring, and their approach practice-oriented:

(2) "You can't say 'Here you get the care plan, just get it done.' That doesn't work in practice, they [care workers] must have access to rebound upon you." (Dementia case manager working with generic home care, The Netherlands!

(3) "It may well be, help them to think through the problem, ... they got some kind of key in, some kind of support which to me is very basic; and most staff don't want from me high flying ideas; they want the practical, the pragmatic, ... I go in and say, It's not as big as you think really, it's manageable ... we are going through stormy times, but we will get through." (Link liaison nurse service linking to care homes, England)

It is worth noting that apart from trust, there is no deeper analysis of the issue of mutual respect in studies on inter-organisational cooperation. In our interviews, respect - defined as an attitude appreciating the value and merits of the others' work-along with trust, was cited as a quality that is essential for success:

(4) "I try to think I'm a guest in this home; l've got to create the feeling and response that first of all I do not know it all, secondly they know more than they think they know, and (there is) the indiviclual for we both have to work together." (Link liaison nurse linking to care homes, England)

(5) "We kept it running between us all and it is very good inter-agency working. ... So there was mutual education, mutual support, mutual respect, which I think was very important, in both directions." (Psychiatric consultant about the relationship of her CMHT with a specialist home care team, England)

Equally, it was mentioned as something lacking in cases of difficulty:

(6) "And I think some five years ago there was still the tendency: We specialists know it better and you stupid GPs should learn from us." (Psychiatrist, The Netherlands)

(7) "They [specialists] have a judgement about the facl that you don't refer, but not about what you know and what you do... In general the GP is the fall guy. ... They have an exaggerated idea about what they are doing - they should have a two-weeks look at a GP's practice." (GP in the same context, The Netherlands) 
The above psychiatrist's statement (6), however, points to the potential for development and change through critical self-reflection.

Leadership style was said to support an attitude of problem-seeking and solving, and thereby the climate for knowledge transfer:

(8) "She [home manager] has this attitude of "we shouldn't be seen having people like this in our home". People support her in that... Whereas, the other one [home manager] is 'well we have difficult people here and we find ways of coping with it'. And some of the staff won't like it, but there is a kind of 'see what you can do we have got to cope with these people'. So if you have got an attitude like that you will take some of the staff with you on that." (Psychologist linking with care homes, England)

As part of professional cultures any perceived (and enacted) professional hierarchy between specialists and generalists builds barriers to cooperation and knowledge transfer. This is also the case between biomedical and psychiatric or geriatric specialists, as reported from general hospitals, where specialist psychiatric or geriatric expertise is not always welcomed or appreciated by staff on general wards. Within the medical professions, geriatric and mental health professionals are more likely to have a perspective and position somewhere between medical and social models, and often more sympathetic with social models than their biomedical colleagues:

(9) "Especially the organ specialists are very busy in their specialty; they are not very interested in the patient as a human being in her care environment ... The junior doctors are inclined to use sedatives rather than to search for understanding, a full blow right away - and then the lady doesn't eat and drink anymore, but she's quiet." (Clinical geriatrician, The Netherlands)

Thus, organisational cultures in hospitals were often described as dominated by hightech biomedical medicine, with geriatric and psychiatric perspectives in a Cinderella position - sometimes to the disadvantage of dementia patients. In this respect it is clear that professional and organisational cultures interact closely with domain perceptions, to which we now turn.

\subsubsection{Domain consensus}

In determining the level of consensus on knowledge transfer in a particular setting the following questions were pertinent:

- Have specialists adopted knowledge transfer as an integral part of their remit, or do they define it as additional burden detracting from their core task, namely patient care? 
- Do generalists perceive it as necessary and desirable to enhance their competence regarding dementia care?

The answers were partly dependent on a third question:

Do both parties define comprehensive care outcomes as a common responsibility which allows them to define common goals - or do they stick to 'their' more narrowly defined task within a comprehensive care pathway?

A broad domain perception, defining care outcomes and the approaches to achieve them in a comprehensive manner, thus strengthened the motivation to engage in knowledge transfer, as illustrated by a geriatrician referring to knowledge transfer with her junior doctors:

(10) "Physically I cannot see every patient, so I have to make sure that those who see them have a minimum of knowledge with which they look at the older person ... If I can just teach them that the old person isn't dense, horrible and disgusting but a nice human being with his own history and background, and with his own problems which can be solved, and that it is very rewarding to deliver quality of life, then l've achieved a lot." (Clinical geriatrician, The Netherlands)

Our findings related to these questions waried considerably across all kinds of settings. A lack of domain consensus affected the motivation to engage in knowledge transfer in different ways. In some settings generic services made clear what they wanted from specialists in respect of their work with people with dementia; while some specialists rejected such demands, referring to their more exclusive domain definition. Domain conflicts around knowledge transfer were sometimes linked with conflicts about resources. The following example illustrates a domain conflict and the interaction of questions about domain with those of resources, mutual trust and respect and continuity of cooperation.

Example. This conflict was between a local CMHT in England and some generic health and social services wanting a mentall health inpult. Mental health specialists defined the more complex cases as their domain, and asked the generic services to build up the competences to deal with 'average' dementia cases themselves.

(11) "What continually comes back from social services is 'you're the expects you need to teach us'. And to some of that I would agree, but I think they should take the responsibility to buy it from somewhere and be consistent with it." (Mental health specialist) 
(12) "And that a lot of the people you want us to see actually have got dementia, there is not a lot about it. What you are wanting to do is offload it on to us and it is not necessary our problem'." (Mental health specialist addressing the intermediate care service)

For their part generalist staff regarded such views as dismissive and unwarranted, and the existing cooperation as insufficient:

(13) "The CPNs [community psychiatric nurses] work at this sort of much higher level ... so when we ask about something about somebody's forgetfulness, it is a bit low on their list really... and they probably think 'what are these guys doing here?' But well, what we need is training about and the understanding of a person's perception with the mental illness and how that evolves so that we can enable them to function at home really..... The other teams have got somebody named who actually links in with them. We never know whom we are getting. We have a review on a weekly basis, ... but it is whoever turns up at the door." (Intermediate care professional)

In other situations specialists saw knowledge transfer as clear part of their remit, but spoke of the negative reactions of some generalist counterparts, in the sense that the latter were disinclined to broaden the scope of their approach towards dementia care; they often seemed to want people with dementia referred or transferred elsewhere. This was reported to occur in all kinds of generic settings - primary and acute care, home care and care homes ${ }^{5}$.

(14) "I think by the time people with challenging behaviours are referred to us very often the management of the home just wants us to say that we should be looking after this person and take them away." (Psychiatrist, England)

(15) "It used to happen in the hospital. It used to be that what people want is a take-away service, they don't want you to go and say 'give this person an anti-depressant and let's them recover from their depression whilst you are giving them psychotherapy for their fractured hip. They actually want you to remove them." (Psychiatrist, England)

In a different way domain consensus was also missing, when generic services regarded possible specialist input as an unnecessary interference into their domain - as was reported e.g. from dementia units in residential homes in The Netherlands:

- As well as positive examples were reported for all kind of settings 
(16) "We give an enormous stimulus for quality to the residential homes; they get insight in dementia. But in general I perceive an attitude that actually they know it already - overestimate their quality of care. Patientorientation is alien in residential homes. Thus, they label it differently, say 'Oh we can do that by ourselves, we just need a doctor to sign for the official registration." (Nursing home psychologist linking to residential homes, The Netherlands)

Sometimes there was domain consensus about cooperation in general, but not about knowledge transfer - specialists then tried to stimulate innovative care approaches in a very diplomatic manner, almost 'undercover' loral communication, community mental health professional, The Netherlands).

More positively there were examples of the potential of flexible domain negotiations between specialists and generalists, based on shared definitions of need. A district nurse reported the following cooperation and knowledge transfer between a dementia case management service and home care:

(17) "If the case managers deals with a district nurse with less experience, they will just be present and coach her a little bit, how she could approach the coordination and other things. ... They could also say, we just take over, but if the district nurse wants to learn how to deal with dementia, the case manager will try to involve her. ... And they [nurses] like to broaden their scope." (District nurse, The Netherlands)

Unsurprisingly, specified liaison services ${ }^{6}$ expressed few domain uncertainties regarding knowledge transfer, since it was defined and adopted as one of their central tasks. They also seemed to accept more readily the existing competences in generic staff as their starting point - and were less inclined than their colleagues to criticise the competences of generic staff. Interestingly, however, those specialists who expressed general respect for generic staff also reported few negative responses from generalists. A cautious conclusion would be, that, on the specialist side, a combination of respect and a positive approach to knowledge transfer, might lesson the defensiveness of generalist staff. The interaction between domain perceptions and mutual attitudes becomes obvious here again, as reflected also by Carrier and Kendlall:

"[Inter-professional] collaboration implies the sharing of knowledge; respect for individual autonomy of different professional groups and administrators;

*n our localities, three specified liaison services existed: a small specialist old age psychiatric liaison service offering consultation and treatment in general hospital wards; a link liailson nurse service specifically for care homes, both in Leeds; and a dementia case management scheme in Amsterdam. 
the surrender of professional territory where necessary; and a shared set of values concerning appropriate responses to shared definitions of need" (Carrier \& Kendall, 1995, p 18).

\subsubsection{Perceived dependency}

As one interviewee said clearly:

(18) "You can't do it alone. You do need the physiotherapist, the occupational therapist and the dietist, and you need the nurse with a bit more awareness and knowledge of older people in order to help them going home better." (Clinical geriatrician, hospital, The Netherlands)

The quote illustrates how perceptions of interdependence are facilitated by a broad domain definition - embracing comprehensive care outcomes rather than sticking to the delivery of one's own more narrowly defined responsibilities.

For the topic of knowledge transfer, generic staff perceived themselves as dependent - and thus more willing to cooperate - if they saw the specialists' input as advantageous or even indispensable to achieve good quality of care; which was in turn supported by the sort of attitude to problem-seeking and solving mentioned above.

(19) "It was very clear that nurses knew they didn't know what to do, but they didn't know how to get help. Recently we have identified problems with ... dealing with people with dementia and delirium. Particularly when the wards are under-staffed as they often are. So I don't have to tell them that there is a problem, they are sort of begging for help." (Psychiatrist, Old Age psychiatric Liaison Service in general hospital, England)

On the specialist side, perceptions of their dependency on generic services develloped from a combination of broad domain definitions and their view about the efficient use of their own scarce resources (cf. also 10):

(20) "I'm a social geriatrician. ... My goal is to work for this population. And cooperation is also about to treat just those you can treat, and to enable other people to do the other things." (Social geriatrician in a comparably small RIAGG team, The Netherlands)

In this way, perceived dependency influenced the motivation for knowledge transfer as well as the perceived capacity to deliver the respective services. Scarce resources (see below), producing efficiency pressures, can sharpen the awareness of interdependency, and thus stimulate the investment of resources in knowledge transfer. 


\subsubsection{Resources}

A general scarcity of resources, which limited opportunities for knowledge transfer, was sometimes said to affect staff motivation, as they found the quality of care suffering:

(21) "The unit feels to fail, everybody is aware about that. We have some clinical lessons with the psychologist, and discuss some topics with the RIAGG, where they [staff] can express their difficulties, but ... for me it's very disturbing, that everything is so scarce in general." (Unit manager day care, The Netherlands)

If specialist services have to invest part of their resources - mainly staff time - to provide knowledge transfer to generic services, the availability of such resources is vital:

(22) "I have no problems anywhere any time or place going to somebody and explaining the principles of dementia care and what we try and do. ... The only problem I do have is the time restraints on me, and what I am expected to do as a unit manager plus all the other responsibilities I have obviously, there are restrictions on my time. So to me it should be logical that somewhere there should be somebody a bit higher than me deciding that yes we will put this package of development and education to this area'." (Mental health professional, England)

But generic services also have to invest resources, initially staff time for learning. Additionally they have to evaluate whether enhanced competencies would make their work more efficient and effective:

(23) "If you steer somebody with less competence about dementia to this situation, then you can screw it up, you loose what you've built up slowly. and you can't continue with that." (Home care manager, The Netherlands)

Or whether, on the contrary, changed care approaches would demand even more staff time (cf. 24). Amongst some specialists, the investment of resources was considered to be cost-efficient and cost-effective, by enabling generic services to deliver higher quality care, prevent crises and decline and thereby reduce specialist servicest workload (cf. 20).

In summary, if resources for knowledge transfer were not included in a service from the outset, it was a matter of the organisation's general evaluation of the efficient use of their resources, how they perceived their capacity to invest in knowledge transfer. 
Finally, issues of resources interacted with domain perceptions and organisational and professional attitudes amongst both specialists and generalists, as one psychiatrist's point about knowledge transfer in relation to care homes illustrates:

(24) "I think it is an area that we have pushed away because if we were to get into it and do anything meaningful, it will be very very time consuming and we don't have that sort of time. Because ... to actually bring about and maintain that attitude and then that behaviour in response to particular challenging behaviours is not an easy thing to do... So its just not happening at that sort of level, it should be, but it isn't. We are not working together with them, we are responding to cries for help and the cry for help is often for medication. And it is often difficult to see what else you can do given their resources. Now if it is a residential home with 20 residents and one member of night staff and they have got somebody who won't sleep, what they want is a sleeping tablet. They don't want to know that its okay if you make them a cup of tea and talk to them, because how can they do that when they have got 19 people to help to the toilet." (Old Age Psychiatrist, England)

\subsubsection{Continuity}

In facilitating trusting personal relationships, continuity was seen as essential for successful knowledge transfer.

(25) "So we have actually got a link nurse system for each GP practice, the health nurses go to the practice meetings ...they see each other face-to-face, which I think is always better. Over the years our CPNs have remained in post so they have been doing the job quite a long time; the relationships have developed and the GPs are confident in the skills of the CPNs." (Clinical manager mental health, England)"

Personal continuity of specialist input, in this way, was generally perceived to require an organisational base, related to explicit task definitions, and thereby to domain clarity:

(26) "I think people [CPNs] do try to give them support; but its clearly a stretched kind of support, because it isn't built into a system and its not built into their working day that they should give them support. So it's very much on demand and ad hoc. ... It's not sufficiently structured in my view to be good "(Home care manager, Englland)

Indeed, continuous specialist input seemed to contribute to an increasing quality of knowledge transfer over time, stimulating a culture of problem-seeking and solving: 
(27) "Seven years ago, there was no time, no space for this at all, I just came for fire-fighting. Which is not the good way of working - ... but this way people happened to discover how it works. ... And they became prepared to invest in influencing [challenging] behaviour rather than to ask me to solve their problems." (Psychologist linking with residential homes, The Netherlands)

On the other hand, discontinuity amongst generic staff could make knowledge transfer seem a Sisyphean task:

(28) "I've proposed to build geriatric work groups on the wards. Sometimes it happens, but within one year it waters down because of continuous staff turnover. And you cannot get everybody interested, it's a tiring process." (Geriatric nurse, hospital, The Netherlands)

(29) "It's a pity, sometimes you see a lot of staff turnover. And you become tired because of that, because you have to invest anew again. Where there is more continuity - influenced by the residential home itself - you see the changes. But that takes years." (Psychologist linking with residential homes, The Netherlands)

Thus, based on the motivation and perceived capacity for knowledge transfer, personal and organisational continuity as a process quality was seen to contribute decisively to success or failure - and also to influence organisational features, especially mutual attitudes and, thereby, the motivation to engage in or sustain knowledge transfer.

\subsection{Discussion AND CONCLUSIONS}

This study has dealt with knowledge transfer in dementia care, focussing on the organisational and team level. It was based on data from four locality-based case studies in England and The Netherlands.

Broadly speaking, our findings confirm what we posited on the basis of our general theoretical starting points: that professional and organisational culture, domain consensus, perceived dependency and resources, as conceptualised for this study, influence the motivation and perceived capacities of specialist and generic teams or organisations to engage successfully in knowledge transfer. Furthermore, personall and organisational continuity was confirmed by our findings as an important process quality for knowledge transfer. 
1681 Chapter 6

\subsubsection{Building a conceptual model: knowledge transfer performance in dementia care}

There were more specific findings: Very importantly, not only domain consensus, but a broad domain perception regarding dementia care seemed essential for the requisite motivation and perceived capacity of participating organisations for knowledge transfer. If both parties agreed on comprehensive dementia care outcomes, and perceived their different tasks as contributing to common goals, the motivation for knowledge transfer was enhanced; moreover this seemed to interact positively with the respective cultures and attitudes, the perceived dependency and the view of the efficient use of resources, and thereby also to influence the perceived capacity for knowledge transfer. Obviously, in situations, where knowledge transfer was explicitly defined as the task of a specialist team or service, a broad and shared domain definition was more likely to exist. Conflicting domain perceptions, on the other hand, were at the heart of reported failures. Issues of professional domain and culture, as reported elsewhere, built barriers to cooperation and knowledge transfer in several cases; there was, however, also some evidence of the awareness and competence to overcome these barriers, so that efforts to implement cooperation and knowledge transferin dementia care seemed already to have led to some success.

With respect to organisational and professional culture, trust was essentially complemented by respect. The emphasis on respect - which is rarely mentioned in general studies on inter-organisational cooperation and knowledge transfer - might be explained partly by the existence of professional cultures in health care with a fallacy of professional exclusiveness. The latter is often cited as a barrier to successful cooperation and knowledge transfer (Beveren, 2003; Hudson, 2002), in large part because of the lack of mutual respect. As well as trust and respect, a culture of problemseeking and solving in generic services seemed to act simultaneously as a motivational base for knowledge transfer, and as an outcome of successful knowledge transfer. One other influential aspect of culture referred to was leadership style.

Mutual dependency was not a priori obvious for most of the teams and organisations, since their primary tasks - the delivery of specific health or social care services to a certain population - were defined separately rather than commonly. The perception of interdependency, which is conducive to knowledge transfer, tended to emerge from a broader perspective incorporated within the cultural attitudes and domain definitions developed in organisations. This in turn contributed to both the motivation and the perceived capacity to engage seriously in knowledge transfer.

The perspective on resources had to be widened. It is not the amount of available resources per se, but rather the evaluation of their most efficient use (related again to 
domain definitions and perceived dependency), which was decisive in determining whether organisational capacity was perceived to exist and was provided for knowledge transter.

In contributing to successful processes of knowledge transter - facilitating increasing quality, and thereby promoting sustainability - personal and organisational contimuity were seen as an important mediating factor between performance and outcomes. Continuty underlines the importance of time for processes of cooperation and knowledge transfer.

In general, it became apparent that the organisational features influencing the motivation and perceived capacity for knowledge transfer, and personal and organisational continuity (as a process characteristic) could be explored separately; but they essen. tially influence each other, as indicated in the conceptual model:

Figure 6.1: Knowledge transfer in dementia care: A model suggesting factors influencing performance

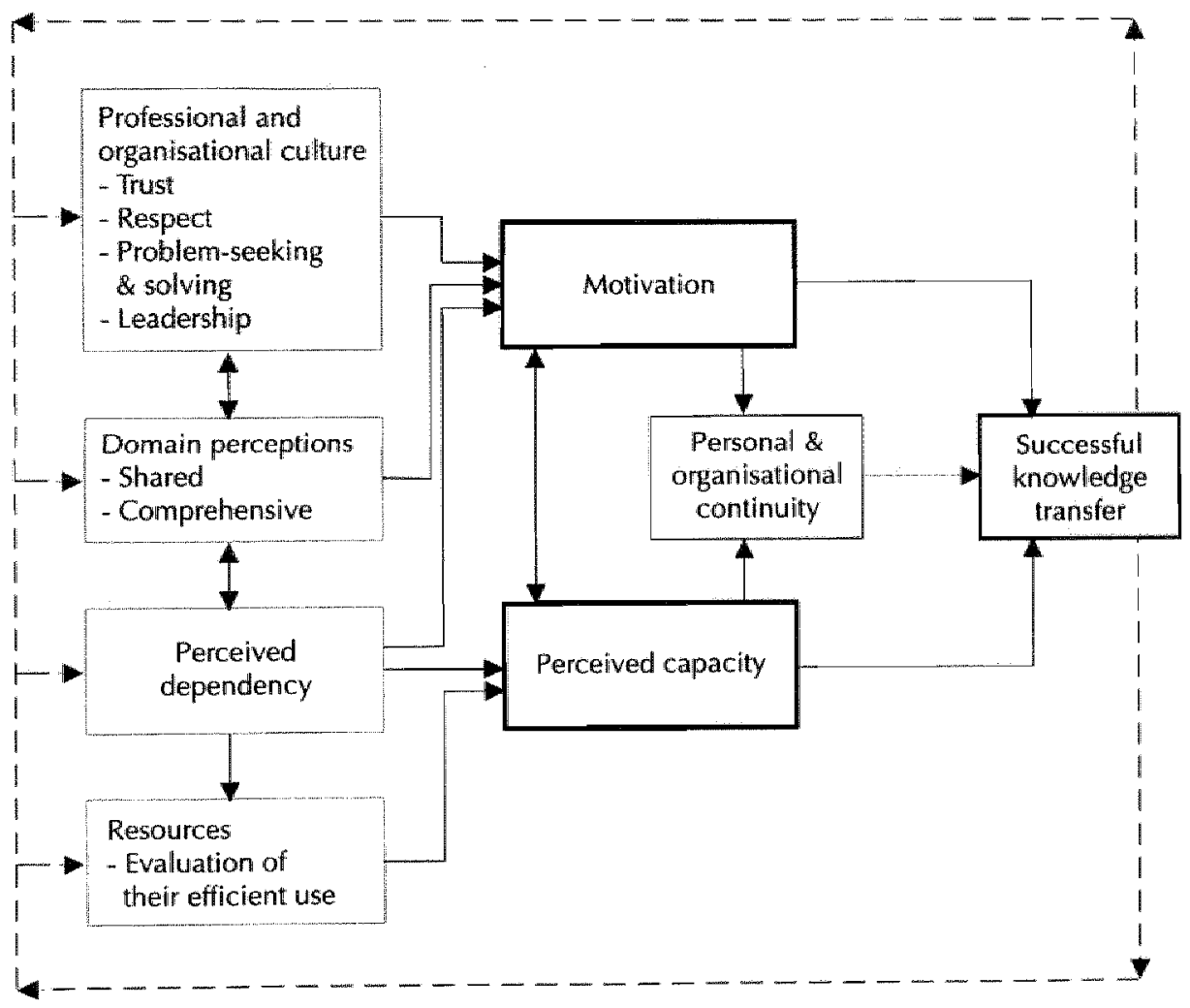


The arrows in the figure indicate only the principal directions of influence, as discussed above. There are probably more. The dotted arrows indicate additional positive or negative feedback loops or 'mutual causality', as conceptualised by cybernetics and new system theory approaches (cf. Morgan, 1986), which caution against clear-cut cause and effect relationships.

\subsubsection{Generalisation}

It is worth raising some questions about the generalisation of our findings.

Our fieldwork data are limited to dementia care settings in four localities in England and The Netherlands. Therefore we cannot be certain how far our findings typify other localities in the two countries, or other localities in other countries. However, the correspondence of our findings with the literature on inter-organisational networks and knowledge management, as outlined above, indicates some potential for generalisation to dementia care in other localities.

Another question arises whether our findings could be valid also for fields of care other than dementia. Except for some specific characteristics of the professional groups involved, the matters discussed here do not seem to be bound exclusively to dementia care. Therefore, knowledge transfer efforts beyond dementia care could, we would argue, benefit from a cautious consideration of the findings presented in this paper.

For this study we took an intra- and inter-organisational viewpoint focusing on those professionals and care workers directly involved with knowledge transfer. It could be argued that we did not investigate specifically the national and local political contexts of or the management perspective within the health and social care settings that operated the processes of knowledge transfer described by our interviewees. However, the consequences of these external contexts appeared to be incorporated naturally in these settings. Some of these issues, pointing to the wider context of knowledge transfer in dementia care, were indicated by our interviewees: e.g. the general low levels of pay in sociall care, which could affect a general willingness to engage in more sophisticated care approaches without feeling properly rewarded; a potential insight in senior hospital managers calculating knowledge transfer as efficient in reducing costs emerging from sub-optimal care; or an ongoing tendency to concentrate mental health services on very complex cases without providing them with the means to engage in knowledge transfer to generic services. Further detailed research is needed in such areas. 
Additionally, it has to be emphasised, though it is beyond the scope of this article, that knowledge transfer in dementia care needs to happen between professionals and patients and carers.

\subsubsection{A useful model?}

Based on our findings, the suggested conceptual model has been shown to have some capacity to describe and explain organisational and inter-organisational features and processes contributing to the relative success and failure of knowledge transfer in dementia care. It can be used for further research on knowledge transter in dementia care, in order to be extended and refined with respect to each element of the model (and their interaction), to improve our understanding of knowledge transfer performance. The model could also provide a starting point to investigate knowledge transfer in other areas of health and social care.

With its simple structure it might be useful as an analytical guide for managers and participants of knowledge transfer processes in dementia care, in order to help to analyse, understand and negotiate knowledge transfer in practice, indicating the difficulties and opportunities, and thereby helping to create beneficial solutions in what are inherently complex and difficult settings.

\section{ACKNOWLEDGEMENTS}

We would like to thank all those who facilitated the fieldwork in Amsterdam Nieuw West, Leeds West, Maastricht and York by helping to map the local context, giving interviews, allowing to attend their meetings, and providing documents. We want to thank the Netherlands Organization for Scientific Research (NWO) for the financial support of the fieldwark in England.

\section{REFERENCES}

Alaszewski AM, Billings I \& Coxon K. 2004. Integrated health and social care for older persons: theoretical and conceptual issues. In Providing integrated health and social care for older persons. A European Overview of issues at stake, Leichsenring $K_{\text {, }}$ Alaszewski AM (eds); Ashgate, Aldershot; 53-94.

Alter C \& Hage J. 1993. Organizations working together. Sage: Newbury Park.

Alzheimer Nederland. 2001a. Handleiding Alzheimer Café Unstruction Alzheimer Café) Alzheimer Nederland: Bunnik, The Netherlands. 
Alzheimer Nederland. 2001b. Hulp bij dementie (Help with dementia). Stichting Alzheimer Nederland: Utrecht, The Netherlands.

Alzheimer's Society. 2000. What's the Society's position on ...? Alzheimer's. Dementia care \& research: London, UK.

Audit Commission. 2000. Forget me not. Mental health services for older people. National Report. Audit Commission publications: London, UK.

Audit Commission. 2002a. Forget me not 2002. Developing mental health services for older people in England. Audit Commission Publications: Wetherby, UK.

Audit Commission. 2002b. Integrated services for older people. Building a whole system approach in England. Audit Commission for local authorities and the National Health Service in England \& Wales: London.

Ballard C, Fossey I, Chithramohan R, Howard R, Burns A, Thompson P, Tadros C \& Fairbairn A. 2001. Quality of care in private sector and NHS facilities for people with dementia: cross sectional survey. British Medical Journal 323: 426-427.

Ballard C, Powell I, James I, Reichelt $K$, NMyint P, Potkins D, Bannister $C$, Lana M, Howard R, O'Brien J, Swann A, Robinson D, Shrimanker I \& Barber R. 2002. Can psychiatric liaison reduce neuroleptic use and reduce health service utilization for dementia patients residing in care facilities. International Journal of Geriatric Psychiatry 17: 140-145.

Barringer BR \& Harrison IS. 2000. Walking a tightrope: creating value through interorganizational relationships. Journal of Management 26: 367-403.

Benson JK. 1975. The interorganizational network as a political economy. Administrative Science Quarterly 20: 229-249.

Beveren Jv. 2003. Does health care for knowledge management? Journal of Knowledge Management 7: 90-95.

Bond 1. 2001. Sociological perspectives. In A handbook of dementia care, Cantley C (ed): Open University Press, Buckingham, Philadelphia; 44-6\#.

Cameron K. 2000. CarenapD (Care needs assessment pack for dementia). A manual to inform care management practice. Dementia Services Development Centre, University of Stirling: Stirling, UK.

Carrier I \& Kendall 1. 1995. Professionalism and interprofessionalism in health and community care: some theoretical issues. In Interprofessional issues in community and primary health care, Owens P, Carrier J, Horder J (eds); Macmillan, Houndmills; 9-36.

Challis D, Reilly $S$, Hughes J, Burns A, Gilchrist H \& Wilson K. 2002. Policy, organisation and practice of specialist old age psychiatry in England. International Journal of Geriatric Psychiatry 17: 1018-1026. 
Collinson $Y$ \& Benbow SM. 1998. The role of an old age psychiaty consultation liaison nurse. International Journal of Geriatric Psychiatry 13: 159-163.

Cox S, Anderson I, Dick S \& Elgar 1. 1998. The person, the community and dementia. Deweloping a value framework. Dementia Services Development Centre: Stirling “ UK.

Crouch J. 1997. The missing link. Nursing Times 93: 57.

Davenport TH \& Prusak L. 1998. Working knowledge. How organizations manage what they know. Harvard University Press: Boston.

De Vault ML \& McCoy L. 2002. Institutional Ethnography. Using interviews to investigate ruling relations. In Handbook of Interview Research. Context and Method, Gubrium JF, Holstein IA (eds); Sage, Thousand Oaks; 751-776.

Department of Health. 2001. National Service Framework for Older People. Department of Health: London, UK.

EACH. 1997a. Examples of good practice in the continum of care. Report and findings, European Alzheimer Clearing House, accessed 20.02.2001: "www.each.be.

EACH. 1997b. Standards of good practice, European Alzheimer Clearing House, accessed 20.02.2001: www.each.be.

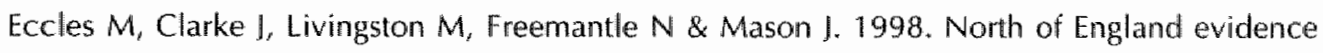
based guidelines development project: guideline for the primary care management of dementia. British Medical Journal 317: 802-808.

Engellhard-Salari MAT. 1995. RIAGG-Ouderenzorg. Inventariserend onderzoek naar het hulpaanbod, de ontwikkeling wan programma's en circuitworming in de RUAGGOuderenzorg (Community mental health care for older people. An inventory of services, pathways and coordination. Nederlandse Vereniging voor Ambulante Geestelijke Gezondheidszorg (Dutch Association for Community Mental Health Care): Utrecht, The Netherlands.

Furnish 5. 2002. Services for people with dementia and their carers: an EU perspective. In Alzheimer's disease. Policy and practice across Europe, Wamer M, Fumish S, Longley M. Lawlor B (eds); Radcliffe Medical Press, Oxan; 89-134.

Gezondheidsraad. 2002. Dementie. Advies van een commissie van de gezondheidsrad (Dementia. Advice by a committee of the Health Council). Gezondheidsraad (Health Council of the Netherlands). Publication no. 2002/04: Den Haag, The Netherlands.

Godfrey M, Brian H \& Wistow G. 2003. Situation in England. In Integrated care in Europe. Description and comparison of integrated care in six EU countries, van Raak $\mathrm{A} A$, Mur-Veeman I, Hardy B, Steenbergen M, Paulus A (eds); Elsevier, Maarssen; 145-167.

Goh SC. 2002. Managing effective knowledge transfer : an integrative rramework and some practice implications. Journal of Knowledge Management 6: 23-30. 
Gróne O \& Garcia-Barbero M. 2001. Integrated Care. A position paper of the WHO European office for integrated health care services. International Journal of Integrated Care 1 : WWw ijic.org.

Herbert G. 1997a. Sharing the caring: Leaming together. A rewiew of services for alder people with mental health problems in North Yorkshire and the City of York. Nuifield Institute for Health: Leeds.

Herbert G. 1997b. Which hat should we wear today? Recruiting and developing the ideal workforce for clementia care. In State of the art in dementia care, Marshall M led); Centre for Policy on Ageing, London; 111-115.

Hollmes 1. 2001. A proposal for the establishment of a multidisciplinary Hospital Mental Health Team for Older People. An innovative and assessment and intervention service for older people presenting with psychiatric illness in the general hospital setting. Leeds Community and Mental Health Trust: Leeds.

Holmes 1. Bentley K \& Cameron 1. 2002. Between two stools: Psychiatric services for older people in general hospitals. Repont of an UK survey. University of Leeds: Leeds, UK.

Holmes J, Bentley K \& Cameron I. 2003. A UK survey of psychiatric services for older people in general hospitals. International Journal or Geriatric Psychiatry 18: 716-721.

Hout Hv, Vernooij-Dassen M, Bakker $K$. Blom M \& Grol R. 2000. General practitioners on dementia: tasks, practices and obstacles. Patient Education and Counseling 39: 219. 225.

Hudson B. 2002. Interprofessionality in health and social care: the Achilles' heel of partnership? Journal of Interprofessional Care 16:7-17.

Hudson B, Hardy B, Henwood M \& Wistow C. 1999. In pursuit of inter-agency collaboration in the public sector. What is the contribution of theory and research? Public Management 1: $235-260$.

lliffe S, Walters K \& Rait G. 2000 . Shortcomings in the diagnosis and management of dementia in primary care: towards an educational strategy. Aging \& Mental Health 4: 286-291.

Johnson P, Wistow G, Schulz R \& Hardy B. 2003. Interagency and interprofessiona! collaboration in community care: the interdependence of structures and values. Journal of interprofessional Care 17: 70-83.

Kerr S \& Slocum JR. 1981. Controlling the performances of people in organizations. In Handbook of organizational design, Nystrom PC, Starbuck WH (eds); Oxford University Press, New York.

Kickert WJM \& Koppenjan JFM. 1997. Public management and network management: An overview. In Managing complex networks. Strategies for the public sector, Klijn $\mathrm{E}_{\text {. }}$ Koppenjan IFM, Kickert W.I.M. (eds); Sage, London; 35-60. 
Kitwood T. 1997. Personhood, dementia and dementia care. In Dementia: challenges and new directions, Hunter S (ed); Jessica Kingsley Publishers, London, UK; $9-23$.

Kodner DL \& Spreeuwenberg C. 2002. Integrated care: Meaning, logic applications and implications: A discussion paper. International loumal of Integrated Care 2: wwwijic.org.

Koning CC. 1994. Ziekenhuis schiet te kort bij bejaarde patiënten (Hospitals fail with respect to older peolel. Tijdschrift voor Verpleegkundigen 16: 489-492.

Kümpers S, van Raak AIA, Hardy B \& Mur-Veeman 1. 2002. The influences of institutions and culture on heath policies: different approaches to integrated care in England and the Netherlands. Public Administration 80: 339-358.

Kümpers, S. Mur, 1., Maarse, H., \& Raak, A. J. A. v. (forthcoming). Understanding similarities and differences in dementia care in England and The Netherlands: A qualitative comparative study using neo-institutionalist perspectives. Qualitative Health Research

Lang JC. 2004. Social context and social capital as enablers of knowledge integration. Journal of Knowledge Management 8: 89-105.

Loughlan C. 2003/2004. Learning needs in health and social care in England. The NHISU Learning Needs Observatory. eurohealth 9: 33-37.

Manthorpe 1, lliffe S \& Eden A. 2003. Early recognition of dementia by nurses. Joumal of Advanced Nursing 44: 183-191.

Marshall M. 1999. "They should not really be here"-people with dementia in the acute sector. Age and Ageing 28:9-11.

Marshall M. 2001. The challenge of looking after people with dementia. British Medical joumal $323: 410411$.

Miesen BML \& lones GMM (eds). 1997. Care-giving in dementia. Research and applications. (Vol. 2). Roulledge: London, New Yortk.

Mijs AA. 1989. Ontstaan en levensvatbaarheid van interorganisationele verbanden (Development and sustainability of inter-organisational networks). Sociologische Gids $1: 48-61$.

Mildenberger U. 1997. Selbstorganisation von Produktionsnetzwerken. Erklärungsansätze auf Basis der neweren Systemtheorie (Self organisation of production networks. Explanatory approaches based on the new systems theory. Deutscher Universitätsverlag: Wiesbaden.

Miles MB \& Huberman AM. 1994. Qualitative data analysis. An expanded sourcebook. Sage: Thowsand Oaks.

Modernisation Agency. 2003. Changing Workforce Programme. Pilot Sites Progress Report Spring 2003, NHS, accessed 06.07.2004: ww. modern.nhs.uk/cwp. 
Morgan G. 1986. Images of organizations. Sage: Thousand Oaks.

Nationale Raad woor de Volksgezondheid. 1994. Psychogeriatrie: zorg voor dementerenden 2. (Psychogeriatrics: Care for people with dementia 2). Nationale Raad voor de Volksgezondheid (Nationall Councill for Public Health): Zoetermeer, The Netherlands.

Nederlands Huisartsen Genootschap. 1998. Dementie M21. NHG-Standaarden Dementia. Standards or the Dutch Association of General Practitioners), accessed 11.04.2001: Www artsen.net/data/custom/nhg/standaarden/M21/kop.htm.

Nies H, Linschoten Pv, Plaisier A \& Romijn C. 2003. Networks as regional structures for collaboration in integrated care for older people, International Journal of integrated Care and World Health Organization European Office for Integrated Health Care Services: Internalional Conference on New Research and Developments in Integrated Care, 21-22 February 2003: Institute for Health Studies, Barcelona, Spain, www.ijic.org/portal/index.htiml.

Nooteboom B. 2002. Trust. Forms, foundations, functions, failures and figures. Edward Elgar: Cheltenham.

Rhodes RAW. 1997. Understanding governance. Policy networks, governance, reflexivity and accountability. Open University Press: Buckingham.

Sichein E. 1985. Organizational culture and leadership. Jossey-Bass: San Francisco.

Scott WR. 1992. Organisations: Rational, natural and open systems. Prentice Hall: Englewood Cliffs.

Sheard D \& Cox 5 (eds). 1998. Teams, multidisciplinary and interororessional working and demenia. Dementia Services Development Centre, University of Stirling: Stirling, UK.

Slaets J, Kauffmann R. Duivenvoorden $\mathrm{H}_{*}$ Pelemans W \& Schudel W. 1997. A randomized trial of geriatric liaison intervention in elderly medical inpatients. Psychosomatic Medicine 59: $585-591$.

Strässer H \& Cofone M. 2000. Innovativer Umgang mit Dementen. Strategien, Konzepte und Einrichtungen in Europa (Innovative approaches to people with dementia. Strategies, concepts and services in Europel. Demenz-Verein Saarlouis e.V.; Landkreis Saarlouis: Leitstelle "Alter werden": Sararlouis, Germany.

Syed $/$ khsan SOS \& Rowland F. 2004. Knowledge management in a public organization: a study on the relationship between organizational elements and the performance of knowledge transter. Journal of Knowledge Management 8: 95-111.

Train GH, Livingston G \& Manela M. 2001. Addressing the needs of carers of older people: the Islington study. International Journal of Geriatric Psychiatry 17: 85 86.

Tummore $R$ \& Thomas $\mathbb{B}$. 1992. Models of psychiatric consultation liaison nursing. British Journal of Nursing 1: 447-450. 
ZonMw. 2004. Van kennisvermeerdering tot implementatie from knowledge increase to implementation), ZonMw (Netherlands Organisation for Health Research and Development), accessed 06.07.2004: http://www.zonmw.nl/index.asp?s $=4544$. 
178| Chapter 6 


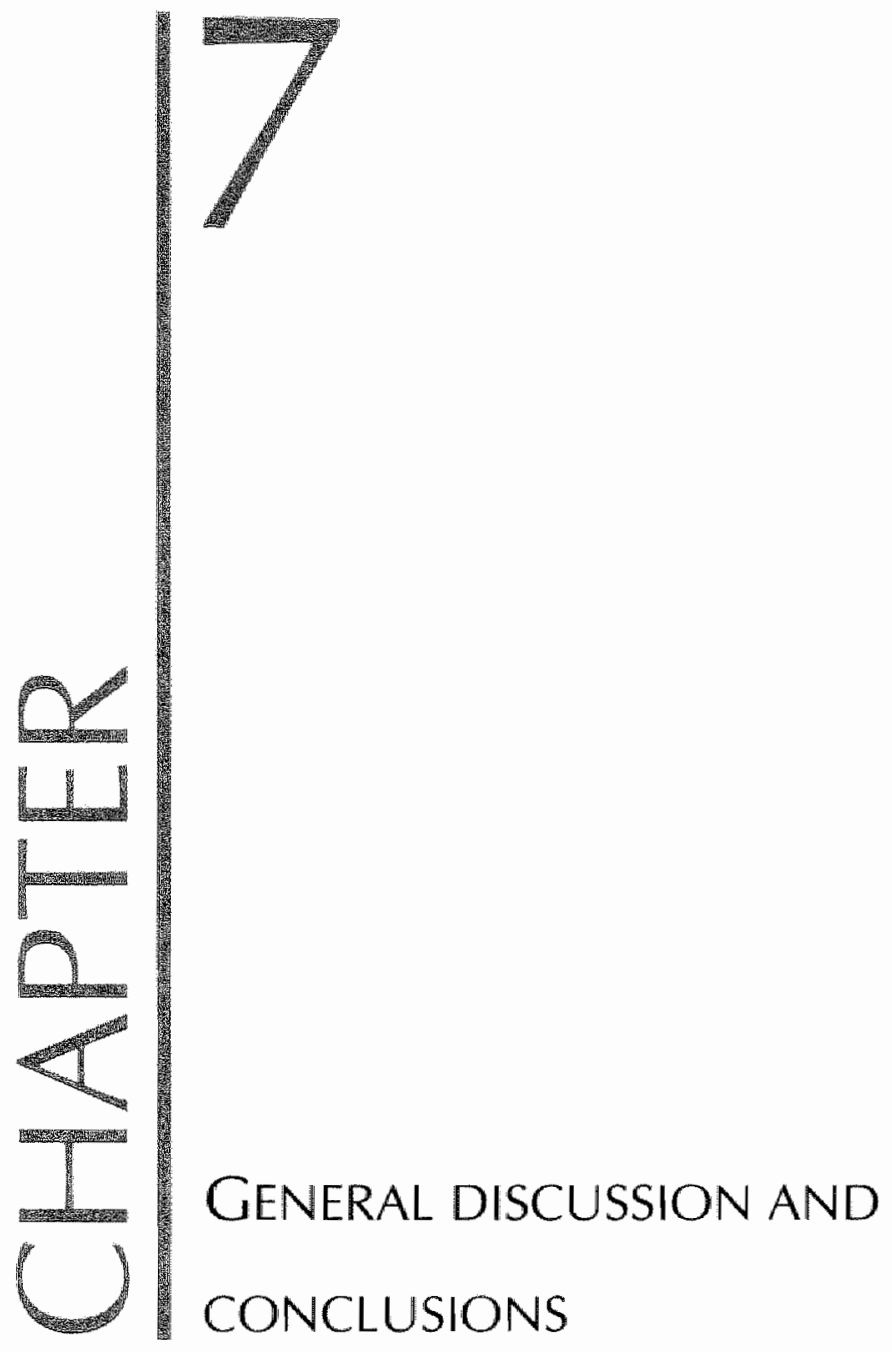


$180 \mid$ Chapter 7 


\subsection{INTRODUCTION}

This research has aimed at understanding the steering processes relevant to the success and failure of integrated care development and delivery, specifically involving dementia care, at national and local level. It has used a comparative approach, involving England and The Netherlands as national cases, and Maastricht and York, Leeds West and Amsterdam Nieuw West as local cases. The principal research questions were as follows:

- How can national steering processes and outcomes for integrated care in England and The Netherlands be described and understood as being shaped by national configurations? (Chapter 3)

- How can similarities and differences in dementia care in England and The Netherlands be described and understood as being shaped by these specific national configurations or by generic patterns? (Chapter 4)

- How can local configurations and their interaction with national configurations be described and understood as shaping local steering processes regarding integrated dementia care? How can variations within and across countries be understood? (Chapter 5)

- How can local (governance, managerial and professional) steering processes and outcomes for integrated dementia care be described and understood as shaped by national and local configurations or generic patterns? (Chapter 5 and 6)

- What conclusions can be drawn from these analyses for successful steering processes for integrated (dementia) care and their required conditions? (Chapter 3 , $4,5,6$ and 7 )

Concepts of neo-institutionalism thave been used as a framework for the questions studied during this research. Neo-institutionalists have developed broad, far-reaching but also diverging statements about the significance of institutions for policy processes, the relation between institutions and actors, the issue of institutional endurance and change, and the characteristics of steering processes. For this thesis, institutions were defined broadly as encompassing formal and informal constraints, and differentiated as institutional structure and culture. Steering was defined as the interactive processes by which governmental and other relevant actors influence each other to maintain or change rules of action. Several general propositions, elaborated in Chapter 2, were taken as the starting point for the study. They can be summarised here as follows:

- Institutions matter for policy development and implementation. Institutions are differentiated here as institutional structure and culture. 
- National, sectoral or local sets of institutions are framed as configurations that shape the respective actors" scope in policy development and implementation, thus steering opportunities.

- Institutional configurations give shape to steering processes, which therefore are 'path dependent' to some degree.

- Institutions can be seen as being in a tension between endurance and change.

- Institutions shape actors and their preferences, but actors also are to some degree independent of institutions, and create and shape them.

- Institutions are not monolithic but varied and complex, and facilitate multiple and therefore to some degree independent - preferences and perspectives of actors.

- Steering is a principle function of political systems with respect to other systems. Steering processes are not linear and easily predictable, but complex and difficult, and influenced by institutional configurations.

- The concepts of hierarchy, market and network, described as institutionalised modes of governance, provide a useful perspective to describe and understand steering processes.

- The network form is related to the concept of integrated care in terms of the latter being a complex issue.

During the research process, these propositions have been developed and specified for the specific areas and questions of the study. To further develop propositions has involved identifying those institutional structural and cultural features, which essentially give shape to the respective field, and to explore and understand how they impact on the processes and outcomes in question. This has involved a cumulative and iterative process of developing - and progressively deepening - research questions and answers.

The topic of integrated dementia care was addressed by four analyses from different starting points, the findings and conclusions of which are described in detail in the previous chapters but summarised below.

Subsequently, an analytical framework is outlined developed that could be used as a diagnostic instrument for analysing steering situations regarding integrated dementia care. For this purpose, the findings and conclusions are turned into questions. This framework should aid strategy development by policy-makers or managers as well as further research about steering of integrated dementia care. It can be used across a range of countries and localities, and other fields of care where integration is sought. Lastly, the potential and limitations of the research process are discussed to put the overall results into perspective, and to reflect not only on the validity and completeness of the analytical framework but future research strategies. 


\subsection{AN OVERVIEW OF THE RESEARCH RESUITS}

The next section gives an overview of the research project. For each stage of analysis, as described in Chapters 3 to 7 , the main topics are repeated, and a figure is presented to give an overview of the scope and the elements of the respective analyses. In the figures, processes are indicated by oval forms. The arrows show the lines of influence as mainly dealt with in the analyses reported; they are not assumed to completely depict all influences. As explained in Chapter 2, influences here are not statistically confirmed causal relations, but propositions about connections as generated through the interpretive process of analysis, and as depicted thoroughly in the narratives, discussions and conclusions within the Chapters above. For each chapter the most important findings are restated. Moreover, the propositions generated from the analyses are presented in a summarised manner, to offer an overview of the results of this thesis.

\subsubsection{National steering processes regarding integrated care}

The first approach, as described in Chapter 3, analysed in general national governance processes regarding integrated care in England and The Netherlands and their outcomes. This comprised an overview of the central political developments in the field under study in the two countries during the 1990s, together with an exploration of the political successes and failures in respect of integrated care. This gave some insight into the specific national approaches required to facilitate local network processes for integrated care. On a more abstract level, a generalised understanding of the relation between characteristics of a national configuration, the respective modes of governance and the specific form of steering processes with respect to integrated care was facilitated. The field of study in this first stage with the essential elements of the analysis are shown in Figure 7.1.

\section{Findings}

The following section outlines the principal findings.

England is characterised by the strong role of central government (single-actor system) in relation to other actors, which are mainly statutory services. With strong hierarchical powers, the government can implement major structural changes. Government policies promoted networks 'in the shadow of hierarchy', with the networks facilitated by both the 'statutory duty to cooperate' and by incentives. Actors in health and social services were used to top-down "command and control", but they expected these instructions to reflect a public service ethos. At the beginning of the 1990s the implementation of market mechanisms had failed to achieve widespread commitment within the services, thereby contributing to the failure of policies pro- 
moting integrated care. In general, a higher capability for politically induced change became obvious; this, however, involved the danger of excessively radical changes not only failing to achieve commitment but damaging social capital.

\section{Figure 7.1: National steering processes regarding integrated care.}

(Oval forms indicate processes; hatched lines indicate feedback processes)



The Netherlands are characterised as a consensus democracy (multiple-actor system), comprising a weaker role for central government in relation to other semiindependent actors (insurers and providers, mainly non-for-profit) and a greater and more longstanding mix of market and network structures as part of policy making. Skilful negotiation is required by government for the successful introduction and implementation of incremental changes. Network-building is stimulated by incentives. 
In this study, independent actors saw the shaping and creating of the care sector as their responsibility. Government attempts to implement a top-down blueprint-plan for a major restructuring of the health and social care system failed in the early 1990 s. There was potential for incremental changes, which could be fine-tuned to complex situations and which left existing networks largely unchanged. The government had to regulate the sector and safeguard public interests. The commitment of the independent actors was divided between public and self interests. The capacity to achieve necessary changes was sometimes lacking; the changes remained partly fragmented.

\section{Propositions}

- Characteristics of a national configuration, its institutional structure and culture as influencing successful steering of integrated care

- Governmental roles differ between countries, specific to each configuration, as do those of other actors relevant for integrated care, and the relations between them. The policy style - the institutionalised political culture, e.g. comprising the mutual expectations of actors - is intertwined with the structurall features of the configuration. If the performance of institutionalised governmental roles does not correspond with the expectations of other relevant actors, this will complicate processes of policy implementation.

- The institutionalised mix of governance modes (i.e. hierarchy, market and network) inherent to a configuration is important for success or failure of steering processes regarding integrated care. This refers to the path dependency of steering processes.

\section{- Policy processes relevant to steering of integrated care}

- The shape of change processes is configuration-specific and pathdependent. Configurations appear to have their specific potential and weaknesses for steering integrated care. In order to be successful, such steering strategies need to consider these configurational features.

- The capacity to implement change is not equivalent to successful steering; changes can involve unintended consequences.

- Steering failures and successes provide policy feedback and can facilitate policy learning. The analysis of steering processes and their outcomes as associated with the configuration renders insights about promising steering strategies for integrated care.

- Modes of governance are bound within the institutional configuration; there is no universal standard for the steering of integrated care. Nevertheless, enabling integrated care requires space and support for network processes at local level. 
- Network-building for integrated care at local level can be facilitated and supported by setting favourable conditions for cooperative and flexible decision-making among semi-autonomous actors

- by making cooperation obligatory;

- by facilitating the commitment of actors;

- by setting sufficient and appropriate incentives for integrated care in general;

- by balancing competitive incentives sufficiently by cooperative ones; and

- by facilitating continuity.

For successful steering, the selection and combination of these instruments have to take account of the configurational characteristics.

- A more extended use of hierarchy by government is associated with a lower autonomy of local actors for processes of network-building, whereas a greater role for market mechanisms corresponds with a higher degree of local actors' autonomy. Neither is basically superior; again it depends on the fit with the configuration, which strategy is possible and most appropriate.

- Networks operating with some continuity can be understood as the social capital of integrated care. This means that steering strategies to implement changes for integrated care should build on the capacity of existing structures and relations as far as possible in order to prevent disruptions to existing networks and the negative consequences of such disruption.

\subsubsection{Integrated dementia care standards and mainstream care}

The second analytical step (Chapter 4) brought into perspective the normative aspect - the recommended standards of dementia care, and their implications for integrated care. These standards were translated to account of best practice of dementia care pathways. This account was then contrasted with the reality of mainstream care, which appeared to be similar in each country. This was followed by an analysis of the institutional contexts of the widespread gaps between standards and reality. Next, the subtle but significant cross-national differences in the operationalisation of standlards and typical dementia care pathways were elaborated and explained as manifestations of national institutional structural and cultural characteristics. The elements of the analysis as elaborated in this second stage are shown in Figure 7.2. 
Figure 7.2: Influences on integrated dementia care practice

(Oval forms indicate processes; hatched lines indicate feedback processes)

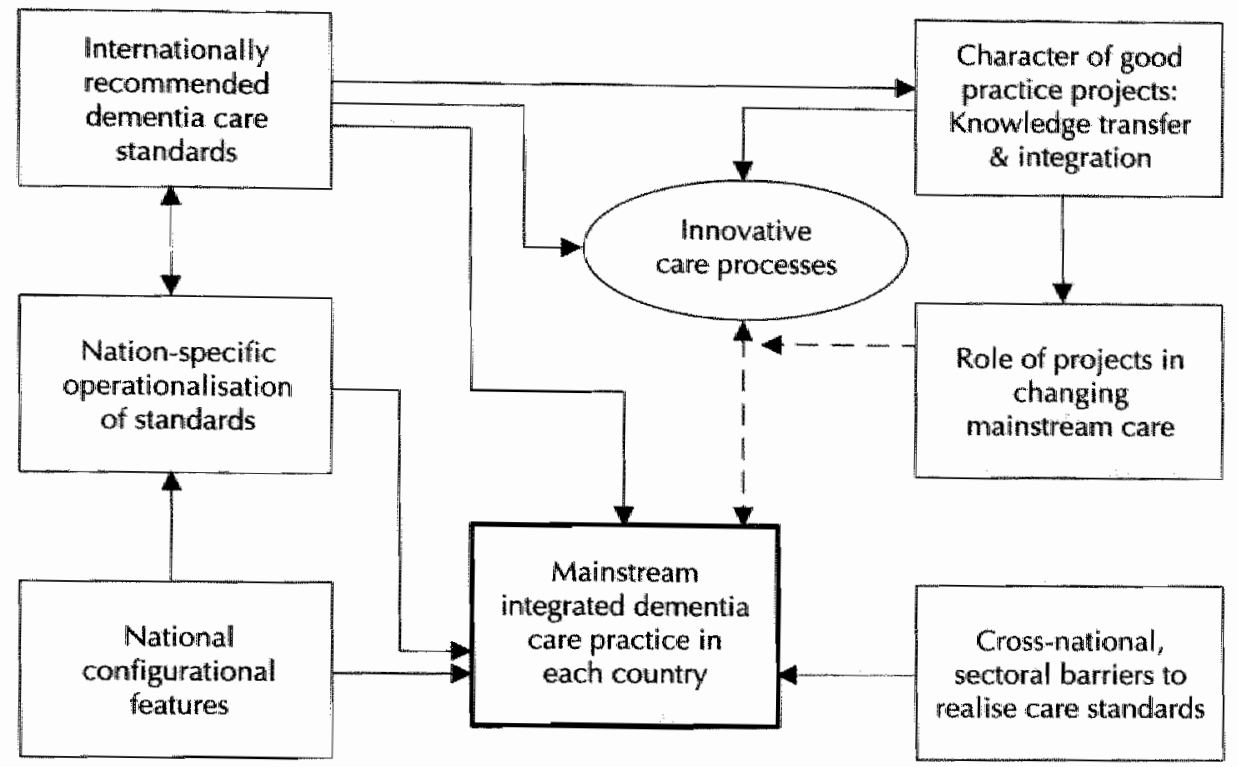

\section{Findings}

The nomative standards of dementia care correspond widely internationally, as indeed they do between England and The Netherlands. These standards have been changing during the last 15 years and increasingly following a social model of care. Significant gaps were reported between standards and reported mainstream practice both in England and The Netherlands, especially in generic services delivering health and social care for people with dementia. They appeared as problems of quality and competence within the services and integration between them.

Underneath the broad correspondence of standards, configuration-specific operationalisations of the 'sociall model' were found in England and The Netherlands. Im England there was a strong focus on independence for vulnerable people, including those with dementia. This combined with a strong priority of non-institutional community care over institutional care', and with widespread negative attitudes towards institutional provision. The latter might have contributed to weaknesses in the integration of service development and delivery of institutional care and to the low provision rates, which again increased the emphasis and pressure on community care. Voluntary services played a major role. These features correspond with the philloso-

1 'Institutional care' means long-term care in residential and nursing homes; the term is not related to the neo-institutional theoretical framework. 
phies of a liberal welfare state. In The Netherlands the historically high level of institutional care - based on societal views about old age and the welfare state - and the significant influence of nursing home professionals' perspectives shaped dementia care pathways in general, and were reinforced by a still wide-spread societal taboo on dementia. The focus was on 'caring for', rather than empowering or enabling people with dementia themselves - caring with. Thus, as compared with England, services in The Netherlands seemed relatively paternalistic. The higher rate of institutional provision exerted less pressure on community care to enable patients and carers to cope at home.

\section{Propositions}

- Similarities: Standards and mainstream practice

- Changing standards for integrated dementia care increase the gap between standards and practice. They enhance the need for innovations in health and social care to adapt the services. Gaps between standards (social modell) and reported mainstream integrated dementia care practice - in both countries - can be explained by interacting structural and cultural barriers; notably the (bio-) medical professional culture, traditional care models in social care, and efficiency pressures through marketisation processes.

- Sectoral institutional characteristics act in both countries as barriers to realise innovative care standards.

\section{- Highlighting differences between countries}

- National configurational characteristics, comprising the welfare state models that exist in each country, but also other historical developments, are associated with cross-national differences in dementia care pathways. For example, as differences in views about issues of autonomy, especially of the dementia patient; in patterns in service provision; in the role and importance of voluntary services and charities; in the balance between community and institutional care provision; in attitudes towards institutional care; and the integration of of institutional care service planning.

- National configurational contexts restrict certain aspects of service development while supporting others. In so doing, they demonstrate the path dependency of the adoption and implementation of care models.

- Both the similar shortcomings in dementia care pathways, and the differences between the profiles of those pathways are partly explained by interacting sectoral or national cultural and structural institutions.

\section{- About change}

- If innovative projects do not lay emphasis on knowledge transfer and integration between generic and specialist services they cannot handle the 
widespread problems of quality and competence in dementia care, since generic services will probably continue to deliver the bulk of services.

\subsubsection{Steering integrated dementia care at local level}

The third stage of the study used the perspectives gained from the first two stages as a background to explore in more detail steering processes for integrated dementia care at local level, as elaborated in Chapter 5. Four localities were selected, in which inventories of local cooperation processes for integrated dementia care development and delivery were made and analysed. An account was given of the respective local story', the narrative, for each of the cases reflecting the intertwined threads of local culture and history, of national governance efforts mediated through specific national-local relations, and of local steering efforts and initiatives. The elements of this third stage analysis are shown in Figure 7.3.

\section{Findings}

England and The Netherlands differed with respect to the degree of central hierarchical power and local autonomy. In England, national policy interventions were more strict and detailed compared to The Netherlands.

Nationally imposed restructurings (more common in England) threatened to interrupt and delay cooperation at the local level, depending on their fit with local configurations (i.e. correspondence of proposed elements with local institutions). The national introduction of new agencies (such as PCTs in England or RIOs in The Netherlands) to existing local power balances required time for them to develop competence and capacity to perform their role.

Variations among local outcomes regarding integrated dementia care in Leeds West, York, Maastricht and Amsterdam Nieuw West were found to emerge from the specific interactions between the national and lacal configurations and steering processes. Each site had a particular history and current situation of cooperation for integrated dementia care. Longstanding local conflicts inhibiting cooperation and integrated care could be explained by such local configuration features as domain perceptions, organisational and professional attitudes, resource conflicts, and effects of restructurings. Conflicts seemed more open to resolution in the big cities with their more flexible and overlapping networks.

Findings in each of the local case study sites confirmed the essential role of specialist mental health services in developing high quality dementia services. The local shape of integrated dementia care pathways relied on multiple factors; e.g. the progress in early support for dementia patients and carers was influenced by the national-local interaction (more prescriptive in England), the size of cities (more developed in large 
cities), national policies regarding $\mathrm{ChEl}$, and specific local service profiles and cooperation patterns.

Figure 7.3: Analysis of local steering processes and integrated dementia care outcomes (Oval forms indicate processes)

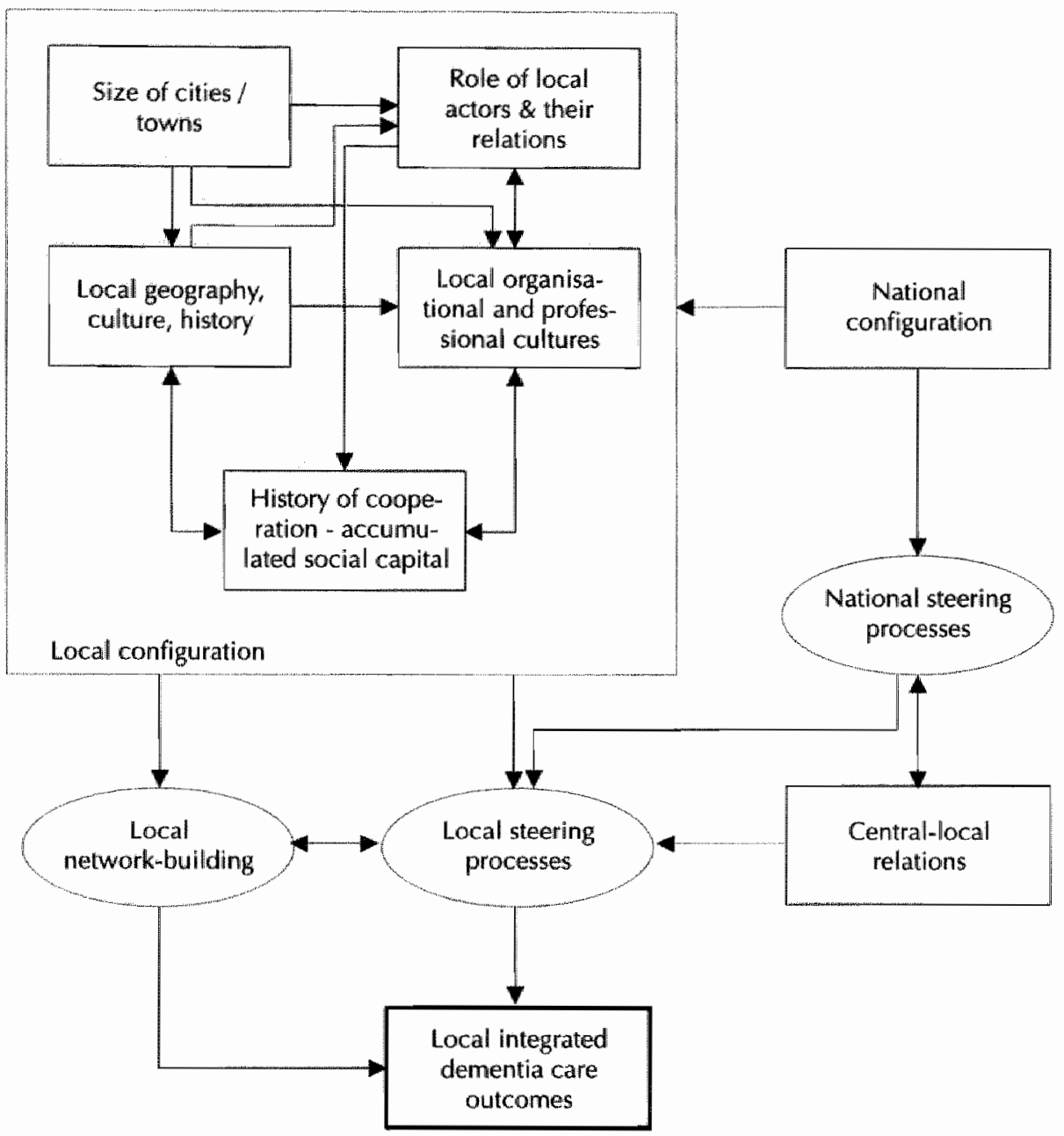

\section{Propositions}

- National - local interactions of steering processes

- Central-local relations in general differ between countries because of their national institutional configuration. The steering of networks thus can be embedded in different mixes of governance modes, i.e. in different central- 
local relationships, with network patterns combined with elements of hierarchical and market mechanisms.

- Successful local network-building processes require continuity of people and domains, commitment of local actors, compatibility of actors' interests over time, and the balancing of competitive by cooperative incentives. Therefore the change of these relationships, e.g. by the introduction of new actors, can only be accomplished successfully by allowing time for institutionalisation.

- Longstanding local power relationships, historically developed, influence the introduction and embedding of new local actors, their capacity building and their standing.

- If they are not careful designed, nationally imposed restructurings tend to lead to unintended consequences at local level, disturbing and destroying existing networks (the social capital of integrated care), and thereby hindering the successful implementation of policies aimed at integrated care.

\section{- Local configurations and steering processes for integrated dementia care}

- The concept of local institutional configuration has proved valuable for the analysis of steering processes regarding integrated care and their local outcomes. The analysis of local configurations can help to explain local variations and prevent failures of national policies.

- Localities affect the outcomes of steering processes for integrated dementia care.

- The particularities of a local configuration, which influence steering of integrated care, are explained by several aspects of structure and culture, historically developed: local traditions, established service structures and domains, political and organisational histories and preferences, and specific issues in the past or present associated with personal and professional agency.

- Local configurations are not just integrated parts or products of national configurations, but entities on their own, which develop in interaction with the national configuration and national steering processes.

- The course of local steering processes, implementing national policies at local level, can be regarded as locally path dependent.

- The size of cities appears to matter.

- The two larger cities in this study (Leeds and Amsterdam) appeared to have configurational characteristics supportive of cooperation, conflict-resolution, and dealing with structural changes. Features such as 
the greater complexity and diversity of local health and social care systems (compared to those in medium-sized towns or cities) requires, and thus produces, more flexibility and openness, thereby promoting the capacity to handle conflicts and changes. (This proposition is made with great caution, since it contrasts a frequently made hypothesis that complexity invariably acts as a barrier to cooperative networks).

\section{- Dementia care pathways}

- Cooperation and knowledge transfer between specialists and generalists are required to integrate dementia care successfully.

\subsubsection{Knowledge transfer between specialists and generalists in integrated de- mentia care}

The fourth analyticall stage used local data gained in the third stage in a generallised way. Empirical results from the second and third stage had highlighted the issue of knowledge transfer between specialists and generalists in dementia care as an essential part of cooperation for integrated dementia care, and as being extremely important for good dementia care. Thus, in Chapter 6 the micro-level of inter-professional cooperation and knowledge transfer was analysed to identify and conceptualise the organisational circumstances for success and failure at this level. The analysis has provided knowledge which is of use for those responsible for steering the integration of dementia care at managerial and professional level. Figure 7.4 shows the essential elements of this analysis.

\section{Findings}

Knowledge transfer was found to happen within different service models (e.g. as an outreach function from a specialist team to generic services, or between connected specialist and generic teams). The nature of the models themselves did not appear to be decisive for success and failure. Certain characteristics at organisational and interorganisational level - such as professional and organisational culture, domain perceptions, perceived dependency and resources - were found to have an effect not only on the motivation and perceived capacity to engage in processes of knowledge transfer but on their outcomes. This was the view of specialists as well as generalists. From the detailed findings as described in Chapter 6, the following propositions were generated. 
Figure 7.4: Factors influencing success of knowledge transfer in dementia care

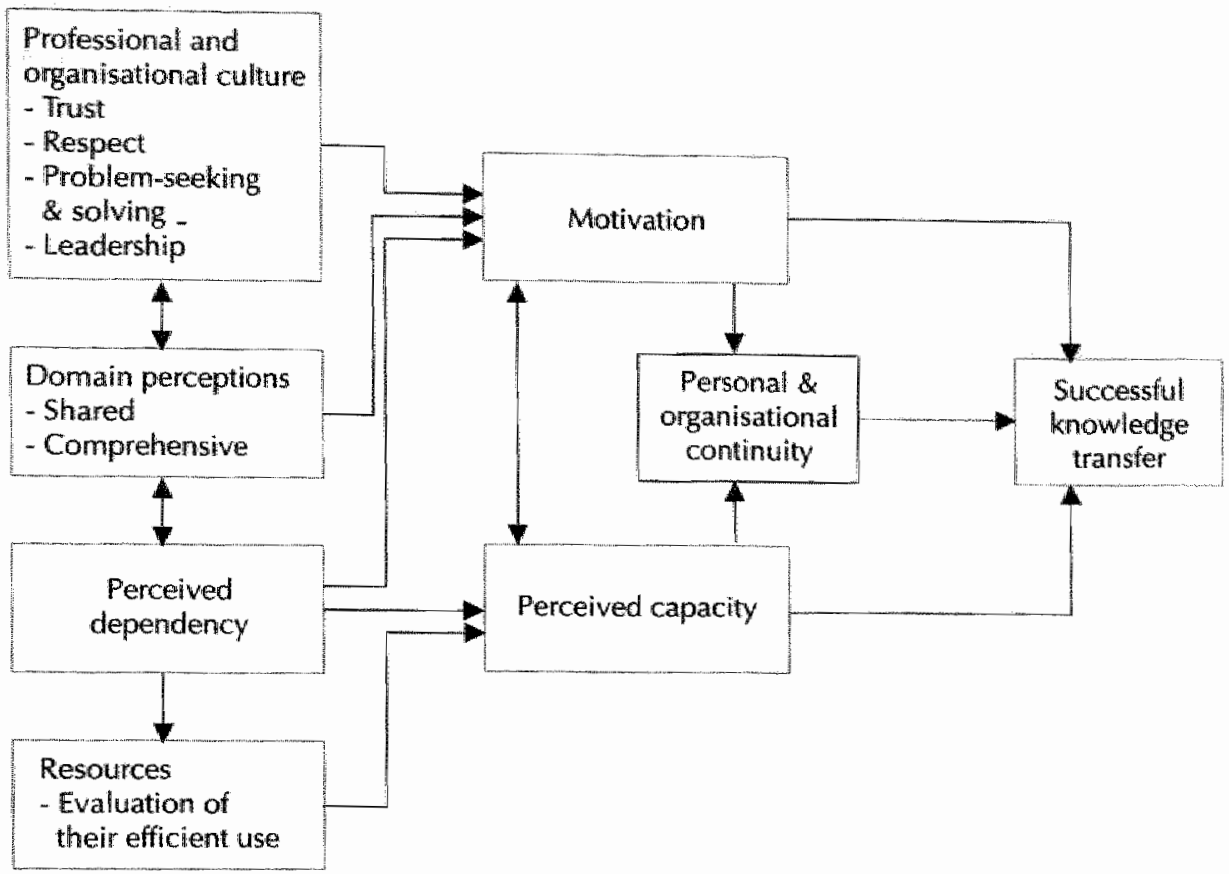

\section{Propositions}

- Characteristics at organisational and inter-organisational level associated with success or failure of knowledge transfer at local level

- At organisational level, the characteristics outlined below are associated with successful knowledge transfer between specialists and generalists in dementia care. Although the configurational environment influences these characteristics, they can be described independently and cross-nationally.

- Professional and organisational culture, domain consensus, perceived dependency and resources, influence the motivation and perceived capacities of specialist and generic teams or organisations to engage successfully in knowledge transfer.

- Especially supportive for the motivation and perceived capacity for knowledge transfer are broad domain perceptions (shared views about comprehensive dementia care outcomes). Narrow or even conflicting domain perceptions, on the other hand, are at the heart of failures. Issues of professional and organisational domain and culture often build barriers to cooperation and knowledge transfer. 
- An organisational and professional culture relying on mutual trust and respect, a problem-seeking and problem-solving attitude, and leadership supportive to learning and cooperation promotes the motivation and perceived capacity for knowledge transfer.

- Perceived mutual dependency is essential. It tends to emerge from a broader perspective incorporated within the cultural attitudes and domain definitions developed in organisations.

- It is not the amount of available resources per se, but rather the evaluation of their most efficient use trelated again to domain definitions and perceived dependencyl, which is decisive in determining whether organisational capacity is perceived to exisit and is provided for knowledge transter.

- Personal and organisational continuity mediate between motivation and perceived capacity and outcomes. The impact of continuity underlines the importance of time for processes of cooperation and knowledge transfer.

- The organisational features affecting the motivation and perceived capacity for knowledge transter, and personal and organisational continuity las a process characteristic), essentially influence each other.

\subsection{TURNING ANSWERS INTO QUESTIONS: A FRAMEWORK FOR THE ANALYSIS OF STEERING PROCESSES OF INTEGRATED DEMENTIA CARE}

After recapitulating the four stages of analysis performed for this thesis, Figure 7.5 shows the connections between all four stages of analysis by synthesizing their essential elements. The figure shows how the four stages have contributed to the understanding of the different categories of outcomes of steering processes related to integrated dementia care: the general perspective on integrated care outcomes at national level; the perspective on integrated dementia care outcomes at national level; and the specific outcomes for integrated dementia care at local level.

In the above paragraph, the findings generated in this study indicate the important elements of analysis and potential connections between them. In the following stage, findings and propositions are again turned into questions. Together these questions build an empirical and analytical framework that is intended as an instrument for investigating steering mechanisms and processes of use for policy-makers and researchers alike (see Appendix 7.1). The framework can assist in conceptualising future analyses of steering of integrated care, whether they focus on other countries, other localities or other fields of care. It is intended as a diagnostic instrument, indicating, for specified fields of study, which data to be collected and which empirical and analytical questions to be answered. However, for any research considering the 
use of this framework, a decision has to be taken about which parts and questions of the framework apply, and how it has to be augmented and adapted in terms of the particular research questions.

Figure 7.5: Overview - Connections between the elements of analysis from all research stages as contributing to integrated dementia care outcomes

(Oval forms indicate processes)

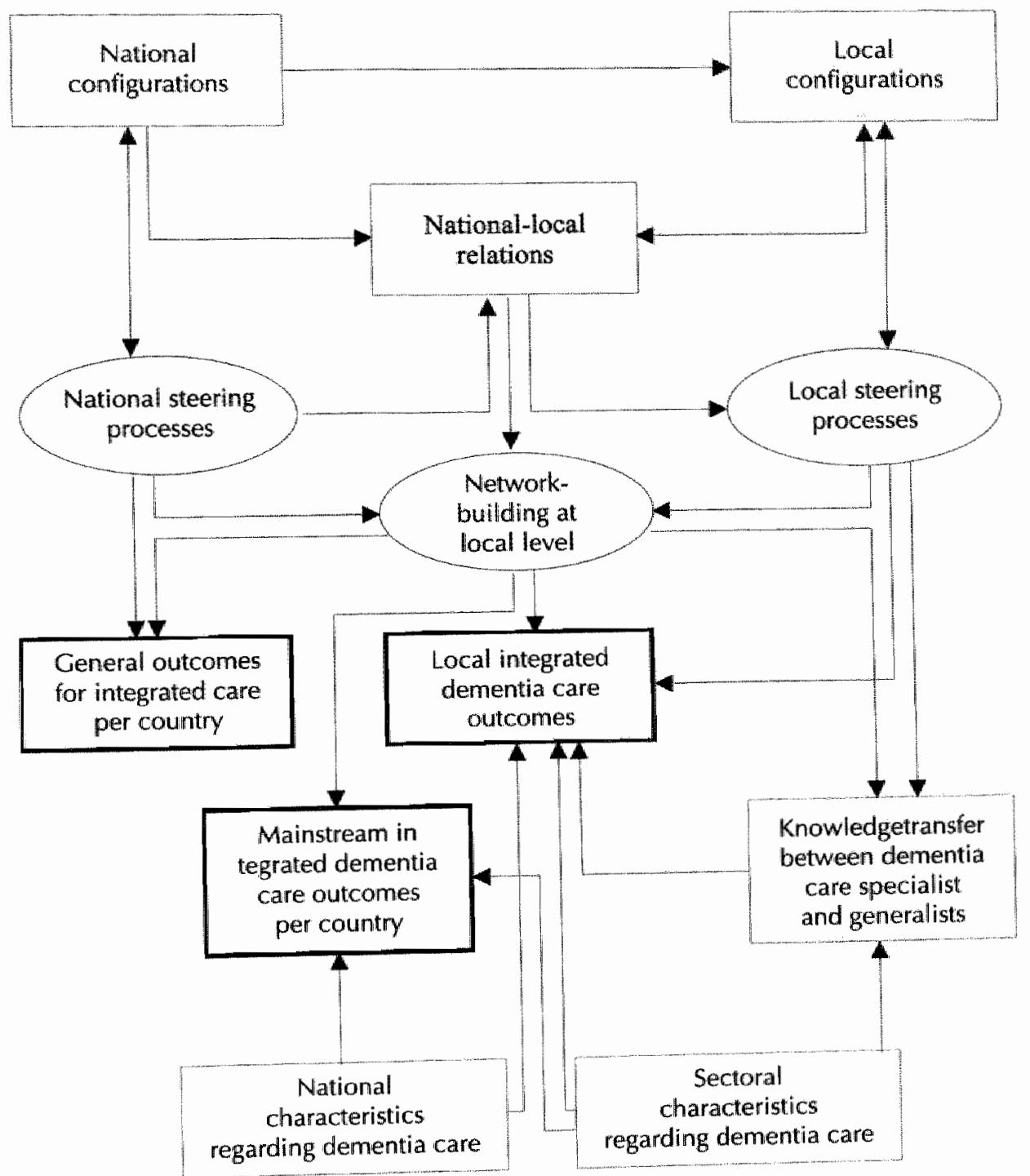


Each section of the framework results from one of the four subsequent stages of analysis.

- Section A can be used for expanded analyses of national governance processes at national level in England and The Netherlands; or guide analogous analyses in other countries.

- Section B can be used to guide an analysis of standards of dementia care pathways and mainstream care in other countries. It also can be translated to a (comparative) analysis of other fields of care where integrated care and innovative care are seen as required; for such purposes the questions need to be considered for their relevance to that topic.

- Section $C$ can be used to help prepare an analysis of local steering processes regarding integrated dementia care in other localities and/or in other countries. It also can be translated to a (comparative) analysis of local steering processes for other fields of care where integrated care is seen as needed, and problems of integration appear, 'prima facie', to be similar.

- Section D can be used to inform an analysis of the organisational circumstances associated with the success and failure of knowledge transfer between specialists and generalists in dementia care in other localities or in other countries. It also can be translated to an (comparative) analysis of knowledge transfer in other fields of care where integrated care is seen as needed.

Subsequently, when discussing the study as a whole, the validity and power of the developing framework also will be discussed.

\subsection{REFLECTIONS ON THE RESEARCH PROCESS - METHODOLOGICAL ISSUES}

The methodological decisions made for this research have shaped its analytical scope and capacity, as well as its limits. In Chapter 2, the methodological decisions were introduced and discussed. The following section returns to those decisions, about which questions have arisen during the research process.

First, the experience of acting as a sole researcher is discussed. Second, the consequences arising from the 'small $n$ ' in the research are considered. Third, the question of the 'verbal bias' is re-considered. Finally the consequences of an article-based dissertation for the process of analysis and writing are addressed.

\subsubsection{The absence of a real research team}

Although it is part of many PhD projects, it is worth noting that a supervisory board, even if working very well, cannot fully replace the interchange that takes place on a 
daily basis within a formal research team. My position as a foreigner in both countries under study surely helped avoid the danger of being (or going) native in one or the other country, and has promoted a meta-perspective on both. Moreover, a foreign researcher is allowed to ask all kinds of questions in most interview situations; since she/he is not expected to know and understand the context in depth. I found a considerable willingness on the side of interviewees to explain and illustrate their views, which helped to investigate their social constructions in-depth. On the other hand, a shared endeavour of natives and foreigners in the daily research process, providing more in-depth background knowledge ${ }^{2}$, could sometimes have allowed a deeper analysis and understanding than the intermittent exchange with the supervisory board could offer.

\subsubsection{Reflections on the 'small $n$ '}

In Chapter 2, some attention was given to a particular characteristic of comparative research, that it focuses primarily on the differences between the cases and might, therefore, mask those features which are similar among the cases and perceived as quasi-natural; and thus which do not emerge as significant phenomena either from the research perspective or from the field perspective. This holds, of course, especially for explorative studies such as this, for which the detailed points of comparative analysis have to be identified during the research process, and which cover a small number of cases.

The restriction to two national cases and four local cases has facilitated the thorough and detailed investigation and has yielded the richness of insights that was expected and intended. This decision therefore seems justified; and the national and local studies build a solid base for the comparative study of further cases.

However, my perspective as a German might illustrate also a limitation, arising from the small number of cases. From a German perspective, the large number of selfaware and highly professionalised nurses and therapists in influential positions, encountered during the fieldwork (on national as well as local level, in both England and The Netherlands) was striking. Experiences in German health and social services suggest a much greater distance between medics and non-medics in terms of their power. In England and The Netherlands, this was, in fact, not a point of discussion for

2 Of course, a systematic preparation for each stage of fieldwork took place, comprising the thorough study of documents and literature. This cannot be equated with the knowledge, insight and familiarity that a native researcher has to offer. On the other hand the native re. searcher might ignore or under-state phenomena that are picked up by a foreign researcher since researchers' perspectives too are influenced by institutions. 
the participants when they reflected on the circumstances promoting or inhibiting integrated care: the participation of non-medics was something seemingly taken for granted $^{3}$. Therefore, this 'phenomenon' did not become significant in the data collected. From an outside view, however, it seems nevertheless important, that in both England and The Netherlands the perspectives of nurses and therapists seemed to exert more influence in integrated care development and delivery than in Germany where medical doctors still dominate the debate about service development. Since Germany was not included as a comparative case, this situation could not serve as a formal reference frame for the analysis. This topic therefore has to be left for further research.

This example confirms an important methodological insight: every further case dissimilar to those under study with respect to particular characteristics - which might not always be known at the beginning - will augment the analytic picture arising from each case and enrich the cross-case analysis. Thus the analytical framework resulting from this research provides useful insights and new propositions but cannot claim to be complete.

\subsubsection{Reflecting the 'verbal bias'}

Chapter 2 discussed the 'verbal bias', referring to the ambiguous relation between language and action, which has to be considered especially in research designs relying primarily on textual data. It raises a question, which could not easily be solved within the methodology applied and would therefore remain unanswered during this study: whether there are national cultural patterns regarding the relation between words and actions. From peripheral observations during this study I detected different cultural patterns regarding the rhetorical and expressive style in the spoken as well as the written words, regarding the topics of research, within the two countries:

- In England, managers and professionals showed more passion, more commitment to a mission in talking about cooperation for integrated care and talking about integrated dementia care practice. Connected to this was a greater willingness to - sometimes sharp - criticism about their own as well as others' achievements, and evaluations turned quickly to the characterisation of practice as good or bad. Correspondingly, there were more often detailed evaluation documents praising or blaming the existent services and practice.

\footnotetext{
3. That does not mean that relations between doctors and others were not a point of discussion at all.
} 
- In The Netherlands, most people had a more business-like and matter-of-fact ${ }^{4}$ manner in speaking about cooperation for integrated care and integrated dementia care practice and the goals connected with it. There was more reservation in expressing ideals or missions, and also more reluctance to criticise their own or others' work. Correspondingly, documents were more vague, and provided less sharp criticism about existing services.

These styles could be attributed to national configurational characteristics as described especially in Chapter 3; however, the methodology chosen did not permit investigation of whether this difference in the use of language in both countries reflects particular aspects of steering processes, or of the daily practice of cooperation and integrated dementia care. Two important questions or propositions arise from these differences. First, whether Dutch agencies can cooperate more easily because the tendency to polarise seems to be less developed, and their capability to compromise therefore might be higher in comparison to England. Second, whether English services are perhaps more devoted to ideals and therefore more willing to cooperate for the sake of the users, since the mission behind the practice seems to play a bigger role in what is said and written. These questions cannot be answered unless the relation between language and action is made a central aspect of the research design.

Chapter 2 discussed the methodological approach to control for any 'verbal bias', as resulting from the predominantly text-based forms of data collection in this research, literature and document study, and interviews. Approaching the analysis of steering processes primarily by observation would have required the shadowing of key persons over months, and would have encountered probably even more serious problems of access, logistics and also other methodological problems. Therefore observation was no real option. As indicated above, this problem was addressed by triangulation within the sample of interviewees: to involve people from different angles and with different perspectives within the field. This strategy was able to reveal gaps between language and actions as perceived from the respective other actors within the field. It could not, however, reveal the eventual meaning of the above-described cultural patterns in written or spoken language for the processes in question. In this respect the relation between language and action could not be further investigated. Different kinds of cultural studies could perhaps render further insights regarding such topics.

"Interestingly, the Dutch word 'zakelijk' covers both the meanings of business-like and matter'of fact. 


\subsubsection{Writing up: consequences arising from the article-based format of the dis- sertation}

In The Netherlands, PhD dissertations are increasingly based on articles published in international scientific journals during the conduct of the research. This practice thas arisen against the background of the competitive pressure on universities to demonstrate their scientific worth, which is usually measured by counting publications in indexed journals. The pressure on universities is translated into a pressure on academic professionals so that, as supervisors of PhD processes, they have little choice but to adopt this form. This format has several advantages. The junior researcher has to structure his or her field in an early period of the research; a learning process is facilitated in dealing with the rules, procedures and agendas of scientific publication; the writing itself has to be focused and disciplined from the very beginning. However, for the sort of research as described in this thesis, there are also disadvantages. The administrative and llayout requirements of academic journals and the procedures involved of reviewing and re-writing are time-consuming and inevitably affect the time spend on the actual research activities. Furthermore, as described in Chapter 2 (par. 2.4.2.2), in qualitative research, analysis and writing are intertwined processes and develop alongside each other: "The analyst weaves several stories though a narrative style that then becomes wrapped up in an overall story." (Agranoff \& Radin, 1991, p. 206). This overall story is presented in thick descriptions, conveying extended and detailed narratives gained from the collected data, from which, step by step, more abstract lines of analysis are distilled. If the writing is focused on the production of articles, the central story - the main topic - has to be fixed earlier. Moreover, journals allow only limited space per article and require a consistent line of argumentation; which, of course, is a reasonable demand for a scientific journal. Finally, the perceived 'publicability' of central topics according to trends within the scientific community may have an influence on the researcher's decisions. Therefore, the analytical expedition through the extended data collected by explorative fieldwork, tracing main lines and sidelines as well, and the degree of freedom of the researcher in that process is partly restricted. As a consequence, the intertwined processes of analysis and writing become more streamlined and limited, and the researcher begins to think of the thesis not as a single, extended whole but as a series of separate - even if closely linked - chunks in article format. Of course, in every piece of writing decisions have to be made about which topics are central and traced further; also, a classical thick description cannot explore every sideline attracting the researcher's attention. In this respect the article-based approach entails a relative rather than an absolute restriction. 
During this research topics came up and were dealt with as subtopics in the articles presented in this thesis, which seem suitable to further exploration and analysis using the collated data. They can be understood as 'unwritten articles'. One topic is about the cultural differences between dementia care standards and practices in England and The Netherlands, which were analysed during the second stage of the research (cf. Chapter 4). Investigation of the data collected in the third stage on this topic would have allowed a deeper analysis; exploring attitudes within the services and their consequences for patients and carers in more detail, and analysing their institutional background. Second, central-local relations were dealt with to some degree within Chapter 5. Making central-local relationship (in each case and comparatively) a main line of analysis could render deeper insights into this important steering topic. These topics have in fact become subjects of analysis, but their deeper investigation was postponed or left in favour of the main topics selected for the articles elaborated. However, the above consideration do not invalidate the presented results, even if the collated data might have been utilised more creatively and with more choices within a different frormat of writing.

\subsubsection{Concluding remarks}

The above methodological discussion does not suggest major omissions or failures that essentially challenge the validity of the results. It is, however, important to bear in mind that this research cannot claim to have generated a complete picture in answering the research questions - which seems legitimate considering the explorative design. Of course, extensions of this research could have contributed to a greater richness of the findings and propositions, and thus of the proposed analytical framework - as further research also can do.

\subsection{OPTIONS FOR FUTURE RESEARCH}

First, as outlined above, an extension of national cases seems desirable. Cuermany as a possible case has been mentioned since it is assumed to provide different characteristics at least with respect to the profiessionalisation of nurses and therapists, which, it has been suggested, is important for the development of integrated care. Moreover, Germany is a country where integrated care has entered the policy agenda more recently compared to England and The Netherlands. Correspondingly, one general strategy for further theoretical sampling - covering more of the variety existing within Europe - could include Denmark or Sweden or another of the Scandinavian countries, which are often mentioned as progressive, and in a contrast, a South European country. In the latter the health care system is still strongly oriented towards tradi- 
tional medicial care, and social care primarily left to family carers, as e.g. in Greece or Spain (van Raak et al, 2003), and integrated care is seen as still in its infancy. This approach could render further insight into the development aspects of steering integrated care.

Another appraach to theoretical sampling would be in relation to the type of health system and political system. England with the Beveridge system and a majoritarian political system (Westminster model) and The Netherlands with a Bismarckian system and a consensus democracy (as investigated in this study) could be complemented by counitries with other combinations; examples of transition countries in particular, would complete the European picture. Such an analysis would strengthen an understanding of the specific steering options associated with the different system charac. teristics. Analogously, the type of welfare state could be made a criterion for further case selection and analysis at the level of the nation, as this turned out to be of importance for the shape of integrated dementia care pathways in the countries investigated in this study.

Regarding the study of local steering processes, a general increase of the number of local cases per country would be a desirable extension of the study. General here means initially more, since obvious criteria for theoretical sampling remain scarce at the end of this study. A research design with more local cases, including the study of central-local interactions with respect to steering processes, would allow deeper investigation of the scope and types of variations between localities, and generate further criteria for theoretical sampling. More local cases also could render cleeper insights into how to fine-tune national political strategies to local situations. Certainly, the size of localities as an important criterion for theoretical sampling became evident from the results of this study, and requires for example the inclusion of rural case study sites to be contrasted with medium-sized cities and metropolitan areas in future research.

Dementia care will not be the only field of interest in which comparative research can render interesting insights into national characteristics and particularities. It became obvious that general as well as dementia-specific topics play a role in understanding the steering processes regarding integrated dementia care; it might therefore be worthwhile to examine other fields of care from a comparative cross-national perspective in order to understand their specific features as well.

Finally, to understand future steering challenges regarding integrated care comprehensively, analysis at supra-national level is required. Supra-national bodies intervene increasingly in national steering, as in the case of the EU and the WTO (World Trade Organisation) for our field of study, e.g. by regulating or liberalising markets for services (Adlung, 2002; Lipson, 2002). Furthermore the pressures emerging from the 
globalising economy allso increasingly impact upon the national health and social care systems and influence steering opportunities.

In terms of the design of further cross-national research about the steering of integrated care, cross-nationally mixed research teams would be an interesting variation, as indicated above. In that case research teams should use, whenever possible, the advantages of both the insider and outsider perspective of researchers for all stages of research - preparation, data collection and analysis - in all participating countries. This means going beyond the frequently used strategy of cross-national research having national sub-teams for national sub-analyses. From the experiences of the research described in this thesis, this strategy might fail to realise the full potential emerging from crossing linguistic and cultural boundaries and thereby exceeding the limitations of researchers' configuration-bound perspectives. Also there is the risk that the non-equivalence of concepts is unrecognised when the researchers remain in their own environment.

\subsection{EPILOGUE: THE ESSENTIAL LESSONS?}

The general framework of neo-institutionalism was suitable to guide the stages of research reported in this thesis. The concepts provided could be spelled out for the more specific research questions elaborated in each stage of the research. At a more general level, the research has resulted in an understanding about and an emphasis on the complexity and variety of steering situations for integrated care that require careful analysis. It has proposed a guide for such analyses. If there is an essential lesson emerging from the study, it might be the following: in order to initiate or facilitate successful steering processes for integrated care - or to help to do that from a research perspective - it is necessary to develop an understanding of the variety of specific national and local steering situations and the historically evolved configurations in which they are embedded. This could be understood as a pessimistic evaluation of the concept of steering in general, theoretically minimising the opportunities of deliberate change and the importance of determined actors. However, the intention here is to emphasise the need for steering efforts on the one hand and their precariousness on the other - in order to support the deliberate and guided reflection of steering strategies for integrated care to enhance their potential success. The institutional framework looks at barriers and chances for successful steering - both of which are represented within the findings of this study - and by this it helps to develop successful change strategies.

It is difficult to look at this research comparatively. It has used a seldomly adopted design, by undertaking the cross-national comparative analysis of a specific topic in health and social policy, and connecting analyses of national and local levels. During 
this study only one other research report was found using a similar design. It looked at national policies and locall implementation of dehospitalisation policies in mental health in Italy and England; here, however, with just one local case per country (Jones, 1999). Looking primarily at the spatial restructuring of mental health services, it used a geographically based conceptual framework. Beyond that, at a more general level, it came to rather similar conclusions: that national and local varieties matter and have to be understood as emerging from the national and local history and culture, so that central-local steering interactions have their nationally specific as well as locally specific shape. Methodologically, Jones also emphasised the added value for the analysis emerging from the cross-national comparative perspective on national and local cases. Thus both studies confirm the benefit that can be gained by the combination of a cross-national with a central-local design for detailed analyses of steering processes.

Finally, a research project like this not only presents the researcher with uncertainties and challenges, but also offers special experiences. As quoted in Chapter 2, crossnational research forces the researcher

"to attempt to adopt a different cultural perspective, to learn to understand the thought processes of another culture and to see it from the native's viewpoint, while also reconsidering their own country from the perspective of a skilled observer from outside." (Hantrais \& Mangen, 1996, p. 3)

In gradually developing this metaperspective, the researcher gets the chance to become someone 'sitting on the fence' between nations or cultures rather than within the fences - of course, restricted to the field under study and to what remains a limited experience. Looking comparatively across countries brings the opportunity to conceive of multiple options for how circumstances could have developed and how they might change.

The kind of fieldwork carried out in a study like this bears some similarities with cultural anthropological research. It seeks to obtain much more than just texts: performing in-depth interviews involves encountering people in multiple situations; to look at them and to communicate with them; to listen to the sound of their voices; to get an impression of their emotions connected with the topics at hand; and to relate all that to their arguments. It involves encountering interviewees within their physical environments, often to be guided around the sites, and to gather visual and auditory impressions of the care environments, in which managers and professionals work and in which the services are delivered. Many such multiple impressions and observations happened outside the systematic collection of data in this project. Even if they could not be completely entered into the research process, several of them evoked further questions by complementing, confirming or contradicting what was said or written. 
Beyond their importance for the specific research, such experiences allow a special kind of insight into aspects of a foreign country which are educationally invaluable.

\section{REFERENCES}

Adlung R. 2002. Health services in a globalising world. eurohealth 8: 18-21.

Agranoff R \& Radin BA. 1991. The comparative case study approach in public administration. Research in Public Administration 1: 203-231.

Hantrais L \& Mangen S. 1996. Method and management of cross-national social research. In Cross-national research methods in the social sciences, Hantrais L, Mangen $S$ (eds): Pinter, London; 1-12.

Jones 1. 1999. Community-based mental health care in Britain and Italy: Geographical perspectives, Department of Geography. University of Sheffield: Sheffield.

Lipson D. 2002. GATs and health services. Implications for EU candidate countries. eurohealth 8: $39-41$.

van Raak A|A, Mur-Veeman I, Hardy B, Steenbergen M \& Paulus A (eds). 2003. Integrated care in Europe. Description and comparison of integrated care in six EU countries. Elsevier: Maarssen, The Netherlands. 
206

Chapter 7 


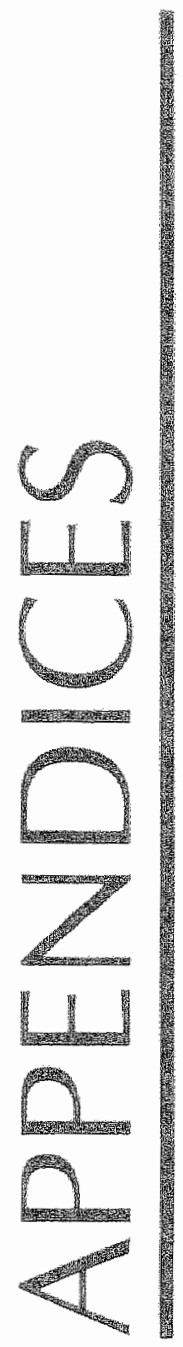




\section{APPENDIX CHAPTER 2}

\section{Appendix 2.1 Research protocol: Steering integrated dementia care development and delivery. A comparative study in England and the Netherlands Susanne Kümpers}

This protocol describes the complete research project. The third part comprises the following research step: sub-case studies on community-level, here specified to the English case. It is described in detail in 3 .

\section{CONTENT}

1 Introduction: Background and goals

1.1 Background

1.2 Goals

2 Theory, outline and design of the project

2.1 Theoretical concepts

2.2 Research outline

2.3 Research design and methods

3 Specification of step 3: The case studies

3.1 Goals and research questions

3.2 Case selection

3.3 Frame and layers of analysis, data collection

3.3.1 Structural aspects of care delivery

3.3.2 Integrated service provision according to patients' pathways

3.3.3 Organising processes with respect to integrated service provision

3.3.4 Organising processes with respect to service planning and integration development, currently and prospects for the future

3.3.5 History of the local processes of cooperation and service development

3.3.6 Exploration of the embeddedness in the national steering processes

3.4 The interviews with informali carers

3.5 Timetable

3.6 Ethical aspects

References 


\section{INTRODUCTION: BACKGROUND AND GOALS}

\subsection{Background}

The 4-years'research project (1999-2003) is based at the University of Maastricht, Faculty of Health Sciences, Department of Health Policy, Organisation and Economics, in cooperation with the University of Leeds, Nuffield Institute of Health, Community Care Division, in England.

In the following the societal developments are described which form the background for this study:

Developments in demography and medical technology bring about an increasing number of people with multiple care demands in the EC countries - the elderly, people with handicaps and/or chronic illnesses. They are in need of medical treatment, nursing and social care in changing combinations, and in a coherent, integrated way. In our study we focus on dementia care. People with dementia represent an especially vulnerable group with complex and difficult care needs; their number is rising. Under the heading 'integrated care' health policy in several countries tries to promote organisational solutions to respond to the complex and diverse care needs, changing over time. The concept describes the organising processes needed to develop and deliver coherent, co-ordinated and continuous sets of services, delivered by cooperating actors, covering the full spectrum of health and (health care related) social care. Integrated care is perceived to be a response to patients' needs, and to the urgent demands for better cost effectiveness in health care as well; integrated care thus is based simultaneously on a humanitarian and an economic rationalle.

There is strong political emphasis for integrated care, as it is in the Netherlands and England; but national and local efforts often show unsatisfactory results. It appears difficult for governments to steer the changes of the national health care system in a way that makes it favourable for integrated care development and delivery. Reasons for this are not always easily to identify.

\subsection{Goals}

This study therefore is dedicated to get insight into steering processes with respect to integrated care in England and the Netherlands.

Purpose of the study:

1. To get insight into steering processes with respect to complex issues like integrated care; 
2. To understand the relevant steering processes and their outcomes on national and local level, as well as their interdependencies;

3. To use a comparative approach in order to explore the variations between countries, and the variations between communities within and between countries;

4. To contribute to an analytical framework which can be used to develop steering strategies for integrated care in communities and countries;

5. To describe, what the concept of integrated care means applied to care for dementia patients.

\section{THEORY, OUTLINE AND DESIGN OF THE PROIECT}

\subsection{Theoretical concepts}

Over the last 15 years, neo-institutionalist approaches in political sciences have buitt a framework to explore cross-national differences in policy development and implementation. They are able to explain the context-specifity of steering processes " and thus their diversity. The characteristics of a national system are understood as a historically evolved 'configuration'. The concept of configuration [1] covers the respective national and sectoral whole - in this case the systems of health and social care. Their institutional structure and culture interact with each other and mould the strategic options and limits of policy development and implementation - thus the steering opportunities. The features of national and sectoral public policies are understood as historically developed paths, arising from a "sequential interaction of the organisation of state and society" (p.75) - from this perspective policy processes are seen as "path dependent" [2]. We use this concept also for the local contexts of integrated care development and delivery.

The concept of steering is defined as the interactive processes by which governmental and other relevant actors influence each other [3] (positive or negative feedback processes, e.g. sanctions, barriers, rewards etc) - in this case with respect to the processes of development and delivery of integrated care. Steering processes are looked at as complex phenomena, since structures, processes, attitudes of actors, and outcomes are closely intertwined with each other, but different in each country.

The ongoing steering processes are described with the help of societal coordinating mechanisms, conceptualised as hierarchy, market, and network [4-6]. The combination of these concepts allow to analyse and explain the steering processes and their outcomes against the background of the national and local conígurations; and to 
characterise the differences between countries and communities with respect to processes and outcomes.

Health care systems thereby become visible as 'configurations in process' rather than as a static picture. It's the exploration of developments and changes, and the comparison between countries and communities, which shed a light on steering.

\subsection{Research outline}

The research is structured in 3 steps building on each other. The focus proceeds from national to local policy processes, and from integrated care as a broad policy goal to the detailed processes of integrated care development and delivery for dementia patients.

Step 1 (2000): Analysis and comparison of the national health care systems and steering processes in England and the Netherlands.

The first step was directed to the comparative study of the national systems of health and social care, and of the national policies and their success and failure with respect to integrated care. Since national policy strategies dedicated to integrated care are mainly general efforts rather than aiming at specific target groups, integrated care developments in this step were analysed in generall. The analysis is completed. Results are published [7].

Step 2 (2001): Analysis and comparison of reference frameworks for integrated care for dementia patients in England and the Netherlands.

The second step is dedicated to develop a reference frame for the local studies in the third step, which will focus on dementia care. To this end the comparison of the two countries was pursued further to the issue of dementia care. Current perceptions about best practice of dementia care were inventoried in both countries, with respect to the stages of patients' pathways, and focusing on the perspective of professionals and patients' organisations [e.g. 8-27]. Based on this the concept of integrated care was specified to the needs of dementia patients. The results of this step are in preparation for publication.

Step 3 (2003), which is the phase for which this request is submitted: Analysis and comparison of local contexts and steering processes of integrated care for dementia patients: Community-based case studies ( 2 in England, 2 in the Netherlands).

This step is dedicated to study the local level where integrated care development and delivery is put into practice. 2 communities in each country are selected. The reference frame developed in step 2 is used twofold: first, as an instrument to guide data collection and description, and later as an instrument of analysis. Local care processes and their outcomes are analysed and compared with respect to integrated care 
for dementia patients. Local steering processes and their outcomes with respect to integrated care for dementia patients are analysed and compared. The relationship between national and local steering processes will be explored within and compared between both countries. For each case (each community), a fieldwork period of 4 weeks is scheduled. The case studies are carried out alternating in the Netherlands and England.

\subsection{Research design and methods}

The design concerns a cross-national comparative approach. It is an explorative study, following a qualitative approach, and using an embedded multiple case study design as described by Yin [28]. England and the Netherlands are the 2 cases, and the communities to be analysed in step 3 are the embedded' subcases. Following Agranoff and Radin [29], a multiple case study design means that the same research questions or propositions are examined in each case, but can further be developed and specified for each case during the course of the study. The cross-case analysis which emerges then from the in-depth analysis of each case, proceeds from the specific to the general. It can be used to develop generalising propositions.

With respect to the subcases, a replication-logic is employed [28]: the first series of cases - one community in each country - is analysed; the research questions and propositions are then refined and further developed to be applied to the second series of cases. The purpose is, by building on existing theoretical insights, to generate knowledge by gradually building and re-developing explanations ("explanationbuilding' is one of the essential analytic strategies in case study designs [28]).

To account for variations between communities within a national configuration 2 cases in each country are selected. Thus it becomes possible to develop propositions about which local features can be attributed to the national configuration, and which are specific for the respective local configuration.

\section{Methods}

For data collection in the first and second step we've used the methods of literature and document study in the first instance.

We then added semi-structured interviews with key persons in order to triangulate, but also to specify, and update the results.

For the last step, the community-based studies, extended document study will be complemented by interviews and, where possible attending services planning and policy-making meetings. 
214 Appendices

\section{SPECIFICATION OF STEP 3: THE CASE STUDIES}

First, goals and research questions are described specifically for the case studies. Second, the specific contents, methods and sources of data collection are described.

\subsection{Goals and research questions}

The case studies will

- deepen the knowledge about integrated care (structure, process and outcome aspects) for dementia patients, which are developed in step 2;

- enable a description of what is achieved in (selected) communities with respect to integrated care for dementia patients compared to the reference frame of best practice developed in step 2;

- help to gain insight into the local factors (local configurations) in both countries, which influence local steering of integrated care and their outcomes; this requires to develop the concept of local configuration further;

- require to study, of what local steering consists with respect to integrated care (which actors, which processes etc.), theoretically and empirically;

- enable us to study the relationship between national and local steering processes with respect to complex issues like integrated care, theoretically and empirically;

- help to gain insight to which extent this relationship differs according to the national (and local) configurations;

The following research questions will be answered:

- In which way has health policy in both countries tried to promote integrated care on local level?

- How do national configurations (institutions and culture) influence the steering processes and outcomes for integrated care on local level in both countries?

- How can local steering processes and outcomes for integrated care be dlescribed, and how are they influenced by local configurations (institutions and culture)? Who are the local actors, what are their steering functions and options?

- What are the interdependences between the local and the national configurations in both countries?

- Which variations can be found between communities within countries, and between countries, with respect to integrated care development and dellivery for dementia patients, and with respect to local steering processes (locall governancel? 
- What are the achievements with respect to integrated care development and devery for dementia on local level (compared to the reference frame of step2)?

- What conclusions can be drawn from this analysis for policy development for integrated care and its requirements; for England and the Nethertands specifically; for both countries in common?

\subsection{Case selection}

Cases were decided to be entities with 100-150 000 inhabitants. The chafacteristics of local configurations could not be defined in-depth before analysis. We therefore decided to select the $1^{\text {st }}$ case in each country by the prima face information that there is material to be studied - i.e. that integrated care activities dedicated to dementia care exist in this community; and according to practicability. It has come out that in both countries the places where the research is based (Maastricht, Leeds) meet these criteria. The selection of the $2^{\text {nd }}$ cases was informed by knowledge gained during the $1^{\text {st }}$; they should be different with respect to important configurational aspects found in the first series of cases. The $2^{\text {nd }}$ cases in each country were matched to the $1^{\text {st }}$ in the respective other country: Amsterdam Nieuw West was chosen as matching Leeds West (both parts of big cities, where the services are steered and shaped on both subcity and city level); York was chosen to match Maastricht (both middle-size cities in a rural environment).

\subsection{Frame and layers of analysis, data collection}

The following paragraphs describe 6 layers of analysis, from practice processes to steering processes on local and national level, not as such subsequent steps of data collection.

With respect to theses layers questions are formulated; sources and methods of data collection are described. Additionally there is a matrix developed which links these layers of analysis to the stages of patients' pathways. This matrix has to be completed during the fieldwork. It is documented in the appendix.

\subsubsection{Structural aspects of care delivery}

- What are the basic data of demand and supply with respect to dementia care in the chosen region?

- What are the providing organisations, their organisational domains (tasks and geographical area) with respect to service delivery (who does what where)? 
What is the number and qualification of staff dedicated to dementia care in the providing organisations?

- What is the number of people aged over 65/75; the number of diagnosed dementia patients (perhaps compared to the number which could be expected from prevalence rates)?

- Inventory of providing organisations, their scope of services, their staff and its qualification profile, their work domain

- home care hours, if possible

- number of places in semi-institutional settings (clay care, day hospitals, respite places)

- number of places in institutional settings (residential \& nursing homes, psychiatry, alternative small scale settings, discriminating whether they are specialised for dementia care; scale of units)

Data sources: documents (Health Improvement Plans, Joint investment Plans, other reports by Health and Local Authorities, Mental Health Trusts etc.), interviews (Health Authorities, Local Authorities, mental health professionals and managers).

\subsubsection{Integrated service provision according to patients' pathways (process and outcome aspects)}

For each stage and the transitions between them the care processes are evaluated, according to process and outcome aspects compared to the frame developed in step 2:

- What are the care activities being delivered to dementia patients and their families?

- What are the activities shaping the transitions between the stages?

- How are the care activities coordinated?

- What is the quality of the activities?

- What is the outcome of the activities?

- How can the care philosophy involved be described?

- What are typical pathways of patients through the system of servieces?

Data sources: documents (organisational documents and reports), interviews (professionals in primary care, mental health and social services, and voluntary organisations, e.g. Alzheimers' Society; informal carers > see 3.5; voluntary carers). 


\subsubsection{Organising processes with respect to integrated serwice provision}

- Which procedures, regulations, agreements exist between providing, commissioning and other relevant organisations?

- Which formal and informal networks exist among providing and other relevant organisations?

- Which actors are involved?

- Which case management schemes exist?

- What is the philosophy of care and the attitude towards cooperation involved?

Data sources: documents (regulations, meeting minutes, cooperation documents, organisational policy documents), interviews (professionals and managers in health and social services and voluntary organisations), attending at service planning meetings (excluding those which deal with patients'confidential details)

3.3.4 Organising processes with respect to service planning and integration development, currently and prospects for the future (steering activities)

- Which processes/initiatives are taking place currently with respect to service planning and development?

- Who are the relevant actors involved?

- What are their goals, interests, and steering efforts?

- What is the philosophy of care and the attitude towards cooperation involved?

- Are there influential regional or local policies?

Data sources: documents (meeting minutes, cooperation documents, organisational policy documents \& reports, Health Improvement Plans, Joint investment Plans), interviews (professionals, managers, local policy-makers), attendance at service planning and policy-making meetings (excluding those which deal with patients'confidential details)

3.3.5 History of the local processes of cooperation and service development (last decade)

Inventory of steering processes: History and present of cooperation and service development, relationships between actors, norms and values with respect to dementia care.

- How has the current service situation developed?

- Which processes/initiatives have taken place with respect to service planning and development? 
- Which actors have been involved?

- What were their goals, interests, and steering efforts?

- What were there relevant conflicts?

- What were the outcomes?

- What was the philosophy of care and the attitude towards cooperation involved?

- Were there influential regional or local policies?

Data sources: documents (project reports, organisational policy documents), interviews (professionals, managers, local policy-makers)

\subsubsection{Exploration of the embeddedness in the national steering processes}

- What have been the influences of national developments in the last decade and today (e.g. changes in policies between the Tories and New Labour, Care Programme Approach (CPA), implementation of Primary Care Groups/Trusts, influence from Alzheimer's Society, etc.)?

- In which way can the local processes be described as part of national developments?

Data sources: documents (project reports, organisational policy documents, national policy documents), interviews (professionals, managers, local policy-makers)

\subsection{The interviews with informal carers}

The interviews with informal carers serve to include the clients' perspective in the analysis, to triangulate and complement the information gained from the professional and expert side. We will ask healthy carers for an interview whose relatives had been transierred to a residential or nursing home already. The informal carers are interviewed on their own behalf, and on the behalf of their dementing relatives who cannot be interviewed in the later stages of the disease. The interviews will deal with the service provision from the beginning to the later stage of the disease, along the stages of patients pathways. Carers will be asked about their perception of the continuity, coherence and appropriateness of the services and the transitions between them, which they themselves and their relatives have received during the course of the disease.

Carers will be approached for interviews either via the staff in residential and/or nursing homes, or via organisations supporting carers like Alzheimer's Society or carers centres. They will receive written information about the research and their participation. No carer will be directly approached by the investigator. 


\subsection{Timetable}

$1^{\text {st }}$ week: Visits of all relevant providing sites, inventory of demand and supply information; observation of care processes, interviews with informal carers; collection of documents.

$2^{\text {nd }}$ week: Continuation of tasks week 1 ; interviews with professionals; observation of multi-agency meetings (case discussions, coordination of integrated care); collection of documents.

$3^{\text {rd }}$ week: Continuation of tasks week $1 \& 2$; interviews with managers and local policy-makers; observation of multi-agency meetings (planning, policy development); collection of documents.

$4^{\text {th }}$ week: Completion of all tasks of week 1-3.

During this fieldwork period, it is planned to visit 4-5 care settings to carry out 5-6 interviews with informal carers, 10-12 interviews with professionals and 10-12 interviews with managers and policy-makers. It is thought to observe 5-6 multi-agency meetings (coordination, planning). These numbers are estimations - due to the possibilities of people and organisations the plan will be handled flexibly. Beyond this base opportunities will be used emerging via the snowball-principle - to contact further people and organisations according to their emerging role for local integrated care processes for dementia patients.

\subsection{Ethical aspects}

All actions in this project will fullfill all legal and ethical requirements.

The participants involved (professionals, managers, informal carers) will be given written information about the project and informed consent will be sought. A week's time (at least) will be given for the potential participants to decide on their participation.

The interviews and any other information collected will be handled in strict confidentiality. Access to the interview tapes will be limited to the researcher who does the interviews and the transcriber. The tapes and the transcripts will be kept in a locked cabinet. They will be identified only by the initials. The list of names will be kept separately. Tapes will be destroyed after the end of the project. No identifiable information will be published; the publications based on this research will only give anonymously collated data.

The participation is entirely voluntary. No one is obliged to answer the questions that may be asked. Participants are free to interrupt or to stop an interview without an 
explanation if they want to at any point in time. If distress emerges during or at the end of an interview, contact and assistance will be offered.

No ethical issues are expected to arise from the results, as there will be no individual identifiers. Based on the expected results some positive impact on the development and delivery of integrated care in general and with respect to dementia should be facilitated.

\section{REFERENCES}

1. Lehmbruch, G., The organization of society, administrative strategies, and policy networks, in Institutions and political choice. On the limits of rationality, R. Czada, A. Héritier, and H. Keman, Editors. 1996, VU University Press: Amsterdam. p. 61-84.

2. Boase, 1.P., Institutions, institutionalized networks and policy choices: Health policy in the US and Canada. Governance: An International fournal of Policy and Administration, 1996.9 (3), p. 287-310.

3. Kooiman, 1. and Associates, Social-political governance and management. Conceptualization. Vol. 1. 1997, Rotterdam: Erasmus Universiteit / Rotterdam School of Management.

4. Thompson, G., J. Frances, R. Levacic, and J. Mitchell, Markets, hierarchies and networks. The coordination of social life. 1991, London etc.: Sage.

5. Scharpf, F.W., Coordination in hierarchies and networks, in Games in hierarchies and networks. Analytical and empirical approaches to the study of governance institutions, F.W. Scharpf, Editor. 1993, Campus: Frankfurt a.M. p. 125-165.

6. Williamson, O.E., The economic institutions of capitalism: firms, markets, relational contracting. 1985, New York: The Free Press.

7. Kümpers, S., A.J.A.v. Raak, B. Hardy, and I. Mur-Veeman, The influences of institutions and culture on health policies: different approaches to integrated care in England and the Netherlands. Public Administration, 2002. 80 (2), p. 339-358.

8. Alkema, F.M.J., M.M. Blom, M. Kootte, and D.H. Sipsma, eds. Dementeren: ziekte en zorg. 2001, Van Gorcum: Assen.

9. Alzheimer Nederland, Hulp bij dementie. 2001, Utrecht: Stichting Alzheimer Nederland.

10. Alzheimer's Society, What's the Society's position on ...? 2000, London: Alzheimer's. Dementia care \& research.

11. Audit Commission, Forget me not. Mental health services for older people. National Report. 2000, London: Audit Commission publications. 
12. Cameron, $K$. and A. edited by Chapman, CarenapD (Care needs assessment pack for demential. A manual to inform care management practice. 2000, Stiling: Dementia Services Development Centre, University of Stirling.

13. Cox, S., Housing and support for people with dementia. 1998, London: HACT (The Housing Associations Charitable Trust).

14. Eccles, M., et al., North of England evidence based guidelines development project: guideline for the primary care management of dementia. Brivish Medical Journal, 1998. 317, p. 802-808.

15. European Alzheimer Clearing House, Standards of good practice. 1997.

16. European Alzheimer Clearing House, Examples of good practice in the continum of care. Report and findings. 1997.

17. Lliffe, 5., K. Walters, and G. Rait, Shortcomings in the diagnosis and management of dementia in primary care: towards an educational strategy. Aging \& Mental Health. 2000. 4 (4), p. 286-291.

18. Kitwood, T. and K. Bredin, A new approach to the evaluation of dementia care Jour. nal of Advances in Health and Nursing Care, 1992. 1 (5), p. 41-60.

19. Marshall, M., ed. State of the art in dementia care. 1. 1997, Centre for Policy on Ageing: London.

20. Miesen, B.M.L. and G.M.M. Jones, eds. Care-giving in dementia. Research and applications. 1. 2. 1997, Routledge: London, New York.

21. Ministerie van Volksgezondheid Welzijn en Sport (Ministry of Health Welfare and Sports), Woonvormen voor dementerenden. Waarom en voor wie. 1997, Rijswijk: WWS.

22. Naidoo, M. and R. Bullock, An integrated care pathway for dementia. Best practice for dementia care. 2001, Swindon: Kingshall Research Centre.

23. Nederlands Huisartsen Genootschap, Dementie M21. NHG-Standaarden. 1998.

24. Nies, H., De patient. Meensbeelden en zorgconcepten in de psychogeriatrie. Denkbeeld, 2000 (februari), p. 4-9.

25. Salari, M.A., Zorgprogrammax's voor de ouderenzorg. GGZ-programmas. 2000, Utrecht: GGZ Nederland.

26. Stoop, $\mathrm{H}$. and $\mathrm{C}$. Vermolen, is het PG-aanbod in uw regio toekomstproef? Toets de mate van diversiteit, compleetheid en bereikbaakheid van het aanbodpakket in uw regio. 1999, Brabants Ondersteuningsinstiturt ZorB \& PON Instituut voor advies, onderzoek en ontwikkeling in Noord-Brabant: Tilburg.

27. Tester, S., The quality challenge. Caring for people with dementia in residential institutions in Europe. 1999. Edinburgh: Alzheimer Scotland. 
222 Appendices

28. Yin, R.K., Case study research. Design and methods. 1994, Thousand Oaks: Sage.

29. Agranoff, R. and B.A. Radin, The comparative case study approach in public administration. Research in Public Administration, 1991. 1, p. 203-231. 


\section{APPENDICES CHAPTER 4}

\section{Appendix 4.1 The health and social care systems in England and The Netherlands. Current contexts for dementia care development}

\section{England}

1. Health care system

Beveridge-type. Tax-funded centrally organised health care system (NHS), services free at the point of delivery. Some private financing based mainly on voluntary insurance, complements the public system to a minor degree.

\section{Actors and services}

Primary care: Professionals (GPs, practice and district nurses, health visitors) work in GP-practices and health centres; GPs have gate-keeping function. Primary care is administratively organised in local Primary Care Trusts (PCTS), responsible for service development and delivery, and for commissioning of secondary sevvices.

Mental health services (with specialized divisions for older people): including memory clinics, community mental health, day hospitals, inmpatient and lialson services), organised either as separate trusts, as a division within (secondary) NHS Acute Trusts, or within PCTs. Memory clinics have an increasing role in diagnosis and treatment in early dementia.

Acute care: (hospital and specialist care) are organised in NHS Trusts.

\section{The Netherlands}

Bismarckian type. Financing: 2-tier insurance system; a compulsory public insurance for long-term care (AWBZ), a social health insurance for acute care (ZFW), with a small share of privately insured. Provision: mainly non-governmental non-profit foundations in both insurance compartments; few private providers.

Primary care: Professionals (GPs and practice nurses) work in GP practices or health centres (privately organised)

Mental health services (with specialized divisions for older people): community mental health services (RIAGGS), partly merged with psychiatric hospitals. Not all RIACGs define dementia care after diagnosis as their tasks. Memory clinics, mastly settled in regional hospitals, have an in creasing role in diagnosis and treatment of early dementia. Psychiatric wards have only a small role in care for dementia (see nursing homes).

Acute care: Hospital care and specialist care (settled in policlinics, in hospitals). 


England
Social care (nncluding home care, day care,
residential and nursing home care): the
responsibility of, and commissioned by,
Social Service Departments (SSDs) within
Local Authorities (LAs), as in-house provi-
sion or, increasingly, from independent,
mostly private providers. Social care, after
assessment, is charged for and means-tested
based on income and assets.

Independent providers." mostly priwate companies (from small-scale home owners up to large-scale, nationally organised care home providers) provide social care, as home care, residential and nursing home care. independent provision was first promoted by the Conservative governments in the 1980 s and 1990s, since replacing SSDs as dominant providers of social care.

Residential and nursing homes: have a social care tradition; a majority of units with less than 50 places. Issues of general concern are low staffing and low training levels. In nursing homes nurses present the highest professional level; medical and mental health care has to be brought in.

Voluntary organisations: provide voluntary and protessional services (often commissiloned and guided by SSDs), like advocacy, carer support, respite services, various group work, day care, neighbourhood services. etc. (Alzheimer's Society, Age Concern and

\section{The Netherlands}

"Zorgkantoor": Regional AWBZ health care offices, insurance-based, allocate finances, commission services, thereby taking a steering role, responsible for care delivery. Copayments of users are based on income.

Independent regional assessment organisations ( $R \|$ Os): implemented in 1997 to enable comprehensive assessments, and to take over the assessment task from provider organisations.

Provider organisations: increasingly go beyond their traditional field boundaries; e.g. care home providers offer community care, merge with home care organisations, or make contracts with hospitals. Residential and nursing homes also provide day centres and day hospitalls.

Home care: provided mainly by founda tions; integrating domiciliary, personal and nursing carre, after a series of mergers of formerly separated organisations initialised by the gowernment in the early 1990 s.

Residential and nursing thomes: provided by increasingly bigger provider organisations, (ongoing waves of mergers since the 1990s). Scale of homes is comparably big, regularly between 50 and 200 places per home. Nursing homes have a medical model tradition, with nursing home doctors, psychologists, occupational therapists etc. building the leading team. Nursing homes have somatic and psychogeriatric departments; the latter provide short- and long-term admission for people with dementia.

Voluntary organisations: Provide carer support and respite services on a small scale. Alzheimer Nederland is regionally implementing Alzheimer Cafés, as regular guided public discussion meetings, also involving patients. 
neighbourhood charities).

Advocacy: service of independent professilonals or qualified volunteers to suppont a vulnerable person in clarifying and representing her interests towards services, or rellatives.

\section{National policy activities}

Integrated care as one of the core targets of New Labour"s health policy: rules (statutory duties), tools and incentives targeted especially to integrate health and social care (Department of Health, 1997, 1998).

National Serwice Framework (NSE) for Older People Deparment of Health, 2001): standards for health services for the elderly, e.g. a single assessment process, and intermediate care, and some mental health aspects. Local implementation relies on the cooperation of all agencies involved.

Intermediate care: a special initiative for the ellderly by the present government, dedicated to prevent unnecessary hospital admissions, and to promote timely discharge. Set up with a focus on physical care, intermediate care teams have often rejected people with dementia. A recent government directive clarified the need for intermediate care to include elderly with mental health problems.
Advocacy (belangenbehartiging = interest representation) is seen as a part of case management, rather than a separate func. tion.

Stimulation of care innovation (zorgvernieuwing) and patient-oriented care (vraaggerichte zorg) by financial incentives since the 1990s. A national database on innovative care projects presents about 130 innovative and cooperative projects in clementia care (NIVEL, 2001; Secretary of State for Health, 2000).

Stimulation of regional pathway development: Non-governmental research and development agencies in the care sector were subsidized to produce frameworks as e.g. a detailed program of cure and care needs for different diagnoses in mental health for the elderly (zorgprogramma's care programs) (Sallari, 2000), or models for the development of geriatric networks (Gerritsen et al. 2001).

The Health Council of The Netherlands recently gave comprehensive advice and recommendations on current and future cure and care needs regarding dementia to the Ministry of Health (Gezondheidsraad, 2002 ).

\section{Other relevant initiatives regarding dementia care}

Alzheimer"s Society (founded 1976): active, influential and highly professionalised organisation, prowiding a network of regional branches. Role: campaigning, disseminating information to patients, carers and the public. educating professionals, facilitating
Alzheimer Nederland (founded in 1984), the Dutch Alzheimer's Society: provides functions similar to the British counterpart with the exception of professional service provision. Therefore the organisation might be less visible within the care system. Patients 


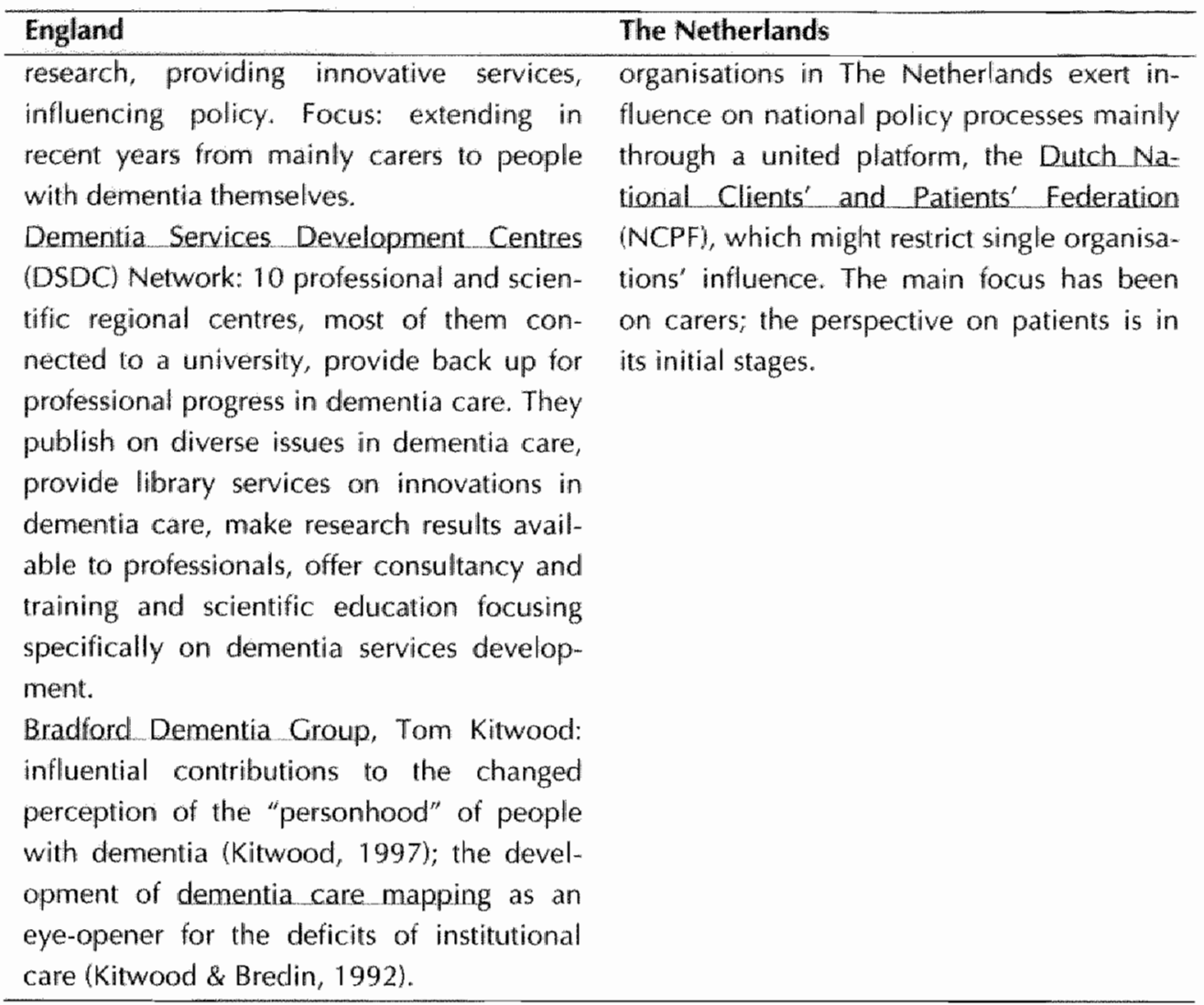

\section{REFERENCES}

Department of Health. 1997. The new NHS. Modern. Dependable. HMSO: London, UK.

Department of Health. 1998. Partnership in action. New opportunities for joint working between health and social care. NHS Executive: London, UK.

Department of Health. 2001. National Service Framework for Older People. Department of Health: London, LK.

Gerritsen H, Linschoten PV, Nies H Romijn C. 2001. Netwerken in de gespecialiseerde gezondheidszorg voor ouderen. ITS, Stichting Katholieke Universiteit te Nijmegen: Nijmegen, The Netherlands.

Gezondheidsraad. 2002. Dementie. Advies van een commissie van de gezondheidsraad (Dementia. Advice by a commiftee of the Health Council). Gezondheidsraad (Health Council of the Netherlands). Publication no. 2002/04: Den Haag, The Netherlands.

Kitwood T. 1997. Personhood, dementia and dementia care. In Dementia: challenges and new directions, Hunter S (ed); Jessica Kingslley Publishers, London, UK; 9-23. 
Kitwood T \& Bredin K. 1992. A new approach to the evaluation of dementia care. fournal of Advances in Health and Nursing Care 1: 41-60.

NIVEL N, Trimbos-instituut. 2001. Databank zorgvernieuwing (database care innovation) $2000 / 2001$ (cdmrom). In Innovatie in de zorgsector. Jaarboek 2000/2001 (Innovation in the care sector. Yearbook 2000/2001), Kip G (ed): Elsevier Gezondheidszorg. Maarssen, The Netherlands.

Salari MA. 2000. Zorgprogramma's voor de oudenenzorg (Care pathways for older people). GGZ Nederland (Dutch Association for Mental Health): Utrecht, The Netherlands.

Secretary of State for Health. 2000. The NHS plan. A plan for investment. A plan for reform. HSMO: Norwich, UK. 


\section{Appendix 4.2 Dementia care pathway in England: Inventory of recommended standards and reported practice}

Abbreviations used in the tables below: $c=$ carers; $\mathrm{GH}=$ general hospital; $I \mathrm{P}=$ independent providers; $\mathrm{LA}=$ local authorities; $M C=$ memory clinic; $M H S=$ mental health services (include community mental health teams (CMHTs), day hospitals, in-patient and liaison services); $\mathrm{NH}=$ nursing home; $\mathrm{p}=$ patients; $\mathrm{pct}=$ primary care team; $\mathrm{PH}$ $=$ psychiatric ward; $\mathrm{RH}=$ residential home; $\mathrm{SS}=$ social services; $\mathrm{VS}=$ voluntary services (esp. Alzheimer"s Society, Age Concern)

Table 1: Service provision to patients and carers

\section{Recommended standards}

Reported practice

\section{Care in the community}

(General goal: Support patients as long as possible in the community)

\subsection{Initiation: diagnosis and early support}

React to early symptoms (pot).

Diagnosis: some GPs don't perform proper

Diagnosis: early, use screening tests; examine diagnoses, don't inform \& support $p$ and $c$. treatable conditions (CPS and, or MC, MHS). Establish differential diagnosis; provide pharmacological treatment (MC, MHS). Inform $p \& \mathbb{C}$ (GPs and, or MC, MHS).

MC or MHS provide differential diagnoses, Support $\mathrm{p} \& \mathrm{c}$ : advise about coping and services (GPS, or MC, MHS). treatment, information (not everywhere in placel.

Psychosocial support to $c$ \& $p$ (less) provided in many places; variations in forms, intensity, accessibility (MC, MHS, VS)

Psychosocial suppont to $p$ \& $C$ (MC, MHS).

\subsection{Care delivery in the community}

Home care: timely; flexible; sufficient; staff continuity; staff having some mental health training. Specialist provision recommended. (SS, IP).

Home care: problems in all qualitative and quantitative aspects, great variations. Seldom specialist provision.

Day centres: specific for dementia, flexible Day centres and day hospitals: inconsistent opening hours, for day structure, social stimulation, respite (SS, VS).

Day hospitals: for assessment and treatment (MHS).

provision (1990: 8,5 places per 1000 over 65), oftem overlapping in functions

Community mental health care: support $p$ Community mental health care: often provided, great variations in quantity. and $c$, treat $p(M H S)$. Respite care: provided in different varieties. and quantities. VS: often very creative. 


\section{Recommended standards}

Respite care: night care \& time-limited admission in care homes (SS, IP). Sitting services and other support (VS).

Medical care to p \& c (pct).

\section{Reported practice}

Medicalcare: access provided.

\subsection{Crisis intervention and short-term admission}

Rapid response in crises;

Intermediate care for people with dementia (pct, SS and, or MHS). New directive explicitly includes people with mental health problems.

Acute care: extra beds for people with physical and mental health needs; care on general wards adapted to dementia needs $(\mathrm{CH})$.

Acute psychiatric care: separate wards; appropriate environments $(\mathrm{PH})$
Rapid response teams (MHS) in few places.

intermediate care often excludes $p$ with de. mentia.

Acute care: few beds for people with physical and mental health needs; many $p$ cared for on badly adapted $\mathrm{GH}$ wards.

\section{Long-term institutional care: Residential \& nursing home care}

Residential and nursing home care: enough Care home provision: ca 49 places per 1000 places (no planning guidelines); suitable people above 65 nationally. Current closures: environments; safeguarded quality of per- decrease in provision, long waiting lists. sonal care; adequately trained staff; prevent Great variations in all aspects, concerns unnecessary transitions. about staff training, quality of care, unsuccessful placements. Unequal access.

Specialist provision (SS, IP, VS): no planning Specialist provision: $18 \%$ in NHs; high perguidelines.

Medical care to residents (pct). centage of $\mathrm{p}$ with dementia in non-specialist RHs and NHs.

Mental health treatment to residents (MHS). Mental health treatment: varies in provision $\&$ quality.

\section{Table 2: Pathway-oriented activities}

\section{Recommended standards}

\section{Reported practice}

\section{Care in the community}

(General goal: Support patients as long as possible in the community)

\subsection{Initiation: diagnosis and early support}

Referral to specialist services: ambiguous Referral: some GPs refer late. recommendations (CPs); Referral acceptance varies among MC MHS. Acceptance of other referrals than physicians' Information to GPS is provided by MC. MHS. 


\section{Recommended standards}

\section{Reported practice}

(MC, MHS);

Information to GPs (MC, MHS).

\subsection{Care delivery in the community}

Assessment: comprehensive, single process, Assessment: often at home; single process at home, separated for $p \& c$, regular reviews partly in place; entrance into the system (SS, pct, best by MHS).

Key worker or case management scheme: to be initiated with assessment (pct, 5S, MHS). Link to case manager (all).

Advacacy for $p \& c$ (VS).

Common procedures for assessment and case management (pct, SS, MHS). determines access to services to some degree (SS, pct, MHS).

Key worker or case management scheme: inconsistent provision, more intensive by MHS than by SS, sometimes by VS.

Advocacy: partly in place.

Common procedures often lacking.

\subsection{Crisis intervention and short-term admission}

Key worker and case management in place (pct, SS, MHIS).

Link to case manager (all),

Key worker, case management often not sufficiently in place (pct, SS, MHS).

Advocacy for $p \&$ c (VS). Advocacy: partly in place.

\section{Long-term institutional care: Residential \& nursing home care}

Assessments for admissions. Inform $p$ and $c$ Assessments, information and reviews mostly about homes;

Review after admission (SS, MHS, IP). provided, quality waries (SS, MHS, IP).

Advocacy: partly in place.

Advocacy for $p$ \& $c$ (VS).

Coordinated administration of admissions by Coordinated administration of vacancies \& IP and SS seldom in place. acmissions locally (SS, IP).

Strategic service planning: cooperative planStrategic service planning by all local actors ning not always in place. cooperating (LA, IP, VS, MHS)

\section{Table 3: Enabling activities}

\section{Recommended standards}

\section{Reported practice}

\section{Care in the community}

(General goal: Support patients as long as possible in the community)

\subsection{Initiation: diagnosis and early support}

Dementia competence to be improved in pct. Consultation \& training to primary care staff (MC, MHS)
Dementia competence: Some GPs: inactive regarding dementia competence.

Initiatives for consultation \& training in many places, successes wary (MC, MHS, VS). 


\subsection{Care delivery in the community}

Dementia competence to be improved in Dementia competence: few training efforts in home care (SS, IP, VS). thome care (SS, IP).

Consulltation \& training for home care staff Consultation and training inconsistently (MHS). provided (MHS).

\subsection{Crisis intervention and short-term admission}

Dementia competence to be improved in Dementia competence: Intermediate care intermediate care and $\mathrm{GH}$. teams must enhance mental health efforts.

Consultation \& training to intermediatte care General hospitals: often lack efforts to ensure and general ward staff (MHS)

dementia-friendly care.

MHS: little provision of liaison services.

Some local activities by $V S$ in GH.

2. Long-term institutional care: Residential and nursing home care

Dementia competence to be improved in Dementia competence: cooperation between care homes (SS, IP, VP); consultation \& train- MHSs and care homes inconsistently in ing to (MHS). place, great variations in capacity and quality. 


\section{Appendix 4.3 Dementia care pathway in The Netherlands: Inventory of recom- mended standards and reported practice}

Abbreviations used in the tables below: $\mathrm{c}=$ carers; $\mathrm{CHP}=$ care home provider; $\mathrm{DW}=$ Local Authorities (Dienst Welzijn); $\mathrm{GH}=$ general hospital; $H C=$ home care agency; $M C=$ memory clinic (geheugenpoli); $N H=$ nursing home; $N H D=$ nursing home doctor; $\mathrm{p}=$ patients; $\mathrm{pct}=\mathrm{GP}$-practice; $\mathrm{RH}=$ residential home; $\mathrm{RIAGG}=$ community mental health team; $\mathrm{RIO}=$ assessment agency; $\mathrm{VS}=$ voluntary agency (esp. Alzheiimer Nederland); ZK = AWBZ administration agency (zorgkantoor)

Table 1: Service provision to patients and carers

\section{Recommended standards}

Reported practice

1. Care in the community

(Ceneral goal: Support patients as long as possible in the community)

\subsection{Initiation: diagnosis and early support}

React to earlly symptoms (pct)

Diagnosis and treatment: diagnose early. examine treatable conditions, inform \& advise $\mathrm{c}$ (pct or MC, RIAGG), Differential diagnosis; pharmacological treatment, eventually with ChEl; inform p \& C (MC, RIAGG).

Psychosocial diagnosis of family situation (RIAGC).

Psychosocial suppott to c (to p unclear) (MC. $\mathbb{R I A G G}$, VS).
Diagnosis \& treatment: Some GPs don't react, don't perform proper diagnoses, don't inform $p$ and $c$ (big variations). RIAGG, MC provide differential diagnoses, treatment, information (partly only to c); RIAGGs mostly provide psychosocial diagnoses.

Psychosocial support to c: provided by MC, RIAGG, VS often, not everywhere. To $p$ : Scarce some MCs provide psycho-education; VS prowide open meetings in several regions.

\subsection{Care delivery in the community}

Home care: timely; flexible: sufficient; with Home care: problems in all qualitative and staff continuity; train staff sufficiently $(\mathrm{HC}$. quantitative aspects, great variations.

Community mental health care: support $c$, Community mental health care: not all treat p (RIAGG). RIAGGs provide dementia care after diagnoDay care \& day hospital: flexible and suffi- sis; capacity insufficient to serve all $\mathrm{p} \& \mathrm{C}$. cient provision, (CHP); planning guidelines. Respite care: time-limited admissions and night care in care homes (CHP). Sitting services, hollidays (VS).

Medical care to $p \&$ c (pct).
Day care \& day hospitals: wariations in quantity of provision (1990:2,5 places per 1000 over 65 nationally).

Respite in care homes: scarcity of places, variations. Sitting services, holidays: small- 
scale provision.

\subsection{Crisis intervention and short-term admission}

Crisis admissions in care homes (CHP).

Crisis admissions in care homes: quantity of Treatment and rehabilitation: time-limited admissions $(\mathrm{NH})$. provision varies.

Acute care: Adapt the care on general wards to dementia needs $(\mathrm{CH})$.

Care on general wards: often unresponsive to dementia, great variations. Rejections reported.

\section{Long-term institutional care: Residential \& nursing home care}

Residential and nursing home care: sufficient Care home provision: nationally ca 80 places places (planning guidelines); a suitable environment: small scale units; quality and continuity of personal care; adequately trained staff; per 1000 people over 65. Variations in all qualitative and quantitative aspects; slow implementation of innovative concepts; concerns about care workers' competences. Specialist provision: planning guidelines (CHP). Traditional big scalle units, current tendency to smaller scale.

Medical cane to residents in RH (GPs). Specialist provision rate ca $55 \%$; considerMental health services in RH (RIAGG). able percentages of patients with dementia in Provide specialist psychiatric treatment (psychiatric services). RHs and somatic NHs.

Medical care provision in RH by CPS, sometimes by NHD, in NH by NHD.

Mental health services in RH by RIAGG. dependent on referral of GP.

\section{Table 2: Pathway-oriented activities}

\section{Recommended standards}

\section{Reported practice}

\section{Care in the community}

(Cieneral goal: Support patients as long as possible in the community)

\section{I Initiation: diagnosis and early support}

Referral to specialist services in unclear cases (GP).

Information to GPS (MC, RIAGG).

Cooperation between MC, RIAGG.

Regional care programs: Inform and involve GPs (all).
Referral: Some GPS refer very late, if at all. MCs: mostly broad referral acceptance. RIAGG: need GP-referrals (since 2002). Information to GPS: variations in timeliness (RIACG, MC).

Cooperation between MC \& RIAGG often missing.

Regional care programs: in beginning stages. 


\subsection{Care delivery in the community}

Assessment: comprehensive, timely, dementia-adequate (RIO).

Key worker, monitoring: (HC).

Case management \& monitoring (RIACG)

Regional care programs to be developed (all).
Assessments: great valiations in quality and timeliness (RIOs).

Key worker, monitoring: often not provided, dependent on quality of home care team.

Case management: provided only for small part of $p$ \& $c$; not by all RIAGGs.

Regional care programs: in beginning stages.

\subsection{Crisis intervention and short-term admission}

Intensive case management (CHP, RIAGG, Intensive case management: locally, for some HCl. $p$, after assessment for admission.

Access to acute care: to be safeguarded $(\mathrm{GH})$. Access to $\mathrm{GH}$ : sometimes hampered, denied in single cases.

\section{Long-term institutional care: Residential \& nursing home care}

(Re-) assessments for admission; inform $p$ and Assessments: Variations in quality and timeliC (RIO). ness (RIOS).

Administration of admissions, transitions, Coordinated administration of admission \& waiting lists (ZK).

Review, care plan after admission (CHP) waiting lists: often implemented (ZK).

Review and careplan: mostly in place, variation in quality (CHP).

\section{Table 3: Enabling activities}

\section{Recommended standards}

\section{Reportted practice}

\section{Care in the community}

(General goal: Support patients as long as possible in the community)

\section{1 initiation: diagnosis and early support}

Dementia competence to be improved (CP). Consultation for GPS (MC, RIAGG).

Dementia_competence: Some GPs are inactive. RIAGG, MC: offer consultation to GPS (greater variations)

\subsection{Care delivery in the community}

Dementia competence to be improved (HC). Dementia competence: great variations in Consultation \& training for home care staff efforts of HCs. Variations in willingness and (unclear norm) (RIAGG) capacity of RIAGGs. 


\section{Recommended standards}

\section{Reported practice}

1.3. Crisis intervention and short-term admission

Dementia competence should be improved Dementia competence on general wards: $(\mathrm{GH})$. Consultation \& training to general ward great variation in provision and acceptance staff (geriatric services). regarding efforts of geriatric services.

2. Long-term institutional care: Residential and nursing home care

Consultation and training for care workers in Dementia competence: Variation in efforts, homes (NH staff, RIAGG, CHP). willingness success (CHP). NH: rely more on On-call consultation for complex psychiatric internal competence development. RH: rely cases in nursing homes (NHD) on NH staff or RIAGG. RIAGGs vary in effort. 
2361 Appendices

APPENDIX CHAPTER 7

Appendix 7.1 Framework for the analysis of steering processes regarding integrated dementia care

SECTION A GUIDING QUESTIONS FOR THE ANALYSIS OF STEERING PROCESSES FOR INTEGRATED CARE AT NATIONAL LEVEL

- Characteristics of a national configuration, its institutional structure and culture as influencing successful stteering of integrated care

- What are the relevant actors (governmental and others) in this configuration, what are their roles, their scope of action, their relative power and dependency, in which stage of the policy process (agenda-setting, development, implementation)?

- What is the character of commissioning and providing organisations fpublic /independent - non-for-profit /for profic)?

- Whose responsibility is the shaping of integrated care?

- To what extent are the expectations of actors towards each other congruent with role capacities and with existing interests? What are the expectations of the public towards government and other actors, and what is the impact of that on policy processes with respect to integrated care?

- Which specific mix of modes of governance is inherent in the configuration under study (hierarchy, market, network mechanisms)?

- How can the institutionalised policy style be characterised (political culture)?

- What are the steering potentials and weaknesses of the specific configuration?

- What is the history of cooperation in the configuration under study, and how can the social capital for integrated care be described?

- Policy processes relevant to steering of integrated care

- What were the policy processes in the past and present relevant to steering of integrated care?

- To what extent and in which way did steering processes regarding integrated care correspond with the national configuration?

- To what extent and in which way have these policies been supportive to network building for integrated care at local level, e.g. 
- by making cooperation obligatory?

- by facilitating continuity?

- by facillitating the commitment of actors?

- by providing sufficient and appropriate incentives for integrated care in general?

- by balancing competitive incentives sufficiently with cooperative ones?

\section{SECIION B GULDINIG QUESTIONS FOR THE ANALYSIS OF INTEGRATED DEMENTIA CARE PATHWAYS}

\section{- Standards}

- What is seen as common and best practice in dementia care? What are the implications for integrated dementia care?

- How have changing knowledge and philosophy about dementia care influenced recommended standards?

- Given a cross-nationall correspondence of standards, is there a nationally specific operationalisation?

\section{- Standards and the reality of mainstream care}

- To what extent do mainstream integrated dementia care processes meet the rec. ommended standards?

- What are the main barriers to realising recommended care standards?

- Are barriers to realising these care standards nation-specific or generic?

- How can these barriers be explained? (E.g. Bio-medical professional cullure, traditional care models in social care, efficiency pressures, competence and integration problems)

\section{- Highlighting differences between countries}

- Beneath the correspondence of standards, is there a configuration-specific operaw tionalisation le.g. issues of autonomy, role of voluntary services, balance between community and institutional care, attitudes towards institutional care, integration of service planning, as issues different between England and The Netherlands)?

- In which ways have institutional configurations shaped integrated dementia care pathways?

- To what extent do configurational differences correspond with wellare state models? 
- To what extent do national institutional configurations support or hinder the realisation of care standards for integrated dementia care?

\section{- About change}

- What is the character of promising innovative projects te.g. oriented at knowledge transfer and integration in order to smooth the knowledge and cooperation gap between generalists and specialists)?

- What is the role of projects and pilots in changing mainstream care?

- Considering institutional configurations, which changes can be expected and /or facilitated for the future? Which change strategies are realistic and promising?

- What can countries learn form each other?

SECTION C: GUIDING QUESTIONS FOR THE ANALYSIS OF LOCAL STEERING PROCESSES FOR INTEGRATED DEMENTIA CARE

- National - local interaction of steering processes

- How do national steering processes influence local steering processes regarding integrated dementia care? What are their intended and unintended consequences?

- To what extent are local configurations/steering processes supportive for national policies? How do national policies relate to local actors" interests?

- What is the local scope for steering regarding national steering interventions?

- How do national and local configurations and national and local steering processes interact regarding integrated dementia care outcomes?

- To what extent and in which ways are national steering interventions supportive to the local network-building required at local level: e.g. continuity of people and domains, compatibility of interests over time, balancing of competitive and cooperative incentives? How far are the outcomes dependent on the characteristics of the local configuration?

- How can the mix of governance modes of a national configuration be described, in which local steering in general and local network-building specifically is embedded? Do they differ between countries?

- Local configurations and steering processes fior integrated dementia care

- What are the essential features of a local configuration for integrated dementia care (looking at local traditions, established service structures and domains, political and organisational histories and preferences)?

- What is the impact of a local configuration on integrated dementia care outcomes 
(in general and specifically)?

- What is the history of a locality regarding integrated dementia care?

- How do local network-building processes cope with nationally imposed changes?

- How can and do old and new actors (agencies) unfold and institutionalise their role regarding integrated dementia care?

- How do locall power balances play a role in change processes for integrated dementia care (e.g. with respect to imposed restructurings)?

- What is the impact of local configurations on conflict-solving?

- In which ways do the size of localities (their metropolitan, medium-seized city, or rural environment) influence their capacity for network-building for integrated dementia care?

\section{- Issues of dementia care pathways}

- How can the task distribution between the local actors be described?

- To what extent do the local steering processes support cooperation and knowledge transfer between mentall health specialists and generallists within health and social services?

- How is integrated dementia care organised with respect to every stage of the care pathway?

SECTIOND GUIDING QUESTIONS FOR THE ANALYSIS OF SITUATIONS OF KNOWLEDGE TRANSFER BETWEEN SPECIALISTS AND GENERALISTS

- Characteristics at organisational and inter-organisational level associated with success or failure of knowledge transfer att local level

- How do professional and organisational culture, domain consensus, perceived dependency and resources, influence the motivation and perceived capacities of specialist and generic teams or organisations to engage successfully in knowleclge transfer?

- To what extent are broad domain perceptions (shared orientation at comprehensive dementia care outcomes) present?

- To what extent do organisational and professional cultures promote trust, respect, a problem-seeking and solving culture, and leadership supportive to learning and cooperation?

- To what extent do local agencies perceive themselves as mutually depend. 
$240 \mid$ Appenclices

ent regarding integrated dementia care?

- How do local agencies evaluate the efficient use of their resources with respect to dementia care in general and knowledge transfer specifically?

- To what extent does the local situation facilitate personal and organisational continuity for knowledge transier? 


\section{SUMMARY}

Chapter 1 provides a general introduction to the background, main topics and goals of the study.

Integrated care has become a key concept in health policies over the last 15 years in Western countries, defined as "a coherent and co-ordinated set of services which are planned, managed and delivered to individual service users across a range of organisations and by a range of co-operating professionals and informal carers" (van Raak et al., 2003). It follows a humanitarian as well as an economic rationale.

Integrated care is seen as a response to changing needs of service users - increasing numbers of people with multiple needs such as older people and those with chronic illnesses and handicaps - and to the increasing differentiation and fragmentation of health and social care systems. The topic of integrated care is exemplary for so-called 'cross-cutting issues', i.e. problems in differentiated societies, which are not restricted to one system, actor or sector, but require re-integration and network solutions across system boundaries. These issues pose special challenges for steering.

Dementia care was chosen as the target area, since people with dementia represent an especially vulnerable group with complex and difficult care needs requiring integrated care and support across health and social services.

This study aimed at

- exploring steering processes with respect to integrated care in England and The Netherlands at national and local level, and their variations;

- investigating the context of dementia care; and finally

- contributing to a framework, which can be used to investigate steering situations for integrated care in other communities and countries.

This thesis compares steering processes that facilitate integrated dementia care, within real-life settings in England and The Netherlands. Steering is understood in a broad sense - comprising governance, managerial and professional processes at national and local level. Therefore steering processes are examined at different levels. A cross-national and comparative perspective was chosen in order to render insights that go beyond purely national perspectives, by identifying similarities and differences and searching for possible explanations. Both England and The Netherlands, selected as the national cases, have had integrated care high on their national agendas for health and social policy for more than a decade; and they represent different types of health care systems and welfare states. In both countries dementia care has been the subject not only of considerable professional debate but innovative care approaches. 
Chapter 2 introduces the conceptual framework and the methodology applied. The study was designed as a cross-national, comparative, multiple case study, comprising. national and local cases. It is based essentially on a neo-institutional conceptual framework and uses a qualitative methodology.

Neo-institutionalist approaches in political science present a framework suitable for exploring cross-national differences in policy development and implementation. They focus on the interrelationship between action and institutional settings. The neoinstitutional framework is capable of grasping the context-specifity of steering processes, thereby their diversity, and thence a better understanding of their outcomes. General propositions drawn from neo-institutional theory were taken as sensitising propositions to guide this study.

A case study is defined as "an empirical inquiry that investigates a contemporary phenomenon within its real-life context." (Yin, 1994, p.13). This study was designed as a series of three case studies, two at national level and one at local level, building on each other. The national case studies encompass the two national cases; the local case study dealt with four local cases, two in each country. The first investigated national steering processes for integrated care in general, the second looked at standards and practice of integrated dementia care in both countries, and the third studied local steering processes with respect to integrated dementia care. The overall design can be categorised as a multiple, embedded case study.

Literature review, document study and analysis, semi-structured interview/s, and, to a small extent, observation were used as methods for data collection. The documentary analysis essentially involved policy papers related to the issues in question. Samples of interviewees comprised managers, professionals, researchers and carers of people with dementia, in different combinations as required for each stage of the research. During the first and second stage 16 interviews were conducted in each stage; more than 100 during the third stage, 25-30 for each local case. Observation was used during the third stage in inter-agency meetings related to integrated dementia care. The different methods as well as the selection of interviewees - representing different perspectives regarding the topics in question - were used to ensure methodological triangulation. The research was based on an interpretive ontology and 'verstehend' in its approach to analysis. It applied an iterative and cumulative approach to data collection and analysis at the different case levels. A 'Qualitative Data Analysis' (QDA) software programme (ATLAS.ti 4.2) was used to process the data and to support the analysis. As common in qualitative research, processes of analysis and writing were intertwined and aimed at building up thick descriptions, by means of which conclusions were drawn to develop and specify the sensitising propositions for the specific issues under study. 
Chapter 3 provides an analysis of steering processes for integrated care at a general level. It compares the characteristics of the Dutch and English health and sociall care systems and policies, analysing how they create the conditions for integrated care. Corresponding to the dissimilarities in the structure and cultural background of the health care systems in these two countries, political strategies and conditions for integrated care differ considerably. By reviewing the last decade's developments in health policy with respect to integrated care, insights were gained into the respective processes in both countries. Using the concepts of hierarchies, markets and networks, policy processes were described and explained in terms of their effects on the conditions of network development for integrated care: The state health care system in England traditionally has relied mainly on hierarchical steering, thus creating tight network structures for integrated care at local level. The Netherlands, relying on multiple actor governance structures at nationall level, and having a health care system in a public-private mix, provides incentives for voluntary, loosely coupled and partly market-driven cooperation at local level. Factors associated with success or failure were mixed in both configurations. English health policy, whilst capable of implementing major changes, risks damaging integrated care networks by repeated, hierarchically imposed restructurings. Health policy in The Netherlands, whilst leaving more autonomy to local actors, risked omitting or fragmenting necessary changes.

Chapter 4 compares dementia care in England and The Netherlands. It explored recommended standards of service provision and their implications for integration of dementia care, and in a next step, perceived achievements in mainstream care. Some similarities were found in recommended standards and in some major shortcomings within mainstream services: nolably, weaknesses of generic services in supporting patients and carers, and failures to achieve integrated care. Differences were found in the priorities about service provision. Whille in England a social model of care was used to encourage empowerment of both the person with dementia and the carer, Dutch care professionals focused more on 'warm care concepts', and on support of the carer rather than the patient. The balance between community care and institutionall care differed, too: in The Netherlands more older people lived in care homes compared to England. Such similarities and differences were explained by the - historically developed - structural and cultural contexts of the respective health and social care systems, in which they were embedded.

Chapter 5 presents a comparative study of the implementation of integrated dementia care at local level in England and The Netherlands. Four local case studies (Amsterdam Nieuw West, Leeds West, Maastricht, York) focus on the interaction between the respective national policies and local contexts and policy processes, in order to explain the variety of local outcomes regarding integrated dementia care. Cooperation 
processes for integrated dementia care development and delivery were explored and analysed within the local configurations, embedded in national configurations. Thereby each locality was shown as an entity with particular institutional contexts and histories, which have specific impacts on processes of policy implementation within the respective national health and social care systems. The results showed that successful local network-building processes require continuity of people and domains, commitment of local actors, compatibility of actors' interests over time, and the balancing of competitive by cooperative incentives. Nationally imposed restructurings challenged and potentially damaged existing networks and, thereby, integrated care, if they ignore local configurations. Furthermore, cooperation and knowledge transfer between specialists and generalists was shown to be at the heart of integrated dementia care.

Chapter 6 deals with knowledge transfer between specialist and generic services in more detail, as it emerged as an important strategy for improving the quality of integrated dementia care. This analysis elaborated on intra- and inter-organisational features associated with successful knowledge transfer, using the local case studies in the third research stage in a generalised way. A provisional conceptual framework was suggested, drawn from literature about inter-organisational networks and knowledge management. Several significant influences upon the motivation and perceived capacity to engage in knowledge transfer were suggested: professional and organisational cultures, domain perceptions, perceived dependency and the availability of resources. Personal and organisational continuity was identified as an important process quality. Data from the local case studies were used to develop and specify the provisional framework. For example, an organisational and professional culture rélying on mutual trust and respect, a problem-seeking and solving attitude, and leadership supportive to learning and cooperation appeared to promote knowledge transfer. Moreover, the different features were shown to influence each other in their impact on processes of knowledge transfer. A conceptual model was developed to explain the relative success or failure of knowledge transfer.

Chapter 7 gives an overview of the research by summarizing the most important findings and propositions generated in the successive stages of this research. A central lesson, distilled from the study as a whole, is that in order to initiate or facilitate successful steering processes for integrated care - or help do so from a research perspective - it is necessary to understand the variety of specific national and local steering situations and the historically evolved configurations in which they are embedded. Based on the detailed results, an empirical and analytical framework is developed as an instrument for investigating steering mechanisms and processes, suitable both for policy-makers and researchers. 
Methodological issues are discussed in terms of the findings of the study.

Finally, options for future research are outlined, such as the development of theoretical sampling strategies for other countries or communities, as cases, or other fields of care, as well as alternative research designs, such as the establishment of crossnational research teams for each level of analysis.

\section{REFERENCES}

van Raak AJA, Mur-Veeman I, Hardy B, Steenbergen M \& Paulus A (eds). 2003. Integrated care in Europe. Description and comparison of integrated care in six EU countries. Elsevier: Maarssen, The Netherlands.

Yin RK. 1994. Case study research. Design and methods. Sage: Thousand Oalks. 
246

Summiary 


\section{SAMENVATTING (SUMMARY IN DUTCH)}

Hoofdstuk 1 geeft een algemene introductie op de achtergrond, hoofdthema's en doelstellingen van de studie.

Integrale zorg is de afgelopen 15 jaar een kembegrip geworden in het zorgbeleid van westerse landen. Het begrip 'integrale zorg' betreft een samenhangende en gecoördineerde verzameling van diensten die -om humanitaire en economische redenenworden gepland, gemanaged en geleverd aan individuele zorggebruikers vanuit een reeks organisaties en door een reeks samenwerkende professionals en informele verzorgers (van Raak et al., 2003). Integrale zorg wordt beschouwd als een antwoord op veranderende behoeften van zorggebruikers -toenemende aantallen mensen met meervoudige behoeften zoals ouderen, chronisch zieken en mensen met een handicap- en op de toenemende differentiatie en fragmentatie van de zorgsystemen. Het thema 'integrale zorg' is een zogenaamd 'grenzenoverschrijdend thema' en heeft daarmee betrekking op typische problemen in gedifferentieerde samenlevingen die niet zijn beperkt tot een enkel systeem, actor of sector, maar die netwerkoplossingen over systeemgrenzen heen vereisen. Zulke problemen bieden bijzondere uitdagingen voor sturing.

Dementiezorg is gekozen als het toepassingsgebied voor deze studie, omdat mensen met dementie een bijzonder kwetsbare groep vertegenwoordigen met complexe en moeilijke zorgbehoeften, die integrale zorg nodig heeft.

Doelstellingen van deze studie zijn:

- begrijpen en verklaren van de sturingsprocessen en hun kenmerken met betrekking tot integrale zorg in Engeland en Nederland op nationaal en lokaal niveau;

- de context van dementiezorg onderzoeken;

- bijdragen tot een raamwerk dat kan worden gebruikt voor onderzoek naar siuring van integrale zorg in andere gemeenschappen en landen.

Dit proefschrift vergelijkt sturingsprocessen die integrale dementiezorg faciliteren binnen praktische omstandigheden in Engeland en Nederland. Sturing is breed omschreven. Het omvat overheids-besturing, management- en professionele processen op nationaal en lokaal niveau. Om die reden worden sturingsprocessen onderzacht op verschillende niveaus. Gekozen is voor een international vergelijkend perspectief om landoverstijgende inzichten te krijgen, door overeenkomsten en verschillen te identificeren en door mogelijke verklaringen te zoeken. In Engeland en Nederland, geselecteerd als nationale cases, staat integrale zorg all gedurende meer dan een decennium hoog op de politieke agenda voor het zorgbeleid. Beide landen vertegenwoordigen verschillende typen zorgsystemen en welzijnsstaten. In beide landen is 
dememtiezorg bovendien het onderwerp van professioneel debat en innovatieve zorgbenaderingen.

Hoofdstuk 2 introduceert het conceptueel raamwerk en de toegepaste methodologie. De studie is opgezet als een internationaal-vergelijkende multiple case study, die nationale en locale cases omvat. De studie is gebaseerd op neo-institutionele theorie en maakt gebruik van kwalitatieve methoden.

Neo-institutionele benaderingen in de politicologie bieden een raamwerk dat geschikt is om verschillen tussen landen te exploreren wat betreft beleidsontwikkeling en -implementatie. Zij concentreren zich op de relaties tussen handelingen en institutionele settings. Het neo-institutionele raamwerk maakt het mogelijk grip te krijgen op de diversiteit en contextspecifieke kenmerken van sturingsprocessen, waardoor een beter inzicht ontstaat in de uitkomsten van sturingsprocessen. Algemene veronderstellingen uit de neo-institutionele theorie zijn als 'sensitizing' veronderstellingen voor deze studie gebruikt.

Een case study is gedefinieerd als een empirisch onderzoek naar een contemporain fenomeen binnen zijn context (Yin, 1994, p. 13). De studie is opgezet als een reeks van drie case studies (twee op nationaal niveau, een op lokaal niveau) die op elkaar voortbouwen. De nationale case studies omvatten de twee nationale cases. De locale case study betrof vier lokale cases, twee in elk land. De eerste case study onderzocht nationale sturingsprocessen voor integrale zorg in het algemeen, de tweede betrof standaarden en werkgewoontes voor integrale dementiezorg in beide landen, en de derde had betrekking op lokale sturingsprocessen voor integrale dementiezorg. Het algehele onderzoeksdesign kan worden getypeerd als een 'multiple, embedded case study".

Literatuurstudie, documentstudie, semi-gestructureerde interviews en -in beperkte mate- observatie zijn gebruikt als methoden voor dataverzameling. De documentstudie betrof in essentie beleidsnota's. Steekproeven van geïnterviewden bevatten managers, professionals, onderzoekers en verzorgers van mensem met dementie. Zij werden in verschillende combinaties geinterviewd, afhankelijk van de fase van het onderzoek. Tijdens de eerste en tweede onderzoeksfase zijn telkens 16 interviews gehouden. In de derde fase vonden meer dan 100 interviews plaats: 25 tot 30 voor elke lokale case. Geobserveerd is in de derde fase tijdens vergaderingen die over integrale dementiezorg gingen. De verschillende methoden en de keuze van geïnterviewden -zij vertegenwoordigen verschillende perspectieven op de onderzoeksthema's- werden gebruikt om methodologische triangulatie mogelijk te maken. De studie is uitgevoerd vanuit een interpretatieve ontologie en is 'verstehend' in haar benadering van de analyse. Voor de dataverzameling en analyse is op de diverse caseniveaus een iteratieve en cumulatieve benadering toegepast. Een 'Qualitative Data 
Analysis' (QDA) software programma (Atlas.ti 4.2) is gebruikt om data te verwerken en de analyse te ondersteunen. Zoals de gewoonte is bij kwalitatief onderzoek waren processen van analyse en rapportage met elkaar verweven en gericht op het opbouwen van 'thick descriptions". Met behulp daarvan zijn conclusies getrokken om de "sensitizing" veronderstellingen voor de onderzoeksthema's te ontwikkelen en te specificeren.

Hoofdstuk 3 biedt een analyse van sturingsprocessen voor integrale zorg in het algemeen. Het hoofdstuk vergelijkt de kenmerken van de Nederlandse en Engelse zorgsystemen en beleid, en analyseert hoe deze de voorwaarden scheppen voor integrale zorg. In overeenstemming met de verschillen in de structuur en culturele achtergrond van de zorgsystemen in beide landen verschillen de politieke strategieèn en condities voor integrale zorg aanzienlijk. Door de ontwikkelingen van het afgelopen decennium in het beleid met betrekking tot integrale zorg te bestuderen, is inzicht verkregen in de diverse sturingsprocessen in beide landen. Met behulp van de concepten hiërarchie, markt en netwerk zijn beleidsprocessen beschreven en verklaard met betrekking tot hun effecten op de voorwaarden voor netwerkontwikkeling voor integrale zorg. Het zorgsysteem in Engeland gebruikt van oudsher vooral hiërarchische sturing vanuit de staat om hechte lokale netwerkstructuren voor integrale zorg te scheppen. Nederland, gebruik makend van multi-actor sturingsstructuren op nationaal niveau binnen een zorgsysteem dat wardt gekenmerkt door een public-private mix, biedt prikkels voor vrijwillige, losgekoppelde en gedeeltelijk door marktwerking gedreven samenwerking op lokaal niveau. In beide configuraties was sprake van een mengsel van factoren, verbonden aan succes en falen. Het Engelse zorgbeleid, dat in staat is grootschalige veranderingen te implementeren, brengt het risico met zich mee dat integrale zorgnetwerken worden beschadigd, door herhaalde, vanuit de hiërarchie opgelegde herstructureringen. Zorgbeleid in Nederland, dat meer autonomie biedt aan lokale actoren, houdt het risico in dat noodzakelijke veranderingen over het hoofd worden gezien of gefragmenteerd plaatswinden.

Hoofdstuk 4 vergelijkt dementiezorg in Engeland en Nederland. Het exploreert aanbevolen standaarden voor dienstverlening en hun implicaties voor de integratie van dementiezorg, en, in een volgende stap, de waargenomen prestaties in de zorg. Een aantal overeenkomsten is gevonden tussen de aanbevolen standaarden en tussen enkele grote tekortkomingen binnen de zorg, in het bijzonder de zwakke ondersteuning van patiënten en hun verzorgers en falende pogingen om integrale zorg te bieden. Gevonden verschillen hadden te maken met prioriteiten in de zorgverlening. Terwijl in Engeland een sociaal model werd gebruikt om enpowerment te bevorderen van de persoon met dementie en de verzorger, concentreerden Nederlandse professionals zich meer op 'warme zorgconcepten' en meer op steun aan de verzorger dan 
aan de patiënt. De balans tussen community care en intramurale zorg verschilde ook. In Nederland woonden relatief meer ouderen in verzorgingshuizen. Dergelijke overeenkomsten en verschillen zijn verklaard vanuit de historisch ontwikkelde structurele en culturele contexten waarin de respectievelijke zorgsystemen zijn ingebed.

Hoofdstuk 5 presenteert een vergelijkende studie naar de implementatie van integrale dementiezorg op lokaal niveau in Engeland en Nederland. Vier lokale case studies (Amsterdam Nieuw West, Leeds West, Maastricht, York) concentreren zich op de interactie tussen het nationale beleid en lakale contexten en beleidsprocessen, met als doel de variëteit te verklaren van lokale uitkomsten voor integrale dementiezorg. Samenwerkingsprocessen voor de ontwikkeling en levering van integrale dementiezorg werden geëxploreerd en geanalyseerd binnen de lokale configuraties die waren ingebed in nationale configuraties. Daarbij werd elke lokatie gepresenteerd als een entiteit met bepaalde institutionele contexten en een geschiedenis die samen een specifieke impact hebben gehad op beleidsimplementatie binnen de twee nationale zorgsystemen. De resultaten laten zien dat succesvolle lokale netwerkontwikkeling continuiteit vereist wat betreft mensen en domeinen, draagwlak onder lokale actoren, in de tijd overeenkomende belangen van actoren, en prikkels voor samenwerking als tegenwicht voor competitie. Landelijk opgelegde herstructureringen bemoeilijkten en beschadigclen naar het zich laat aanzien bestaande netwerken (en daarmee integrale zorg), als deze geen rekening hielden met de kenmerken van lokale configuraties. Tenslotte werd aangetoond dat samenwerking en kennisoverdracht tussen specialisten en generalisten de kern vormen van integrale dementiezorg.

Hoofdstuk 6 gaat dieper in op kennisoverdracht tussen de specialistische en generalistische zorg, omdat dit een belangrijke strategie bleek te zijn voor de verbetering van de kwaliteit van integrale dementiezorg. Deze analyse borduurde voort op intraen interorganisationele kenmerken die zijn verbonden aan succesvolle kennisoverdracht, met behulp van data uit de lokale case studies in de derde onderzoeksfase. Het hoofdstuk bevat een voorlopig conceptueel raamwerk om het succes of falen van kennisoverdiacht te verklaren. Het raamwerk is gebaseerd op de genoemde data en op literatuur over interorganisationele netwerken en kennismanagement. Diverse belangrijke invloeden op de bereidheid en het vermogen om deel te nemen aan kennisoverdracht worden beschreven: professionele en organisatieculturen, domeinpercepties, gepercipieerde afhankelijkheid en de beschikbaarheid van middelen. Persoonlijke en organisationele continuitteit is geïdentificeerd als een belangrijke proceskwaliteit. Bevorderlijk voor kennisoverdracht is bijvoorbeeld een organisatie- en professionele cultuur die is gebaseerd op wederzijds vertrouwen en respect, een probleem- en oplossingsgerichte attitude en leiderschap die leerprocessen en samenwer- 
king ondersteunt. Bovendien werd aangetoond dat de verschillende kenmerken elkaar beïvloeden bij hun impact op processen van kennisoverdracht.

Hoofdstuk 7 biedt een overzicht van de studie. Het vat de belangrijkste bevindingen en proposities samen, die tijdens de opeenvolgende onderzoeksfasen zijn gegenereerd. Uit de studie als geheel kan de centrale les worden getrokken dat, om succesvolle sturing van integrale zorg te initiëren of te faciliteren, het nodig is om de variëteit van specifieke nationale en lokale sturingssituaties te begrijpen, evenals de configuraties waarin zij zijn ingebed en die zich in de loop van de geschiedenis hebben ontwikkeld. Gebaseerd op de onderzoeksresultaten is een empirisch en analytisch raamwerk ontwikkeld als instrument om inzicht te krijgen in sturing. Het raamwerk is bestemd voor beleidsmakers en onderzoekers. Het hoofdstuk bespreekt methodologische kwesties betreffende de studie. Tot slot worden mogelijkheden voor toekomstig onderzoek beschreven, zoals de ontwikkeling van strategieën voor de selectie -op basis van de theorie ("theoretical sampling")-van andere landen en lokaties als cases of voor de selectie van andere zorgsectoren. Ook wordt ingegaan op alternatieve onderzoeksdesigns en het opzetten van onderzoeksteams -voor elk analyseniveaudie zijn samengesteld uit vertegenwoordigers van verschillende landen.

\section{REFERENTIES}

van Raak AJA, Mur-Veeman I, Hardy B, Steenbergen M \& Paulus A (eds). 2003. Integrated care in Europe. Description and comparison of inlegrated care in six EU countries. Elsevier: Maarssen, The Netherlands.

Yin RK. 1994. Case study research. Design and methods. Sage: Thousand Oaks. 


\section{ZUSAMMENFASSUNG (SUMMARY IN GERMAN)}

Das erste Kapitel führt ein in die Hintergründe, Kernthemen und Ziele der Studie. Integrierte Versorgung ist in der Gesundheitspolitik der westlichen Staaten in den letzten 15 Jahren zu einem zentralen Konzept geworden. Es wird definiert als "ein kohärentes und koordiniertes Ganzes, bestehend aus Gesundheits- und Pflegedienstleistungen, die durch mehrere Organisationen und durch Fachleute und pflegende Angehörige gemeinsam geplant, organisiert und durchgeführt werden" (van Raak et al., 2003). Das Konzept fußt sowohl auf humanitären wie auch auf ökonomischen Erwägungen. Integrierte Versorgung kann als Reaktion auf veränderte Bedarfe der Patienten - einer zunehmenden Zahl von Menschen mit multiplen Versorgungsbedarfen, insbesondere alte Menschen und solche mit chronischen Krankheiten und Behinderungen - und auf die zunehmende Differenzierung und Fragmentierung der Gesundheits- und Sozialversorgungssysteme verstanden werden. Das Thema der integrierten Versorgung ist exemplarisch für so genannte, crosscutting issues" (Komplexaufgaben'), das sind solche Probleme in differenzierten Gesellschaften, welche sich nicht auf ein Subsystem, Akteur oder Sektor beschränken, sondern Re-Integration und Netzwerklösungen über Systemgrenzen hin benötigen. Solche Probleme stellen besondere Anforderungen an politische Steuerungsprozesse.

Als Forschungsfeld wurde Demenzversorgung gewählt, weil Demenzerkrankte eine besonders verletzbare Gruppe mit komplexen und schwierigen Versorgungsbedarfen darstellen, und integrierte Versorgung - koordinierte Unterstützung durch vielfältige Gesundheits- und Sozialdienstanbieter - benötigen.

Ziel dieser Studie war es,

- nationale und lokale Steuerungsprozesse und ihre Unterschiedlichkeit in England und den Niederlanden, die auf integrierte Versorgung gerichtet sind, zu untersuchen;

- den Kontext von Demenzversorgung in diesen Ländern zu erforschen;

- und zu einem analytischen und empirischen konzeptuellen Rahmen beizutragen, der die Untersuchung von Situationen, in denen integrierte Versorgung in Kommunen und Ländern der gezielten Steuerung bedarf, lenken kann.

Dazu wurden Steuerungsprozesse, die in England und den Niederlanden auf integrierte Versorgung abzielen, in beiden Ländern mit Hilfe von Feldforschung untersucht und miteinander verglichen. Es wurde ein breiter Steuerungsbegriff zugrunde gelegt, der sowohl politische Steuerung als auch diejenige durch Management und durch Angehörige der Sozial- und Gesundheitsberufe (professionals), auf nationaler wie auf lokaler Ebene, beinhaltet. Entsprechend 
wurden Steuerungsprozesse auf diesen verschiedenen Ebenen untersucht. Um Erkenntnisse zu ermöglichen, die über die rein nationalen Perspektiven hinausgehen, wurde eine transnationale und vergleichende Perspektive gewählt; dementsprechend wurden Ähnlichkeiten und Unterschiede identifiziert und mögliche Erklärungsansätze diskutiert.

England und die Niederlanden wurden ausgewählt, weil integrierte Versorgung in diesen Ländern seit mehr als zehn Jahren auf der politischen Agenda steht; zudem repräsentieren sie verschiedene Typen von Gesundheitssystemen und Wohlfahrtsstaaten. In beiden Ländern wurde Demenzversorgung in Fachkreisen lebhaft diskutiert; sowohl in England als auch in den Niederlanden existierten bereits vielfältige innovative Versorgungsmodelle.

Kapitel 2 der Dissertation gibt eine Einführung in die zugrunde gelegte Theorie und Methodologie der Studie. Diese konstituiert sich als transnationale vergleichende Fallstudie, mit mehreren nationalen wie lokalen Fällen. Sie macht Gebrauch von neo-institutionalistischen Konzepten und qualitativer Methodologie.

Politikwissenschaftliche neo-institutionalistische Theorieansätze sind geeignet um nationale Unterschiede in Politikentwicklung und -implementierung zu konzeptualisieren. Ihr Fokus richtet sich auf die Wechselbeziehungen zwischen Handlungen und institutionellen Kontexten (Konfigurationen). Die Ansätze ermöglichen es, die Kontextgebundenheit und damit die Verschiedenheit von Steuerungsprozessen zu untersuchen, und dadurch zu einem vertieften Verständnis ihrer Wirkungen zu kommen. Allgemeine neo-institutionalistische Annahmen waren, als ,sensitising concepts', Ausgangspunkt für die spezifischeren Fragestellungen des hier beschriebenen Forschungsprojekts.

Eine Fallstudie ist definiert als "eine empirische Forschung, die ein zeitgenössisches Phänomen in seinem realen Kontext studiert" (Yin, 1994). Die dieser Dissertation zugrunde liegende Studie war als eine Reihe von drei aufeinander aufbauenden Fallstudien konzipiert, zwei auf nationaler Ebene und eine auf lokaler Ebene. Die nationalen Fallstudien betreffen jeweils beide Länder; die lokale Fallstudie betriffit vier Städte, bzw. Stadtteile. In der ersten Fallstudie wurden die auf integrierte Versorgung abzielenden nationalen Steuerungsprozesse im Allgemeinen untersucht; die zweite Fallstuclie behandelte die Standards und die Praxis von integrierter Demenzversorgung; und in der dritten Fallstudie wurden konkrete lokalle Steuerungsprozesse für integrierte Demenzversorgung verifiziert. Das Gesamtdesign kann nach Yin als, Mehrebenen- und Mehrfach-Fallstudie' (multiple embedded case study design, Yin, 1994) bezeichnet werden.

Zur Datenerhebung wurden Literatur- und Dokumentenanalyse, teilstandardisierte Interviews, und in geringerem Ausmaß Beobachtung angewandt. Die 
Dokumentenanalyse befasste sich im Wesentlichen mit den jeweils relevanten politisch-programmatischen Texten oder Politikevaluationen. In den Interviews wurden entsprechend der verschiedenen Teilstudien Forscher, Manager, Angehörige der Gesundheits- und Sozialberufe und pflegende Angehörige von Menschen mit Demenz in verschiedenen Kombinationen befragt. Während der ersten beiden Teilstudien wurden jeweils 16 Interviews durchgeführt (acht in jedem Land); während der dritten Teilstudie mehr als 100 (25 bis 30 in jeder Stadt bzw. Stadtteil). In der dritten Teilstudie wurden zudem inter-organisationelle Arbeitstreffen, relevant für integrierte Demenzversorgung, beobachtet. Die verschiedenen Methoden und die Auswahl der Interviewpartner - die unterschiedliche Perspektiven auf die relevanten Sachverhalte repräsentierten - wurden zur methodologischen und DatenTriangulation genutzt. Die Forschung beruhte auf einer interpretativen Ontologie und einem, verstehenden' Analyseansatz. Bei der Datensammlung und -analyse in den Teilstudien wurde iterativ und kumulierend vorgegangen. Ein Softwareprogramm zur computergestützten Analyse qualitativer Daten, ATLAS.ti 4.2, wurde zur Bearbeitung der Daten und zur Unterstützung der Analyse eingesetzt. Wie in qualitativer Forschung üblich, waren Prozesse der Analyse und des Schreibens miteinander verbunden und zielten darauf $a b$, dichte Beschreibungen' (thick descriptions) zu erarbeiten, durch die für die spezifischen Themen dieser Studie Schlussfolgerungen zur Weiterentwicklung und Spezifizierung der, sensitising concepts' gezogen werden konnten.

Das dritte Kapitel beinhaltet eine Analyse der Steuerungsprozesse für integrierte Versorgung im Allgemeinen (d.h. nicht für Demenzversorgung im Besonderen). Es vergleicht die Eigenschaften der englischen und niederländischen Systeme der Gesundheits- und Sozialversorgung und analysiert die jeweiligen Politikansätze im Hinblick darauf, wie sie die Bedingungen für integrierte Versorgung gestalten. Bedingt durch Unterschiede in den Strukturen und den kulturellen Hintergründen der Gesundheitssysteme in diesen beiden Ländern differierten die politischen Strategien und die Bedingungen für integrierte versorgung erheblich. In der Rückschau auf gesundheitspolitische Entwicklungen in Bezug auf integrierte Versorgung zwischen 1990 und 2000 wurden Einsichten in die Steuerungsprozesse in beiden Ländern gewonnen. Mit Hilfe der Konzepte Hierarchie, Markt und Netzwerk, mit denen gesellschaftliche Koordinierungsmechanismen typisiert werden, konnten die politischen Prozesse in ihren Auswirkungen auf Kooperationsnetzwerke für integriente Versorgung beschrieben und erklärt werden: Das staatliche Gesundheitssystem in England, traditionell auf hierarchische 5teuerung gegründet, kreierte in größserem Ausmaß festgelegte Netzwerkbeziehungen für integrierte Versorgung auf lokaler Ebene. Die Niederlande hingegen, mit einer Governance-Konstellation vielfältiger 
Akteure auf nationaler Ebene und mit einem Gesundheitssystem in gemischter offentlicher und privater Verantwortlichkeit, arbeiteten mit Anreizen für freiwillige, weniger verbindliche und teilweise marktorientierte Kooperationen auf lokaler Ebene. Erfolg oder Misserfolg der Steuerungsprozesse waren in beiden Konfigurationen gemischt. Die englische Gesundheitspolitik besitzt die Kapazität, einschneidende Veränderungen durchzusetzen, riskiert allerdings dabei die Beschädigung etablierter Kooperationsnetzwerke für integrierte Versorgung durch wiederkehrende, den lokalen Akteuren aufgezwungene Strukturveränderungen. Gesundheitspolitik in den Niedlerlanden hingegen belässt mehr Autonomie bei den lokalen Akteuren, riskiert aber die Unterlassung oder lückenhafte Einführung von als notwendig erachteten Veränderungen.

In Kapitel 4 wird der Ländervergleich in Hinsicht auf die Demenzversorgung fokussiert. Eine Bestandsaufnahme der Empfehlungen für Versorgungsstandards wurde erarbeitet und deren Implikationen für integrierte Demenzversorgung eruiert. In einem nächsten Schritt wurde die derzeitige allgemeine Versorgungsrealität beschrieben. Es wurden Ähnlichkeiten zwischen den Versorgungsempfehlungen sowie in wesentlichen problematischen Aspekten der Versorgungsrealität gefunden, insbesondere hinsichtlich der Mängel der generalistischen Versorgung in der Unterstützung von Betroffenen und pillegenden Angehörigen und bei Problemen bei der Integration der Versorgung. Unterschiede wurden in Bezug auf Prioritäten der Versorgung deutlich: Während in England ein ,soziales Versorgungsmodell" dazu genutzt wurde, um die Emanzipation von Patienten und pflegenden Angehörigen zu fördern, konzentrierten sich die niederländischen Fachleute stärker aứ ,warme' emotionsorientierte - Versorgungskonzepte, und mehr auf die Unterstützung der pflegenden Angehörigen als auf die der Demenzbetroffenen. Das Verhältnis zwischen ambulanter und stationärer Betreuung war ebenfalls unterschiedlich: in den Niederlanden lebten mehr alte Menschen in Heimen als in England. Solche Ähmlichkeiten und Unterschiede wurden durch die - geschichtlich entwickelten strukturellen und kulturellen Konfigurationen der jeweiligen Gesundheits- und Sozialsysteme erklärt, innerhalb derer sie entstanden sind.

Kapitel 5 präsentiert eine vergleichende Studie der Implementierung von integrierter Demenzversorgung auf lokaler Ebene in England und den Niederlanden. Vier lokale Teilstudien (Amsterdam Nieuw West, Leeds West, Maastricht, York) richteten sich auf die Wechselwirkungen zwischen den jeweiligen nationalen Politikansätzen und den lokalen Kontexten und politischen Prozessen, um die Unterschiedlichkeit der lokalen Ergebnisse integrierter Demenzversorgung zu erklären. Kooperationsprozesse für die Entwicklung und Durchtührung integrierter Demenzwersorgung wurden exploriert und analysiert innerhalb der lokalen institutionellen Konfigurationen und deren 
Einbettung in dien nationalen Konfigurationen. Dabei wurde jeder Ort als Einheit mit je spezifischen institutionellen Kontexten und eigener Geschichte herausgearbeitet, die die lokale Implementierung von Politikansätzen innerhalb der Gesundheits- und Sozialversorgungssysteme beeinflussen. Die Ergebnisse zeigten, dass erfolgreiche lokale Kooperationsprozesse eine gewisse Kontinuität von Personen und Einfluss- und Arbeitsbereichen, die Unterstützung durch lokale Akteure, die Kompatibilität von deren Interessen, und den Ausgleich kompetitiver durch kooperative Anreize erfordern. Durch nationale Politik aufgezwungene Umstrukturierungen gefährden und beschädigen teilweise existierende Kooperationsnetzwerke und dadurch integrierte Versorgung, wenn sie lokale Konfigurationen nicht berücksichtigen. Darüber hinaus zeigten sich die Kooperation und der Wissenstransfer zwischen Demenzspezialisten und Generalisten als von zentraler Bedeutung für integrierte Demenzversorgung.

Kapitel 6 behandelt den Wissenstransfer zwischen Spezialisten und Generalisten im Detail, weil dieser als wesentliche Strategie für die Qualitätsverbesserung von integrierter Demenzversorgung deutlich wurde. Die Analyse erarbeitete inner- und inter-organisationelle Bedingungen, die zu erfolgreichem Wissenstransfer beitragen. Die Daten aus den lokalen Studien wurden dafür zu einem Datenbestand zusammengefasst. Aus der Literatur über inter-organisationelle Netzwerke und über Wissensmanagement wurde ein vorläufiges Rahmenkonzept entwickelt, das bedeutsame Einflüsse auf die Motivation und die wahrgenommene Kapazität konzeptionalisiert: i.e. Professions- und Organisationskulturen, die Definition von Einflussbereichen durch Organisationen und Professionen, die Wahrnehmung von gegenseitigen Abhängigkeiten und das Vorhandensein von Ressourcen; zusätzlich wurde persönliche und organisationelle Kontinuität als wesentliche Prozesscualität vorgeschlagen. Der Datenbestand wurde genutzl, um das vorläufige Rahmenkonzept zu entwickeln und zu spezifizieren. Zum Beispiel scheint eine Professions- und Organisationskultur, die auf gegenseitigem Vertrauen und Respekt, auf problemorientierten und problemlösenden Einstellungen und auf einer Führungskultur, die Lernen und Zusammenarbeit unterstützt, basiert, zu erfolgreichem Wissenstransfer beizutragen. Darüber hinaus wurde deutlich, dass die verschiedenen Einflüsse in ithrer Wirkung auf Wissenstransferprozesse miteinander interagieren. Ein Modell zur Erklärung des relativen Erfolgs oder Misserfolgs von Wissenstransfer wurde entwickelt.

Kapitel 7 gibt schließlich einen Überblick über die gesamte Studie und fasst die wichtigsten Ergebnisse zusammen, die in den aufeinander folgenden Teilstudien generiert wurden. Als zentrale Schlussfolgerung der Studie gilt, dass es zur Initiierung oder Intensivierung erfolgreicher Steuerungsprozesse von integrierter Versorgung - 
oder zu deren Unterstützung aus wissenschaftlicher Perspektive - unerlässlich ist, die Unterschiedlichkeit spezifischer nationaler oder lokaler Steuerungssituationen, und die historisch entwickelten institutionellen Konfigurationen, in denen diese eingebettet sind, zu berücksichtigen. Auf der Basis der detaillierten Ergebnisse aller Teilstudien wird ein empirisch-analytischer Rahmen als Instrument für die Erforschung von Steuerungsmechanismen und -prozessen präsentiert, zum Gebrauch sowohl für Politiker als auch für Wissenschaftler.

Methodologische Fragen werden in ihrem Bezug auf die Gültigkeit und Reichweite der Ergebnisse der Studie diskutiert. Schließlich werden Optionen für zukünftige Forschung vorgeschlagen, wie etwa die Entwicklung von Strategien für ,theoretical sampling' in Bezug auf weitere Länder oder Kommunen, oder weiterer Versorgungsfelder, ebenso wie die Entwicklung von Alternativen im Forschungsdesign, wie etwa die Etablierung von internationalen Forschungsteams für alle Ebenen der Analyse.

\section{LITERATUR}

van Raak AIA, Mur-Veeman I, Hardy B, Steenbergen M \& Paulus A (eds). 2003. Integrated care in Europe. Description and comparison of integrated care in six EU countries. Elsevier: Maarssen, The Netherlands.

Yin RK. 1994. Case study research. Design and methods. Sage: Thousand Oaks. 


\section{ACKNOWLEDGEMENTS - DANKWOORD - DANKWORT}

It's done - es ist geschafft! Die hoffentlich glückliche Vollendung der Arbeit aus 5 Jahren steht bevor, und ich habe mich bei vielen zu bedanken - I have to give my thanks to many after five years of work.

These words of thanks will switch between the three languages I had the opportunity to live with during this time.

Starting with those who supervised the process of my $\mathrm{PhD}$ in the last five years:

Ik wil Hans Maarse bedanken voor zijn grote inzet - in het bijzonder in de laatste fases van de studie en het afronden van het proefschrift, voor zijn belangstelling voor de resultaten van de studie en een grondige theoretische positionering ervan, en uiteindelijk voor de moeite die hij zich getroost heeft om mijn 'Duitse stijl in het Engels' een beetje uit de wereld te helpen.

Mijn dank gaat naar Ingrid Mur, die de gedachte aan op mijn leeftijd nog te kumnen promoveren als eerste überhaupt mogelijk heeft gemaakt; en die als eerste mij het vertrouwen heeft gegeven dat ik deze studie zou kunnen uitvoeren. Haar deur stond gedurende vijf jaar altijd voor me open om alle mogelijken moeilijke, erge, leuke of ook grappige zaken in verband met het onderzoek met haar te kunnen bespreken en op een rij te zetten.

Ik wil Arno van Raak bedanken - voor vijf jaar actieve deelname aan en steun bij mijn onderzoek, in het bijzonder bij het ontwikkelen en doorzetten van mijn denkwerk, voor de bereidheid met mij mee te denken en uitgebreide discussies te voeren, voor zijn geduldig hameren op inhoudelijke en theoretische consistentie, en voor zijn meestal 'verlichtende' humeur. Ik heb zijn grote en altijd betrouwbare betrokkenheid zeer gewaardeerd, en er veel aan gehad.

Last but never least I give my thanks to Brian Hardy! I enjoyed all kinds of scientific, practical and emotional support, whether I was in England for fieldwork or, as most of the time, home at my office in Maastricht. Above all expectations there was his humour, solidarity, comfort when I needed it - and friendly and helpful criticism as well. I always felt welcome and secure in England, thanks to his professional and personal commitment and care.

I have to thank all those who facilitated the different stages of my fieldwork - those who helped me to find and contact the interviewees I needed by sharing their exper tise about the field with me. My special thanks goes to the interviewees themselves, researchers, managers, professionals and carers of people with dementia, who shared 
their time, thoughts, opinions and knowledge with me, and provided the basis of the study in this way. They above all gave colour and intensity to my foreign research experiences. I further want to say 'thank you' to those who accomplished the huge task of carefully transcribing the interviews - Julie Prudhoe in Leeds, and several student assistants in Maastricht. Finally, I enjoyed a wonderful hospitality and friendship from many people in the places where I went for days or weeks to do the fieldwork. Brian and Sue had me several times at their home in Tadcaster, Afke and Paul accommodated me over weeks in Amsterdam, and Micky had me in her home above the roofs of London.

Ich möchte meiner Familie danken, insbesondere Britta, die manchmal viel auszuhalten hatte mit einer Mutter, die für späte akademische Weihen viel Zeit und Energie aufwendete und dafür wenn auch nicht immer Verständnis so doch Toleranz verlangte. Britta hat es mit Neugier, viel Geduld, und manchmal heimlichem Stolz auf ihre Mutter ganz gut mit mir ausgehalten - und hat gleichzeitig ihre eigenen Wege kreativ entwickelt, was wiederum mir gut tat und mich stolz machte. Meiner Mutter möchte ich für ihr großes Interesse, ihre Aufmerksamkeit und Unterstützung danken. Meine Schwestern Christine, Sabine und Marianne haben sich mein Treiben von weitem freundlich und wohlwollend angesehen.

Dass mein Vater den Abschluss dieses Projekts noch miterlebt hätte, hätte ich mir sehr gewünscht. Er hätte sich sicherlich gefreut - auf den Rummel der Feierlichkeiten aber wahrscheinlich gerne verzichtet.

Ich danke meinen Freunden zuhause - besonders Sabine und Uli, Maria F., Pitt, Heidrun und Heinz, Angelika F. und Angelika Z., Biggi, Iris, Peter, Merete, Gabi, Monika - sie alle haben mich begleitel und unterstützt bei den Höhen und Tiefen des Lebens der letzten Jahre, mir geduldig zugehört, ihre Kommentare gegeben, mitgelitten und sich mitgefreut - und einfach Zeit für mich gehabt. Für meinen Ausgleich haben der Sinfonische Chor und Maria und Jan mit ihren geführten Wanderungen gesorgt - und Maria unterstützt mich wunderbar bei der Vorbereitung der Festivitäten.

Meinen Freunden in der Ferne - Christine und Andrew, Ralf, Ila, Bernhard, Rüdiger, Bine, Rita, Micky, Afke und Paul - in Mönchengladbach/Winchester, Itzehoe, Wesel, Paderborn, Kopenhagen/Frankfurt, Christchurch, Leipzig, London und Amsterdam sie haben aut ihre je besondere Art zu mir gehalten, mir Erfolg gewünscht, und mir viel Rückenwind gegeben.

Mijn dank gaat naar alle collega's bij BEOZ, die op veelvuldige wijzen hebben geholpen om mijn werk in de afgelopen jaren mogelijk te maken, en mij hebben mee- 
genomen in de Nederlandse manier van leven en werken. In het bijzonder dank ik Will en Jan, die altijd en op een vriendellijke manier bereid waren om mijn pcvaardigheden vooruit te helpen. Wim Groot heeft als baas vriendelijke steun aan mijn onderzoek gegeven, ook al lag dit onderzoek niet direct in zijn sfeer. Verder denk ik graag aan ons lunchclubje - met Gerry, Emily, Hilde, Milena, Aggie, Angelique, Maria, Silvia, Arno - ik ben dankbaar voor levendige en gezellige pauzes. Bijzonder vriendelijke en competente steun in inhoudelijk of anders, moeilijke situaties heb ik mogen ontvangen van Emily, Jan vdM, Aggie, Angelique en Anna! Ik ga verder met mijn kamergenoten door de jaren theen - met Gladys, mijn eerste, die gevolgd werd door Irmgard, Milena, Femke, en uiteindelijk Anna en Marijke - ik heb het leuk gehad, wederzijdse steun en betrokkenheid ervaren, en goede en minder goede situaties met hun kunnen delen - dat verbindt ons.

Binnen en buiten BEOZ heb ik veel gehad aan het groepje 'aio-soepers': promovendi-collega's, die net als ik kwalitatief in de gezondheidszorg bezig waren en die voor mij waardevolle inhoudelijke discussies hebben mogelijk gemaakt - en de kwalitatieve diaspora bij BEOZ een beetje hebben gecompenseerd. In het bijzonder Hannerieke is een belangrijke, lieve en betrouwbare lotgenoot geweest door de jaren heen.

Also, there were the evening meetings with our foreign $\mathrm{MPH} / \mathrm{PhD}$ ladies group Anna, Milena, Albine - we shared and enjoyed our time!

In het bijzonder Anna, Angelique en Albine hebben mij in hun privé-leven meegenomen - en ik hen in mijn - ik ben blij over onze vriendschap.

Aan prof. Maaike Meijer gaat mijn hartelijke dank uit omdat ze mij op een hele warme en opwekkende wijze heeft geholpen om het leven na de promotie in ogenschouw te nemen.

Anna und Sabine, ich freue mich, Euch als ,Paranymfen" an meiner Seite zu wissen! 
262 Acknowledgements - Dankwoord-Dankwort 


\section{CURRICULUM VITAE}

Susanne Kümpers was born in Rheine, Nordrhein-Westfalen, on 15 May 1956. She has a 19-year-old daughter.

After grammar school she studied town planning and architecture, and later educationall sciences in Aachen, where she graduated in 1982. She obtained additional training as a counsellor and psychotherapist. Between 1983 and 1995 she worked in different agencies as an educational scientist and psychotherapist with a focus on addiction. She also worked, partly freelance, as a teacher, trainer and supervisor for care workers, social workers and speech therapists, among others in the Eastern German countries after the reunification. In 1995 and 1996 she obtained a Master of Public Health degree in an international programme of the Faculty of Health Sciences, University of Maastricht. Afterwards she obtained a position as a consultant in an EU project concerned with organisational development and qualification in small and medium enterprises in Germany. From 1999 to 2004 she worked as a doctoral candidate and lecturer at the Department of Health Organisation, Policy and Economics of the University of Maastricht. In March 2005 she started to work as a research fellow in the Research Group Public Health at the Social Science Research Center Berlin.

Susanne Kümpers

Wissenschaftszentrum Berlin für Sozialforschung

(Social Science Research Center Berlin)

Forschungsgruppe Public Health

Reichpietschufer 50

D 10785 Berlin

kuempers@wz-berlin.de

Stegelstr. 118

D 52134 Herzogenrath

s.kuempers@t-online.de 